\title{
Um estudo de sensibilidade da fatoração PMF - Positive Matrix Factorization - em relação às medidas de incerteza das variáveis
}

\author{
Renato Ciani
}

\author{
DisSERTAÇÃO APRESENTADA \\ $\mathrm{AO}$ \\ Instituto DE MATEMÁticA E Estatística \\ DA \\ Universidade DE SÃo PAUlo \\ PARA \\ OBTENÇÃO DO TÍTULO \\ $\mathrm{DE}$ \\ Mestre em CiênCIAS \\ Programa: Mestrado em Estatística \\ Orientador: Prof. Dra. Lúcia Pereira Barroso
}

Durante o desenvolvimento deste trabalho o autor recebeu auxílio financeiro da CAPES

São Paulo, Setembro de 2016 


\title{
Um estudo de sensibilidade da fatoração PMF - Positive Matrix Factorization - em relação às medidas de incerteza das variáveis
}

\begin{abstract}
Esta versão da dissertação contém as correções e alterações sugeridas pela Comissão Julgadora durante a defesa da versão original do trabalho, realizada em 21/09/2016. Uma cópia da versão original está disponível no Instituto de Matemática e Estatística da Universidade de São Paulo.
\end{abstract}

Comissão Julgadora:

- Prof ${ }^{\mathrm{a}}$. Dra ${ }^{\mathrm{a}}$ Lúcia Pereira Barroso (orientadora) - IME-USP

- Prof ${ }^{a}$. Dra . Maria de Fátima Andrade - IAG-USP

- Prof ${ }^{a}$. Dra . Carmen Diva Saldiva de André - IME 


\section{Agradecimentos}

Agradeço à Professora Lúcia Pereira Barroso por ter aceitado me orientar, por sugerir o tema e ter sempre feito sugestões criativas durante o desenvolvimento deste trabalho. E por ter tido muita paciência, principalmente nos últimos meses.

Agradeço à Professora Carmen Diva Saldiva de André e à Professora Maria de Fátima Andrade por aceitar compor a banca, e pelas críticas e sugestões feitas para o aprimoramento deste trabalho.

Agradeço ao Professor Fábio Prates Machado por ter me orientado mesmo antes de começar o programa de mestrado. Por ter me encorajado a estudar para admissão, e posteriormente por me orientar durante o período em que cursei as disciplinas.

Agradeço pela ajuda e boa vontade das pessoas que eu conheci no IME enquanto estudava para a prova de admissão e que foram fundamentais para que eu tivesse êxito neste curso: ao Ivan Bernardo pela ajuda com as listas intermináveis no início do curso, ao Júlio Trecenti pela monitoria em Probabilidade e Inferência, ao Helton, Maicon, Marcos e Francisco, por estarem sempre dispostos a compartilhar seus conhecimentos no período em que cursamos as disciplinas do programa.

Agradeço ao Professor Luis Gustavo Esteves pela dedicação e pela enorme disposição em tirar dúvidas depois das aulas.

Agradeço novamente à Professora Maria de Fátima Andrade por sempre indicar onde e como obter informações sobre a área de estudo de poluição atmosférica que foi a área de aplicação do método estudado neste trabalho. Agradeço ao Professor Américo Kerr pelos esclarecimentos sobre o funcionamento do método EDXRF e pelas indicações de artigos e livros.

Agradeço à todas as pessoas que de alguma forma contribuiram para a realização deste trabalho cujos nomes não foram citados aqui: o pessoal do laboratório do Ed. Milênio do Instituto de Física da USP, e os alunos de pós-graduação da área de Física Atmosférica e Meteorologia com quem tive a oportunidade de conversar e esclarecer dúvidas.

Agradeço à minha família pelo apoio que tive durante o período deste curso. 


\section{Resumo}

A fatoração PMF - Positive Matrix Factorization - é um método de resolução de problemas em que variáveis observadas conjuntamente são modeladas como a combinação linear de fatores potenciais, representada pela multiplicação de duas matrizes. Este método tem sido utilizado principalmente em áreas de estudo em que as variáveis observadas são sempre não negativas, e quando é aplicada uma modelagem fatorial ao problema. Assume-se a premissa de que são resultantes da multiplicação de duas matrizes com entradas não negativas, ou seja, os fatores potenciais, e os poderadores da combinação linear são desconhecidos, e têm valores não negativos. Neste método além da possibilidade de restringir a busca dos valores das matrizes da fatoração a valores não negativos, também é possível incluir a medida de incerteza relacionada a cada observação no processo de obtenção da fatoração como um modo de reduzir o efeito indesejado que valores outliers podem causar no resultado.

Neste trabalho é feito um estudo de sensibilidade da fatoração PMF em relação a algumas medidas de incertezas presentes na literatura, utilizando o software EPA PMF 5.0 com ME-2. Para realizar este estudo foi desenvolvida uma metodologia de simulação de base de dados a partir de perfis de fontes emissoras conhecidas incluindo valores outliers, e aplicação sequencial da fatoração PMF com o software ME-2 nas bases de dados simuladas.

Palavras-chave: EPA, Incerteza, ME-2, PMF, Simulação. 


\section{Abstract}

The PMF factorization - Positive Matrix Factorization - is a problem solving method in which jointly observed variables are modeled as a linear combination of potential factors, represented by the multiplication of two matrices. This method has been used primarily in study areas in which the observed variables are always non negative, and when it is applied a factor modeling in the problem. It is made the assumption that the variables in study come from the two matrices multiplication both having non negative components, i.e., the potential factors, and the linear combination values are unknown, and all of them have non negative values. In this method, besides the possibility of constraining the search of the matrix factorization values on non negative values, it is also possible to include the uncertainty measure related to each observation on factorization process as a way to reduce the undesired effect which outliers can cause to the outcome.

This paper presents a study of the sensitivity of the factorization PMF over some uncertainties measures present in literature, using EMP PMF 5.0 with ME-2 software. To carry out this study was developed a methodology of database simulation from known emitting sources profiles including outliers values, and a sequential application of PMF factorization with ME-2 software in simulated databases.

Keywords: EPA, ME-2, PMF, Simulation, Uncertainty. 


\section{Sumário}

$\begin{array}{ll}\text { Lista de Abreviaturas } & \text { ix }\end{array}$

Lista de Figuras

$\begin{array}{lc}\text { Lista de Tabelas } & \text { xix }\end{array}$

1 Introdução $\quad 1$

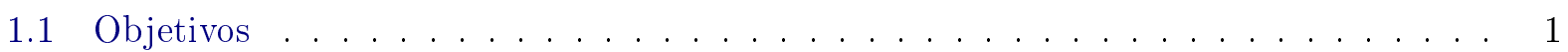

2 Conceitos $\quad 3$

$2.1 \quad$ O Modelo PMF . . . . . . . . . . . . . . . . . . . . . . . . . . 4

2.1 .1 A Função de perda . . . . . . . . . . . . . . . . . 4

2.1 .2 Incertezas das medições . . . . . . . . . . . . . . . . . . . 4

2.1.3 Fatores: identificação e interpretação . . . . . . . . . . . . . . . . 4

2.2 Considerações sobre a aplicação do modelo PMF . . . . . . . . . . . . . . . 5

2.2.1 Métodos para obtenção da fatoração PMF . . . . . . . . . . . . . . . . 5

2.2 .2 Preparação dos dados . . . . . . . . . . . . . . . . . . 5

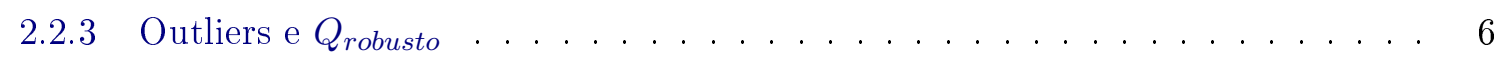

2.3 Considerações sobre métodos de medição de concentração de espécies químicas no contexto de análise de poluentes . . . . . . . . . . . . . . . . . . 7

2.3 .1 Elementos traçadores . . . . . . . . . . . . . . . . . . 7

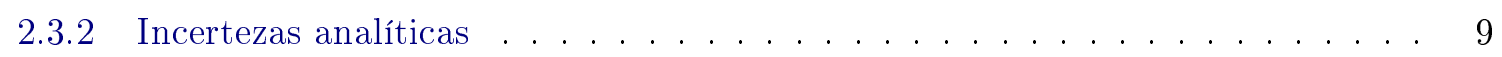

2.3 .3 Limites de Detecção . . . . . . . . . . . . . . . . . . . . 11

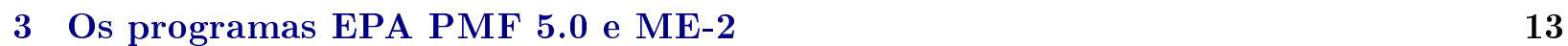

3.1 Recursos do EPA PMF $5.0 \ldots \ldots \ldots \ldots \ldots \ldots \ldots \ldots$

3.1 .1 Model Data . . . . . . . . . . . . . . . . . . . . . . . . 13

3.1.2 Base Model / Base Model Results . . . . . . . . . . . . . . . . . . . . 16

3.1.3 Base Model / Error Estimates . . . . . . . . . . . . . . . . . . . . . . . 20

3.1.4 Base Model / Base Model Displacement Results . . . . . . . . . . . . . . . . . 20

3.1.5 Base Model / Base Model Bootstrap Results . . . . . . . . . . . . . . . . . . 22

3.1 .6 Base Model / BS-DISP Results . . . . . . . . . . . . . . . . 23

3.1.7 Rotational Tools . . . . . . . . . . . . . . . . . . . . . 24 
4 Simulação de base de dados $\quad 27$

4.1 Modelo receptor . . . . . . . . . . . . . . . . . . . . 27

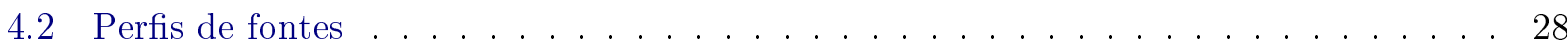

4.3 Distribuições de probabilidade utilizadas na simulação . . . . . . . . . . . . . . . . 29

4.4 Implementação computacional . . . . . . . . . . . . . . . . . . . . . . . 31

4.5 Metodologia . . . . . . . . . . . . . . . . . . . 31

5 Aplicação da fatoração PMF com software ME-2 35

5.1 Configurações do software ME-2 f . . . . . . . . . . . . . . . . . . . 35

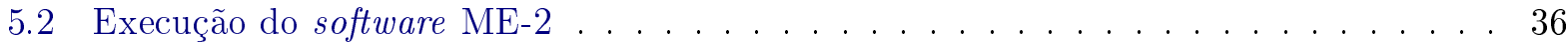

5.3 Identificação de fatores . . . . . . . . . . . . . . . . . . . . . . . 37

5.4 Metodologia de consolidação dos resultados . . . . . . . . . . . . . . 38

6 Resultados $\quad 41$

6.1 Propostas de definição de incertezas . . . . . . . . . . . . . . . . . . . . 41

6.2 Resultados de aplicações de diferentes propostas de definição de incertezas . . . . . . . . . . . . . . . . . . . . . . 43

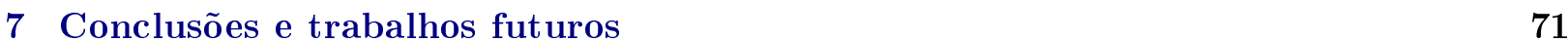

$\begin{array}{ll}\text { A Códigos } & \mathbf{7 3}\end{array}$

A.1 Implementação Computacional - SAS . . . . . . . . . . . . . . . . . . . 73

A.2 Implementação Computacional - C . . . . . . . . . . . . . . . . . 78

$\begin{array}{ll}\text { B Gráficos } & \mathbf{9 7}\end{array}$

B.1 Exemplo de séries de tempo simuladas sem outliers . . . . . . . . . . . . . . . . 97

B.2 Exemplo de séries de tempo simuladas com outliers - Exponencial com média 1,5 _ . 99

B.3 Exemplo de séries de tempo simuladas com outliers - Exponencial média 3 . . . . . 101

B.4 Exemplo de séries de tempo simuladas com outliers - Exponencial média 9 . . . . . 103

B.5 Exemplo de incertezas para uma mesma base simulada sem outliers . . . . . . . . . . 105

B.6 Exemplo de incertezas para uma mesma base simulada com outliers - Exponencial

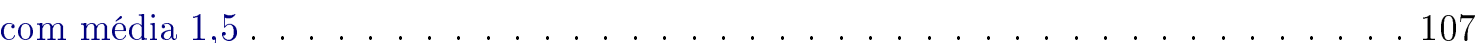

B.7 Exemplo de incertezas para uma mesma base simulada com outliers - Exponencial com média $3 \ldots \ldots \ldots$. . . . . . . . . . . . . . . . . . 109

B.8 Exemplo de incertezas para uma mesma base simulada com outliers - Exponencial com média $9 \ldots \ldots \ldots \ldots \ldots \ldots \ldots \ldots$

Referências Bibliográficas $\quad 113$ 


\title{
Lista de Abreviaturas
}

\author{
CMB Chemical Mass Balance \\ EDXRF Energy Dispersive X-Ray Fluorescence \\ EPA US Environmental Protection Agency \\ LFA Laboratório de Física Atmosférica da USP \\ PMF Positive Matriz Factorization \\ ME-2 Multilinear Engine 2
}




\section{Lista de Figuras}

2.1 Menu SPECIATE - EPA Fonte: https://cfpub.epa.gov/si/speciate/ . . . . . . . . 8

2.2 Perfil SPECIATE - Light Duty Vehicles - Composite - Fonte: https://cfpub.epa.gov/

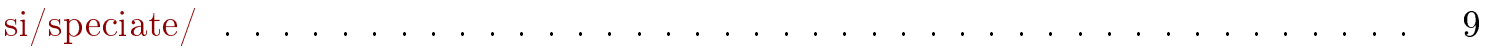

2.3 Incidencia de raio X característico fonte: http://www.handheldxrf.com.au/technology handheld $x r f . p h p \ldots \ldots \ldots \ldots \ldots \ldots$

2.4 EDXRF fonte: http://www.horiba.com/scientific/products/x-ray-fluorescence-analysis/ tutorial $/$ xrf-spectroscopy $/ \ldots \ldots \ldots \ldots \ldots$. . . . . . . . . . . 10

2.5 Sensibilidade elementar em função dos elementos químicos contidos nos padrões fabricados pela MicroMatter Arana (2014) . . . . . . . . . . . . . . . . . . 12

2.6 WinQxas - Espectro típico gerado por EDX. Fonte: Oyama (2010) _ . . . . . . . . 12

3.1 Matriz com parâmetros para calcular incertezas segundo formula pré definida em EPA PMF $5.0 \ldots \ldots \ldots \ldots \ldots \ldots \ldots \ldots$

3.2 Interface de entrada de dados EPA PMF 5.0 Fonte: Norris et al. (2014) . . . . . . . . 14

3.3 Interface de análise da qualidade dos dados EPA PMF 5.0 Fonte: Norris et al. (2014) 15

3.4 Concentration Scatter Plot e Concentration Time Series EPA PMF 5.0 Fonte: Norris et al.

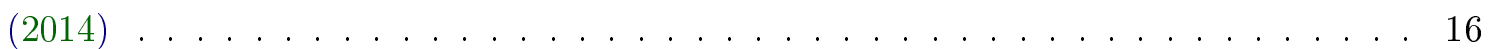

3.5 Menu Base Model Runs . . . . . . . . . . . . . . . . . . . . . . . 16

3.6 Residual Analysis e Obs/Pred Scatter EPA PMF $5.0 \ldots \ldots$. . . . . . . . . . . 17

3.7 Obs/Pred Time Series EPA PMF $5.0 \ldots \ldots \ldots \ldots \ldots \ldots$

3.8 Profiles/Contributions EPA PMF 5.0 Fonte: Norris et al. (2014) . . . . . . . . . . . . 18

3.9 Profile Contribution EPA PMF 5.0 Fonte: Norris et al. (2014) . . . . . . . . . . . . . 18

3.10 G-Space Plot EPA PMF $5.0 \ldots \ldots \ldots \ldots$. . . . . . . . . . . . . 19

3.11 Factor Contributions EPA PMF $5.0 \ldots \ldots \ldots \ldots \ldots$

3.12 Diagnostics EPA PMF $5.0 \ldots \ldots \ldots \ldots \ldots \ldots \ldots \ldots$

3.13 Base Model DISP Box Plots EPA PMF $5.0 \ldots \ldots$. . . . . . . . . . . . . . . 21

3.14 Base Model DISP Summary EPA PMF 5.0 Fonte: Norris et al. (2014) . . . . . . . . 22

3.15 Base Model Bootstrap Boxplots EPA PMF $5.0 \ldots \ldots$. . . . . . . . . . . . . 23

3.16 Base Model Bootstrap Summary EPA PMF $5.0 \ldots \ldots$. . . . . . . . . . . . . 23

3.17 Base Model BS-DISP Summary EPA PMF 5.0 Fonte: Norris et al. (2014) . . . . . . 24

3.18 Rotational Tools / Fpeak/Profiles/Contributions EPA PMF 5.0 Fonte: Norris et al.

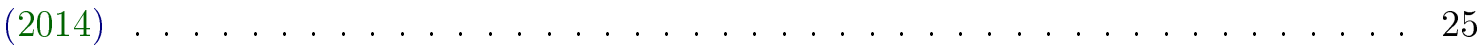

3.19 Rotational Tools / Fpeak / Model Runs EPA PMF 5.0 Fonte: Norris et al. (2014) . . 26

5.1 Arquivos para a execução do ME-2 via linha de comando . . . . . . . . . . . . . . 36 
5.2 Execução do ME-2 via linha de comando . .

6.1 Perfis médios em bases sem outliers - Proposta de incertezas definida em Norris et al. (2014)

6.2 Desvios padrões em bases sem outliers - Proposta de incertezas definida em Norris et al.

6.3 Perfis médios em bases sem outliers - Proposta de incertezas definida em Polissar et al.

6.4 Desvios padrões em bases sem outliers - Proposta de incertezas definida em Polissar et al.

6.5 Perfis médios em bases sem outliers - Proposta de incertezas definida em Ito et al.

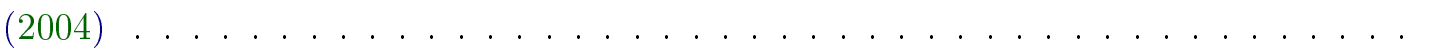

6.6 Desvios padrões em bases sem outliers - Proposta de incertezas definida em Ito et al.

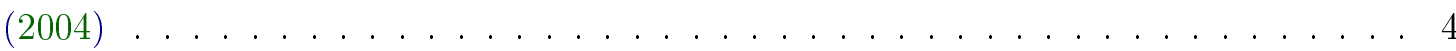

6.7 Perfis médios em bases sem outliers - Proposta de incertezas definida em Chueinta et al.

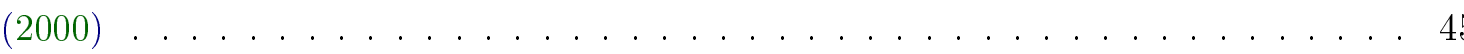

6.8 Desvios padrões em bases sem outliers - Proposta de incertezas definida em Chueinta et al.

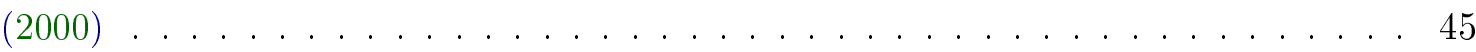

6.9 Perfis médios em bases sem outliers - Proposta de incertezas de 5\% do valor da medição 46

6.10 Desvios padrões em bases sem outliers - Proposta de incertezas de $5 \%$ do valor da

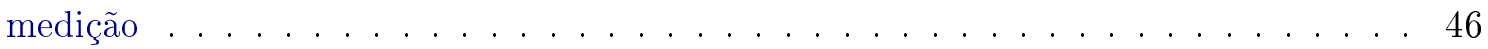

6.11 Perfis médios em bases sem outliers - Proposta de incertezas de $10 \%$ do valor da

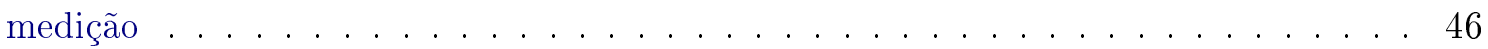

6.12 Desvios padrões em bases sem outliers - Proposta de incertezas de $10 \%$ do valor da

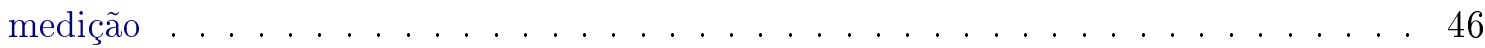

6.13 Perfis médios em bases sem outliers - Proposta de incertezas de $20 \%$ do valor da

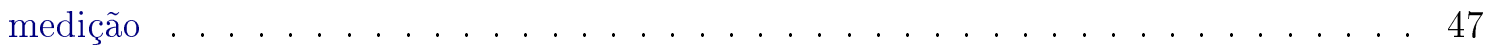

6.14 Desvios padrões em bases sem outliers - Proposta de incertezas de $20 \%$ do valor da

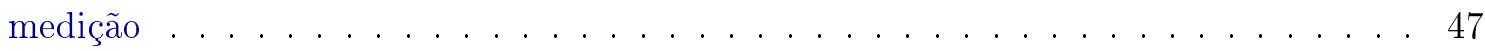

6.15 Perfis médios em bases sem outliers - Análise Fatorial Ortogonal - CP- Rotação Varimax 47

6.16 Desvios padrões em bases sem outliers - Análise Fatorial Ortogonal - CP- Rotação $\operatorname{Varimax} \ldots \ldots \ldots \ldots \ldots \ldots \ldots$

6.17 Gráfico comparativo para o Perfil $1 \ldots \ldots \ldots \ldots$. . . . . . . . 48

6.18 Gráfico comparativo para o Perfil $2 \ldots \ldots \ldots \ldots$. . . . . . . . . 48

6.19 Gráfico comparativo para o Perfil $3 \ldots \ldots$. . . . . . . . . . . . . 49

6.20 Gráfico comparativo para o Perfil $4 \ldots \ldots$. . . . . . . . . . . 49

6.21 Gráfico comparativo para o Perfil $5 \ldots \ldots \ldots \ldots \ldots$. . . . . . . . 50

6.22 Gráfico comparativo para o Perfil $6 \ldots \ldots \ldots \ldots \ldots$

6.23 Perfis médios em bases com outliers - Dist. Exponencial com média 1,5 - Proposta de incertezas definida em Norris et al. (2014) f . . . . . . . . . . . . . 50

6.24 Desvios padrões em bases com outliers - Dist. Exponencial com média 1,5 - Proposta de incertezas definida em Norris et al. (2014) _ . . . . . . . . . . . . . 50

6.25 Perfis médios em bases com outliers - Dist. Exponencial com média 1,5 - Proposta de incertezas definida em Polissar et al. (1998) . . . . . . . . . . . . . . . . . 51 
6.26 Desvios padrões em bases com outliers - Dist. Exponencial com média 1,5 - Proposta de incertezas definida em Polissar et al. (1998) . . . . . . . . . . . . . . . . 51

6.27 Perfis médios em bases com outliers - Dist. Exponencial com média 1,5 - Proposta de incertezas definida em Ito et al. (2004) . . . . . . . . . . . . . . . . . . . . . . 51

6.28 Desvios padrões em bases com outliers - Dist. Exponencial com média 1,5 - Proposta de incertezas definida em Ito et al. (2004) . . . . . . . . . . . . . . . . . . . . 51

6.29 Perfis médios em bases com outliers - Dist. Exponencial com média 1,5 - Proposta de incertezas definida em Chueinta et al. (2000) . . . . . . . . . . . . . . . . . . 52

6.30 Desvios padrões em bases com outliers - Dist. Exponencial com média 1,5 - Proposta de incertezas definida em Chueinta et al. (2000) . . . . . . . . . . . . . . . . . 52

6.31 Perfis médios em bases com outliers - Dist. Exponencial com média 1,5 - Proposta de incertezas de $5 \%$ do valor da medição . . . . . . . . . . . . . . . . . . . . . . 52

6.32 Desvios padrões em bases com outliers - Dist. Exponencial com média 1,5 - Proposta de incertezas de $5 \%$ do valor da medição . . . . . . . . . . . . . . . . . . . . . . 52

6.33 Perfis médios em bases com outliers - Dist. Exponencial com média 1,5 - Proposta de incertezas de $10 \%$ do valor da medição . . . . . . . . . . . . . . . . . . . 53

6.34 Desvios padrões em bases com outliers - Dist. Exponencial com média 1,5 - Proposta de incertezas de $10 \%$ do valor da medição . . . . . . . . . . . . . . . . . . . . 53

6.35 Perfis médios em bases com outliers - Dist. Exponencial com média 1,5 - Proposta de incertezas de $20 \%$ do valor da medição . . . . . . . . . . . . . . . . . . . . . 53

6.36 Desvios padrões em bases com outliers - Dist. Exponencial com média 1,5 - Proposta de incertezas de $20 \%$ do valor da medição . . . . . . . . . . . . . . . . . . . . . 53

6.37 Perfis médios em bases com outliers - Dist. Exponencial com média 1,5 - Análise Fatorial Ortogonal - CP - Rotação Varimax . . . . . . . . . . . . . . . . . . . . . 54

6.38 Desvios padrões em bases com outliers - Dist. Exponencial com média 1,5 - Análise Fatorial Ortogonal - CP - Rotação Varimax . . . . . . . . . . . . . . . . . . . . 54

6.39 Gráfico comparativo para o Perfil 1 . . . . . . . . . . . . . . . . . . . . 54

6.40 Gráfico comparativo para o Perfil 2 . . . . . . . . . . . . . . . . . . . . . . 54

6.41 Gráfico comparativo para o Perfil 3 . . . . . . . . . . . . . . . . . . 55

6.42 Gráfico comparativo para o Perfil 4 . . . . . . . . . . . . . . . . . . . . 55

6.43 Gráfico comparativo para o Perfil 5 . . . . . . . . . . . . . . . . . . . . 56

6.44 Gráfico comparativo para o Perfil 6 . . . . . . . . . . . . . . . . . . . 56

6.45 Perfis médios em bases com outliers - Dist. Exponencial com média 3 - Proposta de incertezas definida em Norris et al. (2014) . . . . . . . . . . . . . . . . . . . 56

6.46 Desvios padrões em bases com outliers - Dist. Exponencial com média 3 - Proposta de incertezas definida em Norris et al. (2014) . . . . . . . . . . . . . . . . . 56

6.47 Perfis médios em bases com outliers - Dist. Exponencial com média 3 - Proposta de incertezas definida em Polissar et al. (1998) . . . . . . . . . . . . . . . . . 57

6.48 Desvios padrões em bases com outliers - Dist. Exponencial com média 3 - Proposta de incertezas definida em Polissar et al. (1998) . . . . . . . . . . . . . . . . 57

6.49 Perfis médios em bases com outliers - Dist. Exponencial com média 3 - Proposta de incertezas definida em Ito et al. (2004) . . . . . . . . . . . . . . . . . . . 57 
6.50 Desvios padrões em bases com outliers - Dist. Exponencial com média 3 - Proposta de incertezas definida em Ito et al. (2004) . . . . . . . . . . . . . . . . . . . . . 57

6.51 Perfis médios em bases com outliers - Dist. Exponencial com média 3 - Proposta de incertezas definida em Chueinta et al. (2000) . . . . . . . . . . . . . . . . . . 58

6.52 Desvios padrões em bases com outliers - Dist. Exponencial com média 3 - Proposta de incertezas definida em Chueinta et al. (2000) . . . . . . . . . . . . . . . . . . 58

6.53 Perfis médios em bases com outliers - Dist. Exponencial com média 3 - Proposta de incertezas de $20 \%$ do valor da medição . . . . . . . . . . . . . . . . . . . . 58

6.54 Desvios padrões em bases com outliers - Dist. Exponencial com média 3 - Proposta de incertezas de $20 \%$ do valor da medição . . . . . . . . . . . . . . . . . . . . . 58

6.55 Perfis médios em bases com outliers - Dist. Exponencial com média 3 - Proposta de incertezas de $10 \%$ do valor da medição . . . . . . . . . . . . . . . . . . 59

6.56 Desvios padrões em bases com outliers - Dist. Exponencial com média 3 - Proposta de incertezas de $10 \%$ do valor da medição . . . . . . . . . . . . . . . . . . . . 59

6.57 Perfis médios em bases com outliers - Dist. Exponencial com média 3 - Proposta de incertezas de $20 \%$ do valor da medição . . . . . . . . . . . . . . . . . . . 59

6.58 Desvios padrões em bases com outliers - Dist. Exponencial com média 3 - Proposta de incertezas de $20 \%$ do valor da medição . . . . . . . . . . . . . . . . . . . . 59

6.59 Perfis médios em bases com outliers - Dist. Exponencial com média 3 - Análise Fatorial Ortogonal - CP - Rotação Varimax . . . . . . . . . . . . . . . . . . . . . 60

6.60 Desvios padrões em bases com outliers - Dist. Exponencial com média 3 - Análise Fatorial Ortogonal - CP - Rotação Varimax . . . . . . . . . . . . . . . . . . . 60

6.61 Gráfico comparativo para o Perfil 1 . . . . . . . . . . . . . . . . . . . . . 60

6.62 Gráfico comparativo para o Perfil 2 . . . . . . . . . . . . . . . . . 60

6.63 Gráfico comparativo para o Perfil 3 . . . . . . . . . . . . . . . . . . . . 61

6.64 Gráfico comparativo para o Perfil 4 . . . . . . . . . . . . . . . . 61

6.65 Gráfico comparativo para o Perfil 5 . . . . . . . . . . . . . . . . . . . . 62

6.66 Gráfico comparativo para o Perfil 6 . . . . . . . . . . . . . . . . . . 62

6.67 Perfis médios em bases com outliers - Dist. Exponencial com média 9 - Proposta de incertezas definida em Norris et al. (2014) . . . . . . . . . . . . . . . . . . . . . . . . 62

6.68 Desvios padrões em bases com outliers - Dist. Exponencial com média 9 - Proposta de incertezas definida em Norris et al. (2014) . . . . . . . . . . . . . . . . . . . . . . 62

6.69 Perfis médios em bases com outliers - Dist. Exponencial com média 9 - Proposta de incertezas definida em Polissar et al. (1998) . . . . . . . . . . . . . . . . . 63

6.70 Desvios padrões em bases com outliers - Dist. Exponencial com média 9 - Proposta de incertezas definida em Polissar et al. (1998) . . . . . . . . . . . . . . . . . . . 63

6.71 Perfis médios em bases com outliers - Dist. Exponencial com média 9 - Proposta de incertezas definida em Ito et al. (2004) . . . . . . . . . . . . . . . . . . . . . . . 63

6.72 Desvios padrões em bases com outliers - Dist. Exponencial com média 9 - Proposta de incertezas definida em Ito et al. (2004) . . . . . . . . . . . . . . . . . . . . . 63

6.73 Perfis médios em bases com outliers - Dist. Exponencial com média 9 - Proposta de incertezas definida em Chueinta et al. (2000) . . . . . . . . . . . . . . . 
6.74 Desvios padrões em bases com outliers - Dist. Exponencial com média 9 - Proposta de incertezas definida em Chueinta et al. (2000) . . . . . . . . . . . . . . . 64

6.75 Perfis médios em bases com outliers - Dist. Exponencial com média 9 - Proposta de incertezas de $5 \%$ do valor da medição . . . . . . . . . . . . . . . . . 64

6.76 Desvios padrões em bases com outliers - Dist. Exponencial com média 9 - Proposta de incertezas de $5 \%$ do valor da medição . . . . . . . . . . . . . . . . 64

6.77 Perfis médios em bases com outliers - Dist. Exponencial com média 9 - Proposta de incertezas de $10 \%$ do valor da medição . . . . . . . . . . . . . . . 65

6.78 Desvios padrões em bases com outliers - Dist. Exponencial com média 9 - Proposta de incertezas de $10 \%$ do valor da medição . . . . . . . . . . . . . . 65

6.79 Perfis médios em bases com outliers - Dist. Exponencial com média 9 - Proposta de incertezas de $20 \%$ do valor da medição . . . . . . . . . . . . . . 65

6.80 Desvios padrões em bases com outliers - Dist. Exponencial com média 9 - Proposta de incertezas de $20 \%$ do valor da medição . . . . . . . . . . . . . . 65

6.81 Perfis médios em bases com outliers - Dist. Exponencial com média 9 - Análise Fatorial Ortogonal - CP - Rotação Varimax . . . . . . . . . . . . . . 66

6.82 Desvios padrões em bases com outliers - Dist. Exponencial com média 9 - Análise Fatorial Ortogonal - CP - Rotação Varimax . . . . . . . . . . . . . . 66

6.83 Gráfico comparativo para o Perfil $1 \ldots \ldots \ldots 6$

6.84 Gráfico comparativo para o Perfil $2 \ldots \ldots \ldots$. . . . . . . . . 66

6.85 Gráfico comparativo para o Perfil $3 \ldots \ldots \ldots$. . . . . . . . . 67

6.86 Gráfico comparativo para o Perfil $4 \ldots \ldots \ldots$. . . . . . . . . 67

6.87 Gráfico comparativo para o Perfil $5 \ldots \ldots \ldots \ldots$

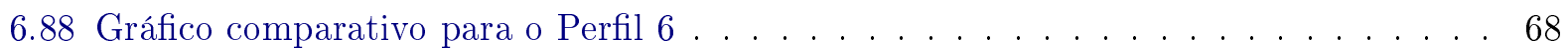

B.1 séries de emissões simuladas segundo perfis da tabela 4.2 - Fator $1 \ldots \ldots 7$

B.2 séries de emissões simuladas segundo perfis da tabela 4.2 - Fator $2 \ldots \ldots$. . . . . . 97

B.3 séries de emissões simuladas segundo perfis da tabela 4.2 - Fator 3 . . . . . . . . 97

B.4 séries de emissões simuladas segundo perfis da tabela 4.2 - Fator $4 \ldots \ldots$. . . . . . 98

B.5 séries de emissões simuladas segundo perfis da tabela 4.2 - Fator 5 . . . . . . . 98

B.6 séries de emissões simuladas segundo perfis da tabela 4.2 - Fator 6 . . . . . . . . 98

B.7 séries de emissões simuladas segundo perfis da tabela 4.2 com outliers - Exponencial com média 1,5 - Fator $1 \ldots \ldots \ldots$. . . . . . . . . . . . 99

B.8 séries de emissões simuladas segundo perfis da tabela 4.2 com outliers - Exponencial com média 1,5 - Fator $2 \ldots \ldots \ldots \ldots$. . . . . . . . . . . 99

B.9 séries de emissões simuladas segundo perfis da tabela 4.2 com outliers - Exponencial com média 1,5 - Fator $3 \ldots \ldots \ldots$. . . . . . . . . . . . . . 99

B.10 séries de emissões simuladas segundo perfis da tabela 4.2 com outliers - Exponencial com média 1,5 - Fator $4 \ldots \ldots$. . . . . . . . . . . . . 100

B.11 séries de emissões simuladas segundo perfis da tabela 4.2 com outliers - Exponencial com média 1,5 - Fator $5 \ldots \ldots$. . . . . . . . . . . . . . 100

B.12 séries de emissões simuladas segundo perfis da tabela 4.2 com outliers - Exponencial

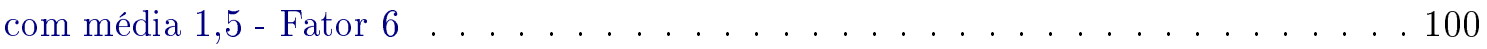


B.13 séries de emissões simuladas segundo perfis da tabela 4.2 com outliers - Exponencial com média 3 - Fator 1 . . . . . . . . . . . . . . . . . . . . . . . . . . 101

B.14 séries de emissões simuladas segundo perfis da tabela 4.2 com outliers - Exponencial com média 3 - Fator 2 . . . . . . . . . . . . . . . . . . . . . . . . . 101

B.15 séries de emissões simuladas segundo perfis da tabela 4.2 com outliers - Exponencial com média 3 - Fator 3 . . . . . . . . . . . . . . . . . . . . . . . . . . 101

B.16 séries de emissões simuladas segundo perfis da tabela 4.2 com outliers - Exponencial com média 3 - Fator 4 . . . . . . . . . . . . . . . . . . . . . . . . . . . . 102

B.17 séries de emissões simuladas segundo perfis da tabela 4.2 com outliers - Exponencial com média 3 - Fator 5 . . . . . . . . . . . . . . . . . . . . . . . . . . . 102

B.18 séries de emissões simuladas segundo perfis da tabela 4.2 com outliers - Exponencial com média 3 - Fator 6 . . . . . . . . . . . . . . . . . . . . . . . . 102

B.19 séries de emissões simuladas segundo perfis da tabela 4.2 com outliers - Exponencial com média 9 - Fator 1 . . . . . . . . . . . . . . . . . . . . . . . . . 103

B.20 séries de emissões simuladas segundo perfis da tabela 4.2 com outliers - Exponencial com média 9 - Fator 2 . . . . . . . . . . . . . . . . . . . . . . . . . 103

B.21 séries de emissões simuladas segundo perfis da tabela 4.2 com outliers - Exponencial com média 9 - Fator 3 . . . . . . . . . . . . . . . . . . . . . . . . . . 103

B.22 séries de emissões simuladas segundo perfis da tabela 4.2 com outliers - Exponencial com média 9 - Fator 4 . . . . . . . . . . . . . . . . . . . . . . . . . . . . . . . . . . 104

B.23 séries de emissões simuladas segundo perfis da tabela 4.2 com outliers - Exponencial com média 9 - Fator 5 . . . . . . . . . . . . . . . . . . . . . . . . . . . . . . . 104

B.24 séries de emissões simuladas segundo perfis da tabela 4.2 com outliers - Exponencial com média 9 - Fator 6 . . . . . . . . . . . . . . . . . . . . . . . . . . . . . . . . 104

B.25 séries de incertezas com proposta ref. Polissar et al. (1998) de emissões simuladas sem outliers segundo perfis da tabela 4.2 - Fator 1 . . . . . . . . . . . . . . . . 105

B.26 séries de incertezas com proposta ref. Chueinta et al. (2000) de emissões simuladas sem outliers segundo perfis da tabela 4.2 - Fator 1 . . . . . . . . . . . . . . . . . . 105

B.27 séries de incertezas com proposta ref. Ito et al. (2004) de emissões simuladas sem outliers segundo perfis da tabela 4.2 - Fator 1 . . . . . . . . . . . . . . . 105

B.28 séries de incertezas com proposta ref. Norris et al. (2014) de emissões simuladas sem outliers segundo perfis da tabela 4.2 - Fator 1 . . . . . . . . . . . . . . . . . . 106

B.29 séries de incertezas com proposta de $5 \%$ do valor de emissões simuladas sem outliers segundo perfis da tabela 4.2 - Fator 1 . . . . . . . . . . . . . . . . 106

B.30 séries de incertezas com proposta de $10 \%$ do valor de emissões simuladas sem outliers segundo perfis da tabela 4.2 - Fator 1 . . . . . . . . . . . . . . . . . 106

B.31 séries de incertezas com proposta de $20 \%$ do valor de emissões simuladas sem outliers segundo perfis da tabela 4.2 - Fator 1 . . . . . . . . . . . . . . . . 106

B.32 séries de incertezas com proposta ref. Polissar et al. (1998) de emissões simuladas com outliers - Exponencial com média 1,5 - segundo perfis da tabela 4.2 - Fator 1 . 107

B.33 séries de incertezas com proposta ref. Chueinta et al. (2000) de emissões simuladas com outliers - Exponencial com média 1,5 - segundo perfis da tabela 4.2 - Fator 1 . . 107 
B.34 séries de incertezas com proposta ref. Ito et al. (2004) de emissões simuladas com outliers - Exponencial com média 1,5 - segundo perfis da tabela 4.2 - Fator 1 . . . . 107

B.35 séries de incertezas com proposta ref. Norris et al. (2014) de emissões simuladas com outliers - Exponencial com média 1,5 - segundo perfis da tabela 4.2 - Fator 1 . . . . 108

B.36 séries de incertezas com proposta de $5 \%$ do valor de emissões simuladas com outliers

- Exponencial com média 1,5 - segundo perfis da tabela 4.2 - Fator 1 . . . . . . . 108

B.37 séries de incertezas com proposta de $10 \%$ do valor de emissões simuladas com outliers

- Exponencial com média 1,5 - segundo perfis da tabela 4.2 - Fator 1 . . . . . . . . 108

B.38 séries de incertezas com proposta de $20 \%$ do valor de emissões simuladas com outliers

- Exponencial com média 1,5 - segundo perfis da tabela 4.2 - Fator 1 . . . . . . . . 108

B.39 séries de incertezas com proposta ref. Polissar et al. (1998) de emissões simuladas com outliers - Exponencial com média 3 - segundo perfis da tabela 4.2 - Fator 1 . . . 109

B.40 séries de incertezas com proposta ref. Chueinta et al. (2000) de emissões simuladas com outliers - Exponencial com média 3 - segundo perfis da tabela 4.2 - Fator 1 . . . 109

B.41 séries de incertezas com proposta ref. Ito et al. (2004) de emissões simuladas com outliers - Exponencial com média 3 - segundo perfis da tabela 4.2 - Fator 1 . . . . . . 109

B.42 séries de incertezas com proposta ref. Norris et al. (2014) de emissões simuladas com outliers - Exponencial com média 3 - segundo perfis da tabela 4.2 - Fator 1 . . . . . 110

B.43 séries de incertezas com proposta de $5 \%$ do valor de emissões simuladas com outliers

- Exponencial com média 3 - segundo perfis da tabela 4.2 - Fator 1 . . . . . . . . . 110

B.44 séries de incertezas com proposta de $10 \%$ do valor de emissões simuladas com outliers

- Exponencial com média 3 - segundo perfis da tabela 4.2 - Fator 1 . . . . . . . . . 110

B. 45 séries de incertezas com proposta de $20 \%$ do valor de emissões simuladas com outliers

- Exponencial com média 3 - segundo perfis da tabela 4.2 - Fator 1 . . . . . . . . 110

B.46 séries de incertezas com proposta ref. Polissar et al. (1998) de emissões simuladas com outliers - Exponencial com média 9 - segundo perfis da tabela 4.2 - Fator 1 . . . 111

B.47 séries de incertezas com proposta ref. Chueinta et al. (2000) de emissões simuladas com outliers - Exponencial com média 9 - segundo perfis da tabela 4.2 - Fator 1 . . . 111

B.48 séries de incertezas com proposta ref. Ito et al. (2004) de emissões simuladas com outliers - Exponencial com média 9 - segundo perfis da tabela 4.2 - Fator 1 . . . . . 111

B.49 séries de incertezas com proposta ref. Norris et al. (2014) de emissões simuladas com outliers - Exponencial com média 9 - segundo perfis da tabela 4.2 - Fator 1 . . . . . . 112

B.50 séries de incertezas com proposta de $5 \%$ do valor de emissões simuladas com outliers

- Exponencial com média 9 - segundo perfis da tabela 4.2 - Fator 1 . . . . . . . . . 112

B.51 séries de incertezas com proposta de $10 \%$ do valor de emissões simuladas com outliers

- Exponencial com média 9 - segundo perfis da tabela 4.2 - Fator 1 . . . . . . . . . 112

B.52 séries de incertezas com proposta de $20 \%$ do valor de emissões simuladas com outliers

- Exponencial com média 9 - segundo perfis da tabela 4.2 - Fator 1 . . . . . . . . . 112 


\section{Lista de Tabelas}

2.1 Fontes identificadas e sua participação para a formação de $M P_{2.5}$, na campanha de inverno de 1997 (Castanho e Artaxo (2001)) . . . . . . . . . . . . . 7

2.2 Fontes identificadas e sua participação para a formação de $M P_{2.5}$, na campanha de verão de 1998 (Castanho e Artaxo (2001)) . . . . . . . . . . . . . . 8

2.3 Coeficientes de calibração sistema LFA EDXRF(Arana (2014)) . . . . . . . . . . . . 11

4.1 Cargas fatoriais rotacionadas, solução com 6 fatores explicando 78, $6 \%$ da variância da base de dados do estudo de dos Santos et al. (2014) . . . . . . . . . . . . . . 29

4.2 Matriz com perfis de fontes utilizadas para simulação . . . . . . . . . . . . . . 29

5.1 Matriz $\mathrm{F}-\mathrm{PMF} \ldots \ldots \ldots \ldots \ldots \ldots \ldots$

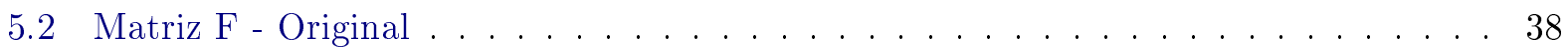

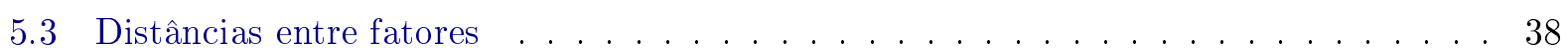

6.1 Limites de detecção mínimos $-n g / m^{3} \ldots \ldots \ldots \ldots$. . . . . . . . . . . 42

6.2 Valores médios de Q Robusto e desvios padrões para propostas de incertezas aplicadas em bases simuladas sem outliers . . . . . . . . . . . . . . . 68

6.3 Valores médios de Q Robusto e desvios padrões para propostas de incertezas aplicadas em bases simuladas com outliers - Dist. Exponencial média 1,5 . . . . . . . . 69

6.4 Valores médios de Q Robusto e desvios padrões para propostas de incertezas aplicadas em bases simuladas com outliers - Dist. Exponencial média 3 . . . . . . . . . 69

6.5 Valores médios de Q Robusto e desvios padrões para propostas de incertezas aplicadas em bases simuladas com outliers - Dist. Exponencial média 9 . . . . . . . . . 69

6.6 Coeficiente de variação para Q Robusto nos cenários de simulação . . . . . . . . . . . 69

6.7 Relação de grandeza entre os valores médios de Q-Robusto com base na referência Chueinta et al. (2000) para quatro situações de simulação . . . . . . . . . . . . 70 


\section{Capítulo 1}

\section{Introdução}

No estudo de poluição do ar, uma das formas usadas para a identificação de fontes emissoras de poluentes é o modelo receptor. Este modelo consiste em identificar e quantificar a partir da análise de concentração dos elementos químicos existentes no material particulado retido no receptor - por exemplo um filtro - as diversas fontes emissoras de poluentes existentes em determinada região. $\mathrm{O}$ modelo receptor mais utilizado é o CMB (Chemical Mass Balance). O modelo CMB consiste em um sistema de equações que representam a conservação de massa entre o que foi emitido e o que foi captado, considerando que não houve reação química entre os elementos emitidos até atingir o receptor (Henry et al. (1984)). Para resolver esse sistema, quando não se tem conhecimento sobre os perfis das fontes, nem em que quantidade se apresentam na região estudada, pode-se utilizar, entre outros métodos, modelos multivariados. Neste trabalho será analisado o modelo PMF(Positive Matrix Factorization), que tem entre suas características principais a fatoração da matriz de dados no produto de duas matrizes com entradas positivas, e também a possibilidade de inserção de medidas de incertezas para cada elemento, de cada medição, propiciando o controle sobre a influência de dados outliers na fatoração.

\subsection{Objetivos}

O método PMF apresentado em Paatero e Tapper (1994) tem como característica importante, além de manter a restrição de positividade dos dados, a possibilidade de inserir a incerteza relacionada a cada variável medida para cada indivíduo. Neste trabalho será desenvolvido um estudo de sensibilidade do modelo em relação a essas incertezas no contexto de análise de fontes emissoras de poluentes. No Capítulo 2 é feita uma introdução sobre o contexto de estudo de fontes poluentes, emissoras de material particulado, e da motivação do uso do modelo PMF. Em seguida é apresentada a estrutura matemática do modelo PMF. Como a motivação deste trabalho é estudar o comportamento do método conforme são inseridas as incerterzas de medição, também há uma seção para discutir sobre os procedimentos de preparação dos dados, e as principais fontes de incertezas. No Capítulo 3 é feito um resumo das principais funcionalidades dos programas EPA PMF 5.0 e ME-2, que foram os utilizados no desenvolvimento deste trabalho. No Capítulo 4 é feita a descrição da metodologia de simulação das bases de dados que foram utilizadas no estudo de sensibilidade da fatoração PMF. No Capítulo 5 são apresentados os detalhes técnicos de como foi feita a aplicação em série da fatoração PMF em cada uma das bases de dados simuladas utilizando o software ME-2, bem como a metodologia de identificação de perfis de fontes e de consolidação de resultados. No Capítulo 6 são apresentadas algumas das principais propostas de definição de incertezas presentes na literatura, e os resultados da aplicação da fatoração PMF nas bases de dados simuladas utilizando cada uma das propostas de definição de incertezas citadas. No Capítulo 7 são feitas algumas discussões sobre os resultados e apresentadas propostas para estudos futuros. 


\section{Capítulo 2}

\section{Conceitos}

Consideremos $X$ uma matriz de dados, em que cada linha representa uma observação, e cada coluna representa uma espécie química. Tais dados provêm de medições que geralmente são feitas através de um dispositivo receptor durante um determinado período - um dia por exemplo. O modelo receptor CMB consiste em um sistema de equações lineares que expressa a concentração dos elementos no receptor como uma soma de produtos entre os perfis das fontes (source profiles) e as contribuições das fontes (source contributions). Os perfis das fontes representam as proporções de massa ou concentração relativas a cada elemento emitido pela fonte, e as contribuições das fontes, a massa ou concentração emitida pela fonte que ele representa. Em outras palavras, o CMB representa cada observação com suas respectivas concentrações, como uma mistura de perfis de fontes, em que a contribuição de cada perfil na mistura é ponderada pela emissão de material que a fonte correpondente teve no período de medição. Podemos representar uma situação com $m$ observações e $n$ espécies químicas, e $p$ fontes, usando a seguinte notação matricial:

$$
X_{(m \times n)}=G_{(m \times p)} F_{(p \times n)},
$$

em que cada linha da matriz $F$ representa um perfil de fonte, e as $m$ linhas da matriz $G$ representam as contribuições de cada fonte - em suas colunas - para as $m$ observações.

Quando os perfis das fontes presentes são conhecidos, ou seja, a matriz $F$ é conhecida, o problema é aproximar a matriz $G$, isto é, obter as contribuições em massa ou concentração de cada fonte em cada medição. Para isso pode-se usar diversos métodos, como o método de mínimos quadrados. Em Henry et al. (1984) é feita uma sumarização de possíveis abordagens de solução para esta situação. Quando não se conhece o número de fontes presentes, e nem quais são, temos um problema multivariado, em que as matrizes $G$ e $F$ são desconhecidas.

Existem diversas formas de se estimar as matrizes $G$ e $F$. Duas formas muito conhecidas são a decomposição em valores singulares (SVD) e a Análise Fatorial ortogonal. Porém, estas duas formas de fatoração geram matrizes $G$ e $F$ com entradas não necessariamente não negativas. Quando o estudo em questão trata de medições de concentrações, quantidades negativas nem sempre têm algum significado (pode-se dizer que houve algum tipo de drenagem, mas em muitas situações esta possibilidade não existe).

Considerando tal restrição, um método que tem sido bastante utilizado em problemas de análises de poluentes nos quais se procura estimar as matrizes $G$ e $F$ do modelo CMB (2.1) apresentado acima, é o PMF, proposto em Paatero e Tapper (1994). Porém, ao estimar as matrizes $G$ e $F$, consideramos que pode haver erros oriundos do método de estimação, e para incluir tais erros no modelo reescrevemos a equação (2.1) como,

$$
X_{(m \times n)}=G_{(m \times p)} F_{(p \times n)}+E_{(m \times n)},
$$

incluido a matriz $E$ como a representação dos erros de estimação. 


\subsection{O Modelo PMF}

PMF é uma ferramenta de análise fatorial que decompõe uma matriz de dados amostrais positivos no produto de duas matrizes. No contexto de análise de poluentes, podemos interpretar como uma matriz que caracteriza os perfis das fontes, e outra que caracteriza as contribuições em concentração em massa total de material particulado de cada fonte em cada período de medição. Estes perfis posteriormente precisam ser interpretados de acordo com os conhecimentos que se tem sobre a composição química do material emitido por fontes que existem na região de coleta. A seguir serão apresentadas algumas características mais gerais sobre o modelo e na seção seguinte detalhes sobre aspectos práticos.

\subsubsection{A Função de perda}

A aproximação dos valores de $F$ e $G$ é obtida através da minimização de uma função de perda. Nesta função impõe-se a restrição de não negatividade ${ }^{1}$ aos elementos das matrizes, e inserem-se as incertezas (pesos) que estão relacionadas aos erros de medição. A função de perda é definida como:

$$
\begin{gathered}
Q=\sum_{i=1}^{m} \sum_{j=1}^{n}\left[\frac{x_{i j}-\sum_{k=1}^{p} g_{i k} f_{k j}}{u_{i j}}\right]^{2}, \\
\text { com } \quad g_{i k} \geq 0 \quad \text { e } f_{k j} \geq 0
\end{gathered}
$$

em que $u_{i j}$ é a incerteza relativa ao elemento $j$ na medição $i$. No caso da análise de elementos químicos, as incertezas $u_{i j}$ podem variar de elemento para elemento, pois dependem do método de análise e do limite de detecção dos aparelhos utilizados. Há também o caso de valores faltantes, em que se define um método para fazer imputação e um método para obter a incerteza (peso) relativa a esse valor obtido artificialmente.

\subsubsection{Incertezas das medições}

A matriz com as incertezas $u_{i j}$ deve ser definida como uma entrada do modelo. Existem diversos métodos para se obter a matriz de incertezas: um valor fixo para determinado elemento, ou uma fração da concentração, ou fórmulas que envolvam algum outro parâmetro e o limite de detecção dos equipamentos utilizados (Reff et al. (2007)). Como a estrutura da função de perda permite a inserção individual das incertezas para cada elemento da matriz de dados $X$, é possível definir estratégias para tratar dados outliers, pois quanto maior o valor da incerteza em relação à medição, menor influência o valor da medição terá no processo de minimização da função de perda, e consequentemente menor influência na definição dos valores das matrizes $F$ e $G$.

\subsubsection{Fatores: identificação e interpretação}

O número de fatores, ou o posto $p$ do modelo (2.2) geralmente é definido após diversas tentativas, até que se chegue a uma solução com fatores que contenham perfis de fontes que tenham algum sentido do ponto de vista físico. Ou seja, tendo conhecimento prévio do perfil de fontes emissoras de poluentes - proporção entre elementos químicos emitidos, ou quais são preponderantes em determinadas fontes - identificar entre as colunas de $F$ quais seriam equivalentes às fontes conhecidas. Diferentemente do modelo fatorial baseado na covariância dos dados, no modelo PMF não existe hierarquia entre os fatores, que também não são necessariamente ortogonais. Segundo Paatero e Tapper (1994), em ciências físicas os fatores raramente são ortogonais, embora no contexto de análise de poluentes seja comum assumir que as fontes emissoras sejam independentes, e dessa forma, utilizar a Análise Fatorial Ortogonal, como foi feito em dos Santos et al. (2014). Assim

\footnotetext{
${ }^{1}$ Notemos que embora o nome da fatoração seja Fatoração em Matrizes Positivas ou Positive Matrix Factorizarion em inglês, a restrição na definição do modelo é de não negatividade (vide Paatero e Tapper (1994)).
} 
como no modelo de análise fatorial, em que o número de fatores retidos geralmente depende de uma estratégia - no caso, analisam-se os autovalores da matriz de correlação, e os fatores relacionados com os autovalores maiores que 1 são retidos, ou a análise do scree plot com os autovalores - alguns autores também definem uma estratégia para se ter um palpite inicial sobre o número de fatores no modelo PMF. Uma estratégia que é citada em Reff et al. (2007), é analisar o valor de $Q$ em (2.3). Procura-se definir inicialmente o número de fatores de maneira que ao se obter um valor de mínimo para a função de perda (2.3), este seja aproximadamente m.n. Entretanto, veremos mais adiante que conforme mudamos o método usado para calcular as incertezas das medições, esse número tem uma variação muito grande, de modo que a eficácia de tal estratégia se torna questionável.

\subsection{Considerações sobre a aplicação do modelo PMF}

Embora o objetivo deste trabalho seja a análise do comportamento do modelo de acordo com os dados inseridos, alguns detalhes sobre questões práticas são importantes para facilitar o entendimento da aplicação do modelo. Detalhes sobre os métodos numéricos e softwares disponíveis para realizar os cálculos e a análise prévia dos dados serão discutidos nesta seção.

\subsubsection{Métodos para obtenção da fatoração PMF}

O modelo PMF é totalmente determinístico. Se não existissem os erros atribuídos às medições, as matrizes $G$ e $F$ determinariam a matriz $X(X=G F)$ "correta". Porém, considerando que existam os erros de medição $E$, a matriz $X$ que obteremos $(X=G F+E)$ será uma aproximação da matriz que seria a matriz "correta". Existem diversos métodos numéricos para a minimização da função de perda (2.3), e segundo Ramadan et al. (2003), conforme o algoritmo usado é possível obter resultados diferentes. Esses métodos dependem de um ponto inicial, que pode fazer o algoritmo chegar a um ponto de mínimo local, não definindo assim a fatoração $G F$ que gera a melhor aproximação de $X$. É importante notar, que a função de perda pode não ter apenas um ponto de mínimo local, o que pode levar a diversos resultados dependendo do ponto inicial escolhido. Segundo Norris et al. (2014) seção 1.1, o procedimento recomendado para aumentar a chance de se obter o ponto de mínimo global da função de perda, é aplicar o método 20 vezes para se obter uma solução inicial e 100 vezes para uma solução final, sempre iniciando o método em um ponto diferente.

O software utilizado neste estudo é o EPA PMF 5.0, desenvolvido pela U.S Environment Protection Agency, (Norris et al. (2014) e Norris et al. (2009)), que utiliza o software Multilinear Engine - ME-2, desenvolvido por Pentti Paatero em Paatero (1999) para o cálculo da fatoração GF.

No contexto de análise de poluentes, a fatoração apresentada até aqui é comumente referida como PMF (Positive Matriz Factorization), mas também é conhecida em outros contextos como por exemplo, bioinformática (Wang et al. (2006)) e classificação de documentos (Shahnaz et al. (2006)) por NMF (Non-negative matrix factorization). Em (Lee e Seung (1999)) foi apresentado um algoritmo muito usado para se obter a fatoração em estudo, onde também são apresentadas referências sobre aplicações. Embora existam diversos tipos de problemas para os quais é possível aplicar essa fatoração, em poucos as incertezas relacionadas às medições são inseridas no modelo. Em Wang et al. (2006) é apresentada uma modificação do algoritmo proposto em Lee e Seung (1999) para se considerar as incertezas no algoritmo de aproximação das matrizes $G$ e $F$.

\subsubsection{Preparação dos dados}

Inicialmente, todas as variáveis - elementos químicos - da base de dados coletada são consideradas, e em seguida é feita uma análise para decidir quais variáveis serão utilizadas no modelo. A escolha das variáveis e as incertezas associadas a elas dependem do objetivo do estudo e da qualidade dos dados. A seleção prévia das variáveis pode facilitar a interpretação da solução final do modelo. Geralmente alguns itens são analisados previamente, listamos alguns dos principais descrevendo os seus objetivos: 
- Relevância das variáveis (espécies químicas): verificar se há associação entre as variáveis, e se determinada variável é indicativa de algumas das fontes de interesse no estudo;

- Duplicação das medidas: verificar a presença de espécies redundantes, como enxofre e sulfatos (que contém enxofre);

- Dados faltantes: como o modelo requer que todos os dados da matriz sejam preenchidos, é preciso definir de antemão como tratar os casos de dados faltantes. Três propostas podem ser consideradas:

1. Excluir a observação na qual a medida da variável não está disponível. Esse procedimento é feito quando espécies químicas de grande importância, ou muitas espécies estão faltando para uma determinada observação;

2. Retirar a espécie da análise. Isso geralmente é feito quando um percentual grande de dados não estão disponíveis para tal espécie;

3. Definir uma estratégia de inserção artificial para os dados faltantes, e associar a estes dados artificiais incertezas grandes. As estratégias mais comuns de imputação são usar a média aritmética, geométrica ou ainda a mediana da variável;

- Dados abaixo do limite de detecção: cada espécie química pode ter um limite de detecção diferente, que depende do método utilizado para medir a concentração. Veremos adiante alguns detalhes sobre determinação dos limites de deteç̧ão. Assim como no caso de dados faltantes, medidas abaixo do limite de deteç̧ão são substituídos ou manipulados de acordo com alguma estratégia de imputação que está relacionada com o método adotado para determinar as incertezas de cada espécies química;

- Qualidade dos dados: analisar as incertezas se não são muito grandes em relação às medidas das variáveis (signal-to-noise ratio), ou se há contaminação nas medidas dos elementos. Espécies com resíduos escalonados $\left(\left(x_{i j}-g_{i k} f_{k j}\right) / u_{i j}\right)$ com valores muito grandes ou distribuídos de uma forma não normal, ou com grandes desvios, são indícios de um ajuste pobre para a espécie química.

Maiores detalhes podem ser encontrados em Reff et al. (2007) e Polissar et al. (1998).

\subsubsection{Outliers e $Q_{\text {robusto }}$}

Na Seção 2.1.2, falamos sobre a possibilidade de definir estratégias para tratar dados outliers, controlando sua importância ou peso na definição do resultado. Apesar de as matrizes de medições e a matriz com suas respectivas incertezas poderem ser manipuladas antes de serem inseridas no modelo, um controle é implementado durante processo de minimização da função de perda. Determina-se um parâmetro $\alpha$ que é chamado de distância-outlier, em que é determinado o tamanho máximo do resíduo escalonado. Seja o resíduo:

$$
e_{i j}=x_{i j}-g_{i k} f_{k j} .
$$

Uma função de perda alternativa é definida da seguinte forma:

$$
Q_{\text {robusto }}=\sum_{i=1}^{m} \sum_{j=1}^{n}\left(\frac{e_{i j}}{h_{i j} u_{i j}}\right)^{2},
$$

em que

$$
\begin{gathered}
\text { se }\left|e_{i j} / u_{i j}\right|>\alpha \quad \text { então } \quad h_{i j}=\left|e_{i j} / u_{i j}\right| / \alpha \\
h_{i j}=1 \quad \text { caso contrário. }
\end{gathered}
$$




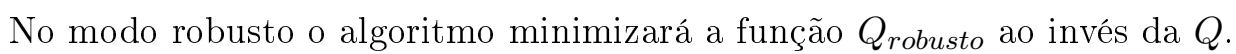

\subsection{Considerações sobre métodos de medição de concentração de espécies químicas no contexto de análise de poluentes}

Com o objetivo de entender como se formam as incertezas durante o processo de coleta e medição, para posteriormente fazer um estudo de sensibilidade do método PMF, parte deste trabalho foi dedicado ao estudo das metodologias analíticas usadas para obtenção dos dados. Nesta seção será feito um resumo destes processos.

Começamos descrevendo os tipos de materiais particulados atmosféricos estudados, que geralmente são de dois grupos: o de diâmetro aerodinâmico entre 2.5 e $10 \mu \mathrm{m}$ chamado de material particulado grosso, e o de diâmetro aerodinâmico inferior a $2.5 \mu \mathrm{m}$, chamado de material particulado fino. O interesse nesses dois tipos existe por serem inaláveis, e consequentemente por serem potenciais causadores de problemas de saúde. No trabalho de dos Santos Junior (2015) é feita uma descrição mais detalhada sobre as propriedades físicas e químicas de aerossóis atmosféricos, e dos processos de emissão destes na atmosfera. Os amostradores são filtros que são acoplados a uma bomba de sucção, que durante um determinado período de tempo, geralmente de 24 horas, filtra um volume determinado de ar. Uma amostra de controle de amostradores sem uso geralmente é separada - do mesmo lote dos que serão usados na amostragem - para poder medir a contaminação destes filtros que ainda estão em "branco", - pois isso afeta a medição - e posteriormente subtrair a média da concentração dos elementos presentes no amostrador em "branco" das amostras finais. Nem todas as espécies químicas são medidas através de um mesmo método, ou equipamento. Neste trabalho nos restringiremos à descrição do método de Fluorescência de Raios-X(EDXRF), pois através dele é possível quantificar grande parte dos elementos químicos de interesse na análise de poluentes. No trabalho de Oyama (2010) há uma descrição detalhada sobre outros métodos de quantificação de espécies químicas. Há também casos em que as medições são feitas com dois ou três filtros num mesmo local de interesse. Após a análise, considera-se o desvio da medição entre eles como mais uma medida de incerteza do processo, geralmente relacionada ao processo de manipulação dos amostradores e fatores de campo.

\subsubsection{Elementos traçadores}

Como dito na Seção 2.2.2, sobre o tratamento dos dados, um dos fatores a se considerar é a relevância das variáves medidas. A caracterização de uma fonte emissora de poluente se dá pela identificação de determinados elementos químicos que ela emite conjuntamente, e em proporções específicas. Esse conjunto de informações é chamado de assinatura da fonte, ou perfil da fonte. Os elementos químicos dos componentes desta assinatura, são chamados de traçadores. Seguem abaixo alguns exemplos extraídos da compilação feita no trabalho de Oyama (2010) de estudos realizados em São Paulo:

Tabela 2.1: Fontes identificadas e sua participação para a formação de $M P_{2.5}$, na campanha de inverno de 1997 (Castanho e Artaxo (2001))

\begin{tabular}{cccc}
\hline \hline Fator & Elementos-Traço & Fonte Identificada & Participação(\%) \\
\hline 1 & $\mathrm{Al}, \mathrm{Si}, \mathrm{Ca}, \mathrm{Ti}$ e Fe & Solo & 20 \\
2 & $\mathrm{Cu}, \mathrm{BC}$ e Pb & Emissões Veiculares & 28 \\
3 & $\mathrm{~S}, M P_{2.5}$ e K & Sulfatos & 23 \\
4 & $\mathrm{~V} \mathrm{e} \mathrm{Ni}$ & Queima de óleo combustível & 18 \\
5 & $\mathrm{Zn}, \mathrm{Pb}$, e Mn & Emissões Industriais & 5 \\
6 & $\mathrm{Ti}, \mathrm{Ca}, \mathrm{Mn}$, e Fe & Solo 2 & 5 \\
\hline
\end{tabular}


Tabela 2.2: Fontes identificadas e sua participação para a formação de $M P_{2.5}$, na campanha de verão de 1998 (Castanho e Artaxo (2001))

\begin{tabular}{cccc}
\hline \hline Fator & Elementos-Traço & Fonte Identificada & Participação(\%) \\
\hline 1 & $\mathrm{Ca}, \mathrm{Ti}, \mathrm{Si} \mathrm{e} \mathrm{Fe}$ & Solo & 30 \\
2 & $\mathrm{Zn}, \mathrm{Mn} \mathrm{e} \mathrm{Pb}$ & Emissões Industriais & 6 \\
3 & $\mathrm{~S}, M P_{2.5}$ e K & Sulfatos & 17 \\
4 & $\mathrm{BC} \mathrm{e} \mathrm{Cu}$ & Emissões Veiculares & 24 \\
5 & $\mathrm{Ni} \mathrm{e} \mathrm{Mn}$ & Queima de óleo combustível & 21 \\
\hline
\end{tabular}

Nas Tabelas 2.1 e 2.2, nas colunas "Elementos-Traço" estão agrupados os elementos químicos presentes nas amostras que foram utilizadas para identificar cada tipo de fonte presente no local de estudo. Notemos que um mesmo tipo de fonte, como por exemplo "solo", pode ter elementos traçadores diferentes dependendo das características da região onde é realizado o estudo.

A agência de proteção ambiental dos Estados Unidos, EPA (Enviroment Protection Agency), mantém em seu website uma base de dados com um inventário de diversos perfis de fontes já identificados nos EUA. Esta base de dados se chama "SPECIATE", e atualmente está na versão 4.4. São possíveis consultas online, com filtro por categoria de fontes de poluentes, como por exemplo, por compostos orgânicos voláteis (VOC - Volatile Organic Compound), por perfis de fontes em materiais particulados (PM - Particulate Matter), ou fazer a busca por uma espécie química específica nas diversas fontes poluentes que ela possa compor (Figura 2.1). Também é possível fazer download do banco de dados inteiro no formato MS Access, caso seja necessário manipular essas bases de dados.

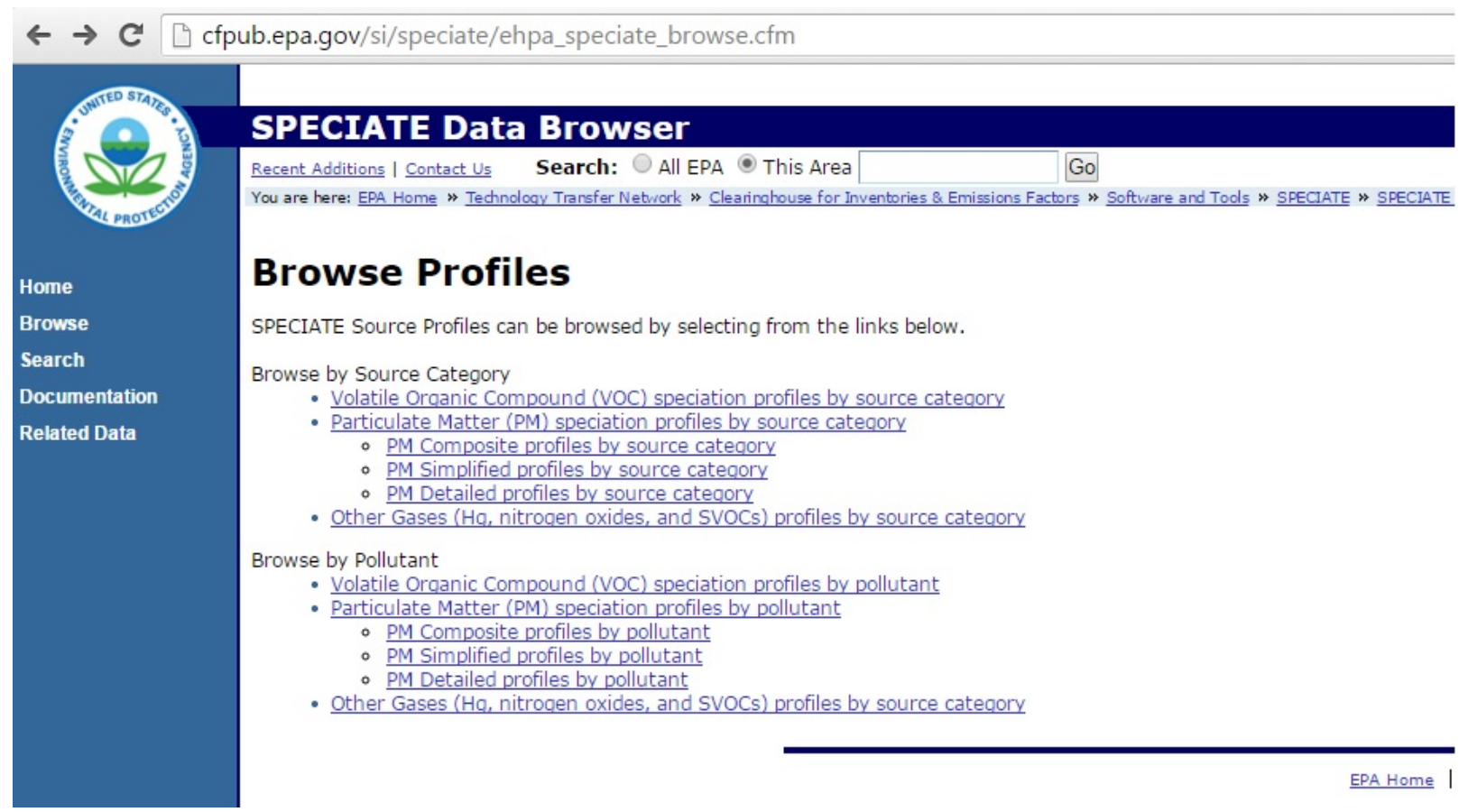

Figura 2.1: Menu SPECIATE - EPA Fonte: https://cfpub.epa.gov/si/speciate/

A Figura 2.2 mostra o perfil de Light Duty Vehicles, com os percentuais em massa de cada espécie química desta fonte, bem como a incerteza relacionada a cada espécie medida. 


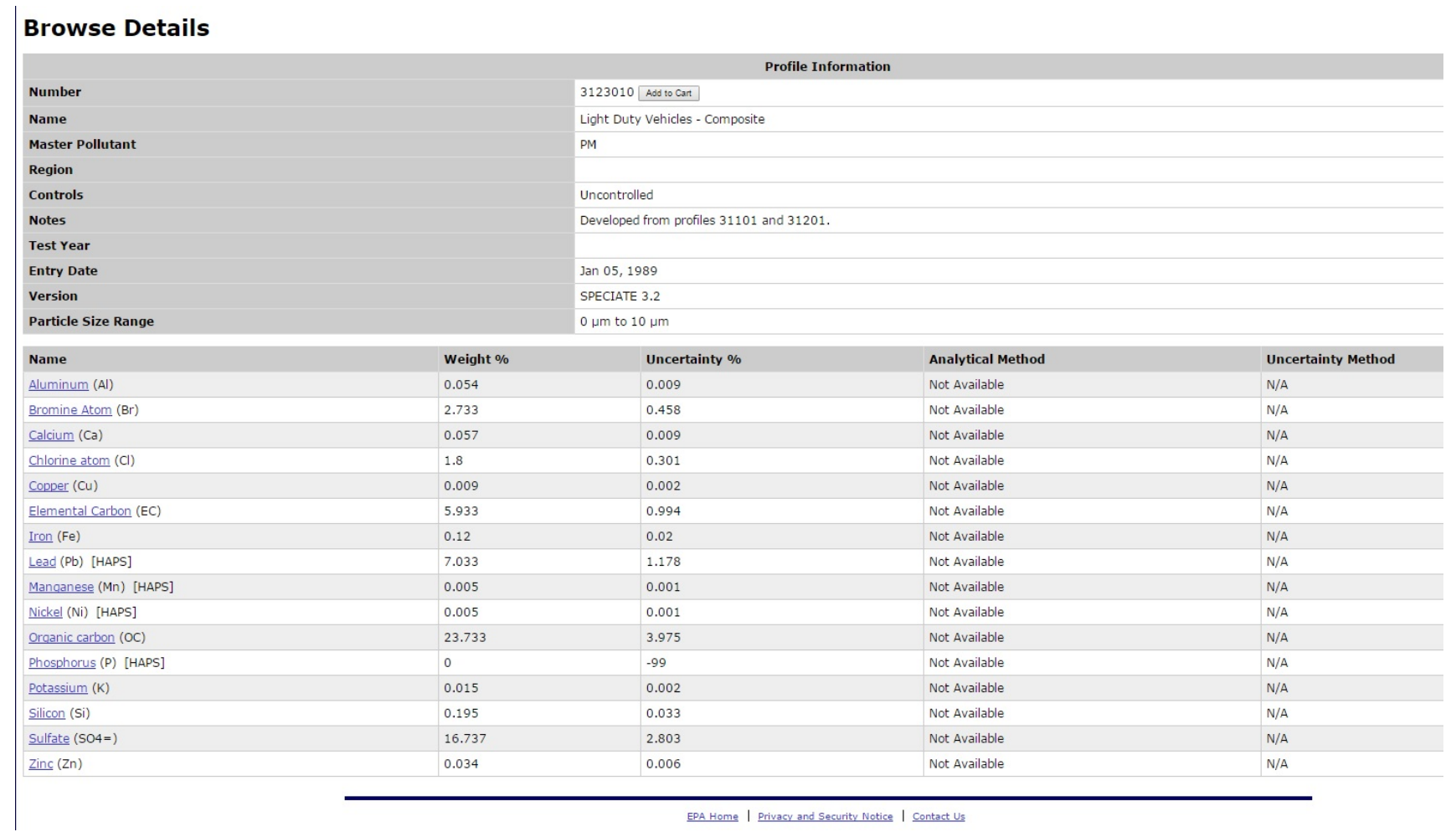

Figura 2.2: Perfil SPECIATE - Light Duty Vehicles - Composite - Fonte: https://cfpub.epa.gov/si/ speciate/

Embora seja uma base de dados com muita informação, em muitos casos os métodos analíticos usados para a medição das espécies e a metodologia para auferir a incerteza não estão disponíveis, como podemos notar na Figura 2.2. Ainda sobre o "SPECIATE", em alguns perfis a soma do percentual das massas das espécies químicas não somam 100, pois conforme dito anteriormente, pode haver repetição de um mesmo elemento químico em duas espécies químicas que foram medidas usando metódos diferentes, o que gera redundância. A documentação completa desta base de dados pode ser encontrada em Kosusko (2014).

\subsubsection{Incertezas analíticas}

A literatura se refere à incerteza analítica como toda medida de incerteza que é relacionada ao dispositivo, ou método de medição da concentração de uma espécie química. Para um mesmo método, como é o caso de Fluorescência de Raios-X (EDXRF - do inglês Energy Dispersive Xray Flourescence), a incerteza pode variar de elemento para elemento. Como grande parte dos elementos químicos usados para identificar as fontes de poluentes podem ser medidos através do método EDXRF, nesta seção apresentaremos alguns aspectos técnicos deste método, e algumas fontes de incertezas relacionadas a ele.

Existe um extensa teoria sobre os raios X, e suas interações com a matéria. O que vamos expor é apenas a ideia básica de parte desta teoria, baseada na síntese feita por Arana (2014), que tem relação com o método em questão, com o objetivo de identificar como as incertezas de medição podem surgir.

Os raios X são ondas eletromagnéticas, assim como os raios de luz visíveis, carregadas por partículas chamadas fótons, que possuem energia da mesma ordem de magnitude das energias de ligação dos elétrons nas camadas internas de um átomo. Quando os raios X incidem sobre a matéria um dos resultados é a flourescência, que é de interesse do método EDXRF. A flourescência depende da espessura, densidade e composição do material e também da energia dos raios X incidentes.

$\mathrm{O}$ raios $\mathrm{X}$ podem ser ajustados para ter a energia característica da camada atômica de interesse 
de um determinado elemento. Ao ser direcionado à amostra contendo o elemento químico de interesse, o fóton pode ser absorvido por um elétron da camada interna do átomo, e este será expulso deixando o átomo em uma situação de instabilidade. A situação de estabilidade é retomada quando um elétron de uma camada mais externa, este com mais energia, assume a posição do primeiro elétron, que foi expulso. A energia excedente deste elétron mais externo pode ser dissipada em forma de flourescência, ou seja, um raio X característico do elemento, como ilustrado na Figura 2.3. É importante notar que nem sempre esse processo é preciso.

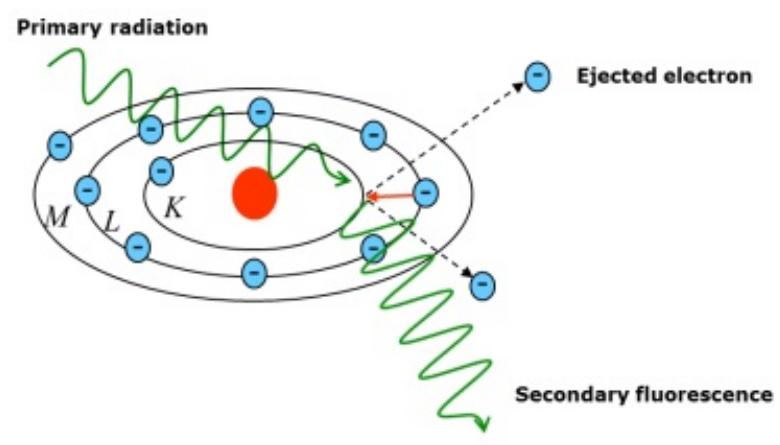

Figura 2.3: Incidencia de raio $X$ característico fonte: http://www.handheldxrf.com.au/technology_handheld_xrf.php

Conforme vemos na Figura 2.4, os raios X emitidos são captados por um detector que faz a contagem dos fótons emitidos em um período de tempo fixo, e a partir dessa contagem é possível medir a quantidade de cada elemento químico presente na amostra. É importante notar que não são todos os elementos químicos que o método EDXRF é capaz de medir.

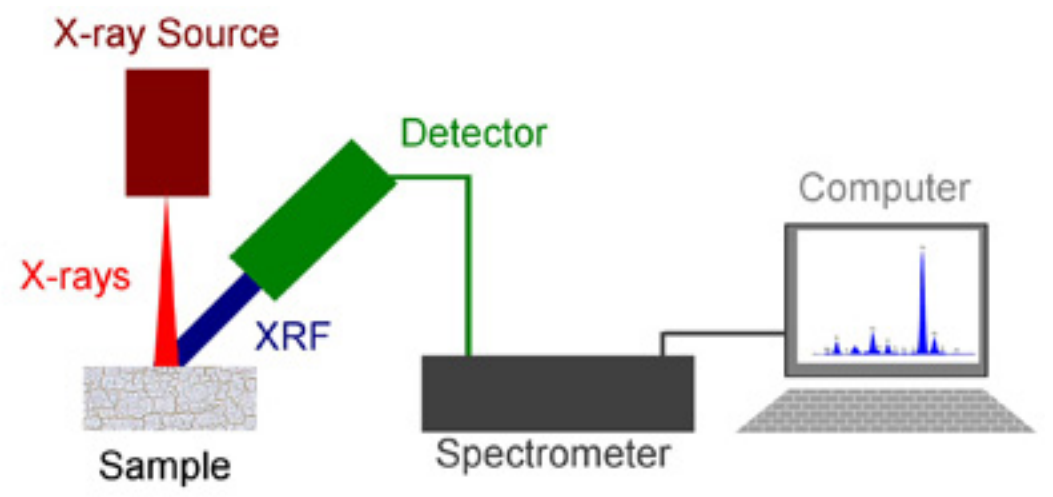

Figura 2.4: EDXRF fonte:

http://www.horiba.com/scientific/products/x-ray-fluorescence-analysis/tutorial/xrf-spectroscopy/

Baseando-se em quantidades conhecidas de elementos químicos em um recorte com área determinada do filtro amostrador (padrões), obtêm-se pontos com valores registrados pelo detector, em contagens de fótons, de acordo com a quantidade do elemento presente no padrão. Aqui vale notar, que mesmo essas quantidades conhecidas apresentam uma determinada incerteza.

Então é feito o ajuste de uma reta sobre estes pontos, obtendo-se um gráfico com a concentração por área no eixo $\mathrm{x}$, e no eixo $\mathrm{y}$, o valor da intensidade em contagens por segundo. Na Tabela 2.3 é apresentado um exemplo dos valores de calibração do dispositivo de EDXRF, do Laboratório de Física Atmosférica da Universidade de São Paulo (LFA/IFUSP) obtidos para o trabalho de Arana (2014).

Notemos que os valores da coluna Incerteza Relativa da Tabela 2.3 são obtidos a partir da 
Tabela 2.3: Coeficientes de calibração sistema LFA EDXRF(Arana (2014))

\begin{tabular}{ccc}
\hline \hline Elemento & Coeficientes de calibração $\left(\mathrm{cps} \mathrm{mA} n g^{-1} \mathrm{~cm}^{2}\right)$ & Incerteza relativa(\%) \\
\hline $\mathrm{Na}$ & $7,18 E-05 \pm 2,59 E-06$ & 3,61 \\
$\mathrm{Mg}$ & $1,39 E-04 \pm 3,66 E-06$ & 2,63 \\
$\mathrm{Al}$ & $1,79 E-04 \pm 4,84 E-06$ & 2,70 \\
$\mathrm{Si}$ & $3,48 E-04 \pm 1,32 E-05$ & 3,79 \\
$\mathrm{P}$ & $4,86 E-04 \pm 2,29 E-05$ & 4,71 \\
$\mathrm{~S}$ & $1,60 E-03 \pm 4,04 E-05$ & 2,53 \\
$\mathrm{Cl}$ & $2,54 E-03 \pm 1,02 E-04$ & 4,02 \\
$\mathrm{~K}$ & $4,70 E-03 \pm 8,38 E-05$ & 1,78 \\
$\mathrm{Ca}$ & $1,99 E-03 \pm 5,47 E-05$ & 2,75 \\
$\mathrm{Ti}$ & $1,42 E-03 \pm 2,93 E-05$ & 2,06 \\
$\mathrm{~V}$ & $1,80 E-03 \pm 4,50 E-05$ & 2,50 \\
$\mathrm{Cr}$ & $2,50 E-03 \pm 6,27 E-05$ & 2,51 \\
$\mathrm{Mn}$ & $4,34 E-03 \pm 1,25 E-04$ & 2,88 \\
$\mathrm{Fe}$ & $5,35 E-03 \pm 1,27 E-04$ & 2,37 \\
$\mathrm{Ni}$ & $8,23 E-03 \pm 2,06 E-04$ & 2,50 \\
$\mathrm{Cu}$ & $9,22 E-03 \pm 1,89 E-04$ & 2,05 \\
$\mathrm{Zn}$ & $1,16 E-02 \pm 3,02 E-04$ & 2,60 \\
$\mathrm{Br}$ & $7,93 E-03 \pm 2,81 E-04$ & 3,54 \\
$\mathrm{Rb}$ & $1,04 E-02 \pm 1,48 E-05$ & 0,14 \\
$\mathrm{~Pb}$ & $2,20 E-03 \pm 4,49 E-05$ & 2,04 \\
\hline
\end{tabular}

margem de variação proveniente do ajuste dos coeficientes de calibração, em que cada valor de incerteza relativa é a porcentagem da margem em relação ao coeficiente. Essa medida de incerteza é tomada como incerteza analítica do método de medição.

\subsubsection{Limites de Detecção}

No processo de medição dos elementos, é preciso considerar a quantidade mínima que os métodos podem detectar. Como o método EDXRF é usado para detectar a maioria dos elementos traçadores - partir do número atômico 11, elemento $\mathrm{Na}$ - e por ele apresentar a peculiaridade de ter variação de elemento a elemento, tanto nas incertezas quanto no limite de detecção mínimo, vamos nos ater a continuar a descrição deste método.

O limite de deteção no método EDXRF depende diretamente do ruído que o dispositivo produz quando o ajuste da medição para um determinado elemento é feita a partir de um filtro em branco. A medida deste ruído é também chamada de background, fundo ou continuum. Portanto, o limite de detecção pode variar de acordo com a amostra de controle de filtros em branco.

Existem diferentes abordagens para calcular o limite de detecção a partir do background. No trabalho de Arana (2014) foi calculado como sendo 3 vezes a raiz quadrada da razão do background, $r_{b}$, pelo tempo, $t_{b}$, de medição aplicado em cada elemento em particular:

$$
L D=\frac{3}{S} \sqrt{\frac{r_{b}}{t_{b}}}
$$

em que S é a sensiblidade resultante do número de contagens por segundo, Figura 2.5.

Uma outra a maneira para se aproximar o limite de detecção, é obter um número suficientemente grande de amostras, e fazer uma análise gráfica. Medindo algumas vezes uma mesma observação, espera-se uma variação de resultados. Conforme a concentração diminui, e se aproxima do limite de detecção, os desvios tendem a se estabilizar, determinando assim um parâmetro para estimar o limite de deteç̧ão. 


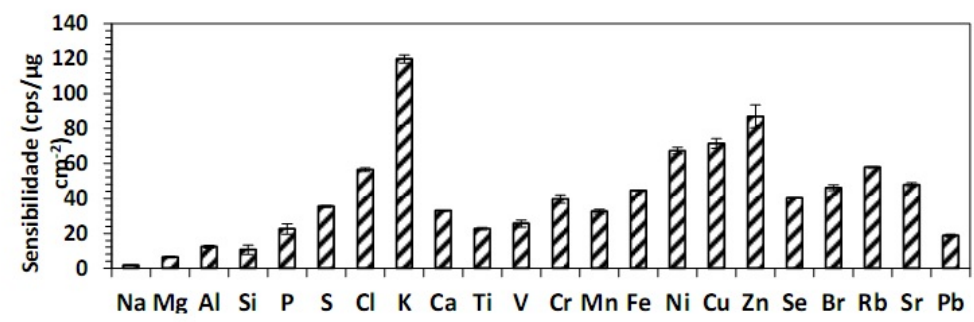

Figura 2.5: Sensibilidade elementar em função dos elementos químicos contidos nos padrões fabricados pela MicroMatter Arana (2014)

Em Gieken e Markowicz (2002), Capítulo 5, é feita uma discussão mais detalhada sobre a aproximação do limite de deteç̧ão, levando em conta detalhes do procedimento.

A Figura 2.6 apresenta um exemplo de espectro ajustado pelo programa WinQxas, ilustrando os picos de contagem acima do background.

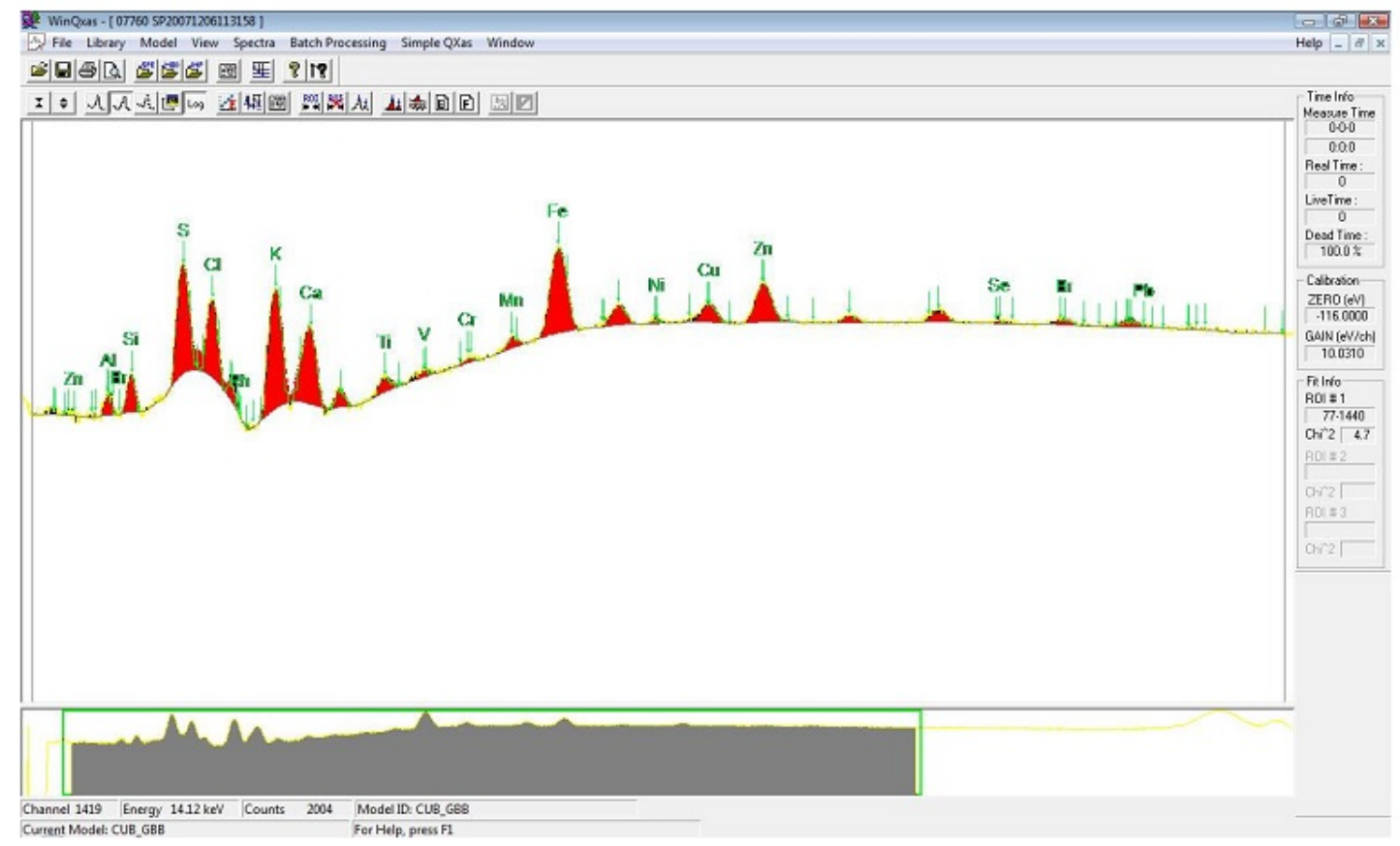

Figura 2.6: WinQxas - Espectro típico gerado por EDX. Fonte: Oyama (2010) 


\section{Capítulo 3}

\section{Os programas EPA PMF 5.0 e ME-2}

Como dito na Seção 2.2.1, o software usado para o estudo da fatoração PMF foi o EPA PMF 5.0, que por sua vez usa o software Multilinear Engine 2 - ME-2. Ambos operam no ambiente do sistema operacional Microsoft Windows. Basicamente, todos os resultados do program da EPA, são calculados pelo ME-2. Porém, o ME-2 é um programa em que suas configurações são feitas via arquivos de script. $\mathrm{O}$ arquivo de entrada tem de ser montado com um formato específico em texto, e os arquivos de saída também são arquivos de texto, sem gráficos, ou outros recursos visuais que facilitem a interpretação dos resultados pelo usuário. Toda a execução é feita via linha de comando. Esse modo de operação torna a sua utilização pouco prática.

O EPA PMF 5.0 é uma interface gráfica que faz com que a operação fique mais ágil. A definição da entrada das matrizes de dados pode ser feita apontando para planilhas eletrônicas, e os resultados também são montados em planilhas eletrônicas. Há uma gama de recursos gráficos para análise prévia e preparação dos dados (Menu Model Data), como dito na Seção 2.2.2, cujos detalhes vamos expor mais adiante. Para a análise dos resultados (Menu Base Model), também existem diversos recursos, como gráficos que facilitam a identificação dos perfis das fontes, a visualização do comportamento da série de tempo do modelo predito, e histogramas com a distribuição dos resíduos por variável. O ME-2 implementa também recursos para a análise da qualidade da solução, como reamostragens (bootstrap) de um subconjunto dos dados, e recursos para exploração de ambiguidades rotacionais, que não serão explorados neste trabalho, embora mais adiante façamos uma breve exposição destes recursos que acompanham a interface EPA PMF 5.0.

\subsection{Recursos do EPA PMF 5.0}

Nesta seção será feita a exposição de alguns dos recursos do EPA PMF 5.0 com o objetivo de ilustrar as funções que ele indiretamente opera do motor de fatoração ME-2 (Multilinear Engine 2).

\subsubsection{Model Data}

A interface inicial, "Model Data", Figura 3.2 é a de entrada de dados, onde o usuário define as planilhas com as matrizes de dados e incertezas. No lugar da matriz de incertezas também é possível inserir parâmetros para que as incertezas sejam calculadas como uma função - pré-definida pelo programa - dos valores das medidas e do limite de deteç̧ão $u_{i j}$ de cada espécie química (equação $3.1)$,

$$
u_{i j}= \begin{cases}(5 / 6) \times L D_{j} & \text { se } x_{i j}<L D_{j}, \\ \sqrt{\left(\operatorname{Perc}_{j} \times x_{i j}\right)^{2}+\left(0,5 \times L D_{j}\right)^{2}} & \text { se } x_{i j} \geq L D_{j},\end{cases}
$$

em que $L D_{j}$ é o limite de deteç̧ão da $j$-ésima espécie química, e $P e r c_{j}$ é a porcentagem da medição da $j$-ésima espécie química. A Figura 3.1, ilustra a forma como os parâmetros devem ser definidos na planilha que é inserida no lugar da matriz de incertezas. A primeira linha deve conter o nome 
das espécies químicas medidas, na segunda linha os respectivos limites de detecção $\left(L D_{j}\right)$. A terceira linha deve conter a porcentagem da medição $\left(P e r c_{j}\right)$ da respectiva espécie química, conforme descrito em (3.1).

\begin{tabular}{|r|r|r|r|r|r|}
\hline \multicolumn{1}{|c|}{ A } & \multicolumn{1}{c|}{ B } & \multicolumn{1}{c|}{ C } & \multicolumn{1}{c|}{ D } & \multicolumn{1}{c|}{ E } \\
\hline 1 & BOD $_{5}$ & TSS & $\mathrm{NH}_{3}$ & TP & Cd \\
\hline 2 & 5 & 20 & 5 & 0.2 & 0.00005 \\
\hline 3 & 10 & 10 & 10 & 10 & 10 \\
\hline 4 & & & & & \\
\hline
\end{tabular}

Figura 3.1: Matriz com parâmetros para calcular incertezas segundo formula pré definida em EPA PMF 5.0

Nesta interface também é possível definir um número marcador para dados faltantes e optar pelas duas estratégias de tratamento para estes: excluir toda a observação da análise ou fazer a imputação com a mediana da variável para a qual o dado está faltando. Estão disponíveis também outros recursos, como o tipo de arquivo de saída, o nome padrão deste, e ao se optar por mais de uma execução do método variando o ponto inicial, escrever apenas a execução com o menor valor de mínimo para a função de perda dentre todas as execuções no arquivo de saída, ou todos os resultados não apenas o de menor valor.

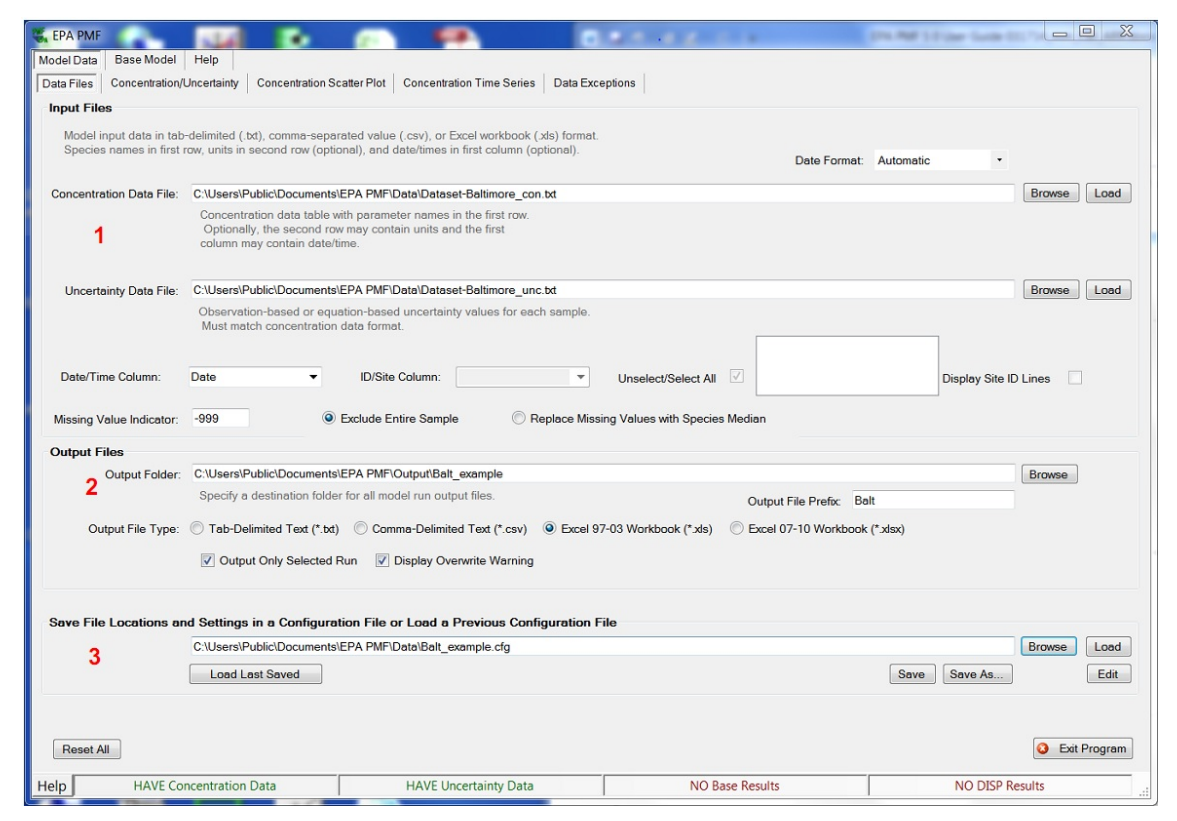

Figura 3.2: Interface de entrada de dados EPA PMF 5.0 Fonte: Norris et al. (2014)

Após os dados serem inseridos, algumas estatísticas descritivas e modos gráficos são disponibilizados, juntamente com alguns recursos para manipular as dados antes de aplicar a fatoração. Na Figura 3.3, são exibidas as espécies químicas inseridas para a análise. Entre as estatísticas descritivas, vale notar o $S / N$ - Signal to Noise Ratio. Essa estatística fornece uma medida de quanto de ruído as medições de uma determinada espécie química é composta (considerando as incertezas dadas a cada observação). O cálculo desta quantidade para uma variável é feito da maneira a seguir.

Seja:

$$
\begin{gathered}
d_{i j}=\left(\frac{x_{i j}-u_{i j}}{u_{i j}}\right) \quad \text { se } \quad x_{i j}>u_{i j} \\
d_{i j}=0 \quad \text { se } \quad x_{i j} \leq u_{i j} .
\end{gathered}
$$


Usando (3.2) calculamos:

$$
\left(\frac{S}{N}\right)_{j}=\frac{1}{n} \sum_{i=1}^{m} d_{i j} .
$$

Pela equação (3.2) podemos ver que quanto mais próximo de $x_{i j}$ a sua incerteza $u_{i j}$ estiver, mais próxima de zero a contribuição de $x_{i j}$ será em seu $S / N$. Segundo Norris et al. (2014), espécies com $S / N$ maiores que 1 tem um "bom" sinal. Na Figura 3.3, podemos ver opções Bad, Weak e Strong. Por padrão o programa define todas como Strong, e cabe ao usuário, conforme julgue necessário mudar esta marcação para cada variável, afetando assim o valor das incertezas originalmente atribuídas a cada observação da variável. Quando a marcação é alterada para Weak, o programa triplica a incerteza original, quando é alterada para $B a d$, a variável é excluída da amostra. A opção Total Variable (Defaults to Weak) é usada quando a massa total do material particulado é inserido no modelo como uma espécie química. Esta opção automaticamente muda a variável selecionada para tipo Weak. A discussão sobre a aplicação desta opção foge ao escopo deste trabalho, mais informações podem ser encontradas na seção Data Preparation de Reff et al. (2007). Há ainda a opção Extra Modeling Uncertainty (0-100\%), que se atribuída uma porcentagem acima de zero, soma a todas as incertezas de todas as variáveis, uma porcentagem da medição de cada variável, como na equação (3.4) abaixo:

$$
u(\text { total })_{i j}=u_{i j}+x_{i j} * \text { percentual }
$$

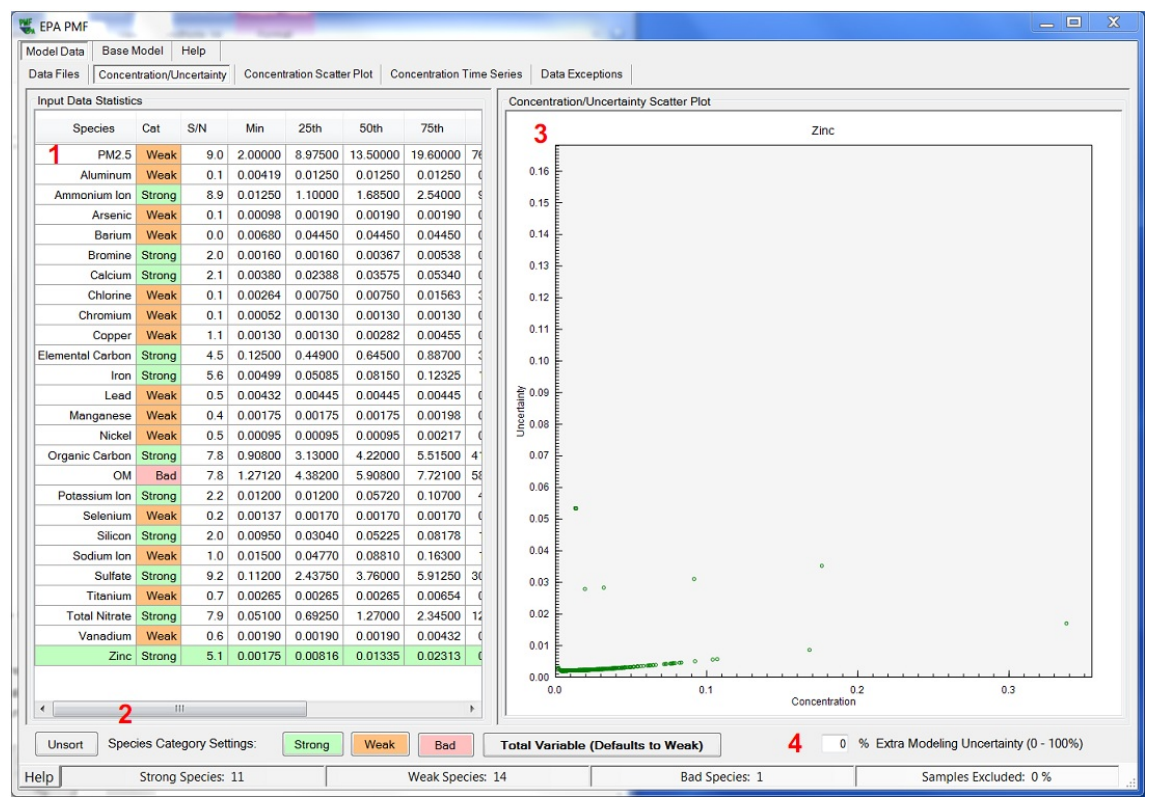

Figura 3.3: Interface de análise da qualidade dos dados EPA PMF 5.0 Fonte: Norris et al. (2014)

Recursos gráficos com a possibilidade de cruzamento de variáveis para análise de correlação ou observação da série de tempo das variáveis para verificação de eventos aberrantes (e a possibilidade de exclusão destes períodos) estão disponíveis em Concentration Scatter Plot e Concentration Time Series, Figura 3.4. 

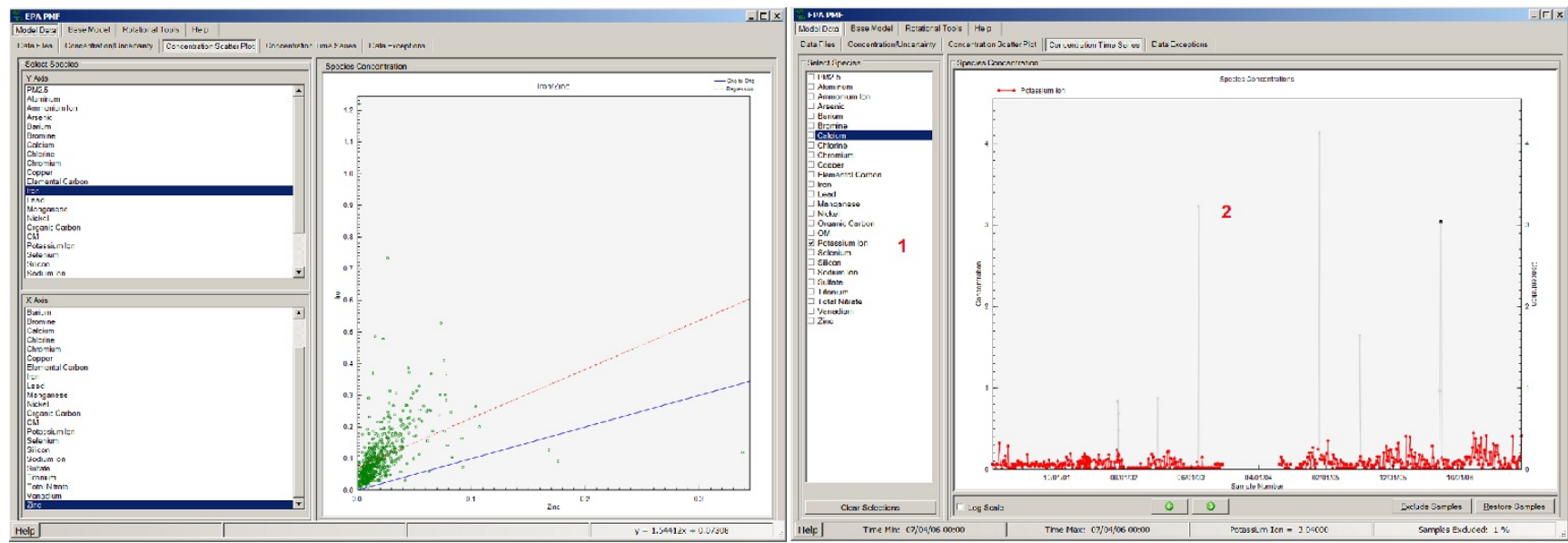

Figura 3.4: Concentration Scatter Plot e Concentration Time Series EPA PMF 5.0 Fonte: Norris et al. (2014)

\section{Base Model/ Base Model Runs}

Após realizar a análise preliminar dos dados, em Base Model/Base Model Runs, Figura 3.5, é possível ajustar os três parâmetros que são necessários para executar a fatoração: o número de rodadas de fatoração que o usuário deseja realizar variando o ponto inicial do algoritmo, o número de fatores, ou seja, $p$ em (2.3), deixar que o programa escolha aleatoriamente um número inicial para as sementes do algoritmo, ou fixar um em particular com o propósito de repetir o experimento.

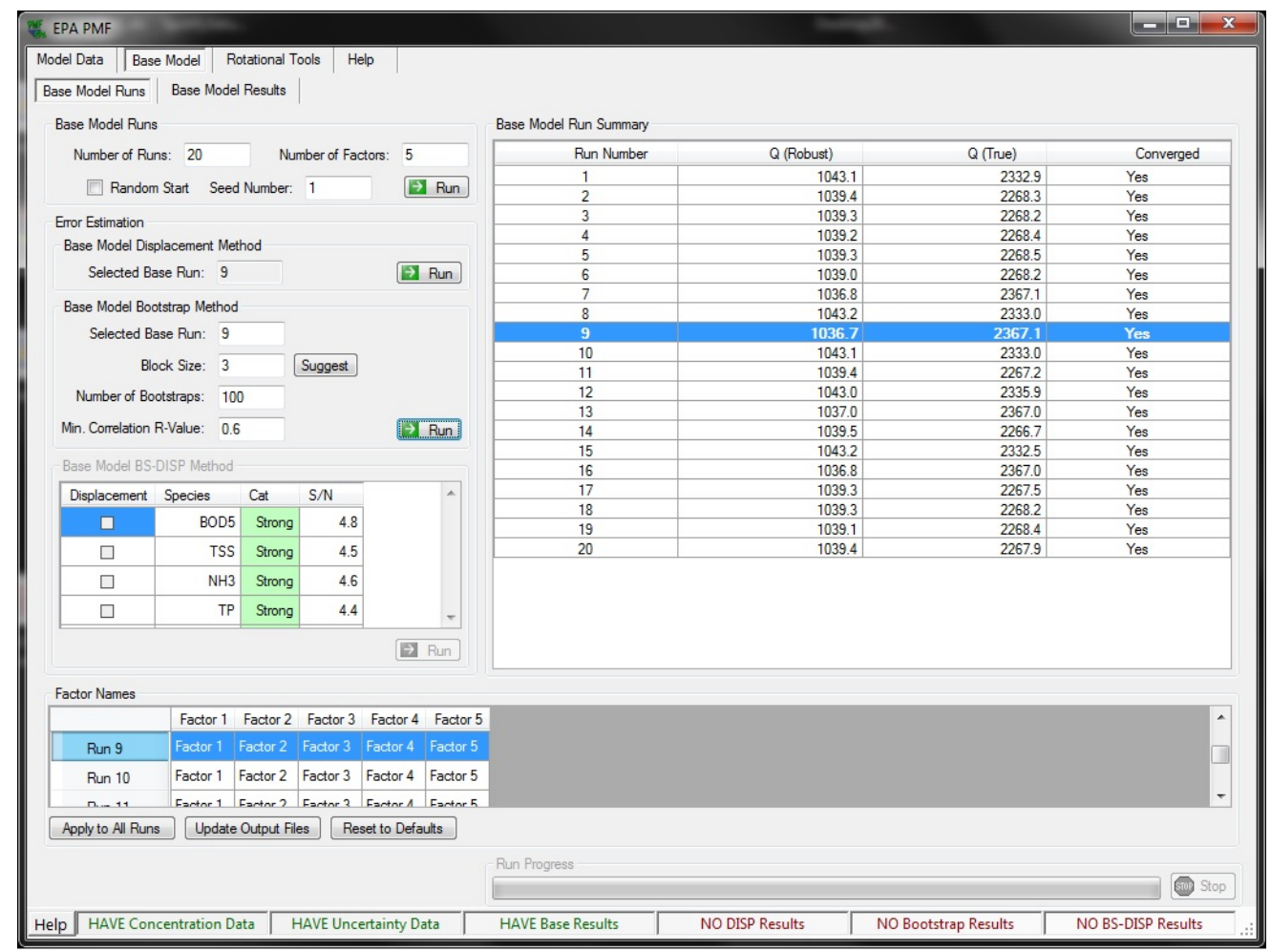

Figura 3.5: Menu Base Model Runs

\subsubsection{Base Model/ Base Model Results}

Os resultados são disponibilizados após a execução do processo na opção Base Model Results à direita de Base Model Runs. Ao selecionar esse menu é possível analisar o histograma da distribuição 
dos resíduos de cada variável, escalonados pelas incertezas destas, e também a distribuição geral dos resíduos escalonados na opção Residual Analysis, Figura 3.6 à esquerda. Na opção Obs/Pred Scatter Plot, é possível verificar a dispersão dos resultados em relação aos dados inseridos. O programa ajusta um modelo de regressão, fornece as estatísticas da regressão, e exibe um gráfico um-para-um e a reta da regressão para facilitar a percepção de ajuste do modelo, Figura 3.6 à direita.

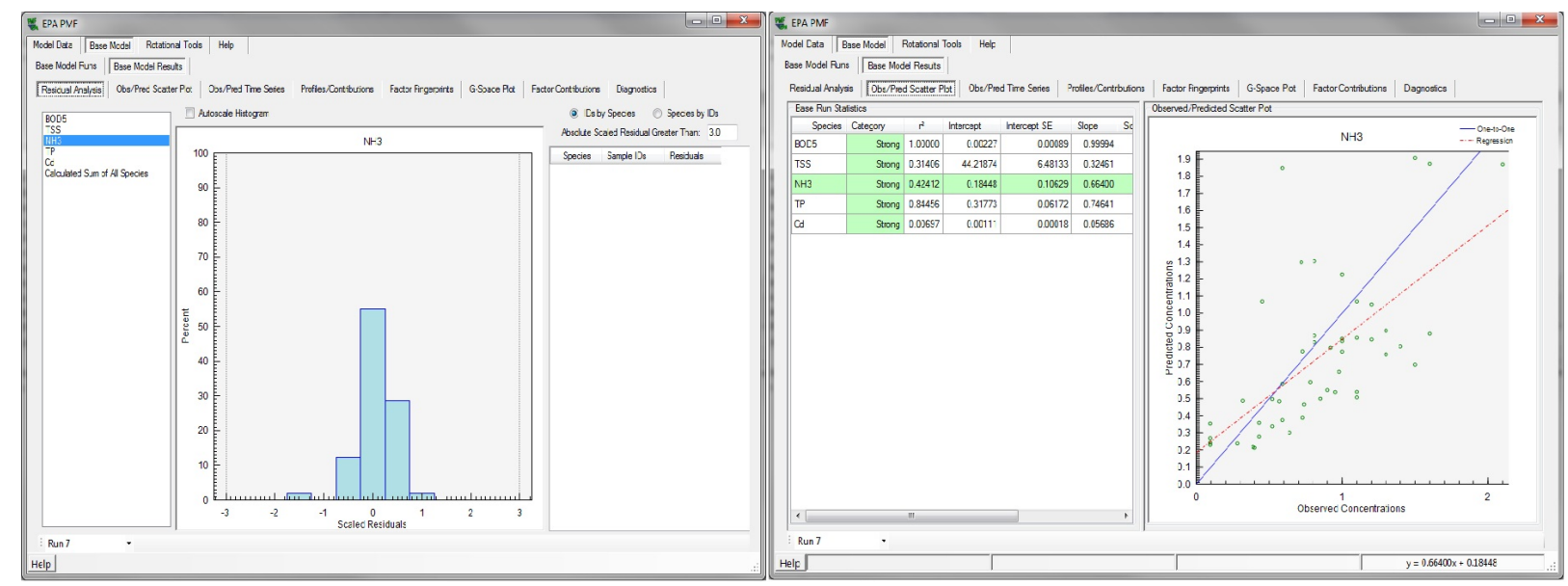

Figura 3.6: Residual Analysis e Obs/Pred Scatter EPA PMF 5.0

A opção Obs/Pred Time Series apresenta o gráfico da série de tempo predita pelo modelo para cada variável, e a compara com a original, para que o pesquisador possa verificar a aderência do resultado do modelo, Figura 3.7.

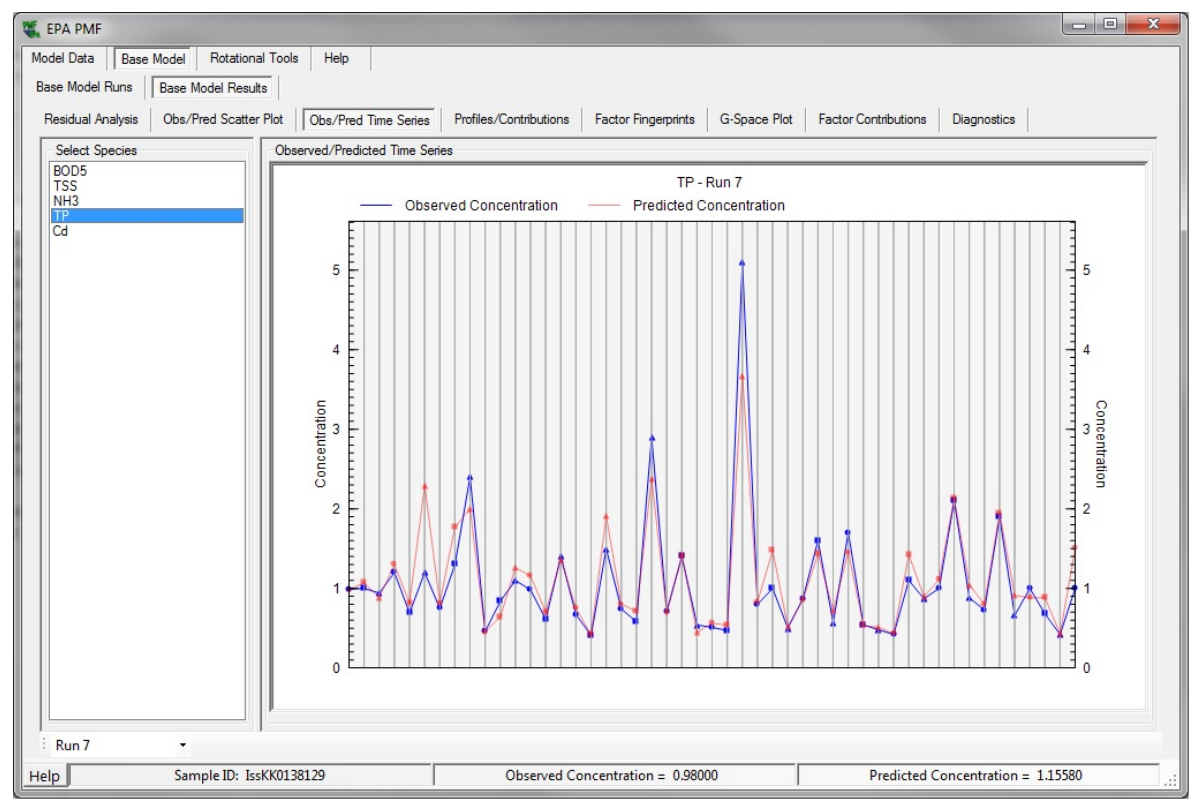

Figura 3.7: Obs/Pred Time Series EPA PMF 5.0

Em Profiles/Contributions é possível identificar o perfil do fator selecionado na seção superior, marcada com (1). As barras em azul representam a concentração de cada espécie no fator selecionado, a medida está em notação científica no eixo esquerdo do gráfico, os quadrados em vermelho representam, da massa total de cada especie química, o quanto em porcentagem esta massa está distribuída no fator selecionado. Neste menu também há um gráfico na seção inferior, marcada com (2), da série de tempo das contribuições de cada fator. Notemos que esta série está normalizada pela média, portanto terá média um, Figura (3.8). 


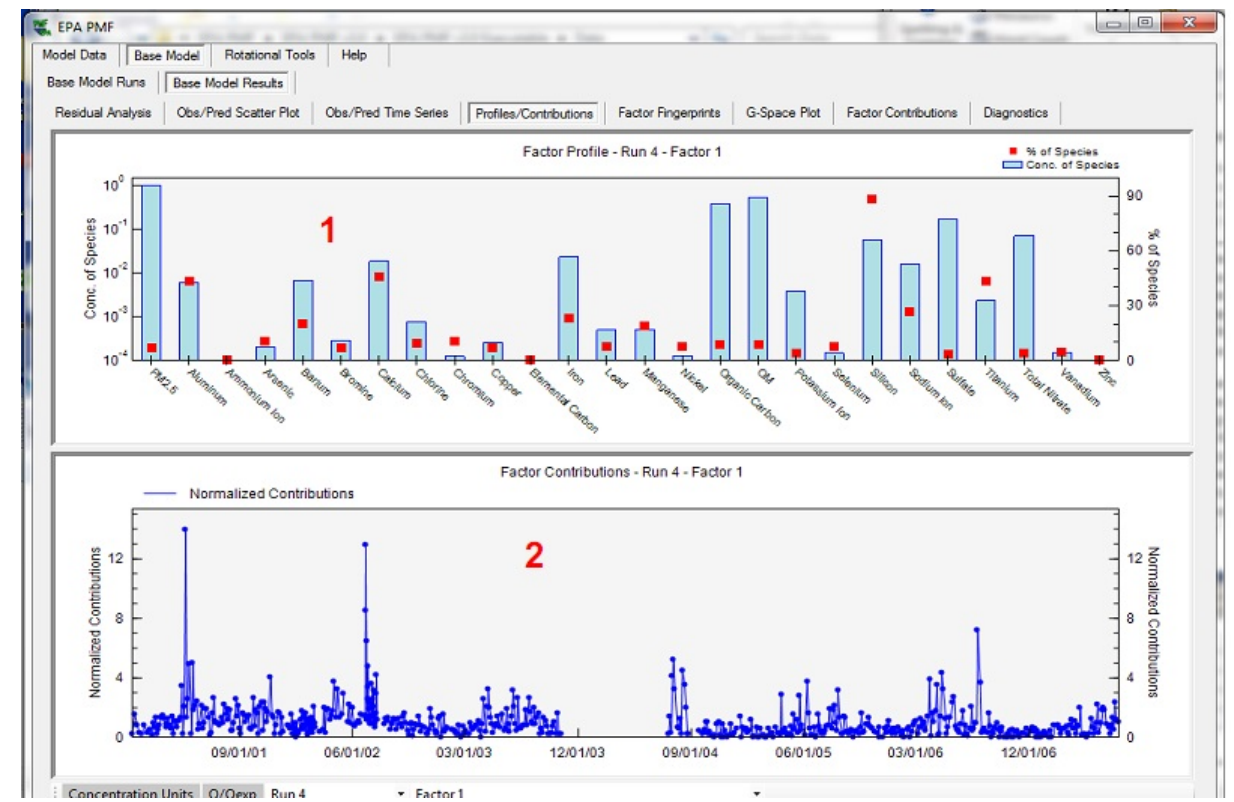

Figura 3.8: Profiles/Contributions EPA PMF 5.0 Fonte: Norris et al. (2014)

No menu Factor Fingerprints o pesquisador pode analisar quanto em porcentagem de massa de cada espécie química está distribuída entre os fatores, Figura 3.9.

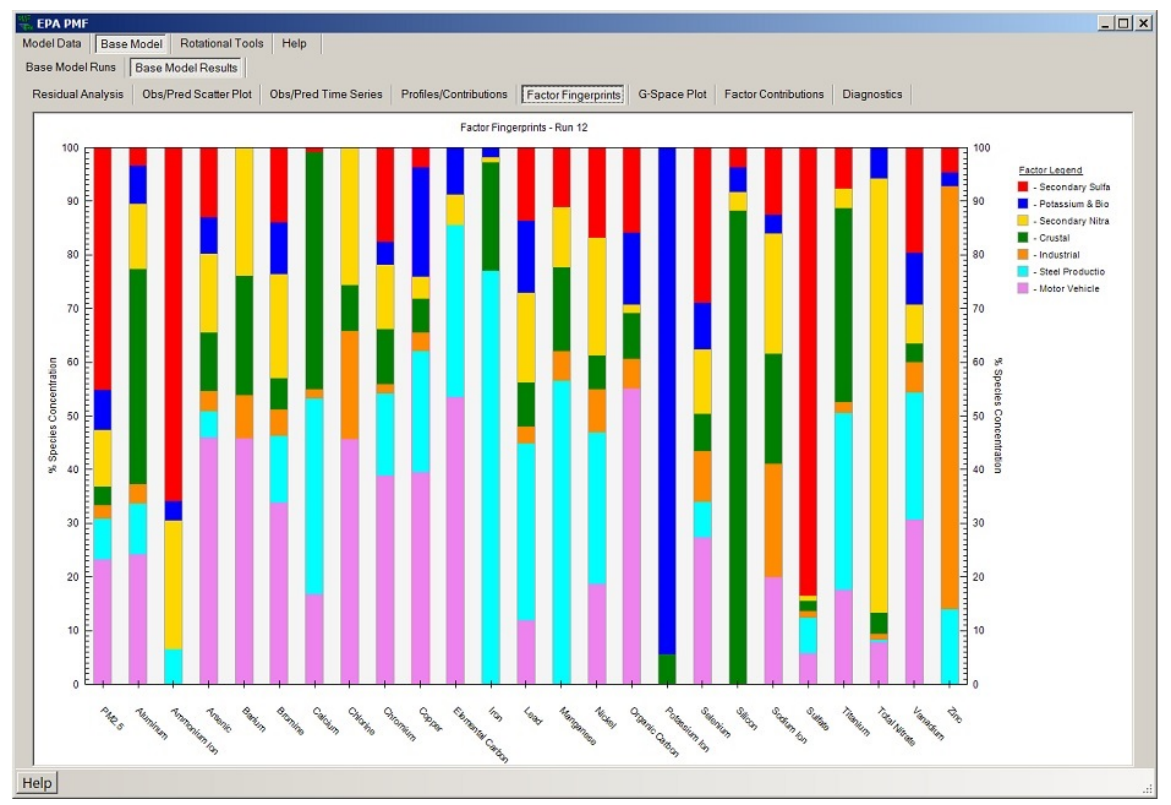

Figura 3.9: Profile Contribution EPA PMF 5.0 Fonte: Norris et al. (2014)

No menu G-Space Plot o pesquisador pode analisar a relação entre as contribuições de dois fatores, Figura 3.10. Também segundo Norris et al. (2014), quanto mais amostras com contribuições com valor zero, menos ambiguidade existe na solução, assim neste gráfico é possível averiguar essa hipótese. 


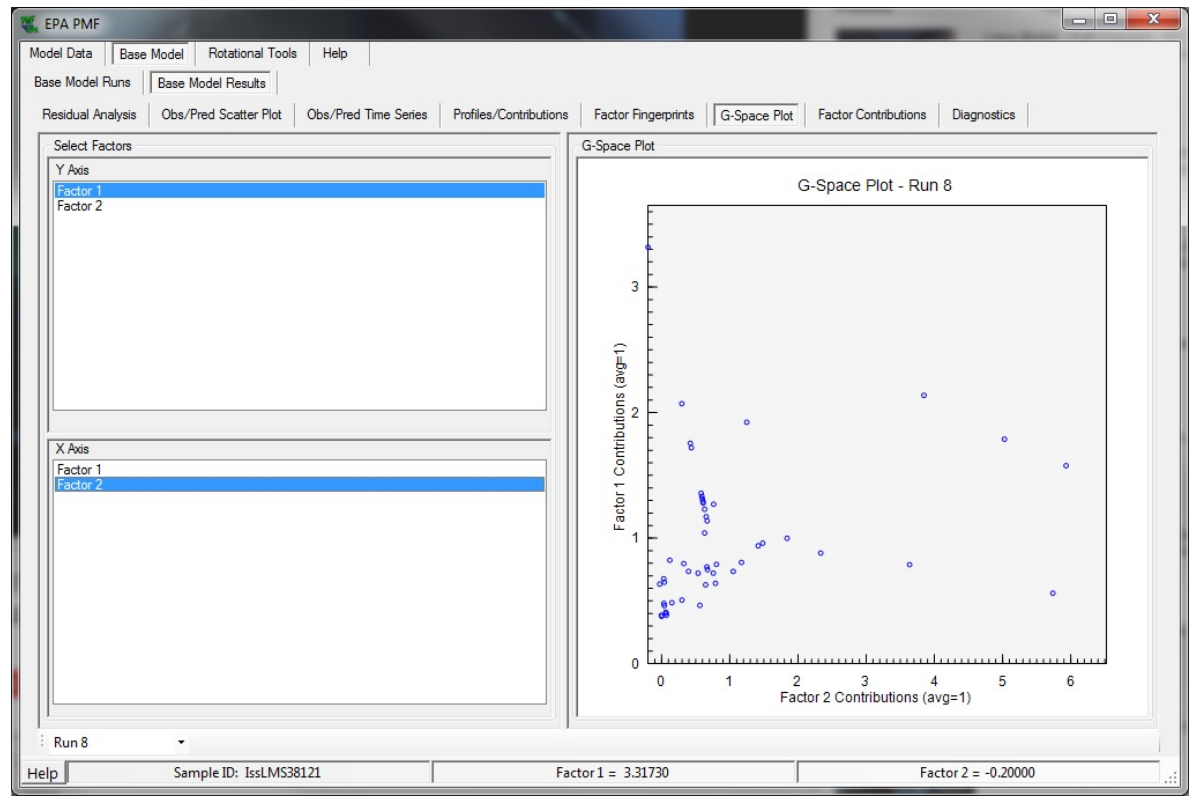

Figura 3.10: G-Space Plot EPA PMF 5.0

No menu Factor Contribution é exibido um gráfico de setores, Figura 3.11, para cada espécie química da análise. Neste gráfico o pesquisador pode analisar a contribuição de cada fator na massa/concentração total medida de cada espécie química.

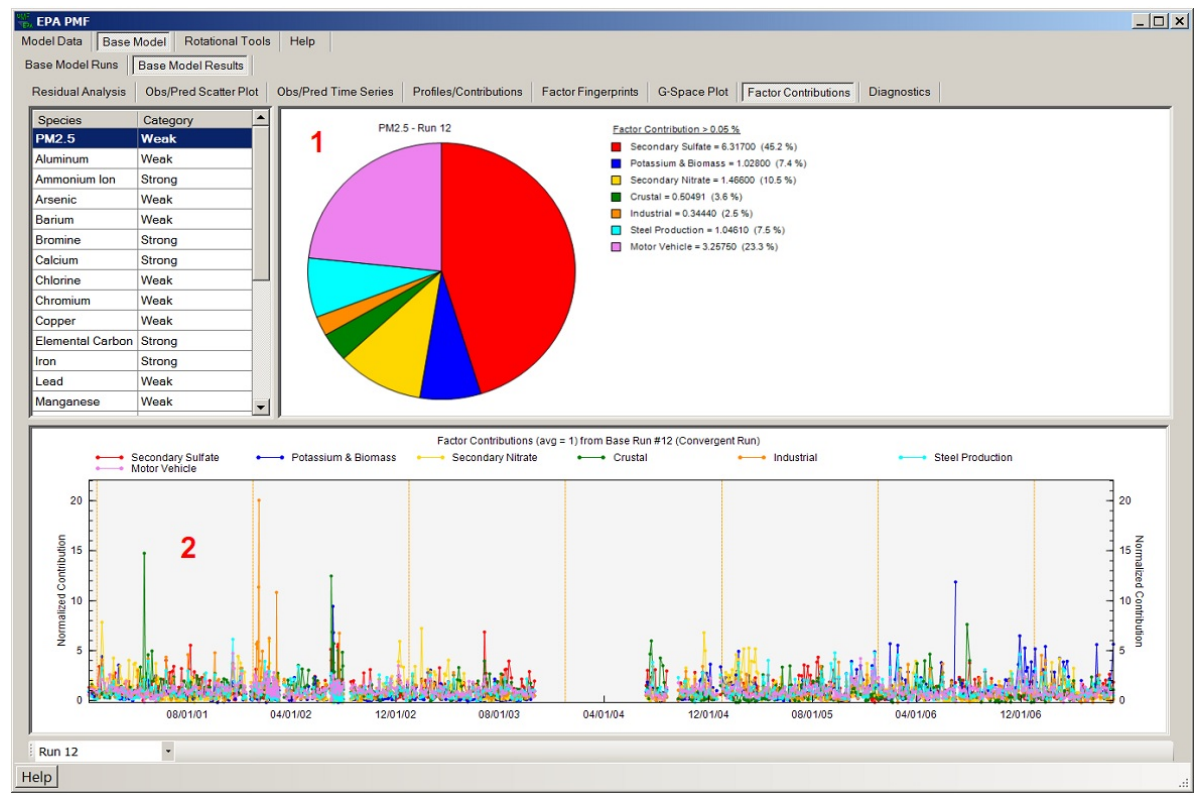

Figura 3.11: Factor Contributions EPA PMF 5.0

O último menu da seção Base Model Results é o Diagnostics, onde o pesquisador pode encontrar estatísticas e comparativos entre os resultados de cada execução, Figura 3.12. 


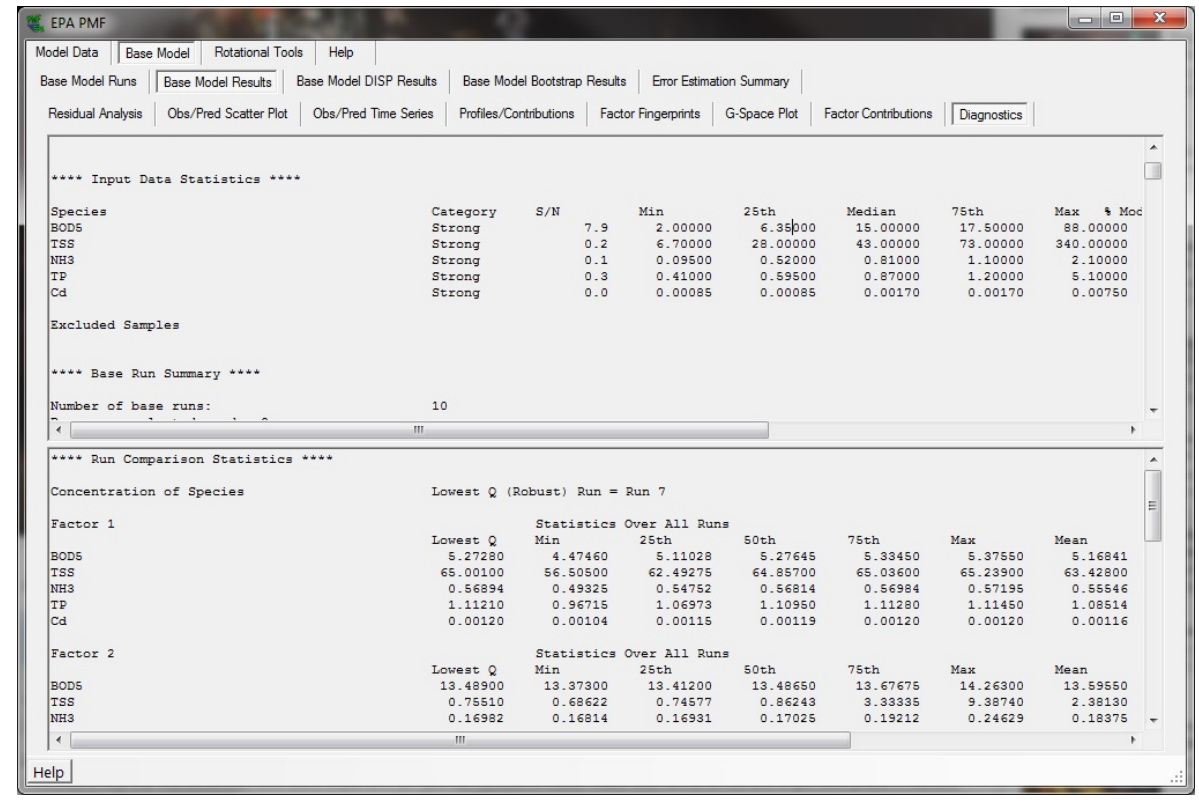

Figura 3.12: Diagnostics EPA PMF 5.0

\subsubsection{Base Model / Error Estimates}

Na Figura 3.5, podemos encontrar a seção Error Estimation, onde o pesquisador pode executar os módulos Base Model Displacement Method (DISP), Base Model Bootstrap Method (BS) e Base Model BS-DISP Method que é uma combinação dos dois anteriores. Esses métodos podem ser utilizados para que o pesquisador faça uma verificação da qualidade dos dados inseridos, analisando a variabilidade de soluções que esses métodos geram fazendo relaxamento do valor de $Q$, no caso do método DISP, e reamostragens aleatórias de blocos dos dados inseridos no caso BS, de modo que algumas observações se repitam e outras sejam descartadas nessa "nova" amostra.

\subsubsection{Base Model / Base Model Displacement Results}

O método DISP explora possíveis ambiguidades da solução. Este método pode ser aplicado após obter as matrizes $G$ e $F$ e o respectivo valor $Q$-mínimo para a função de perda (2.3), resultantes da fatoração de uma matriz de dados $X$. A proposta do método é fixar uma determinada entrada na matriz $F$ e minimizar a função (2.3) com esta restrição - aceitando que o novo valor de $Q$ minimo terá acréscimos - e analisar o comportamento das matrizes novas $G$ e $F$. Executando este procedimento, existe a possibilidade de haver intercâmbio entre as posições iniciais dos fatores, e a ocorrência ou não destes intercâmbios segundo Norris et al. (2014), seção 5.7, é um indicador de estabilidade da solução do PMF.

Para executar o método DISP, basta escolher o "run" desejado na seção Error Estimation, Base Model Displacement Method, Figura 3.5. Ao final da execução, o menu Base Model DISP Results aparecerá ao lado de Base Model Results. Este método consiste em encontrar os valores máximos e mínimos para cada elemento $f_{k j}$ da matriz $F$, que representa o perfil de cada fonte, de modo que o valor de Q-mínimo obtido inicialmente para o "run" selecionado, aumente no máximo de um certo valor pré-determindo.

Seja a notação $Q\left(f_{k j}=d\right)$ a menor soma de quadrados em (2.3), restringindo o elemento $f_{k j}$ a um valor $d$ viável. Minimizando a função (2.3) para todas outras componentes de $G$ e $F$ com essa restrição, o valor $Q$-disp obtido será maior que o $Q$-minimo obtido inicialmente, assumindo que a solução associada a $Q$-minimo é um valor de mínimo global. A diferença $d Q=Q\left(f_{k j}=d\right)-$ Q-minimo é determinada de antemão, sendo uma restrição para o modelo. Então, o método buscará valores máximos e mínimos para $d$, tal que o valor $d Q$ não exceda o valor pré-determinado citado anteriormente. No software EPA PMF 5.0, é feito o cálculo para quatro valores de $d Q=4,8,16$ e 
32. Detalhes sobre a implementação do método foge ao escopo deste estudo e podem ser encontrados em Paatero et al. (2014).

Após a execução do método, dois menus são disponibilizados, DISP Box Plots, Figura 3.13, onde é apresentado um gráfico indicando a variação máxima e mínima de cada espécie química do modelo, em relação ao valor da solução encontrada para o "run" selecionado, e o menu DISP Summary que discutiremos a seguir. Na Figura 3.13, os quadrados em azul representam a solução inicial, e as barras em amarelo indicam o quanto foi possível variar o valor da espécie no fator selecionado $\left(d^{\text {max }}\right.$ e $\left.d^{\text {min }}\right)$. No software EPA PMF 5.0, somente é apresentada em forma de gráfico, Figura 3.13, a solução para o valor $d Q=4$, que segundo Norris et al. (2014), provê os intervalos mais robustos para a maioria dos conjuntos de dados analisados. As soluções para os valores de $d Q$ $=4,8,16$ e 32 estão em arquivos de texto na pasta de saída dos resultados definida pelo usuário, com os sulfixos *_DISPres $1, *$ _DISPres $2, *$ DISPres 3, e *_DISPres4, respectivamente para os valores $4,8,1 \overline{6}$ e 32 de $d Q$. Mais detalhes sobre os formatos de saída podem ser encontrados em Norris et al. (2014).

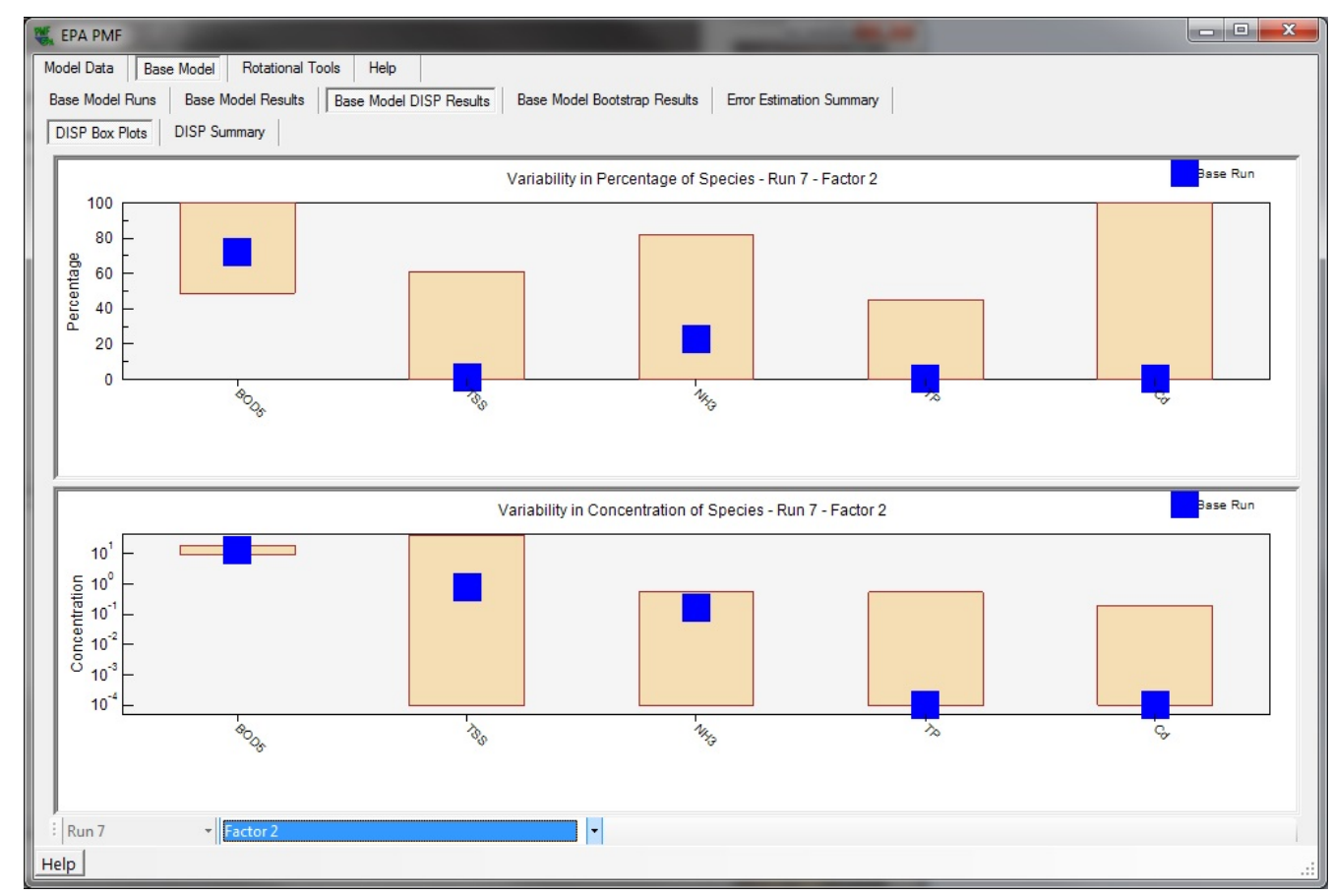

Figura 3.13: Base Model DISP Box Plots EPA PMF 5.0

O menu DISP Summary, Figura 3.14, apresenta uma tabela que contém dois números na primeira linha. Na primeira posição é um indicador de erro, 0 se a execução ocorreu sem problemas, 6 ou 9 é indicação de que a execução foi abortada. Na segunda posição é, caso tenha acontecido, o valor da diminuição no valor de Q-mínimo durante a execução de alguma das fases do método. Embora tenhamos assumido que a solução base escolhida seja relativa a um ponto de mínimo global, Norris et al. (2014), seção 5.7, sugere que pode ocorrer uma pequena diminuição no valor após execução do método, e recomenda caso o valor da diminuição seja maior do que $1 \%$ do valor de Q-minimo, que a solução analisada não seja considerada como uma solução final, e que o pesquisador procure eventos anômalos na série de tempo dos dados, ou que considere a possibilidade de aumentar ou diminuir o número de fatores, ou até mesmo excluir espécies da amostra, e refazer a análise.

Após a execução do método, considerando as restrições citadas anteriormente, a solução obtida pode apresentar troca de posição entre os fatores em relação à solução base selecionada. Em Norris et al. (2014) não há uma explicação de como a identificação dos fatores obtidos após a execução do método é feita em relação à solução base. Paatero et al. (2014) sugere que a identificação 
pode ser feita aplicando correlação cruzada entre os fatores, ou uma análise baseada em regressão. No menu DISP Summary abaixo da primeira linha, há uma matriz cujas linhas se referem às execuções do método, para cada valor de $d Q=4,8,16$ e 32 , respectivamente, e os valores nas colunas se referem às quantidades de trocas entre os fatores que ocorreram durante as execuções - cada coluna está relacionada a um fator obtido inicialmente. A Figura 3.17 mostra um caso em que não houve intercâmbio entre os fatores - solução com 7 fatores -, para todos os valores $d Q$ em que o método foi executado. Norris et al. (2014), seção 5.7, sugere que se houver intercâmbios de fatores para o valor de $d Q=4$ a solução não deve ser usada.

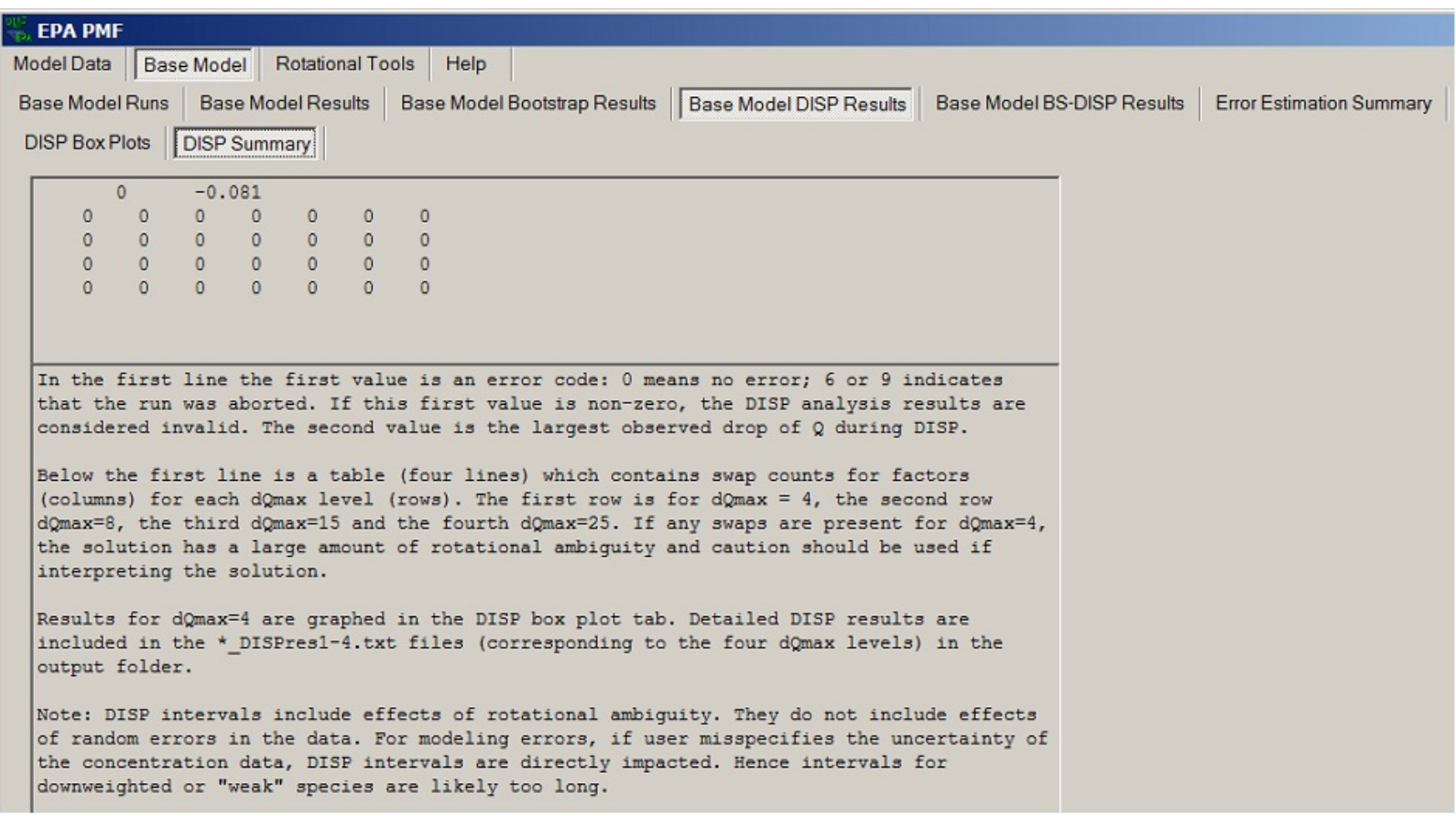

Figura 3.14: Base Model DISP Summary EPA PMF 5.0 Fonte: Norris et al. (2014)

\subsubsection{Base Model / Base Model Bootstrap Results}

O método BS pode ser usado para avaliar efeitos de blocos da amostra com dados desproporcionais geralmente relacionados a eventos sazonais, que podem causar viés na solução do modelo. O método consiste em reamostragens aleatórias dos dados originais feitas por blocos sequenciais da amostra original. O propósito de sortear blocos sequenciais é preservar a correlação serial das informações. São então sorteados blocos de mesmo tamanho, até que seja composta uma nova amostra com o mesmo tamanho da original. Os parâmetros necessários para executar este método são: o "run" com a melhor solução, tamanho dos blocos das reamostragens, a quantidade de novas amostras (bootstrap) que se deseja ter na análise, e o valor da correlação mínima para a identificação posterior dos fatores.

Após a nova amostra ser composta, e a fatoração ser executada, os fatores podem mudar de ordem, ou alguns podem nem mesmo ser identificados novamente. Para cada novo resultado o programa compara os fatores resultantes com os fatores do resultado base, usando a correlação de Pearson como medida de parecença. Os novos fatores que apresentarem correlação menor que a mínima definida são marcados como não identificados. O resultado do método é apresentado em Boxplots demonstrando a variabilidade obtida entre as novas amostras, Figura 3.15. As estatísticas sobre os resultados, e quantas vezes cada fator da solução base foi identificado podem ser encontradas no submenu Boostrap Summary, Figura 3.16. 


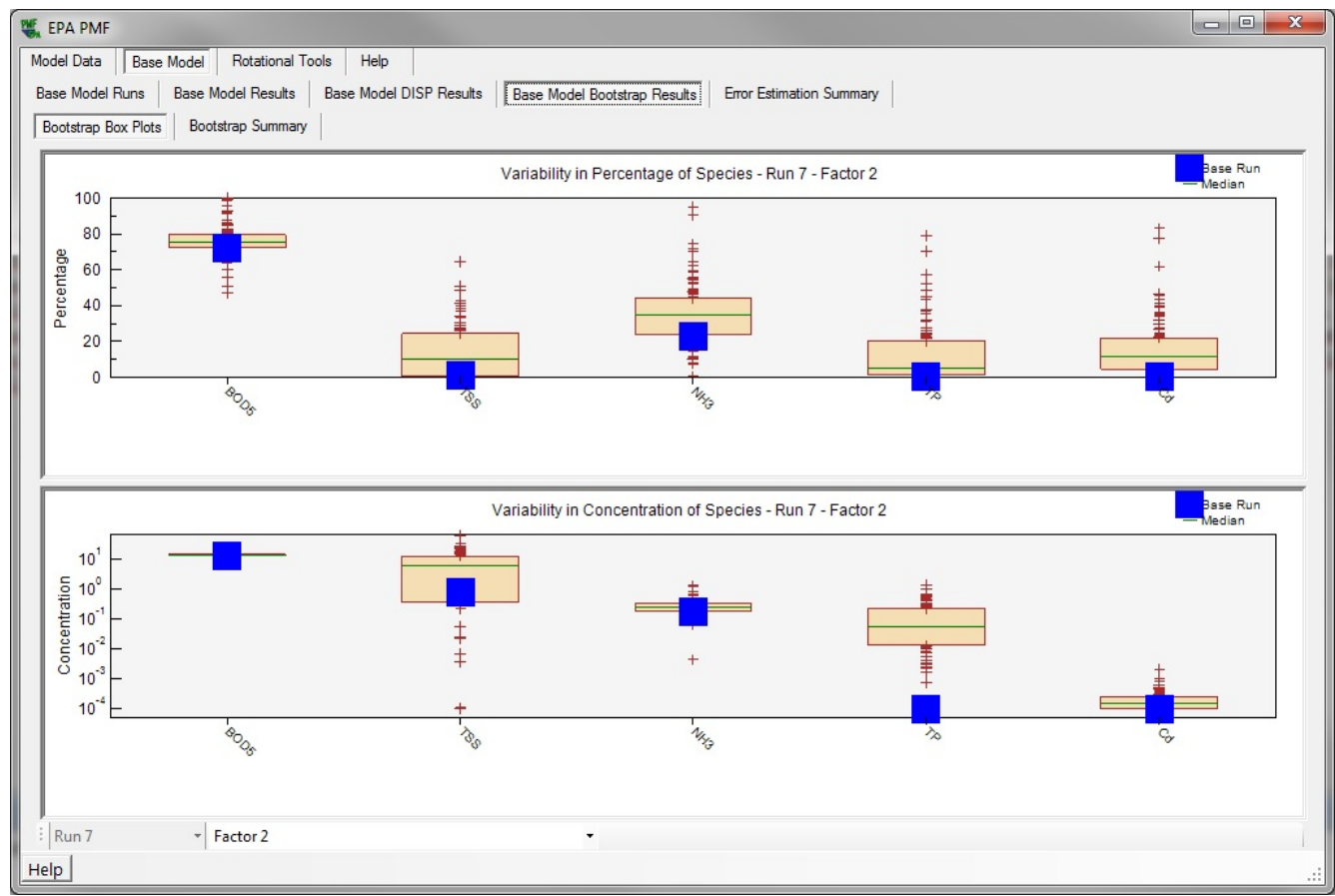

Figura 3.15: Base Model Bootstrap Boxplots EPA PMF 5.0

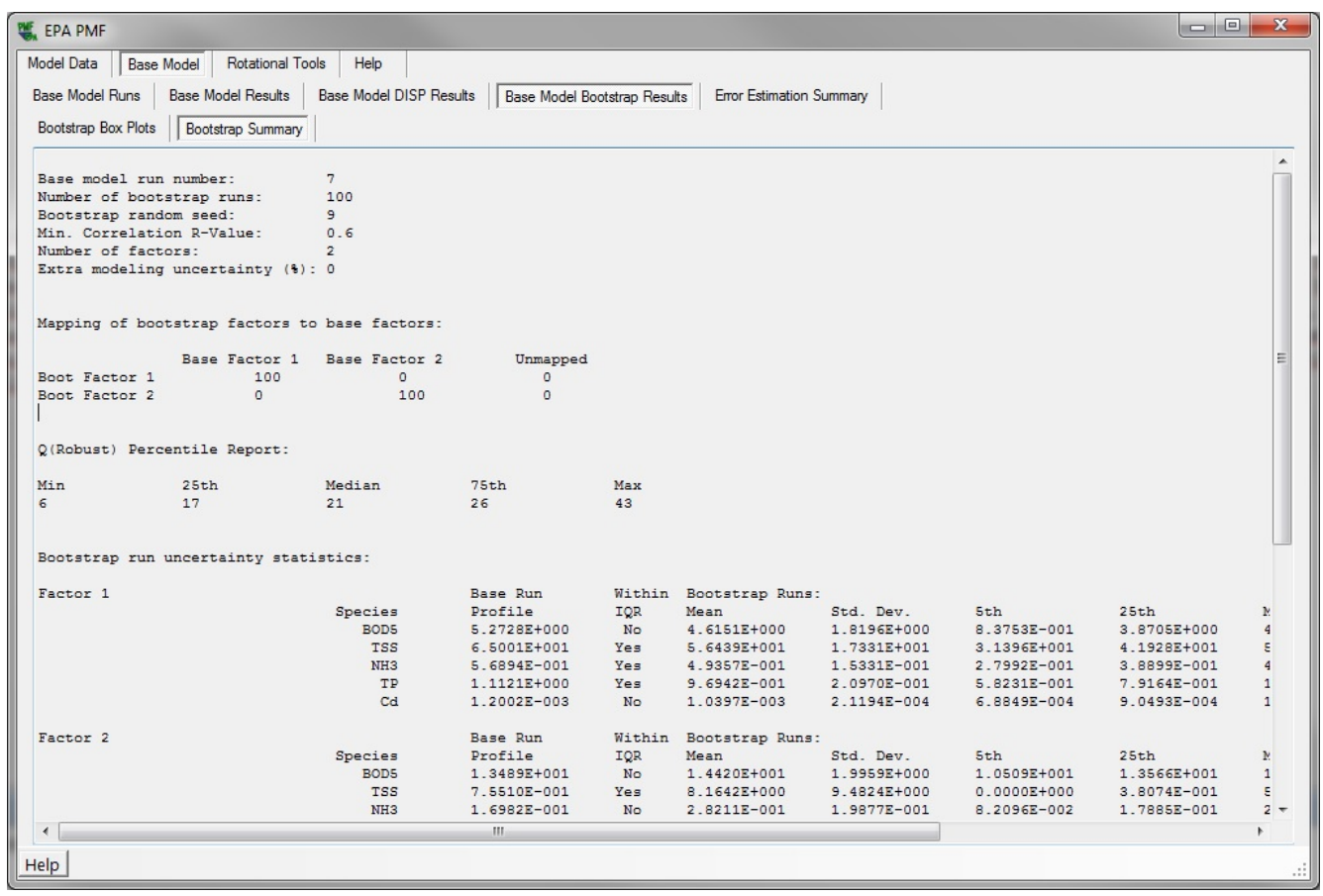

Figura 3.16: Base Model Bootstrap Summary EPA PMF 5.0

\subsubsection{Base Model / BS-DISP Results}

Após executar o método BS é possível executar o método BS-DISP, que é uma combinação do BS com o DISP. Esta combinação é feita da seguinte maneira, cada nova amostra obtida na execução prévia do BS é submetida à execução do método DISP, mas agora com os seguintes valores de $d Q$ $=0,5 ; 1 ; 2$ e 4 . Os resultados destas combinações permitem diversas análises e questionamentos sobre a qualidade da solução base. Porém, segundo Norris et al. (2014), Seção 5.9, o ponto chave 
do resultado destas combinações é analisar os intercâmbios dos fatores que ocorrem nas diversas execuções do método, sugerindo que se há muitas trocas, a solução base não está bem definida. O menu BS-DISP Summary, Figura 3.17, que é disponibizado ao término da execução do método, contém uma matriz cujas linhas se referem às execuções do método, para cada valor de $d Q=0,5$; 1; 2 e 4, respectivamente. As colunas são as quantidades de trocas entre os fatores que ocorreram durante as execuções. A Figura 3.17 é um caso de intercâmbio entre os fatores 4 e 6 , para todos os valores $d Q$, considerando cada execução do método, no caso de uma solução de 7 fatores.

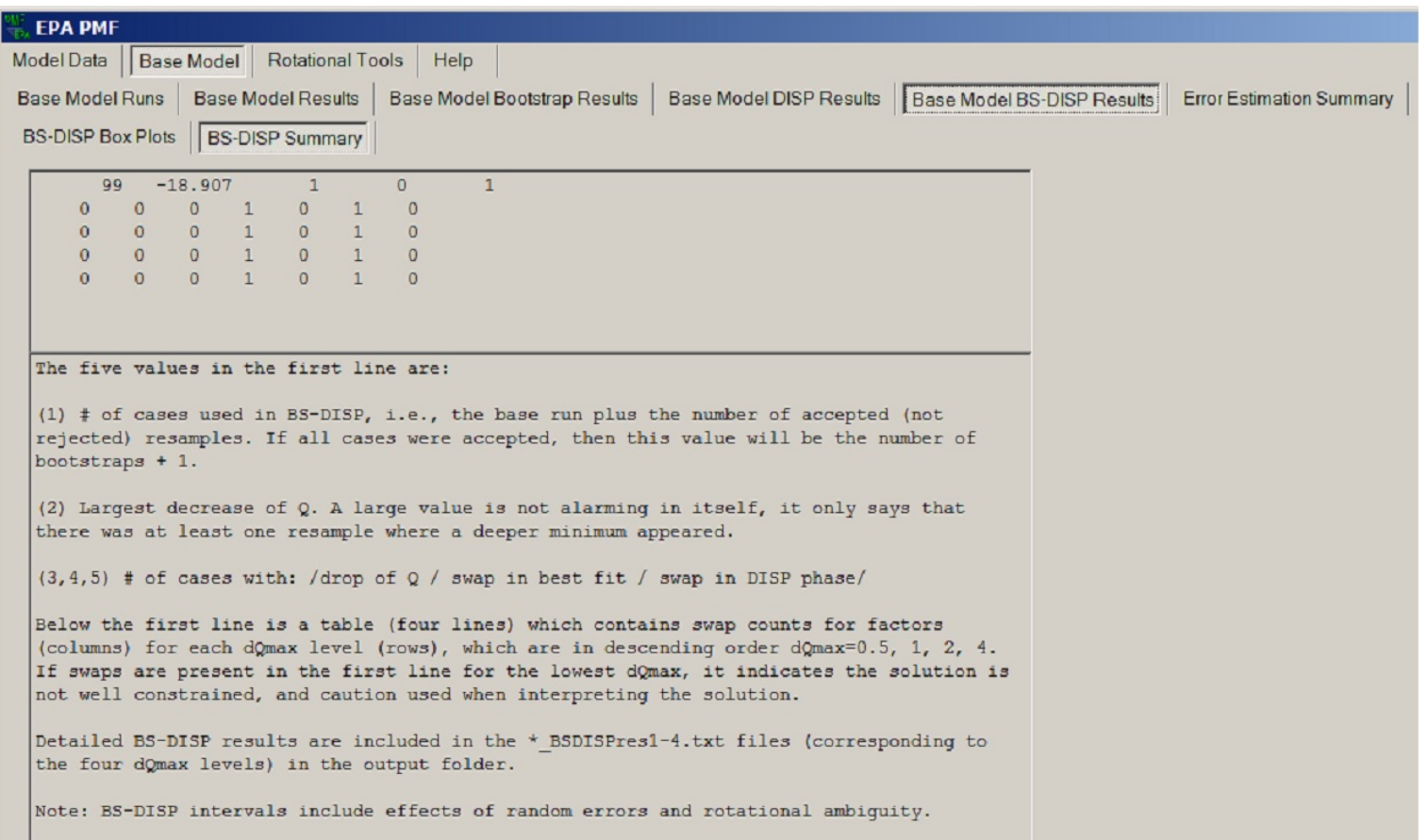

Figura 3.17: Base Model BS-DISP Summary EPA PMF 5.0 Fonte: Norris et al. (2014)

\subsubsection{Rotational Tools}

Além dos métodos DISP, BS e BS-DISP que descrevemos nas seções anteriores, que podem ser usados para avaliar a qualidade dos dados e da solução, o software EPA PMF 5.0 possui uma ferramenta chamada Fpeak para analisar as ambiguidades que podem existir na solução escolhida, diferentemente do método DISP, desta vez aplicando transformações lineares que não alteram muito o valor de Q-mínimo obtido para o solução ótima.

A restrição de não negatividade em (2.3) não é suficiente para garantir a unicidade da solução. Para um par de matrizes $G F$ multiplicadas, é possível obter um par de matrizes $G^{*} F^{*}$ tais que $G^{*}=G T$ e $F^{*}=T^{-1} F$, com $T$ sendo uma matriz $p \times p$, onde $p$ é o número de fatores, com um mesmo valor de Q-mínimo. As matrizes $G^{*}$ e $F^{*}$ são chamadas de matrizes rotacionadas. Se não é possível aplicar uma rotação, a solução é única. Entretanto, é possível aplicar uma transformação linear que se "aproxime" de uma rotação, considerando a restrição de não negatividade para os elementos de $G^{*}$ e $F^{*}$, mas permitindo que o valor de Q-minimo aumente. Uma discussão mais detalhada sobre a aplicação de rotações neste contexto pode ser encontrada em Paatero et al. (2002).

Quanto mais elementos com valor zero na matriz que representa os perfis das fontes, no caso a matriz $F$, Figura 3.18, mais fácil é de se identificar os perfis do resultado frente aos já conhecidos pelo pesquisador. Um dos objetivos deste método é forçar uma solução, mesmo que aumentando o valor de Q-mínimo de um valor aceitável, com o propósito de se obter uma solução, mesmo que não seja a ótima para o modelo, mas que facilite a percepção do pesquisador no trabalho de identificação das fontes existentes na solução base. 


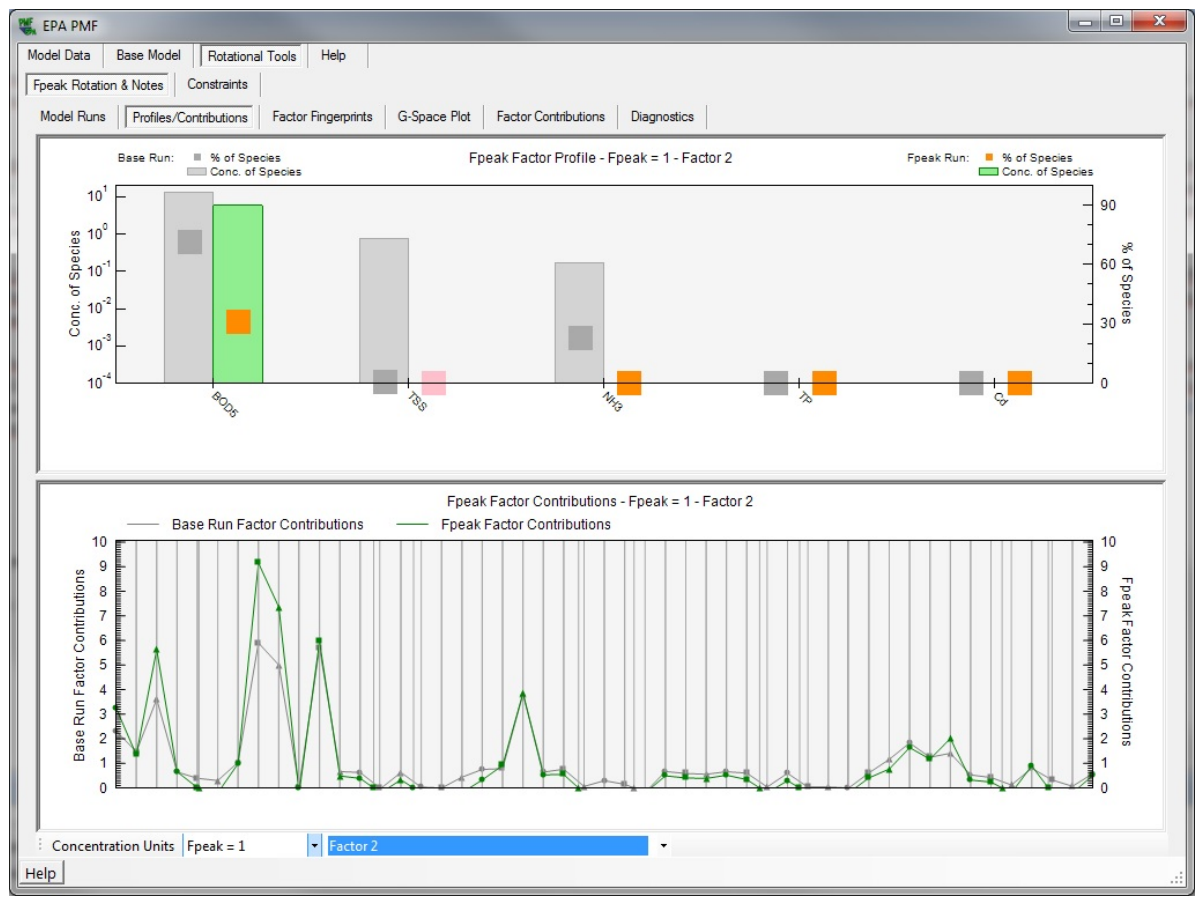

Figura 3.18: Rotational Tools / Fpeak/Profiles/Contributions EPA PMF 5.0 Fonte: Norris et al. (2014)

Para executar o Fpeak, é preciso definir a "força" com que o método irá executar a transformação nas matrizes $G$ e $F$, referentes ao "run" ótimo. Para isso, no menu Rotational Tools / Fpeak Rotation 63 Notes/Model Runs, Figura 3.19, há a opção Selected Fpeak Runs, onde é possível inserir até cinco valores para analisar simultaneamente os seus resutados. Não há limites para estes valores, porém, em Norris et al. (2014), seção 6.1, é recomendado que sejam utilizados inicialmente valores entre -5 e 5 . Valores positivos, forçam o aparecimento de valores próximos de zero na matriz $F^{*}$, e valores negativos forçam valores próximos de zero na matriz $G^{*}$. Ainda em Norris et al. (2014), é recomendado que se considere soluções em que o valor de Q-robusto não aumente mais do que $5 \%$. O sumário dos valores para cada valor de Fpeak pode ser encontrado à direta, na seção destacada em vermelho na Figura 3.19. 


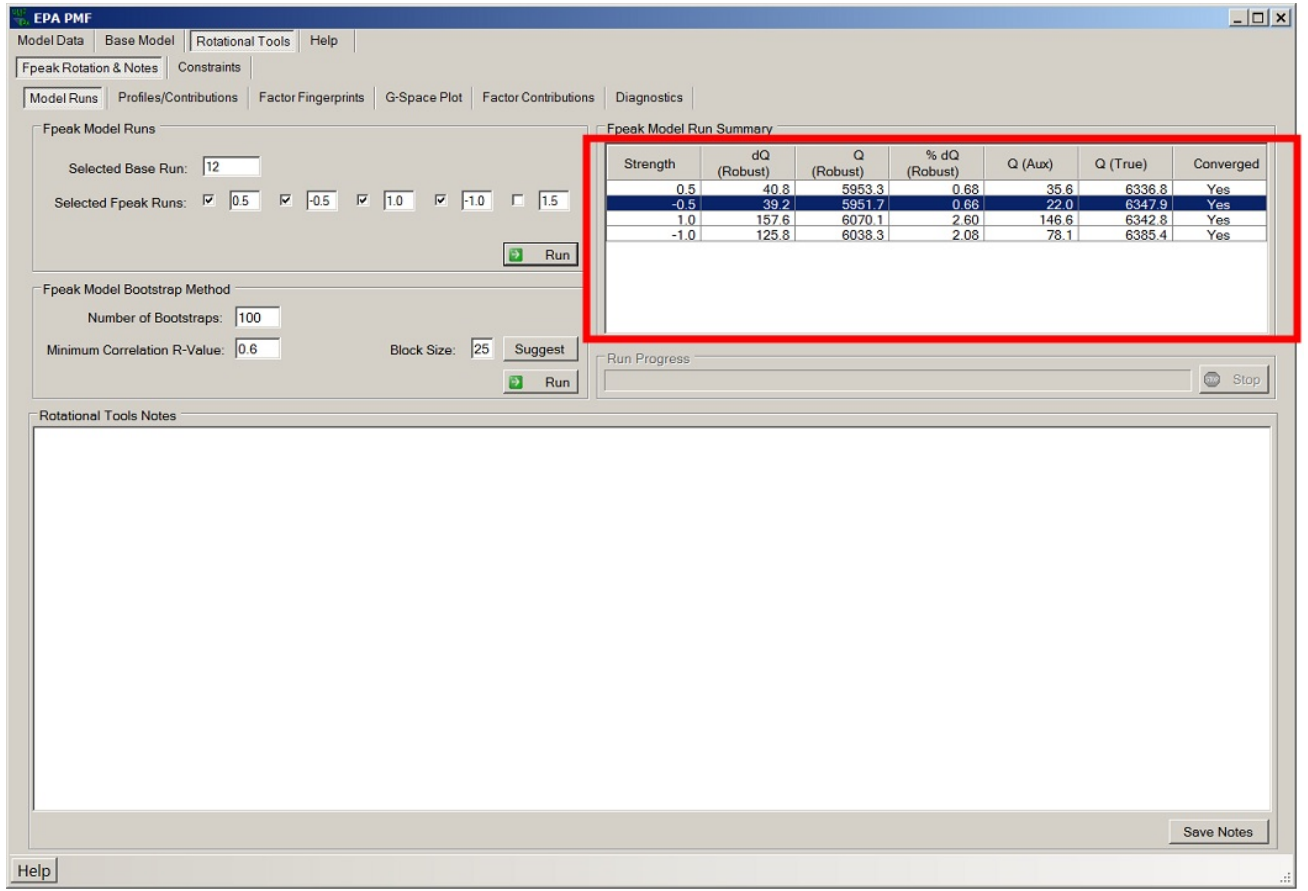

Figura 3.19: Rotational Tools / Fpeak / Model Runs EPA PMF 5.0 Fonte: Norris et al. (2014) 


\section{Capítulo 4}

\section{Simulação de base de dados}

Como foi dito na Seção 1.1, o propósito deste trabalho é fazer um estudo de sensibilidade do método PMF. Para realizar este estudo, simularemos algumas bases de dados representando as medições de elementos químicos presentes no material particulado captado na atmosfera, seguindo um modelo receptor com uma estrutura de perfis de fontes conhecidas, para posteriormente aplicar a fatoração PMF testando diferentes propostas de definição de incertezas que estão presentes na literatura, com o objetivo de comparar os resultados da fatoração com a estrutura original usada para gerar os dados. Neste capítulo descreveremos a metodologia usada para fazer a simulação das bases de dados bem como a implementação computacional.

\subsection{Modelo receptor}

Consideremos novamente a equação (2.2), com a matriz $F$ conhecida, representando em suas colunas os perfis das $p$ fontes existentes no sistema. Consideremos também que haja um resíduo $E$ para cada medição, representando a informação não captada pelo modelo.

$$
X_{(m \times n)}=G_{(m \times p)} F_{(p \times n)}+E_{(m \times n)}
$$

A ideia básica da simulação consiste em gerar as entradas da matriz $G$, em que cada coluna representa as contribuições em massa de cada uma das $p$ fontes, em um determinado período de medição, ou seja, uma observação.

Cada elemento das colunas da matriz $G$ é considerado como uma variável aleatória, positiva, que representa a massa, ou mais precisamente, a concentração do material particulado na atmosfera, que foi emitido por cada fonte presente no período da medição. Existem estudos que procuram modelar a distribuição de probabilidade que melhor se ajusta à concentração de material particulado na atmosfera em períodos determinados. Como podemos ver em Kan e Chen (2004) e em Rumburg et al. (2001), distribuições de probabilidade como lognormal, gama, weibull, entre outras, são testadas. Por questão de simplicidade, neste estudo utilizaremos a distribuição lognormal para simular os valores relativos à concentração de material particulado emitido por cada fonte. Também consideraremos os elementos da matriz $E$, de resíduos, como variáveis aleatórias, e para gerar os seus elementos utilizaremos a distribuição normal.

Considerando que temos cada elemento da matriz $F$ em (4.1) como uma informação para a simulação, definimos previamente a estrutura de perfil de fontes segundo o modelo receptor, onde $f_{k j}$ é conhecido, e representa a porcentagem em massa do material particulado emitido pela fonte $k$, que é relativa à espécie química $j$. Portanto para simular uma medição $x_{i j}$ de uma espécie química $j$, em um ambiente com $p$ fontes, basta gerar aleatoriamente um vetor $g$ com $p$ elementos que representam a massa emitida por cada uma das $p$ fontes em um determinado período de medição, 
um resíduo $e_{i j}$, e efetuar a seguinte operação da equação (4.2), conforme o modelo receptor,

$$
x_{i j}=\sum_{k=1}^{p} g_{i k} f_{k j}+e_{i j} .
$$

\subsection{Perfis de fontes}

Como foi dito na seção anterior, sobre o modelo receptor, a matriz $F$ de perfis de fontes é uma informação prévia para a simulação, assim como os parâmetros das distribuições de probabilidades utilizadas para gerar os valores para a simulação. Os perfis de fontes de emissão de material particulado podem variar conforme a região onde a fonte está localizada, ou conforme varia o tipo de combustível que a alimenta. Tomemos como exemplo emissões veiculares, que podem ter perfis diferentes dependendo do país onde são medidas, pois a composição dos combustíveis também podem variar de país para país. Portanto, na determinação do conjunto de perfis para a simulação, não tivemos a pretensão de chegar à composição de um conjunto que refletisse com total exatidão uma situação real, mas que também não fosse uma estrutura "simples" do ponto de vista prático, e que não pudesse ser comparado à realidade. Tomamos como base, o trabalho de dos Santos et al. (2014), em que foi feito um estudo de identificação da quantidade e fontes e de seus respectivos perfis na cidade de Recife, entre os anos de 2007 e 2008.

Em dos Santos et al. (2014), para identifição e quantificação dos fatores relativos aos perfis de fontes, foi aplicada a Análise Fatorial com rotação Varimax, e também o método PMF. A Tabela 4.1, contém a matriz de cargas fatoriais da Análise Fatorial aplicada, com uma solução de seis fatores, que explicam 78,6\% da variância dos dados. As cargas fatoriais em negrito são as cargas relativas aos elementos traçadores de cada fonte, como foi comentado na Seção 2.3.1. Para este trabalho, vamos tomar como base esse cenário do estudo feito em dos Santos et al. (2014). Consideraremos os seis perfis de fontes, tomaremos como elementos traçadores os elementos com as cargas fatoriais em negrito. Por questões de simplicidade, consideraremos as cargas fatoriais dos elementos traçadores para definir a porcentagem em massa da composição do elemento no perfil de fonte hipotético que vamos considerar na simulação. Para facilitar o entendimento, consideremos o Fator 1 na Tabela 4.1, para o qual temos os seguintes valores, 0,$976 ; 0,967 ; 0,963 ; 0,668 ; 0,596$, em que a soma é 4,17 , respectivamente para os elementos traçadores $\mathrm{Si}, \mathrm{Ti}, \mathrm{Al}, \mathrm{Fe}$ e Ca. Considerando como medida de distribuição da porcentagem de massa a porcentagem que cada carga fatorial representa da soma, obtemos 0, 2341; 0, 2319; 0, 2309; 0, 1602; 0, 1429 respetivamente para Si, Ti, Al, Fe e Ca. Estendendo este procedimento a todos os fatores da Tabela 4.1, obtemos a matriz $F$ representada na Tabela 4.2, da equação (2.2), de perfis de fontes que utilizaremos para realizar parte das simulações deste estudo. Reiteramos que esta abordagem é apenas uma simplificação para obtermos porcentagens que representem a distribuição de massa das espécies químicas, não é um procedimento preciso para obter perfis de fontes que representam a realidade com exatidão a partir de cargas fatoriais. Em dos Santos et al. (2014) é utilizada a técnica de fatores absolutos, que considera a variância e a carga fatorial da massa total para ponderar as cargas fatoriais originais como uma forma de ter uma relação mais precisa entre as cargas fatoriais e o peso do elemento químico na caracterização do fator. A Tabela 4.1, foi utilizada apenas como uma motivação, e uma referência para basear a simulação que será feita mais adiante. 
Tabela 4.1: Cargas fatoriais rotacionadas, solução com 6 fatores explicando 78, $6 \%$ da variância da base de dados do estudo de dos Santos et al. (2014)

\begin{tabular}{ccccccc}
\hline \hline & Fator 1 & Fator 2 & Fator 3 & Fator 4 & Fator 5 & Fator 6 \\
\hline Elemento & Solo & Veículos & Queima de Biomassa & Cloro & Spray Marinho & Níquel \\
\hline $\mathrm{Si}$ & $\mathbf{0 , 9 7 6}$ & 0,067 & 0,051 & $-0,043$ & 0,018 & $-0,077$ \\
$\mathrm{Ti}$ & $\mathbf{0 , 9 6 7}$ & 0,081 & 0,088 & $-0,05$ & 0,018 & $-0,056$ \\
$\mathrm{Al}$ & $\mathbf{0 , 9 6 3}$ & 0,053 & 0,047 & $-0,107$ & 0,022 & $-0,08$ \\
$\mathrm{Fe}$ & $\mathbf{0 , 6 6 8}$ & 0,652 & 0,046 & 0,066 & $-0,078$ & $-0,11$ \\
$\mathrm{Ca}$ & $\mathbf{0 , 5 9 6}$ & 0,049 & 0,263 & 0,474 & $-0,19$ & $-0,031$ \\
$\mathrm{Zn}$ & $-0,043$ & $\mathbf{0 , 9 0 3}$ & $-0,044$ & 0,052 & $-0,116$ & $-0,167$ \\
$\mathrm{Mn}$ & 0,194 & $\mathbf{0 , 8 4 6}$ & 0 & 0,091 & $-0,126$ & $-0,172$ \\
$\mathrm{~Pb}$ & $-0,029$ & $\mathbf{0 , 8 0 3}$ & 0,098 & 0,054 & $-0,179$ & 0,13 \\
$\mathrm{Cr}$ & 0,163 & $\mathbf{0 , 5 5 1}$ & $-0,027$ & 0,04 & 0,212 & 0,195 \\
$\mathrm{BC}$ & 0,098 & $\mathbf{0 , 4 9 1}$ & 0,321 & 0,344 & $-0,285$ & $-0,062$ \\
$\mathrm{Br}$ & $-0,101$ & $-0,099$ & $\mathbf{0 , 8 6 9}$ & $-0,023$ & 0,02 & 0,066 \\
$\mathrm{~S}$ & 0,404 & 0,073 & $\mathbf{0 , 7 7 3}$ & $-0,133$ & 0,074 & $-0,15$ \\
$\mathrm{~K}$ & 0,464 & 0,294 & $\mathbf{0 , 6 2 4}$ & 0,225 & $-0,207$ & 0,083 \\
$\mathrm{Cl}$ & $-0,074$ & $-0,056$ & $-0,092$ & $\mathbf{0 , 9 1 7}$ & 0,034 & 0,002 \\
$\mathrm{Cu}$ & $-0,083$ & 0,284 & 0,059 & $\mathbf{0 , 7 0 9}$ & 0,041 & 0,138 \\
$\mathrm{Mg}$ & 0,078 & $-0,172$ & $-0,071$ & $-0,059$ & $\mathbf{0 , 8 0 2}$ & 0,236 \\
$\mathrm{Na}$ & $-0,3$ & $-0,118$ & 0,524 & 0,278 & $\mathbf{0 , 5 8 4}$ & $-0,127$ \\
$\mathrm{Ni}$ & $-0,198$ & $-0,051$ & $-0,002$ & 0,116 & 0,176 & $\mathbf{0 , 8 8 9}$ \\
Massa Total & 0,391 & 0,28 & 0,537 & 0,49 & 0,222 & 0,085 \\
\%a variância explicada & 23,1 & 18,3 & 13,3 & 11,2 & 7,1 & 5,6 \\
\hline
\end{tabular}

Tabela 4.2: Matriz com perfis de fontes utilizadas para simulação

\begin{tabular}{ccccccc}
\hline \hline Elemento & Fator 1 & Fator 2 & Fator 3 & Fator 4 & Fator 5 & Fator 6 \\
\hline $\mathrm{Si}$ & 0,2341 & 0 & 0 & 0 & 0 & 0 \\
$\mathrm{Ti}$ & 0,2319 & 0 & 0 & 0 & 0 & 0 \\
$\mathrm{Al}$ & 0,2309 & 0 & 0 & 0 & 0 & 0 \\
$\mathrm{Fe}$ & 0,1602 & 0 & 0 & 0 & 0 & 0 \\
$\mathrm{Ca}$ & 0,1429 & 0 & 0 & 0 & 0 & 0 \\
$\mathrm{Zn}$ & 0 & 0,2513 & 0 & 0 & 0 & 0 \\
$\mathrm{Mn}$ & 0 & 0,2354 & 0 & 0 & 0 & 0 \\
$\mathrm{~Pb}$ & 0 & 0,2234 & 0 & 0 & 0 & 0 \\
$\mathrm{Cr}$ & 0 & 0,1533 & 0 & 0 & 0 & 0 \\
$\mathrm{BC}$ & 0 & 0,1366 & 0 & 0 & 0 & 0 \\
$\mathrm{Br}$ & 0 & 0 & 0,3835 & 0 & 0 & 0 \\
$\mathrm{~S}$ & 0 & 0 & 0,3411 & 0 & 0 & 0 \\
$\mathrm{~K}$ & 0 & 0 & 0,2754 & 0 & 0 & 0 \\
$\mathrm{Cl}$ & 0 & 0 & 0 & 0,5640 & 0 & 0 \\
$\mathrm{Cu}$ & 0 & 0 & 0 & 0,4360 & 0 & 0 \\
$\mathrm{Mg}$ & 0 & 0 & 0 & 0 & 0,5786 & 0 \\
$\mathrm{Na}$ & 0 & 0 & 0 & 0 & 0,4214 & 0 \\
$\mathrm{Ni}$ & 0 & 0 & 0 & 0 & 0 & 1 \\
\hline
\end{tabular}

\subsection{Distribuições de probabilidade utilizadas na simulação}

Assim como foi dito na seção anterior sobre modelo receptor em simulação, utilizaremos a distribuição lognormal para simular as contribuições das fontes, e a distribuição normal para simular o resíduo no modelo. Nesta seção vamos fazer uma breve descrição sobre as distribuições de probabilidades utilizadas e os valores utilizados nos seus parâmetros.

A distribuição normal provavelmente é a distribuição mais conhecida e importante da estatística, 
pela gama de fenômenos que ela descreve em diversas áreas do conhecimento. Sua função densidade de probabilidade é da forma apresentada na equação (4.3):

$$
f(x, \mu, \sigma)=\frac{1}{\sqrt{2 \pi \sigma^{2}}} e^{-\frac{(x-\mu)^{2}}{2 \sigma^{2}}} \quad,-\infty<x<\infty, \quad \sigma>0 .
$$

Denotamos uma variável aleatória $X$ que segue a distribuição normal com média $\mu$ e variância $\sigma^{2}$ por $X \sim N\left(\mu, \sigma^{2}\right)$.

A distribuição lognormal está relacionada com a distribuição normal da seguinte maneira: se a variável aleatória $Y$ tem distribuição lognormal, então $X=\ln (Y)$ tem distribuição normal. É comum que os softwares de estatística tenham uma função que gere uma variável aleatória da distribuição normal com a média e variância desejada. Para a distribuiçãso lognormal, não é tão comum ter disponível a implementação de uma função que gere uma variável aleatória de tal distribuição. Podemos obter uma variável aleatória da distribuição lognormal com a média e variância desejada, se conseguirmos gerar uma da distribuição normal. Para os parâmetros média e variância temos as seguintes relações entre as duas distribuições:

$$
\mu=\ln \left(\frac{m^{2}}{\sqrt{v+m^{2}}}\right), \quad \sigma^{2}=\ln \left(1+\frac{v}{m^{2}}\right),
$$

em que $m$ e $v$ em (4.4), são a média e variância da distribuição lognormal desejada, e $\mu$ e $\sigma$, são a média e variância da distribuição normal que poderemos gerar diretamente. Invertendo as funções em (4.4), obtemos os valores de $\mu$ e $\sigma^{2}$ necessários para gerar uma variável aleatória lognormal com média $m$ e variância $v$ desejadas. Seja:

$$
\phi=\sqrt{v+m^{2}} .
$$

As equações em (4.4) podem ser escritas da seguinte forma:

$$
\mu=\ln \left(\frac{m^{2}}{\phi}\right), \quad \sigma^{2}=\ln \left(\frac{\phi^{2}}{m^{2}}\right),
$$

evitando replicar cálculos no processo de implementação computacional.

Utilizamos também a distribuição exponencial - que é uma distribuição de valores positivos - para simular valores outliers. Sua função densidade de probabilidade é apresentada na equação (4.7), com parâmetro de escala $\beta$, média $\beta$ e variância $\beta^{2}$ :

$$
f(x ; \beta)= \begin{cases}\frac{1}{\beta} e^{-\frac{1}{\beta} x} & x \geq 0, \\ 0 & x<0 .\end{cases}
$$

Nem sempre os softwares de estatística disponibilizam a geração de variáveis aleatórias segundo a distribuição exponencial com o parâmetro de escala escolhido pelo usuário, mas apenas com o parâmetro de escala unitário. Porém, podemos utilizar a seguinte transformação $Y=\beta X$, em que $X$ é uma variável aleatória com distribuição exponencial e parâmetro de escala unitário, e $Y$ uma variável com distribuição exponencial com parâmetro de escala $\beta$.

Também foi utilizada a distribuição uniforme para sortear em quais amostras, e em quais variáveis os outliers deveriam ser inseridos. Sua distribuição de probabilidade é da forma apresentada na equação (4.8), com os parâmetros $a$ e $b$ sendo os limites para os valores da distribuição, e a média $\frac{1}{2}(a+b)$ e variância $\frac{1}{12}(b-a)^{2}$ dependendo de $a$ e $b$.

$$
f(x)= \begin{cases}\frac{1}{b-a} & \text { se } a \leq x \leq b, \\ 0 & \text { c.c. }\end{cases}
$$




\subsection{Implementação computacional}

Para realizar a simulação foi utilizado o software SAS 9.2, com a interface Enterprise Guide 4.1. A escolha deste software foi devida não só às suas funções estatísticas, mas também aos seus recursos computacionais, como a execução de macros e a possibilidade de programação em linguagem SQL, que facilitam a manipulação e a consulta a bases de dados. Os códigos utilizados nas simulações e nos procedimentos de manipulação de base de dados estão integralmente no Apêndice A.1. Na próxima seção, em que explicaremos a metodologia da simulação das bases de dados, vamos expor alguns trechos com breves explicações para facilitar o entendimento do procedimento.

\subsection{Metodologia}

Para testar a fatoração PMF, utilizamos o conjunto de perfis de fontes da Tabela 4.2. Geramos mil amostras, cada uma com trezentas "observações", em quatro situações diferentes: uma sem valores outliers, outras três com outliers distribuídos aleatorimente em aproximadamente metade das 300 "observações", sorteados uniformemente entre as dezoito variáveis - ou seja, a "observação" escolhida para ter outlier, terá um valor somado a uma de suas dezoito variáveis -, e cada uma dessas três situações com outliers, tendo valores gerados seguindo a distribuição exponencial com médias 1, 5; 3 e 9 respectivamente. Conforme descrevemos na Seção 4.1, considerando que temos a matriz dos perfis de fontes, geramos os elementos $g_{i k}$, e os elementos $e_{i j}$ de (4.2). Os elementos $g_{i k}$, conforme descrito em (4.1) seguem distribuição lognormal e os elementos $e_{i j}$, a distribuição normal. Para o conjunto de perfis da Tabela 4.2, tomamos média da emissão hipotética de material particulado de cada fonte como sendo $1,5 \mu \mathrm{g} / \mathrm{m}^{3}$ e a variância como 1. Para uma situação com 6 fontes, teremos a média de $9 \mu \mathrm{g} / \mathrm{m}^{3}$ de material particulado emitido. Esse valores foram escolhidos com o propósito de não se distanciar de uma situação real - em dos Santos et al. (2014) as medições foram $7,8 \mu \mathrm{g} / \mathrm{m}^{3}$ no período total do estudo.

A implementação da simulação das contribuições de seis fontes pode ser verificada abaixo, para o caso de uma "observação".

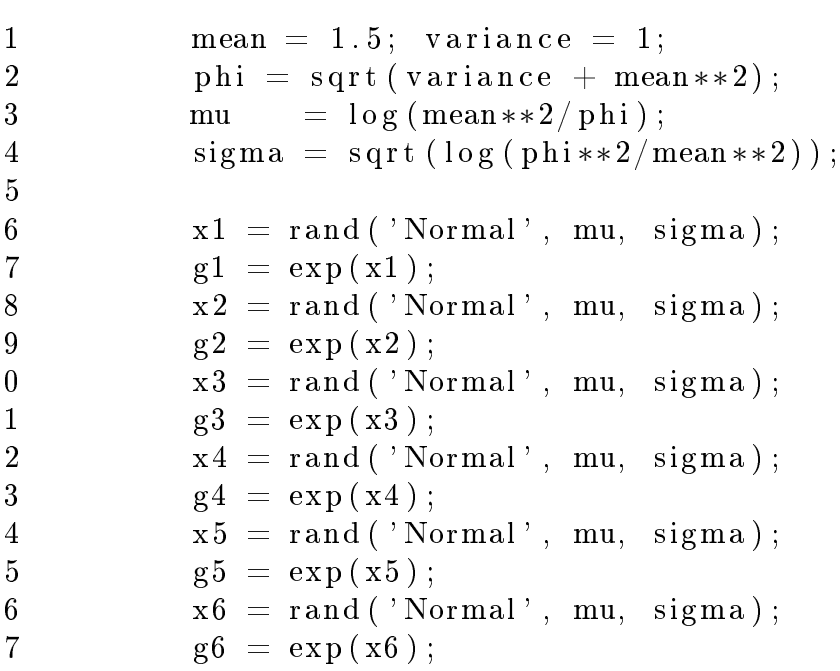

Na Tabela 4.2 temos dezoito variáveis "observadas". Para cada variável no modelo, temos uma quantidade que representa o ruído, ou seja, os elementos $e_{i j}$ de (4.2). A implementação da simulação destes valores foi feita conforme descrito a seguir. 


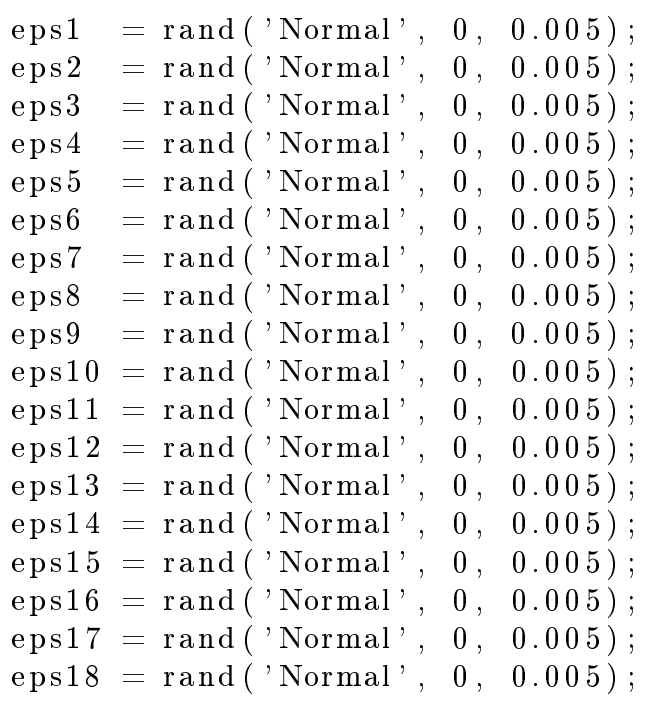

Notemos que as observações neste contexto representam concentrações, que são valores positivos. Os elementos $e_{i j}$ gerados segundo a distribuição normal, terão distribuição simétrica em torno da média, que é zero neste caso. Entretanto, conforme aumentamos a variância, podemos ter valores $e_{i j}$ negativos muito distantes de zero, de modo que quando somados à composição $g_{i k} f_{k j}$ resultará em uma observação com valor negativo. Para reduzir a possibilidade de termos um valor negativo, foi escolhida uma variância com valor pequeno. Ainda, para nos certificarmos que não houve nenhum valor negativo na simulação das variáveis, introduzimos uma verificação que pode ser encontrada no Apêndice A.1.

A geração de uma observação com as dezoito variáveis, para os seis perfis da Tabela 4.2, ou seja,

$$
X_{(1 \times 18)}=G_{(1 \times 6)} F_{(6 \times 18)}+E_{(1 \times 18)},
$$

segue a implementação computacional descrita a seguir.

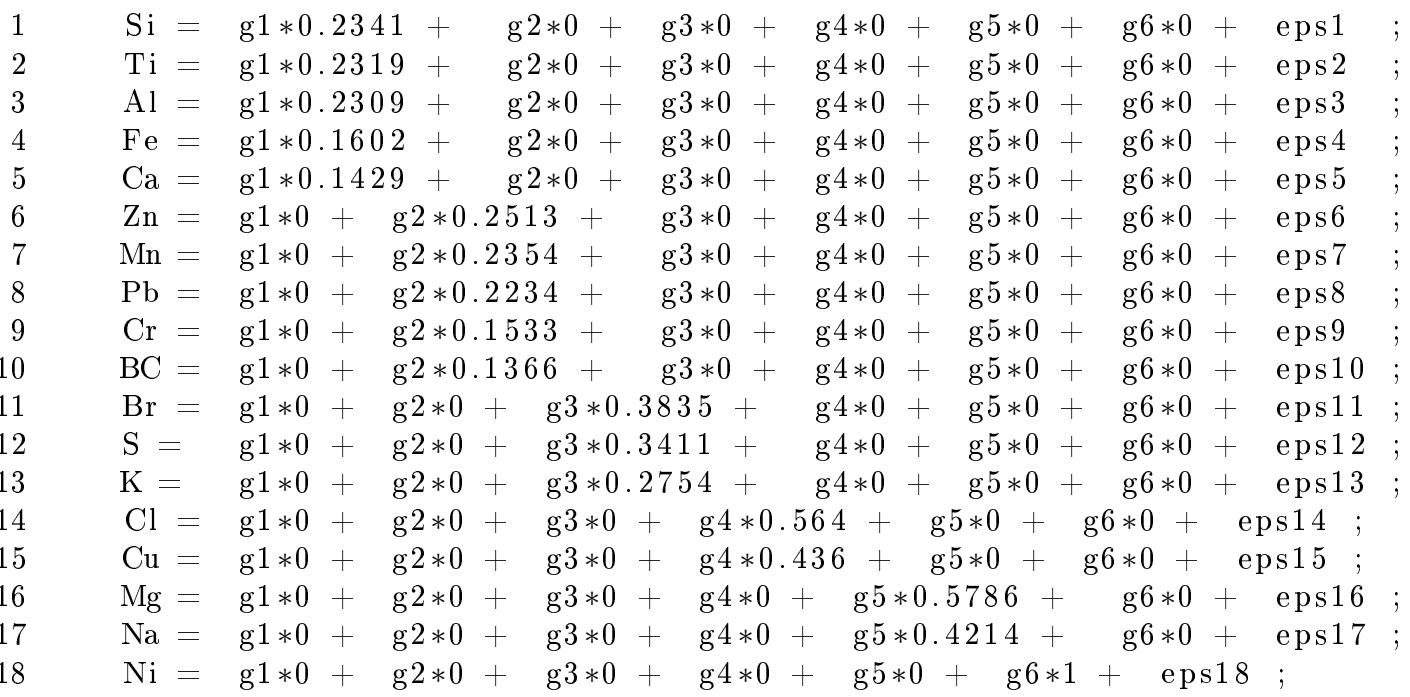

Portanto, ao executar os três blocos de códigos apresentados anteriomente, repetidas vezes, teremos um conjunto de "observações simuladas". Neste caso geramos trezentas "observações".

A rotina de inserção de outliers em uma "observação" utiliza dois valores gerados segundo a distribuição uniforme, e um segundo a distribuição exponencial. Considerando que estamos fazendo uma sequência de iterações para gerar as trezentas observações, para cada uma devemos decidir se o valor outlier será inserido ou não, e um dos valores de distribuição uniforme é usado para este caso. Na linha um e dois do bloco de código a seguir, é onde se escolhe se a "observação" terá outlier, gerando uma variável com distribuição uniforme entre 0 e 1, e com $50 \%$ de probabilidade de inserimos outlier. Nas linhas restantes, é feita uma discretização do segundo valor de distribuição 
uniforme para a quantidade de variáveis do modelo, e então é inserido um valor gerado segundo distribuição exponencial na posição do ruído correspondente.

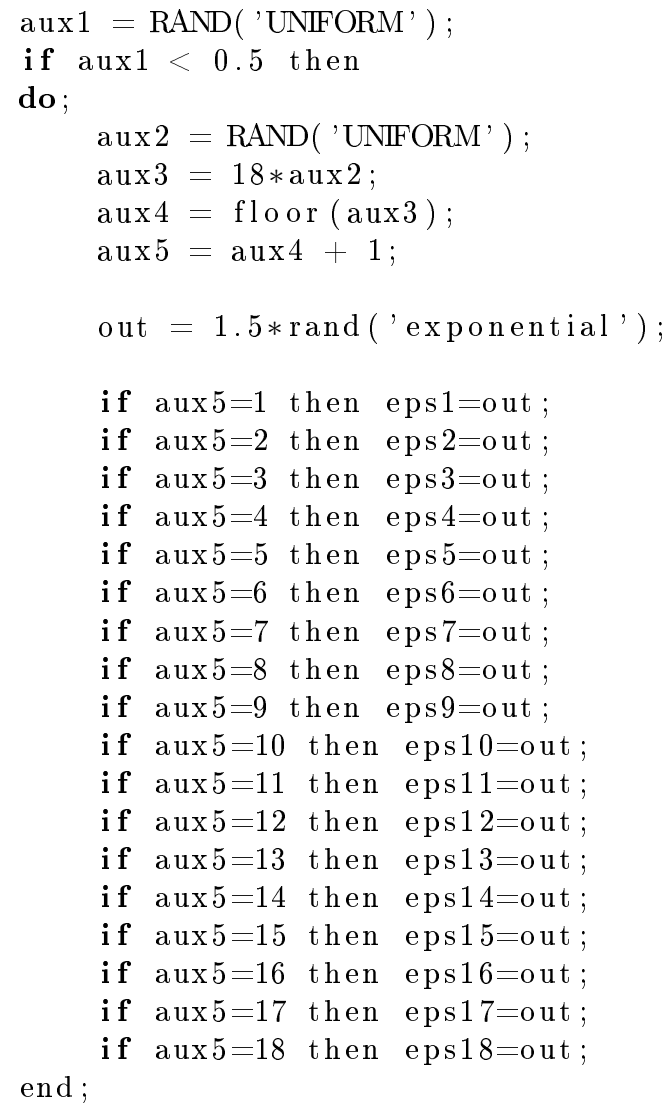

Nos Apêndices B.1, B.2, B.3 e B.4 é possível encontrar gráficos com exemplos de séries de tempo simuladas para cada uma das quatro situações prospostas no início desta seção. 


\section{Capítulo 5}

\section{Aplicação da fatoração PMF com software ME-2}

Conforme dissemos no Capítulo 3, embora o software EPA PMF 5.0 ofereça recursos gráficos que facilitem a operação de inserção e análise de dados, não é viável utilizá-lo para obter a fatoração em série de uma sequência de bases de dados simuladas. Para realizar esta tarefa utilizamos diretamente o motor ME-2. Neste capítulo vamos fazer uma descrição de alguns detalhes técnicos de como executar o motor ME-2 via linha de comando, e de como o aplicamos nas bases de dados simuladas e consolidamos os resultados.

\subsection{Configurações do software ME-2}

Ao realizar a instalação do software EPA PMF 5.0, na pasta principal do programa, é possível encontrar os arquivos que são operados indiretamente pela interface gráfica. A versão 5.0 do programa EPA PMF utiliza a versão lançada em 3 de março de 2014. O arquivo executável desta versão, e o arquivo de configuração são respectivamente, me2gfP4_1345c4.exe e PMF_bs_6f8xx_sealed_GUI.ini, [vide seção 1.2 de Norris et al. (2014)]. Embora seja necessário invocar apenas esses dois aquivos na linha de comando, outros arquivos são necessários constar na pasta do arquivo principal para que o programa execute. A Figura 5.1 apresenta de maneira simplificada o conteúdo e a função de cada arquivo necessário para executar o ME-2. Existem dois arquivos que controlam as configurações e funcionalidades do ME-2 que são o $P M F_{-} b s_{-} 6 f 8 x x_{-}$sealed_GUI.ini como dito anteriormente, e o iniParams.txt. Ambos são arquivos de texto, que podem ser editados em um editor simples, que interpreta de maneira correta, tabulações, espaçamentos e quebras de linhas. O primeiro arquivo contém todas as configurações das funcionalidades implementadas no ME-2. Trata-se de um arquivo extenso, com algumas seções comentadas ${ }^{1}$ identificando a posição no arquivo em que cada funcionalidade pode ser alterada ${ }^{2}$.

\footnotetext{
${ }^{1}$ As linhas referentes a comentários são iniciadas pelo símbolo \%.

${ }^{2}$ Notemos que como estamos utilizando a versão do ME-2 que acompanha o software EPA PMF 5.0, todas as modificações permitidas são as que estão sob a licença do software EPA PMF 5.0. Existem parâmetros e funcionalidades em que não são permitidas alterações, e tais seções estão identificadas através de comentários. No site http://www.helsinki.fi/ paatero/PMF/ é possível fazer download de outra versão, e obter informações sobre licenciamento do software.
} 


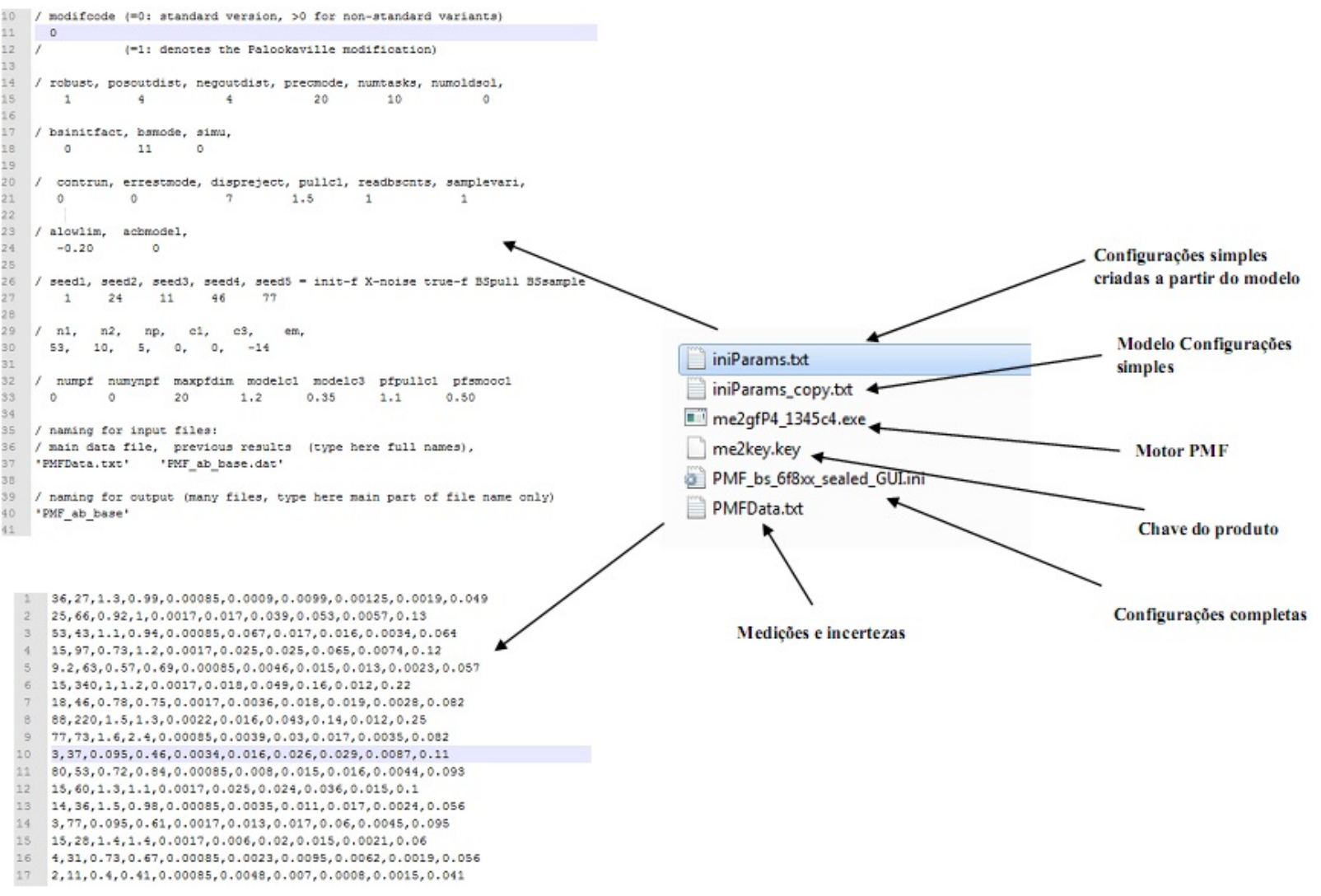

Figura 5.1: Arquivos para a execução do ME-2 via linha de comando

$\mathrm{O}$ arquivo iniParams.txt é um arquivo simplificado, em que as configurações que nele forem definidas sobrescreverão as configurações definidas no arquivo PMF_bs_6f8xx_sealed_GUI.ini. Podemos notar na Figura 5.1, por exemplo, a posição onde é possível alterar o número de observações, de variáveis e de fatores, 53, 10 e 5, respectivamente. A semente da execução pode ser definida, logo abaixo do comentário ${ }^{3}$ seed1, e o número de "rodadas", logo abaixo do comentário numtasks. Também é possível definir o nome dos aquivos de entrada e saída, que vamos comentar a seguir, no caso da figura 'PMFData.txt', é o nome do arquivo de entrada, e 'PMF_ab_base' o arquivo de saída. A matriz com as observações e as suas respectivas incertezas associadas devem estar na mesma pasta do arquivo executável, e com o nome definido no arquivo iniParams.txt. As observações devem estar dispostas nas linhas e as variáveis nas colunas separadas por vírgulas. A matriz de incertezas deve estar disposta da mesma forma, mas logo abaixo da matriz de observações, como se estivessem empilhadas. Ao executar o programa, o arquivo com a chave do produto será verificado e como ilustrado na figura, este arquivo é o me2key.key, que também é instalado juntamente com o EPA PMF 5.0.

\subsection{Execução do software ME-2}

Para executar o programa, é necessário abrir o console de comando e acessar a pasta onde os arquivos foram copiados, digitar o nome do arquivo executável seguido do nome do arquivo de configuração principal, como ilustrado na Figura 5.2.

\footnotetext{
${ }^{3}$ As linhas de comentário neste aquivo são iniciadas com /.
} 


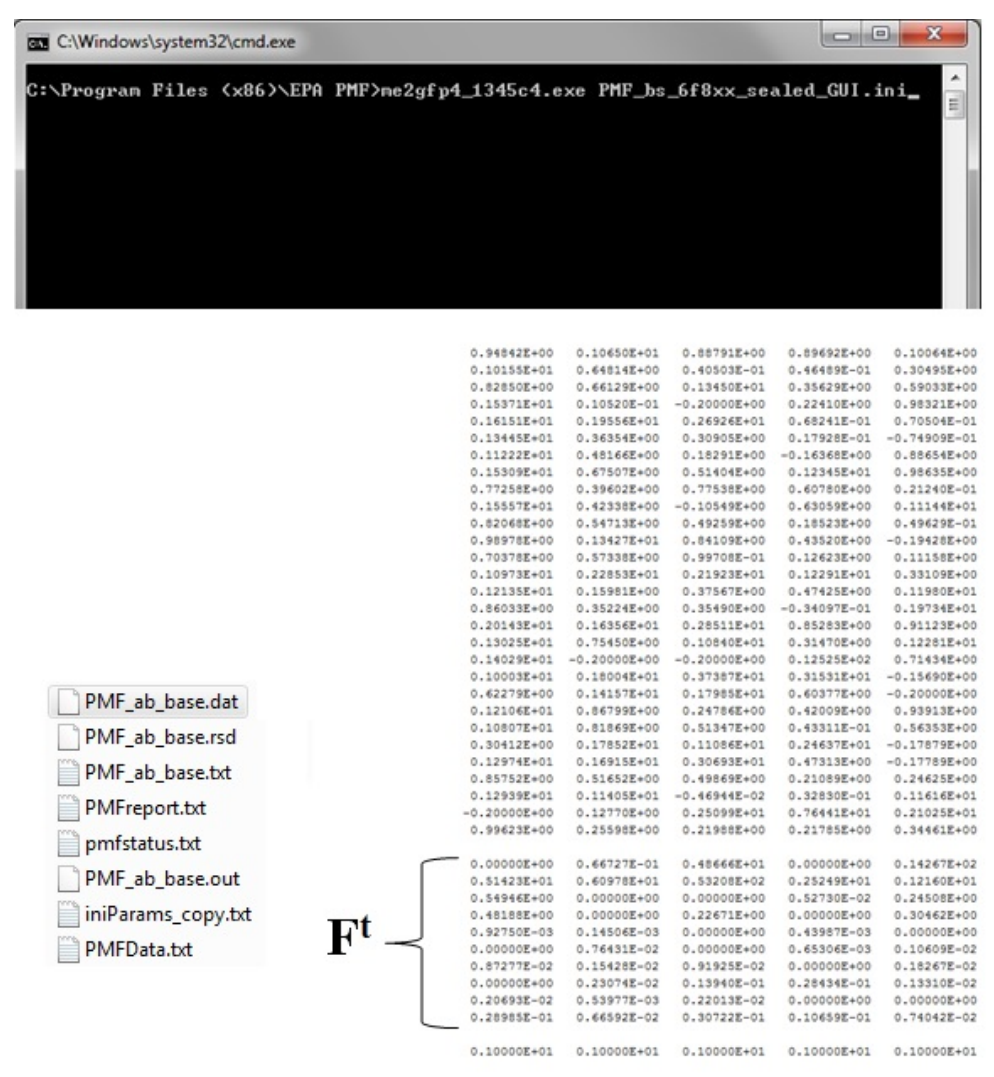

Figura 5.2: Execução do ME-2 via linha de comando

Após executar o ME-2 com as configurações desejadas, na mesma pasta teremos os arquivos com os resultados da fatoração. Dois arquivos são de interesse neste estudo, o arquivo com as matrizes da fatoração, que tem o nome de acordo com o que foi definido no arquivo de configuração - no caso do exemplo da Figura 5.1, o arquivo será PMF_ab_base.dat - e o arquivo PMFreport.txt que contém o valores de Q-robusto de cada "run" executado, que é utilizado para identificar o "run" ótimo. Na Figura 5.2 é exibida parte do conteúdo do arquivo de saída - em uma situação com 5 fatores e 10 variáveis - onde está destacada a seção que contém a matriz $\mathrm{F}$ transposta. Logo acima do bloco da matriz F transposta está a matriz G. O delimitador do bloco de uma fatoração é a linha com zeros abaixo do bloco da matriz $\mathrm{F}$ transposta. Haverá a quantidade de blocos com este formato de maneira empilhada conforme o número de "runs" definido no arquivo de configuração. É importante destacar que após finalizar a execução, o arquivo iniParams.txt é apagado da pasta pelo programa; para a próxima execução é necessário refazer o arquivo. O programa EPA PMF 5.0 utiliza uma cópia, iniParams_copy.txt como modelo, e que também será utilizada no procedimento descrito na próxima seção.

\subsection{Identificação de fatores}

Após executar a fatoração o pesquisador tem a tarefa de identificar os perfis contidos na matriz F. Neste trabalho, como os perfis são conhecidos, foi aplicada uma metodologia para identificar os perfis resultantes em relação aos utilizados para gerar as bases de dados, Tabela 4.2.

Foi calculado um indicador de proximidade de cada perfil resultante da fatoração a cada perfil usado para gerar a base de dados, resultando em uma matriz quadrada $p \times p$ com $p$ sendo a quantidade de perfis, com as "distâncias" entre os perfis. Esta distância é definida pela soma dos quadrados das diferenças de cada variável de dois perfis comparados. Matematicamente podemos 
expressar da seguinte maneira a distância entre dois perfis $f^{1}$ e $f^{2}$ com $m$ variáveis:

$$
\operatorname{distancia}(f 1, f 2)=\sum_{i=1}^{m}\left(f 1_{i}-f 2_{i}\right)^{2} .
$$

Consideremos por exemplo as matrizes apresentadas nas Tabelas 5.1 e 5.2, em que temos, respectivamente, os perfis resultantes da fatoração e os perfis utilizados para simular uma base de dados.

Tabela 5.1: Matriz F - PMF

\begin{tabular}{cccc}
\hline \hline Variável & Perfil 1 & Perfil 2 & Perfil 3 \\
\hline v1 & $9,56 \%$ & $16,71 \%$ & $16,17 \%$ \\
v2 & $32,77 \%$ & $27,59 \%$ & $32,29 \%$ \\
v3 & $28,83 \%$ & $27,85 \%$ & $25,77 \%$ \\
v4 & $28,84 \%$ & $27,84 \%$ & $25,78 \%$ \\
\hline
\end{tabular}

Tabela 5.2: Matriz F - Original

\begin{tabular}{cccc}
\hline \hline Variável & Perfil 1 & Perfil 2 & Perfil 3 \\
\hline v1 & $12,50 \%$ & $3,80 \%$ & $10,00 \%$ \\
v2 & $37,50 \%$ & $19,20 \%$ & $20,00 \%$ \\
v3 & $5,00 \%$ & $38,50 \%$ & $30,00 \%$ \\
v4 & $25,00 \%$ & $38,50 \%$ & $40,00 \%$
\end{tabular}

Calculadas as distâncias conforme a equação (5.1), e considerando todas as combinações entre os perfis das Tabelas 5.1 e 5.2, teremos a seguinte matriz de distâncias:

Tabela 5.3: Distâncias entre fatores

\begin{tabular}{cc|ccc} 
& \multicolumn{4}{|c}{ Original } \\
& & 1 & 2 & 3 \\
\hline \multirow{3}{*}{ PMF } & 1 & 0,006036546 & $\mathbf{0 , 0 4 0 1 4 8 1 0 9}$ & 0,028935084 \\
& 2 & 0,013205395 & 0,046074824 & $\mathbf{0 , 0 2 5 5 1 0 6 8 1}$ \\
& 3 & $\mathbf{0 , 0 0 4 1 8 2 7 7 1}$ & 0,064409241 & 0,040910678
\end{tabular}

Após ter a matriz com as distâncias, é necessário identificar as menores distâncias conforme a disponibilidade de perfis. Por exemplo, na Tabela 5.3, a menor distância está na posição $(3,1)$, o que identifica o perfil PMF 3 com o perfil Original 1. As posições disponíveis para identificação após o primeiro passo são as relativas aos perfis PMF 1 e 2 e Original 2 e 3, ou seja, apenas é possível considerar as distâncias nas posições $(1,2),(1,3),(2,2)$ e $(2,3)$. Neste conjunto restante, a menor distância está na posição (2,3), o que vincula o perfil PMF 2 ao Original 3, restanto apenas a posição disponível $(1,2)$ na matriz, o que identifica o perfil PMF 1 ao Original 2.

\subsection{Metodologia de consolidação dos resultados}

Cada matriz de observações simuladas, que foi gerada conforme descrito no Capítulo 4, foi gravada em um arquivo de texto com um nome que a identifica unicamente. Para viabilizar a obtenção dos resultados, foi desenvolvido um programa em linguagem $\mathrm{C}$ que executa os seguintes passos:

1. Cria um novo arquivo iniParams.txt com as configurações desejadas a partir do arquivo modelo iniParams_copy.txt;

2. Lê cada arquivo de observações simuladas e cria um novo arquivo com formato de entrada para o ME-2, conforme descrito na Seção 5.1, inserindo também as medidas de incertezas;

3. Executa o programa ME-2;

4. Busca o "run" com o menor Q-robusto no arquivo PMFreport.txt;

5. Extrai do arquivo de saída a fatoração correspondente ao "run" com o menor Q-robusto; 
6. Executa a rotina de identificação dos fatores resultantes conforme descrito na Seção 5.3.

7. Calcula a média e o desvio padrão de cada variável entre cada fator identificado entre todas aplicações do PMF nas bases simuladas (fatores médios).

O código escrito em linguagem $\mathrm{C}$ usado para executar os passos descritos estão no Apêndice A.2. 


\section{Capítulo 6}

\section{Resultados}

Neste capítulo serão apresentadas as propostas de definição de incertezas testadas com PMF nas bases de dados simuladas conforme descrito no Capítulo 4, e uma comparação com a Análise Fatorial ortogonal sem considerar medidas de incerteza, e análise dos resultados.

\subsection{Propostas de definição de incertezas}

Na literatura sobre estudos de detecção de fontes emissoras de material particulado utilizando a fatoração PMF podem ser encontradas diversas abordagens sobre como definir a matriz de incertezas de medições. Para as bases simuladas conforme os perfis da Tabela 4.2, inicialmente foram escolhidas quatro abordadens diferentes presentes na literatura. A primeira foi a que está implementada no programa EPA PMF 5.0, conforme descrito na equação (3.1), na Seção 3.1.1, cujos detalhes podem ser encontrados em Norris et al. (2014). A segunda foi utilizada no estudo apresentado em Polissar et al. (1998), a terceira em Ito et al. (2004), e a quarta em Chueinta et al. (2000).

As fórmulas utilizadas para definição de incertezas de medições e tratamento de caso abaixo do limite de detecção dependem do limite de deteç̧ão $L D_{j}$ correspondente ao elemento $j$ medido, da própria medida $x_{i j}$, e em alguns casos também da incerteza analítica $p_{j}$ correspondente ao elemento $j$ medido. As fórmulas estão sumarizadas a seguir conforme as suas referências:

1. EPA PMF 5.0 - Norris et al. (2014)

$$
\begin{gathered}
u_{i j}= \begin{cases}(5 / 6) \times L D_{j} & \text { se } x_{i j}<L D_{j}, \\
\sqrt{\left(0,05 \times x_{i j}\right)^{2}+\left(0,5 \times L D_{j}\right)^{2}} & \text { se } x_{i j} \geq L D_{j} .\end{cases} \\
x_{i j}= \begin{cases}L D_{j} / 2 & \text { se } x_{i j}<L D_{j}, \\
x_{i j} & \text { c.c. }\end{cases}
\end{gathered}
$$

2. Polissar et al. (1998)

$$
\begin{gathered}
u_{i j}= \begin{cases}(5 / 6) \times L D_{j} & \text { se } x_{i j}<L D_{j}, \\
p_{j} \times x_{i j}+L D_{j} / 3 & \text { se } x_{i j} \geq L D_{j} .\end{cases} \\
x_{i j}= \begin{cases}L D_{j} / 2 & \text { se } x_{i j}<L D_{j}, \\
x_{i j} & \text { c.c. }\end{cases}
\end{gathered}
$$


3. Ito et al. (2004)

$$
\begin{gathered}
u_{i j}= \begin{cases}L D_{j} / 2 & \text { se } x_{i j}<L D_{j}, \\
\left(0,05 \times x_{i j}+L D_{j}\right) & \text { se } x_{i j} \geq L D_{j} .\end{cases} \\
x_{i j}= \begin{cases}L D_{j} / 2 & \text { se } x_{i j}<L D_{j}, \\
x_{i j} & \text { c.c. }\end{cases}
\end{gathered}
$$

4. Chueinta et al. (2000)

$$
\begin{gathered}
u_{i j}= \begin{cases}L D_{j} / 2 & \text { se } x_{i j}<L D_{j}, \\
\left(p_{j} \times x_{i j}+0,2 \times x_{i j}\right) & \text { se } x_{i j} \geq L D_{j} .\end{cases} \\
x_{i j}= \begin{cases}L D_{j} / 2 & \text { se } x_{i j}<L D_{j}, \\
x_{i j} & \text { c.c. }\end{cases}
\end{gathered}
$$

Notemos que nas referências Ito et al. (2004) e Chueinta et al. (2000), não são citados os tratamentos dados aos casos de medidas abaixo do limite de deteç̧ão. Para este estudo foi escolhido arbitrariamente o valor $L D_{j} / 2$, tanto para a substituição do valor da medida, quanto para o valor da respectiva incerteza. Nas equações (6.4) e (6.8) os valores utilizados para $p_{j}$ foram os valores de incerteza relativa contidos na Tabela 2.3, ou seja, utilizamos como incerteza analítica para tais fórmulas o desvio da medição obtido em um procedimento de calibração de um equipamento de EDXRF.

Os valores dos limites de detecção $L D_{j}$, utilizados na simulação, Tabela 6.1, foram baseados no estudo apresentado em Landsberger e Creatchman (1999), Capítulo 2.

Tabela 6.1: Limites de detecção mínimos - $n g / m^{3}$

\begin{tabular}{cc}
\hline \hline Elementos & XRF \\
\hline $\mathrm{Si}$ & 2 \\
$\mathrm{Ti}$ & 1 \\
$\mathrm{Al}$ & 5 \\
$\mathrm{Fe}$ & 0.7 \\
$\mathrm{Ca}$ & 1 \\
$\mathrm{Zn}$ & 0.2 \\
$\mathrm{Mn}$ & 0.8 \\
$\mathrm{~Pb}$ & 1 \\
$\mathrm{Cr}$ & 1 \\
$\mathrm{BC}$ & 0.1 \\
$\mathrm{Br}$ & 0.1 \\
$\mathrm{~S}$ & 1 \\
$\mathrm{~K}$ & 1 \\
$\mathrm{Cl}$ & 1 \\
$\mathrm{Cu}$ & 0.3 \\
$\mathrm{Mg}$ & 15 \\
$\mathrm{Na}$ & 30 \\
$\mathrm{Ni}$ & 0.3 \\
\hline
\end{tabular}


Também é muito comum adotar as medidas de incertezas como uma porcentagem dos valores das observações. Portanto, além das quatro abordagens citadas, também foram aplicadas neste estudo de sensibilidade as porcentagens de $5 \%, 10 \%$ e $20 \%$, dos valores das bases simuladas conforme os perfis das Tabelas 4.2, como medidas de incerteza. Exemplos de séries de tempo das abordagens de definição de incertezas apresentadas nesta seção podem ser encontrados nos Apêndices B.5, B.6, B.7 e B.8, em que cada exemplo corresponde à aplicação das abordagens de definição de incerteza a uma das quatro situações de simulação de base de dados citadas no início da Seção 4.5. As séries de tempo simuladas em que foram baseados tais exemplos de incertezas são os apresentados nos Apêndices B.1, B.2, B.3 e B.4.

\subsection{Resultados de aplicações de diferentes propostas de definição de incertezas}

Nesta seção são apresentados os resultados da aplicação da fatoração PMF nas bases de dados simuladas conforme os perfis da Tabela 4.2, com as quatro variações descritas na Seção 4.5, uma sem outliers, e três outras com outliers seguindo a distribuição exponencial com média 1, 5; 3 e 9 . Para cada uma destas quatro variações, foi aplicada a fatoração PMF quatro vezes, utilizando em cada vez uma das quatro propostas de definição de incerteza, baseadas na literatura, apresentadas na Seção 6.1, e mais as três propostas de porcentagens das medidas, $5 \% ; 10 \%$ e $20 \%$. Nos resultados da aplicação da fatoração foram calculadas as porcentagens da concentração das espécies químicas dentro de cada fator, e então conforme descrito no item 7 da Seção 5.4, foi calculada a média destas porcentagens - média das entradas das matrizes -, gerando desta forma uma média de cada fator ou perfil entre todas as simulações. A seguir os resultados são apresentados em forma de matrizes e gráficos. No caso das matrizes, os perfis estão dispostos sequencialmente do primeiro ao sexto perfil nas colunas, e à direita de cada matriz com os perfis médios, está uma matriz com os desvios padrões de cada entrada considerando todos os resultados da aplicação da fatoração. Ainda para cada variação das bases simuladas foi aplicada a Análise Fatorial Ortogonal, com extração de fatores via componentes principais $(\mathrm{CP})$ e com rotação Varimax, sem nenhuma consideração em relação às incertezas para critério de comparação com um método alternativo. Após a aplicação da Análise Fatorial foi calculada a média das cargas fatoriais entre todas as simulações - dentro de cada variação das bases, com ou sem outliers -, e os seus respectivos desvios padrões. Os gráficos apresentam a comparação dos resultados entre as propostas de definição de incerteza para cada perfil. Cada proposta é identificada na legenda pela referência bibliográfica ou pela porcentagem que reflete a incerteza da medida, e a legenda com o número do perfil se refere ao perfil original usado para gerar as bases de dados. Assim como nas matrizes, os valores apresentados nos gráficos são referentes às médias dos perfis obtidos nas simulações, formando assim perfis médios. Estes valores referentes às porcentagens médias das espécies químicas são representados por blocos nos gráficos para que facilitem a interpretação da diferença entre os perfils médios obtidos resultantes da aplicação de cada proposta de incerteza e o perfil original, em azul, utilizado para simular as bases de dados. Em cada gráfico, que corresponde a um perfil, no eixo das ordernadas estão as porcentagens médias de cada elemento químico, e no eixo das abscissas os elementos químicos. 


\section{Simulações sem outliers}

\begin{tabular}{|l|l|l|l|l|l|}
0.195118 & 0.008120 & 0.009162 & 0.009928 & 0.009600 & 0.012851 \\
0.193321 & 0.008033 & 0.009081 & 0.009838 & 0.009496 & 0.012712 \\
0.192422 & 0.008013 & 0.009046 & 0.009816 & 0.009464 & 0.012676 \\
0.133637 & 0.005522 & 0.006241 & 0.006776 & 0.006531 & 0.008758 \\
0.119250 & 0.004920 & 0.005539 & 0.006025 & 0.005817 & 0.007794 \\
\hline 0.009361 & 0.209829 & 0.009575 & 0.010662 & 0.010225 & 0.013446 \\
0.008748 & 0.196593 & 0.008927 & 0.010002 & 0.009558 & 0.012633 \\
0.008302 & 0.186526 & 0.008509 & 0.009479 & 0.009083 & 0.011972 \\
0.005679 & 0.128119 & 0.005789 & 0.006465 & 0.006202 & 0.008177 \\
0.005024 & 0.114261 & 0.005154 & 0.005745 & 0.005520 & 0.007272 \\
\hline 0.013115 & 0.013515 & 0.314304 & 0.017417 & 0.016412 & 0.017890 \\
0.011661 & 0.012035 & 0.279559 & 0.015472 & 0.014589 & 0.015914 \\
0.009407 & 0.009679 & 0.225798 & 0.012498 & 0.011771 & 0.012814 \\
\hline 0.018399 & 0.018459 & 0.019684 & 0.447914 & 0.025180 & 0.027920 \\
0.014197 & 0.014243 & 0.015216 & 0.346293 & 0.019471 & 0.021596 \\
0.019262 & 0.019489 & 0.019743 & 0.022028 & 0.458089 & 0.027847 \\
0.014025 & 0.014207 & 0.014370 & 0.016043 & 0.333630 & 0.020271 \\
\cline { 1 - 4 } 0.029072 & 0.028437 & 0.034303 & 0.037599 & 0.039362 & 0.747457 \\
\hline
\end{tabular}

\begin{tabular}{|l|l|l|l|l|l|}
\hline 0.014500 & 0.007677 & 0.008434 & 0.009096 & 0.008681 & 0.010362 \\
0.014345 & 0.007619 & 0.008349 & 0.009010 & 0.008609 & 0.010270 \\
0.014276 & 0.007559 & 0.008321 & 0.008982 & 0.008568 & 0.010206 \\
\hline 0.009938 & 0.005266 & 0.005805 & 0.006253 & 0.005966 & 0.007101 \\
0.008865 & 0.004687 & 0.005152 & 0.005580 & 0.005300 & 0.006324 \\
\hline 0.008710 & 0.015543 & 0.008836 & 0.009671 & 0.009417 & 0.010847 \\
0.008145 & 0.014575 & 0.008318 & 0.009054 & 0.008820 & 0.010160 \\
0.007725 & 0.013804 & 0.007846 & 0.008574 & 0.008354 & 0.009644 \\
\hline 0.005300 & 0.009482 & 0.005398 & 0.005881 & 0.005744 & 0.006626 \\
0.004742 & 0.008474 & 0.004815 & 0.005258 & 0.005118 & 0.005906 \\
\hline 0.014130 & 0.013880 & 0.023331 & 0.015852 & 0.015808 & 0.016637 \\
0.012553 & 0.012365 & 0.020722 & 0.014107 & 0.014055 & 0.014801 \\
0.010145 & 0.009990 & 0.016748 & 0.011407 & 0.011345 & 0.011960 \\
\hline 0.021952 & 0.022225 & 0.022730 & 0.034962 & 0.024626 & 0.026328 \\
0.016992 & 0.017198 & 0.017539 & 0.027044 & 0.019037 & 0.020346 \\
\cline { 4 - 6 } 0.023985 & 0.024159 & 0.024077 & 0.024744 & 0.036137 & 0.027521 \\
0.017469 & 0.017590 & 0.017539 & 0.018029 & 0.026330 & 0.020050 \\
\hline 0.041993 & 0.042140 & 0.042667 & 0.043462 & 0.044042 & 0.053659 \\
\hline
\end{tabular}

Figura 6.1: Perfis médios em bases sem outliers - Figura 6.2: Desvios padrões em bases sem outliers Proposta de incertezas definida em Norris et al.

$$
\text { (2014) }
$$

- Proposta de incertezas definida em Norris et al.$$
\text { (2014) }
$$

\begin{tabular}{|c|c|c|c|c|c|}
\hline 0.197036 & 0.007955 & 0.008151 & 0.010358 & 0.010410 & 0.011307 \\
\hline 0.195261 & 0.007875 & 0.008083 & 0.010276 & 0.010307 & 0.011193 \\
\hline 0.194343 & 0.007848 & 0.008051 & 0.010240 & 0.010274 & 0.011154 \\
\hline 0.134952 & 0.005417 & 0.005555 & 0.007083 & 0.007101 & 0.007708 \\
\hline 0.120379 & 0.004833 & 0.004934 & 0.006296 & 0.006322 & 0.006863 \\
\hline 0.009437 & 0.210576 & 0.009006 & 0.009787 & 0.011485 & 0.012329 \\
\hline 0.008822 & 0.197265 & 0.008400 & 0.009184 & 0.010735 & 0.011584 \\
\hline 0.008373 & 0.187208 & 0.008006 & 0.008705 & 0.010207 & 0.010985 \\
\hline 0.005734 & 0.128527 & 0.005455 & 0.005942 & 0.006979 & 0.007503 \\
\hline 0.005061 & 0.114598 & 0.004836 & 0.005265 & 0.006197 & 0.006656 \\
\hline 0.012092 & 0.013017 & 0.320078 & 0.015353 & 0.018077 & 0.020079 \\
\hline 0.010750 & 0.011599 & 0.284709 & 0.013641 & 0.016077 & 0.017862 \\
\hline 0.008679 & 0.009332 & 0.229982 & 0.011023 & 0.012979 & 0.014396 \\
\hline 0.016100 & 0.019202 & 0.019540 & 0.456361 & 0.026789 & 0.026651 \\
\hline 0.012424 & 0.014824 & 0.015111 & 0.352869 & 0.020724 & 0.020627 \\
\hline 0.016662 & 0.017500 & 0.017560 & 0.018083 & 0.445744 & 0.023459 \\
\hline 0.012132 & 0.012753 & 0.012779 & 0.013170 & 0.324623 & 0.017073 \\
\hline 0.031763 & 0.029671 & 0.029764 & 0.036364 & 0.044970 & 0.762571 \\
\hline
\end{tabular}

\begin{tabular}{|c|c|c|c|c|c|}
\hline 0.015031 & 0.007987 & 0.008014 & 0.009265 & 0.009764 & 0.010120 \\
\hline 0.014898 & 0.007932 & 0.007927 & 0.009196 & 0.009660 & 0.010034 \\
\hline 0.014809 & 0.007876 & 0.007889 & 0.009138 & 0.009613 & 0.009982 \\
\hline 0.010321 & 0.005467 & 0.005483 & 0.006346 & 0.006676 & 0.006949 \\
\hline 0.009188 & 0.004894 & 0.004917 & 0.005664 & 0.005974 & 0.006195 \\
\hline 0.008588 & 0.015944 & 0.008732 & 0.009801 & 0.010452 & 0.010815 \\
\hline 0.008028 & 0.014937 & 0.008184 & 0.009156 & 0.009809 & 0.010121 \\
\hline 0.007655 & 0.014180 & 0.007772 & 0.008684 & 0.009312 & 0.009595 \\
\hline 0.005229 & 0.009757 & 0.005339 & 0.006001 & 0.006386 & 0.006605 \\
\hline 0.004685 & 0.008713 & 0.004775 & 0.005332 & 0.005696 & 0.005898 \\
\hline 0.012976 & 0.013593 & 0.024121 & 0.014996 & 0.016185 & 0.016650 \\
\hline 0.011525 & 0.012068 & 0.021410 & 0.013327 & 0.014359 & 0.014813 \\
\hline 0.009304 & 0.009782 & 0.017298 & 0.010801 & 0.011629 & 0.011953 \\
\hline 0.019702 & 0.022075 & 0.022422 & 0.036901 & 0.024678 & 0.025722 \\
\hline 0.015254 & 0.017071 & 0.017334 & 0.028538 & 0.019081 & 0.019873 \\
\hline 0.023841 & 0.024529 & 0.023981 & 0.024325 & 0.034313 & 0.026122 \\
\hline 0.017379 & 0.017855 & 0.017454 & 0.017731 & 0.024978 & 0.019032 \\
\hline 0.041722 & 0.041175 & 0.040344 & 0.043705 & 0.044846 & 0.056757 \\
\hline
\end{tabular}

Figura 6.3: Perfis médios em bases sem outliers - Figura 6.4: Desvios padrões em bases sem outliers Proposta de incertezas definida em Polissar et al. - Proposta de incertezas definida em Polissar et al. (1998) (1998) 


\begin{tabular}{|c|c|c|c|c|c|}
\hline 0.196074 & 0.007917 & 0.008700 & 0.010068 & 0.010049 & 0.011834 \\
\hline 94266 & 0.007828 & 0.008615 & 0.009982 & 0.009947 & 0.011711 \\
\hline 0.193378 & 0.007809 & 0.008586 & 0.009952 & 0.009915 & 0.011673 \\
\hline 34280 & 0.005387 & 0.005923 & & 0.006847 & 0.008072 \\
\hline 0.119797 & 0.004806 & & & & \\
\hline 0.008507 & 0.210291 & 0.009517 & 0.010306 & 0.0117 & 0.012891 \\
\hline 0.007948 & 0.197012 & 0.008883 & 0.009671 & 0.011007 & 0.012 \\
\hline 0.007543 & 0.186930 & 0.008462 & 0.009164 & 0.010460 & 0.011484 \\
\hline 0.005164 & 0.128356 & 0.005765 & 0.006255 & 0.007152 & 0.007844 \\
\hline 0.004564 & 0.114511 & 0.005124 & 0.005554 & 0.006360 & 0.006969 \\
\hline 0.012849 & 0.012510 & 0.316103 & 0.015986 & 0.018476 & 0.018444 \\
\hline 0.011425 & 0.011144 & 0.281149 & 0.014196 & 0.016429 & 0.016409 \\
\hline 0.009215 & 0.008964 & 0.227060 & 0.011471 & & \\
\hline 0.016960 & & 0.020320 & & & 0.026889 \\
\hline 0.013086 & 0.014676 & 0.015705 & 0.351389 & 0.021957 & \\
\hline 0.019127 & 0.01841 & 0.017596 & 0.018415 & & 0.023722 \\
\hline 0.013932 & 0.013420 & 0.012806 & 0.013414 & 0.321912 & 0.017261 \\
\hline 0.031885 & 0.031014 & 0.034417 & 0.036680 & 0.047949 & 0.761494 \\
\hline
\end{tabular}

\begin{tabular}{|c|c|c|c|c|c|}
\hline 0.014921 & 0.008000 & 0.008521 & 0.009155 & 0.009599 & 0.010441 \\
\hline 0.014780 & 0.007950 & 0.008427 & 0.009056 & 0.009519 & 0.010354 \\
\hline 0.014721 & 0.007886 & 0.008380 & 0.009009 & 0.009473 & 0.010312 \\
\hline 0.010270 & 0.005470 & 0.005830 & 0.006263 & 0.006585 & 0.007150 \\
\hline 0.009139 & 0.004900 & 0.005194 & 0.005596 & 0.005866 & 0.006395 \\
\hline 0.008139 & 0.016158 & 0.009108 & 0.009682 & 0.010499 & 0.010662 \\
\hline 0.007625 & 0.015153 & 0.008542 & 0.009077 & 0.009843 & 0.009972 \\
\hline 0.007231 & 0.014371 & 0.008098 & 0.008601 & 0.009336 & 0.009477 \\
\hline 0.004963 & 0.009857 & 0.005572 & 0.005900 & 0.006409 & 0.006498 \\
\hline 0.004427 & 0.008821 & 0.004963 & 0.005286 & 0.005706 & 0.005801 \\
\hline 0.013487 & 0.013889 & 0.024786 & 0.015411 & 0.016304 & 0.017285 \\
\hline 0.011998 & 0.012381 & 0.022023 & 0.013715 & 0.014500 & 0.015365 \\
\hline 0.009687 & 0.009981 & 0.017774 & 0.011062 & 0.011716 & 0.012417 \\
\hline 0.020729 & 0.021568 & 0.022969 & 0.034943 & 0.025075 & 0.025843 \\
\hline 0.016038 & 0.016673 & 0.017744 & 0.027044 & 0.019373 & 0.019983 \\
\hline 0.024752 & 0.025837 & 0.024081 & 0.024624 & 0.035254 & 0.026758 \\
\hline 0.018014 & 0.018823 & 0.017530 & 0.017925 & 0.025670 & 0.019491 \\
\hline 0.040681 & 0.043650 & 0.042066 & 0.043437 & 0.045705 & 0.055644 \\
\hline
\end{tabular}

Figura 6.5: Perfis médios em bases sem outliers Proposta de incertezas definida em Ito et al. (2004)
Figura 6.6: Desvios padrões em bases sem outliers - Proposta de incertezas definida em Ito et al. (2004)

\begin{tabular}{|l|l|l|l|l|l|}
\hline 0.193507 & 0.008484 & 0.009074 & 0.010118 & 0.009713 & 0.013233 \\
0.191727 & 0.008398 & 0.008991 & 0.010038 & 0.009604 & 0.013091 \\
0.190855 & 0.008366 & 0.008951 & 0.010008 & 0.009565 & 0.013051 \\
0.132546 & 0.005769 & 0.006179 & 0.006910 & 0.006605 & 0.009018 \\
0.118285 & 0.005140 & 0.005481 & 0.006142 & 0.005881 & 0.008022 \\
\hline 0.009581 & 0.208593 & 0.009552 & 0.010521 & 0.011207 & 0.013456 \\
0.008951 & 0.195437 & 0.008909 & 0.009868 & 0.010477 & 0.012640 \\
0.008498 & 0.185431 & 0.008496 & 0.009347 & 0.009958 & 0.011986 \\
0.005814 & 0.127382 & 0.005769 & 0.006382 & 0.006801 & 0.008180 \\
0.005141 & 0.113593 & 0.005140 & 0.005664 & 0.006050 & 0.007268 \\
\hline 0.013264 & 0.013594 & 0.311729 & 0.017263 & 0.016333 & 0.019694 \\
0.011793 & 0.012106 & 0.277270 & 0.015338 & 0.014522 & 0.017516 \\
0.009514 & 0.009737 & 0.223954 & 0.012391 & 0.011718 & 0.014108 \\
\hline 0.020187 & 0.020520 & 0.020896 & 0.443641 & 0.024924 & 0.027405 \\
0.015581 & 0.015836 & 0.016154 & 0.342992 & 0.019271 & 0.021202 \\
0.021459 & 0.018924 & 0.023308 & 0.025109 & 0.454696 & 0.028211 \\
0.015610 & 0.013802 & 0.016963 & 0.018284 & 0.331187 & 0.020526 \\
0.027687 & 0.028888 & 0.033184 & 0.039984 & 0.041488 & 0.741393 \\
\hline
\end{tabular}

\begin{tabular}{|l|l|l|l|l|l|}
\hline 0.014336 & 0.008203 & 0.008492 & 0.009304 & 0.008946 & 0.010347 \\
0.014211 & 0.008123 & 0.008394 & 0.009251 & 0.008895 & 0.010255 \\
0.014115 & 0.008090 & 0.008395 & 0.009193 & 0.008831 & 0.010215 \\
\hline 0.009864 & 0.005609 & 0.005819 & 0.006382 & 0.006126 & 0.007079 \\
0.008782 & 0.005010 & 0.005203 & 0.005700 & 0.005468 & 0.006324 \\
\hline 0.008580 & 0.015388 & 0.009222 & 0.009666 & 0.009425 & 0.010788 \\
0.008015 & 0.014413 & 0.008676 & 0.009053 & 0.008810 & 0.010125 \\
0.007609 & 0.013681 & 0.008203 & 0.008570 & 0.008364 & 0.009610 \\
\hline 0.005230 & 0.009396 & 0.005660 & 0.005899 & 0.005745 & 0.006604 \\
0.004667 & 0.008402 & 0.005016 & 0.005255 & 0.005105 & 0.005884 \\
\hline 0.014276 & 0.014296 & 0.023882 & 0.015948 & 0.015179 & 0.016946 \\
\hline 0.012690 & 0.012702 & 0.021202 & 0.014208 & 0.013482 & 0.015078 \\
0.010245 & 0.010263 & 0.017104 & 0.011440 & 0.010887 & 0.012163 \\
\hline 0.022686 & 0.022655 & 0.022964 & 0.034384 & 0.024609 & 0.025996 \\
0.017533 & 0.017550 & 0.017755 & 0.026580 & 0.019020 & 0.020086 \\
\cline { 1 - 4 } 0.023343 & 0.022958 & 0.023577 & 0.025102 & 0.035873 & 0.026669 \\
0.017019 & 0.016709 & 0.017181 & 0.018288 & 0.026099 & 0.019449 \\
\hline 0.040606 & 0.042785 & 0.042561 & 0.044471 & 0.045113 & 0.051704 \\
\hline
\end{tabular}

Figura 6.7: Perfis médios em bases sem outliers - Figura 6.8: Desvios padrões em bases sem outliers

Proposta de incertezas definida em Chueinta et al. (2000)
- Proposta de incertezas definida em Chueinta et al. (2000) 


\begin{tabular}{|l|l|l|l|l|l|}
0.194163 & 0.008486 & 0.009338 & 0.010300 & 0.009990 & 0.011831 \\
0.192368 & 0.008398 & 0.009258 & 0.010214 & 0.009880 & 0.011697 \\
0.191507 & 0.008368 & 0.009212 & 0.010182 & 0.009837 & 0.011671 \\
0.132989 & 0.005774 & 0.006360 & 0.007032 & 0.006791 & 0.008060 \\
0.118673 & 0.005143 & 0.005649 & 0.006254 & 0.006056 & 0.007164 \\
\hline 0.009286 & 0.209581 & 0.009694 & 0.011047 & 0.010219 & 0.013153 \\
0.008675 & 0.196363 & 0.009040 & 0.010362 & 0.009551 & 0.012351 \\
0.008240 & 0.186302 & 0.008619 & 0.009822 & 0.009078 & 0.011711 \\
\hline 0.005635 & 0.127977 & 0.005861 & 0.006696 & 0.006195 & 0.007992 \\
0.004991 & 0.114126 & 0.005218 & 0.005950 & 0.005515 & 0.007107 \\
\hline 0.012773 & 0.012809 & 0.313827 & 0.017220 & 0.016667 & 0.019004 \\
0.011352 & 0.011414 & 0.279136 & 0.015299 & 0.014809 & 0.016909 \\
0.009156 & 0.009178 & 0.225454 & 0.012364 & 0.011948 & 0.013617 \\
\hline 0.019078 & 0.018818 & 0.019923 & 0.443670 & 0.022503 & 0.029152 \\
0.014721 & 0.014523 & 0.015401 & 0.343009 & 0.017397 & 0.022553 \\
0.019752 & 0.019841 & 0.020046 & 0.025324 & 0.460381 & 0.028454 \\
0.014366 & 0.014463 & 0.014592 & 0.018449 & 0.335336 & 0.020702 \\
\cline { 1 - 4 } 0.032275 & 0.028436 & 0.033372 & 0.036806 & 0.037847 & 0.746872 \\
\hline
\end{tabular}

Figura 6.9: Perfis médios em bases sem outliers Proposta de incertezas de $5 \%$ do valor da medição

\begin{tabular}{|c|c|c|c|c|c|}
\hline 0.014956 & 0.008017 & 0.008491 & 0.008937 & 0.009044 & 0.010482 \\
\hline 0.014784 & 0.007947 & 0.008401 & 0.008868 & 0.008959 & 0.010382 \\
\hline 0.014784 & 0.007909 & 0.008353 & 0.008802 & 0.008946 & 0.010319 \\
\hline 0.010312 & 0.005494 & 0.005805 & 0.006148 & 0.006204 & 0.007178 \\
\hline 0.009137 & 0.004914 & 0.005179 & 0.005477 & 0.005524 & 0.006393 \\
\hline 0.008519 & 0.015235 & 0.009182 & 0.009802 & 0.009176 & 0.010754 \\
\hline 0.007994 & 0.014290 & 0.008615 & 0.009160 & 0.008595 & 0.010060 \\
\hline 0.007583 & 0.013545 & 0.008160 & 0.008689 & 0.008193 & 0.009561 \\
\hline 0.005209 & 0.009294 & 0.005618 & 0.005978 & 0.005612 & 0.006573 \\
\hline 0.004660 & 0.008327 & 0.004998 & 0.005344 & 0.005010 & 0.005865 \\
\hline 0.014169 & 0.013855 & 0.024296 & 0.015927 & 0.015622 & 0.017253 \\
\hline 0.012599 & 0.012324 & 0.021613 & 0.014172 & 0.013891 & 0.015342 \\
\hline 0.010193 & 0.009978 & 0.017439 & 0.011439 & 0.011225 & 0.012402 \\
\hline 0.022438 & 0.022514 & 0.022858 & 0.034856 & 0.023996 & 0.026434 \\
\hline 0.017366 & 0.017416 & 0.017676 & 0.026971 & 0.018551 & 0.020434 \\
\hline 0.022599 & 0.022956 & 0.022577 & 0.025696 & 0.036018 & 0.026893 \\
\hline 0.016477 & 0.016740 & 0.016466 & 0.018711 & 0.026247 & 0.019604 \\
\hline 0.042831 & 0.042019 & 0.042919 & 0.043232 & 0.043738 & 0.052936 \\
\hline
\end{tabular}

Figura 6.10: Desvios padrões em bases sem outliers - Proposta de incertezas de $5 \%$ do valor da medição

\begin{tabular}{|c|c|c|c|c|c|}
\hline 0.194132 & . 008468 & 0.009198 & 0.010339 & 0.009445 & \\
\hline & & & & & \\
\hline & & & & & \\
\hline & 0057 & & & & \\
\hline & 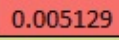 & & & & \\
\hline & & & & & \\
\hline & & & & & \\
\hline 0.008 & 0.18 & 0.008473 & 0.00 & 0.00 & \\
\hline & 0.12 & & & & \\
\hline & & & & & \\
\hline & & & & & \\
\hline & & & & & \\
\hline & 0.009743 & 0.224405 & 0.0114 & & \\
\hline & & & & & \\
\hline & & & & 0.01 & \\
\hline & & & & & \\
\hline 0.015413 & 0.014583 & 0.015754 & 0.019371 & 0.334076 & 0.019799 \\
\hline & & & & & \\
\hline
\end{tabular}

Figura 6.11: Perfis médios em bases sem outliers - Proposta de incertezas de $10 \%$ do valor da medição

\begin{tabular}{|l|lllll|}
\hline 0.014937 & 0.008027 & 0.008545 & 0.009245 & 0.008600 & 0.010362 \\
0.014791 & 0.007955 & 0.008469 & 0.009142 & 0.008552 & 0.010255 \\
0.014757 & 0.007920 & 0.008396 & 0.009121 & 0.008506 & 0.010207 \\
\hline 0.010256 & 0.005492 & 0.005851 & 0.006324 & 0.005886 & 0.007097 \\
0.009154 & 0.004918 & 0.005238 & 0.005625 & 0.005287 & 0.006343 \\
\hline 0.008651 & 0.015847 & 0.009035 & 0.009605 & 0.009488 & 0.011034 \\
0.008117 & 0.014921 & 0.008456 & 0.008992 & 0.008905 & 0.010354 \\
0.007694 & 0.014097 & 0.008018 & 0.008538 & 0.008438 & 0.009820 \\
0.005282 & 0.009690 & 0.005500 & 0.005844 & 0.005808 & 0.006730 \\
0.004706 & 0.008670 & 0.004925 & 0.005245 & 0.005166 & 0.006024 \\
\hline 0.013873 & 0.014414 & 0.023950 & 0.015638 & 0.015725 & 0.017204 \\
0.012354 & 0.012800 & 0.021277 & 0.013926 & 0.013969 & 0.015318 \\
\hline 0.009982 & 0.010360 & 0.017173 & 0.011243 & 0.011289 & 0.012387 \\
\hline 0.022825 & 0.023300 & 0.023690 & 0.034918 & 0.024144 & 0.026130 \\
0.017660 & 0.018027 & 0.018302 & 0.027009 & 0.018667 & 0.020206 \\
0.023448 & 0.022963 & 0.022828 & 0.025433 & 0.034824 & 0.026662 \\
0.017065 & 0.016724 & 0.016641 & 0.018501 & 0.025330 & 0.019442 \\
0.042622 & 0.042449 & 0.042297 & 0.045963 & 0.044749 & 0.051941 \\
\hline
\end{tabular}

Figura 6.12: Desvios padrões em bases sem outliers - Proposta de incertezas de $10 \%$ do valor da medição 


\begin{tabular}{|l|l|l|l|l|l|}
\hline 0.193649 & 0.008492 & 0.009474 & 0.010148 & 0.010179 & 0.012076 \\
0.191860 & 0.008403 & 0.009385 & 0.010062 & 0.010066 & 0.011946 \\
0.190995 & 0.008369 & 0.009348 & 0.010036 & 0.010024 & 0.011908 \\
0.132632 & 0.005776 & 0.006451 & 0.006929 & 0.006923 & 0.008226 \\
0.118371 & 0.005141 & 0.005726 & 0.006162 & 0.006164 & 0.007319 \\
\hline 0.009291 & 0.207505 & 0.009577 & 0.011023 & 0.010698 & 0.013696 \\
0.008680 & 0.194421 & 0.008931 & 0.010342 & 0.010000 & 0.012858 \\
0.008240 & 0.184460 & 0.008514 & 0.009799 & 0.009500 & 0.012194 \\
\hline 0.005637 & 0.126718 & 0.005786 & 0.006685 & 0.006487 & 0.008321 \\
0.004985 & 0.113014 & 0.005149 & 0.005941 & 0.005774 & 0.007402 \\
\hline 0.013646 & 0.014062 & 0.311244 & 0.016928 & 0.016240 & 0.018872 \\
0.012127 & 0.012529 & 0.276841 & 0.015037 & 0.014441 & 0.016787 \\
\hline 0.009787 & 0.010071 & 0.223600 & 0.012148 & 0.011646 & 0.013519 \\
\hline 0.019596 & 0.020137 & 0.020560 & 0.444698 & 0.024186 & 0.028114 \\
0.015120 & 0.015544 & 0.015890 & 0.343801 & 0.018700 & 0.021749 \\
0.019887 & 0.020831 & 0.023414 & 0.024668 & 0.457477 & 0.029334 \\
0.014465 & 0.015184 & 0.017045 & 0.017964 & 0.333221 & 0.021349 \\
0.031032 & 0.029343 & 0.033065 & 0.037629 & 0.038274 & 0.744330 \\
\hline
\end{tabular}

Figura 6.13: Perfis médios em bases sem outliers - Proposta de incertezas de $20 \%$ do valor da medição

\begin{tabular}{|l|l|l|l|l|l|}
\hline 0.014951 & 0.008109 & 0.008753 & 0.009021 & 0.008831 & 0.010111 \\
0.014803 & 0.008061 & 0.008667 & 0.008959 & 0.008752 & 0.010045 \\
0.014711 & 0.008007 & 0.008627 & 0.008912 & 0.008701 & 0.009969 \\
\hline 0.010210 & 0.005547 & 0.005969 & 0.006198 & 0.006051 & 0.006921 \\
0.009160 & 0.004970 & 0.005348 & 0.005541 & 0.005384 & 0.006169 \\
\hline 0.008647 & 0.016099 & 0.009331 & 0.009882 & 0.009730 & 0.010884 \\
0.008104 & 0.015122 & 0.008758 & 0.009261 & 0.009124 & 0.010192 \\
0.007700 & 0.014337 & 0.008318 & 0.008769 & 0.008664 & 0.009689 \\
\hline 0.005280 & 0.009836 & 0.005723 & 0.006032 & 0.005955 & 0.006660 \\
0.004724 & 0.008825 & 0.005093 & 0.005370 & 0.005284 & 0.005913 \\
\hline 0.014578 & 0.014309 & 0.023336 & 0.015869 & 0.015767 & 0.017164 \\
0.012968 & 0.012726 & 0.020776 & 0.014134 & 0.014014 & 0.015274 \\
\hline 0.010479 & 0.010314 & 0.016729 & 0.011397 & 0.011310 & 0.012332 \\
0.022304 & 0.023007 & 0.022552 & 0.034659 & 0.024020 & 0.025667 \\
0.017248 & 0.017783 & 0.017426 & 0.026773 & 0.018566 & 0.019858 \\
\cline { 1 - 2 } 0.023032 & 0.023069 & 0.024328 & 0.024863 & 0.035759 & 0.027102 \\
0.016784 & 0.016812 & 0.017715 & 0.018110 & 0.026066 & 0.019735 \\
\cline { 1 - 2 } 0.042014 & 0.043123 & 0.042448 & 0.044116 & 0.043921 & 0.052040 \\
\hline
\end{tabular}

Figura 6.14: Desvios padrões em bases sem outliers - Proposta de incertezas de $20 \%$ do valor da medição
Figura 6.15: Perfis médios em bases sem outliers - Análise Fatorial Ortogonal - CP-Rotação Varimax
Figura 6.16: Desvios padrões em bases sem outliers - Análise Fatorial Ortogonal - CPRotação Varimax 

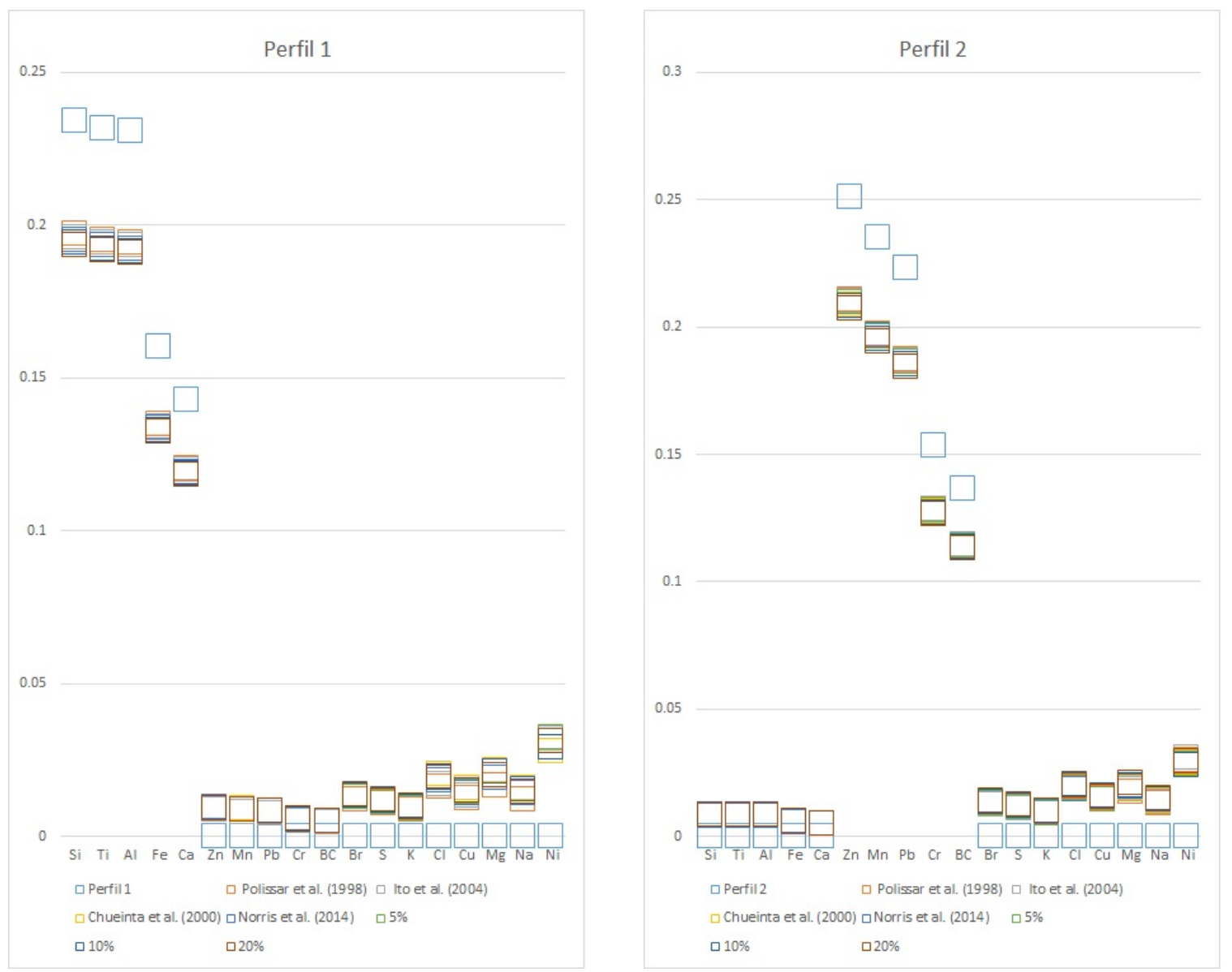

Figura 6.17: Gráfico comparativo para o Perfil 1 Figura 6.18: Gráfico comparativo para o Perfil 2 

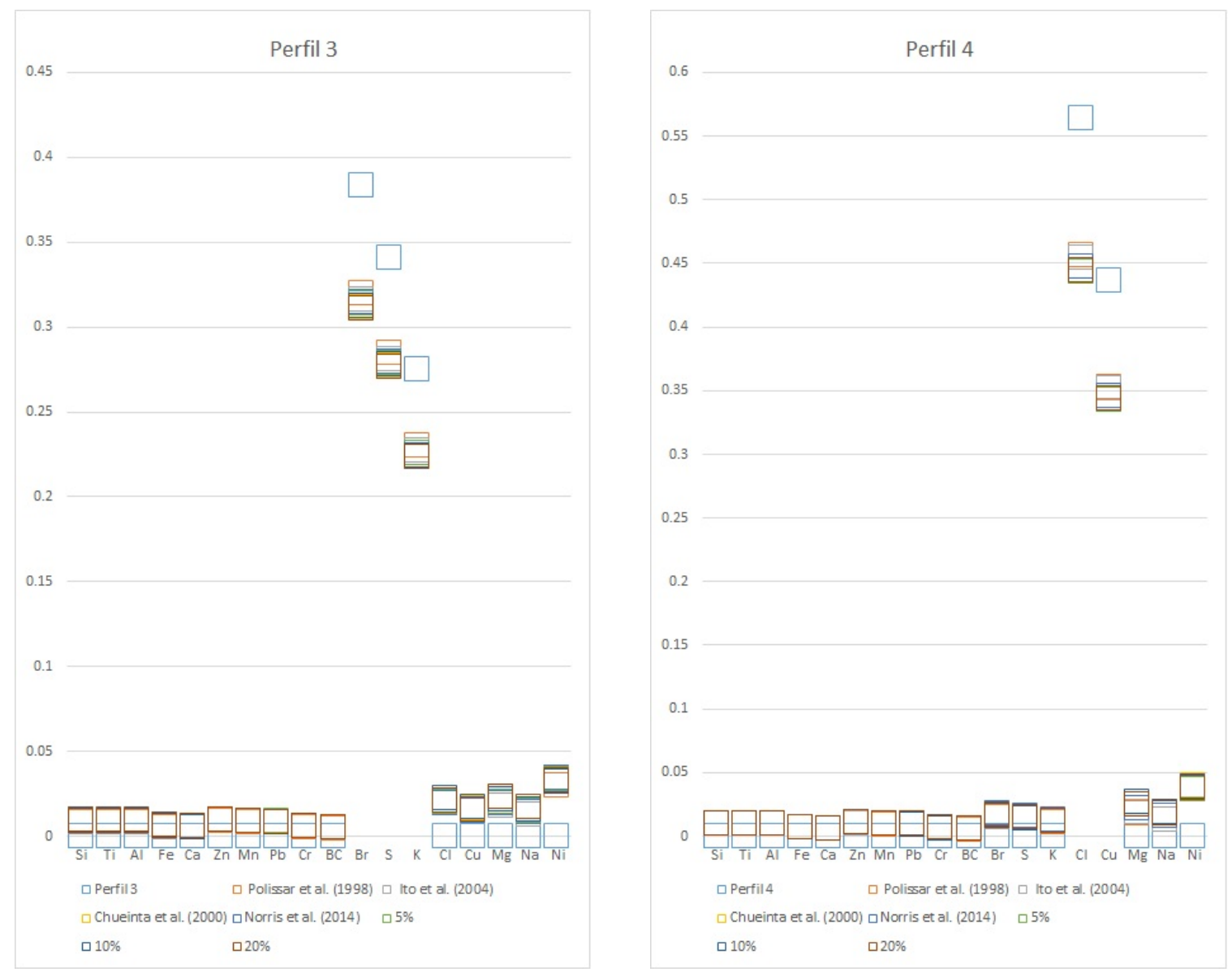

Figura 6.19: Gráfico comparativo para o Perfil 3 Figura 6.20: Gráfico comparativo para o Perfil 4 

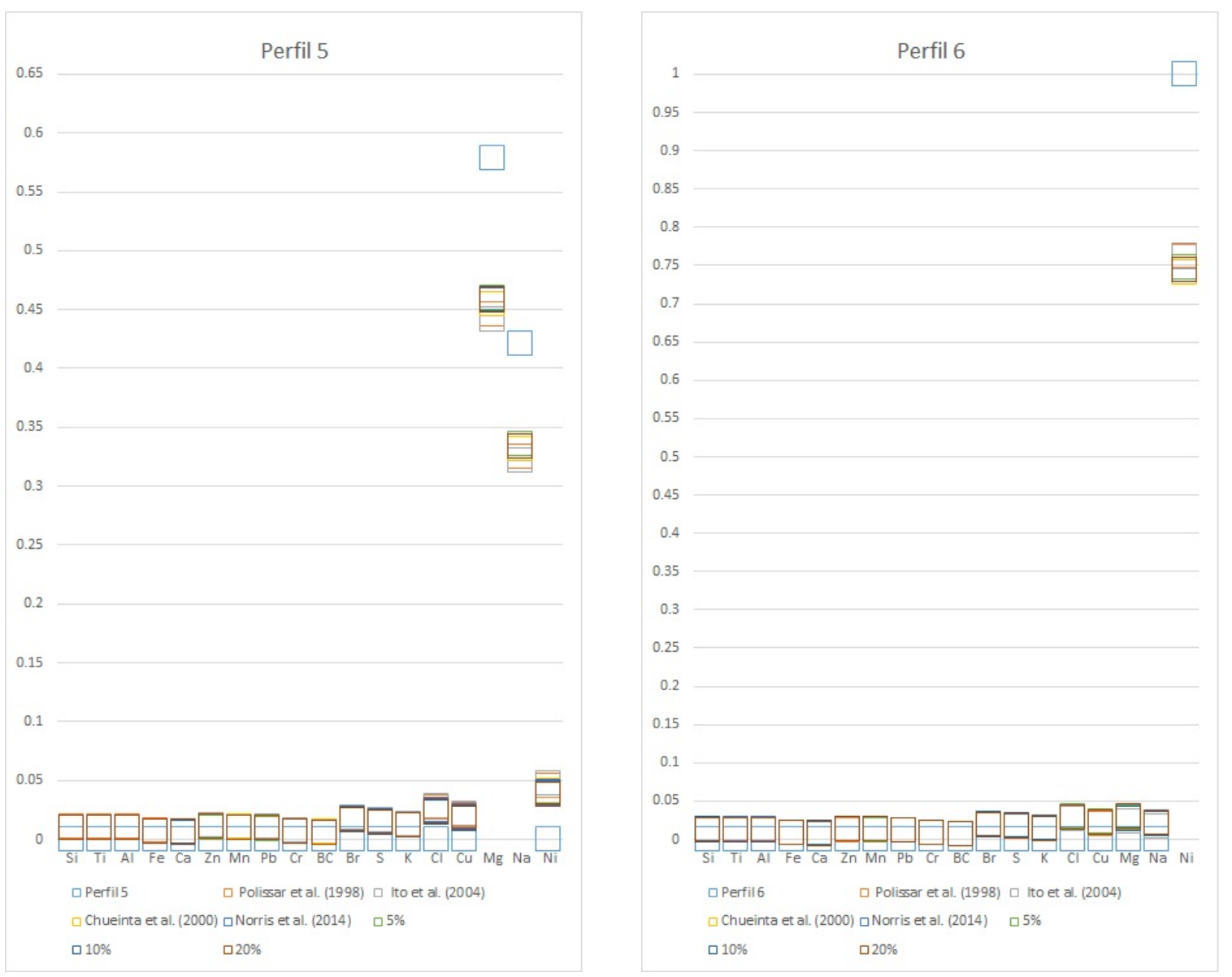

Figura 6.21: Gráfico comparativo para o Perfil 5 Figura 6.22: Gráfico comparativo para o Perfil 6

\section{Simulações com outliers - distribuição exponencial com média 1,5}

\begin{tabular}{|l|l|l|l|l|l|}
0.195698 & 0.008254 & 0.009464 & 0.010214 & 0.009923 & 0.011512 \\
0.193855 & 0.008163 & 0.009378 & 0.010120 & 0.009829 & 0.011411 \\
0.193031 & 0.008147 & 0.009328 & 0.010097 & 0.009772 & 0.011358 \\
0.133951 & 0.005613 & 0.006468 & 0.006965 & 0.006762 & 0.007828 \\
0.119551 & 0.005007 & 0.005736 & 0.006190 & 0.006010 & 0.006977 \\
\hline 0.008946 & 0.210019 & 0.010098 & 0.010715 & 0.011098 & 0.012886 \\
0.008372 & 0.196724 & 0.009436 & 0.010031 & 0.010403 & 0.012062 \\
0.007924 & 0.186767 & 0.008942 & 0.009505 & 0.009863 & 0.011447 \\
\hline 0.005398 & 0.128221 & 0.006086 & 0.006499 & 0.006744 & 0.007835 \\
0.004818 & 0.114294 & 0.005431 & 0.005759 & 0.005983 & 0.006944 \\
\hline 0.012842 & 0.013076 & 0.311488 & 0.016621 & 0.016695 & 0.018855 \\
0.011403 & 0.011616 & 0.277059 & 0.014785 & 0.014831 & 0.016761 \\
\hline 0.009204 & 0.009354 & 0.223635 & 0.011960 & 0.011982 & 0.013495 \\
0.018376 & 0.018637 & 0.020941 & 0.448165 & 0.026018 & 0.026501 \\
0.014192 & 0.014365 & 0.016207 & 0.346451 & 0.020087 & 0.020453 \\
0.019057 & 0.018979 & 0.020161 & 0.022116 & 0.454703 & 0.027030 \\
0.013822 & 0.013859 & 0.014714 & 0.016064 & 0.330858 & 0.019694 \\
\hline 0.029560 & 0.028905 & 0.035428 & 0.037743 & 0.038439 & 0.756951 \\
\hline & & & &
\end{tabular}

Figura 6.23: Perfis médios em bases com outliers - Dist. Exponencial com média 1,5 - Proposta de incertezas definida em Norris et al. (2014)

\begin{tabular}{|l|l|l|l|l|l|}
\hline 0.014435 & 0.007740 & 0.008723 & 0.009074 & 0.008745 & 0.009500 \\
0.014305 & 0.007662 & 0.008678 & 0.009009 & 0.008686 & 0.009420 \\
0.014275 & 0.007621 & 0.008607 & 0.008951 & 0.008614 & 0.009366 \\
0.009875 & 0.005283 & 0.005978 & 0.006226 & 0.005984 & 0.006520 \\
0.008852 & 0.004705 & 0.005356 & 0.005560 & 0.005382 & 0.005801 \\
\hline 0.008333 & 0.015447 & 0.009034 & 0.009617 & 0.009433 & 0.010163 \\
0.007821 & 0.014479 & 0.008477 & 0.009026 & 0.008810 & 0.009501 \\
0.007423 & 0.013790 & 0.008036 & 0.008557 & 0.008386 & 0.009020 \\
\hline 0.005094 & 0.009417 & 0.005536 & 0.005882 & 0.005753 & 0.006201 \\
0.004560 & 0.008390 & 0.004931 & 0.005274 & 0.005114 & 0.005538 \\
\hline 0.013747 & 0.014415 & 0.023916 & 0.015777 & 0.015952 & 0.016853 \\
0.012217 & 0.012790 & 0.021290 & 0.014016 & 0.014174 & 0.015013 \\
0.009864 & 0.010336 & 0.017125 & 0.011322 & 0.011443 & 0.012095 \\
\cline { 1 - 5 } 0.021472 & 0.021676 & 0.022701 & 0.034890 & 0.023978 & 0.024381 \\
0.016620 & 0.016764 & 0.017599 & 0.027046 & 0.018518 & 0.018855 \\
\cline { 1 - 3 } 0.023134 & 0.024657 & 0.023933 & 0.025030 & 0.035223 & 0.025670 \\
0.016863 & 0.017912 & 0.017375 & 0.018217 & 0.025587 & 0.018718 \\
\hline 0.041626 & 0.041529 & 0.043353 & 0.043630 & 0.042806 & 0.053501 \\
\hline
\end{tabular}

Figura 6.24: Desvios padrões em bases com outliers - Dist. Exponencial com média 1,5 -

Proposta de incertezas definida em Norris et al.

(2014) 


\begin{tabular}{l|llllll|}
0.197147 & 0.007689 & 0.008258 & 0.009783 & 0.010652 & 0.011392 \\
0.195267 & 0.007604 & 0.008191 & 0.009686 & 0.010552 & 0.011296 \\
0.194437 & 0.007597 & 0.008148 & 0.009665 & 0.010495 & 0.011244 \\
0.134926 & 0.005236 & 0.005654 & 0.006670 & 0.007265 & 0.007751 \\
0.120381 & 0.004677 & 0.005013 & 0.005930 & 0.006466 & 0.006909 \\
\hline 0.008880 & 0.210303 & 0.009011 & 0.010401 & 0.011261 & 0.012182 \\
0.008311 & 0.197008 & 0.008417 & 0.009737 & 0.010557 & 0.011408 \\
0.007873 & 0.187030 & 0.007978 & 0.009234 & 0.010018 & 0.010828 \\
0.005368 & 0.128379 & 0.005437 & 0.006316 & 0.006856 & 0.007409 \\
0.004779 & 0.114488 & 0.004829 & 0.005583 & 0.006064 & 0.006562 \\
\hline 0.012244 & 0.012686 & 0.319259 & 0.015134 & 0.018417 & 0.018172 \\
0.010876 & 0.011274 & 0.283938 & 0.013464 & 0.016369 & 0.016153 \\
0.008785 & 0.009079 & 0.229344 & 0.010902 & 0.013221 & 0.013022 \\
0.018236 & 0.019487 & 0.020952 & 0.455679 & 0.026554 & 0.024817 \\
0.014038 & 0.014985 & 0.016186 & 0.353900 & 0.020493 & 0.019131 \\
0.017123 & 0.018595 & 0.016266 & 0.018536 & 0.446319 & 0.022948 \\
0.012482 & 0.013609 & 0.011963 & 0.013530 & 0.323486 & 0.016782 \\
0.028847 & 0.030274 & 0.031156 & 0.035850 & 0.044955 & 0.771994 \\
\hline
\end{tabular}

Figura 6.25: Perfis médios em bases com outliers - Dist. Exponencial com média 1,5 - Proposta de incertezas definida em Polissar et al. (1998)

\begin{tabular}{|l|l|l|l|l|l|}
\hline 0.014321 & 0.007711 & 0.008181 & 0.009167 & 0.009341 & 0.009519 \\
0.014200 & 0.007643 & 0.008097 & 0.009098 & 0.009257 & 0.009439 \\
0.014147 & 0.007593 & 0.008075 & 0.009041 & 0.009210 & 0.009388 \\
\hline 0.009804 & 0.005275 & 0.005615 & 0.006274 & 0.006398 & 0.006529 \\
0.008737 & 0.004702 & 0.005012 & 0.005596 & 0.005694 & 0.005806 \\
\hline 0.008362 & 0.015591 & 0.008507 & 0.009532 & 0.010266 & 0.010297 \\
0.007793 & 0.014655 & 0.007959 & 0.008935 & 0.009606 & 0.009620 \\
0.007414 & 0.013935 & 0.007568 & 0.008476 & 0.009150 & 0.009143 \\
\hline 0.005099 & 0.009572 & 0.005215 & 0.005833 & 0.006282 & 0.006278 \\
0.004548 & 0.008574 & 0.004641 & 0.005183 & 0.005597 & 0.005607 \\
\hline 0.012939 & 0.013544 & 0.024440 & 0.015274 & 0.016084 & 0.016031 \\
0.011493 & 0.012039 & 0.021784 & 0.013594 & 0.014296 & 0.014242 \\
0.009279 & 0.009730 & 0.017539 & 0.010978 & 0.011547 & 0.011515 \\
\cline { 3 - 6 } 0.020733 & 0.022445 & 0.023130 & 0.034809 & 0.024722 & 0.024527 \\
0.016081 & 0.017417 & 0.017965 & 0.027046 & 0.019196 & 0.019057 \\
\cline { 5 - 7 } 0.023768 & 0.025086 & 0.023439 & 0.024097 & 0.034684 & 0.024960 \\
0.017188 & 0.018159 & 0.016981 & 0.017482 & 0.025100 & 0.018039 \\
\hline 0.040717 & 0.041842 & 0.040914 & 0.042968 & 0.044268 & 0.053775 \\
\hline
\end{tabular}

Figura 6.26: Desvios padrões em bases com outliers - Dist. Exponencial com média 1,5 -

Proposta de incertezas definida em Polissar et al. (1998)

\begin{tabular}{|l|l|l|l|l|l|l|l|l|l|l|l|}
\hline 0.195826 & 0.007459 & 0.008310 & 0.009918 & 0.011241 & 0.011223 & 0.014247 & 0.007832 & 0.008407 & 0.009502 & 0.009818 & 0.009680 \\
0.193979 & 0.007366 & 0.008228 & 0.009815 & 0.011131 & 0.011132 & 0.014122 & 0.007747 & 0.008324 & 0.009417 & 0.009728 & 0.009585 \\
0.193189 & 0.007377 & 0.008198 & 0.009811 & 0.011086 & 0.011084 & 0.014006 & 0.007711 & 0.008291 & 0.009374 & 0.009683 & 0.009560 \\
0.134011 & 0.005071 & 0.005679 & 0.006757 & 0.007667 & 0.007633 & 0.009744 & 0.005353 & 0.005774 & 0.006524 & 0.006723 & 0.006632 \\
0.119576 & 0.004534 & 0.005038 & 0.006011 & 0.006819 & 0.006811 & 0.008697 & 0.004767 & 0.005133 & 0.005815 & 0.006007 & 0.005901 \\
\hline 0.008700 & 0.210429 & 0.010124 & 0.009929 & 0.012134 & 0.012765 & 0.008282 & 0.016394 & 0.008975 & 0.009224 & 0.010390 & 0.010333 \\
0.008149 & 0.197109 & 0.009465 & 0.009294 & 0.011372 & 0.011953 & 0.007730 & 0.015356 & 0.008418 & 0.008660 & 0.009704 & 0.009695 \\
0.007714 & 0.187134 & 0.008966 & 0.008807 & 0.010791 & 0.011345 & 0.007338 & 0.014644 & 0.007956 & 0.008211 & 0.009220 & 0.009182 \\
\hline 0.005263 & 0.128427 & 0.006123 & 0.006026 & 0.007387 & 0.007766 & 0.005039 & 0.010032 & 0.005478 & 0.005648 & 0.006342 & 0.006316 \\
0.004689 & 0.114516 & 0.005445 & 0.005336 & 0.006544 & 0.006883 & 0.004504 & 0.008925 & 0.004880 & 0.005001 & 0.005663 & 0.005627 \\
\hline 0.013050 & 0.012272 & 0.315343 & 0.015880 & 0.018397 & 0.018588 & 0.013595 & 0.013594 & 0.024076 & 0.015560 & 0.016636 & 0.015997 \\
0.011586 & 0.010908 & 0.280473 & 0.014123 & 0.016352 & 0.016528 & 0.012105 & 0.012114 & 0.021409 & 0.013832 & 0.014789 & 0.014230 \\
0.009354 & 0.008777 & 0.226394 & 0.011431 & 0.013207 & 0.013305 & 0.009761 & 0.009751 & 0.017304 & 0.011165 & 0.011953 & 0.011494 \\
\hline 0.018388 & 0.020625 & 0.019433 & 0.453973 & 0.028885 & 0.025809 & 0.021390 & 0.022613 & 0.021513 & 0.036421 & 0.024573 & 0.024442 \\
0.014199 & 0.015900 & 0.015046 & 0.350964 & 0.022305 & 0.019930 & 0.016563 & 0.017430 & 0.016663 & 0.028166 & 0.018994 & 0.018869 \\
0.017007 & 0.018279 & 0.019678 & 0.019591 & 0.438418 & 0.023236 & 0.023762 & 0.025094 & 0.024918 & 0.024950 & 0.033483 & 0.025326 \\
0.012416 & 0.013499 & 0.014542 & 0.014338 & 0.317283 & 0.017061 & 0.017200 & 0.018147 & 0.018075 & 0.017950 & 0.024148 & 0.018314 \\
0.032904 & 0.030318 & 0.033515 & 0.037996 & 0.048981 & 0.766948 & 0.042015 & 0.041206 & 0.041691 & 0.042550 & 0.045820 & 0.053640 \\
\hline
\end{tabular}

Figura 6.27: Perfis médios em bases com outliers - Dist. Exponencial com média 1,5 - Proposta de incertezas definida em Ito et al. (2004)
Figura 6.28: Desvios padrões em bases com outliers - Dist. Exponencial com média 1,5 Proposta de incertezas definida em Ito et al. (2004) 


\begin{tabular}{|l|l|l|l|l|l|}
0.193360 & 0.008553 & 0.009757 & 0.010354 & 0.010807 & 0.011017 \\
0.191605 & 0.008451 & 0.009653 & 0.010248 & 0.010726 & 0.010936 \\
0.190773 & 0.008438 & 0.009606 & 0.010225 & 0.010660 & 0.010861 \\
0.132356 & 0.005816 & 0.006669 & 0.007052 & 0.007374 & 0.007483 \\
0.118130 & 0.005187 & 0.005900 & 0.006266 & 0.006553 & 0.006669 \\
\hline 0.009104 & 0.207331 & 0.009535 & 0.011139 & 0.011504 & 0.013364 \\
0.008540 & 0.194175 & 0.008907 & 0.010401 & 0.010788 & 0.012512 \\
0.008073 & 0.184406 & 0.008436 & 0.009867 & 0.010229 & 0.011871 \\
\hline 0.005488 & 0.126570 & 0.005736 & 0.006744 & 0.006998 & 0.008121 \\
0.004895 & 0.112755 & 0.005119 & 0.005973 & 0.006197 & 0.007200 \\
\hline 0.012695 & 0.014672 & 0.309559 & 0.017695 & 0.015945 & 0.019085 \\
0.011233 & 0.013032 & 0.275503 & 0.015751 & 0.014149 & 0.016976 \\
0.009065 & 0.010487 & 0.222497 & 0.012724 & 0.011448 & 0.013655 \\
\hline 0.019321 & 0.020999 & 0.021812 & 0.441717 & 0.023832 & 0.027095 \\
0.014878 & 0.016118 & 0.016889 & 0.342695 & 0.018365 & 0.020888 \\
0.020775 & 0.019966 & 0.022815 & 0.024587 & 0.454915 & 0.028791 \\
0.015056 & 0.014553 & 0.016630 & 0.017854 & 0.331043 & 0.020986 \\
0.034653 & 0.028491 & 0.034977 & 0.038708 & 0.038467 & 0.752490 \\
\hline
\end{tabular}

Figura 6.29: Perfis médios em bases com outliers - Dist. Exponencial com média 1,5 - Proposta de incertezas definida em Chueinta et al. (2000)

\begin{tabular}{|l|l|l|l|l|l|}
\hline 0.013999 & 0.007993 & 0.008688 & 0.009038 & 0.009164 & 0.009513 \\
0.013835 & 0.007935 & 0.008612 & 0.008966 & 0.009094 & 0.009474 \\
0.013819 & 0.007907 & 0.008579 & 0.008901 & 0.009031 & 0.009413 \\
0.009556 & 0.005456 & 0.005947 & 0.006195 & 0.006279 & 0.006527 \\
0.008576 & 0.004919 & 0.005312 & 0.005543 & 0.005575 & 0.005811 \\
\hline 0.008345 & 0.015014 & 0.008811 & 0.009986 & 0.009978 & 0.010662 \\
0.007821 & 0.014072 & 0.008223 & 0.009398 & 0.009358 & 0.009949 \\
0.007403 & 0.013374 & 0.007785 & 0.008935 & 0.008867 & 0.009476 \\
\hline 0.005087 & 0.009179 & 0.005367 & 0.006142 & 0.006113 & 0.006505 \\
0.004561 & 0.008179 & 0.004781 & 0.005442 & 0.005419 & 0.005806 \\
\hline 0.013540 & 0.015075 & 0.024008 & 0.015781 & 0.015208 & 0.016161 \\
0.012028 & 0.013408 & 0.021263 & 0.014016 & 0.013492 & 0.014419 \\
0.009768 & 0.010848 & 0.017212 & 0.011354 & 0.010904 & 0.011654 \\
0.022122 & 0.023450 & 0.023163 & 0.034405 & 0.024187 & 0.024594 \\
0.017200 & 0.018144 & 0.018006 & 0.026716 & 0.018742 & 0.019099 \\
0.023328 & 0.023245 & 0.023549 & 0.025211 & 0.033752 & 0.025560 \\
0.016980 & 0.016925 & 0.017127 & 0.018375 & 0.024698 & 0.018656 \\
\cline { 1 - 4 } 0.044738 & 0.040746 & 0.042991 & 0.043811 & 0.042742 & 0.053959 \\
\hline
\end{tabular}

Figura 6.30: Desvios padrões em bases com outliers - Dist. Exponencial com média 1,5 -

Proposta de incertezas definida em Chueinta et al. (2000)

\begin{tabular}{|l|l|l|l|l|l|}
0.194431 & 0.008460 & 0.009603 & 0.010176 & 0.010229 & 0.011229 \\
0.192594 & 0.008362 & 0.009520 & 0.010082 & 0.010135 & 0.011131 \\
0.191808 & 0.008343 & 0.009465 & 0.010047 & 0.010066 & 0.011069 \\
0.133087 & 0.005757 & 0.006568 & 0.006937 & 0.006973 & 0.007629 \\
0.118790 & 0.005133 & 0.005817 & 0.006165 & 0.006201 & 0.006800 \\
\hline 0.008851 & 0.209684 & 0.009866 & 0.010756 & 0.011510 & 0.012940 \\
0.008285 & 0.196418 & 0.009214 & 0.010065 & 0.010788 & 0.012120 \\
0.007841 & 0.186481 & 0.008732 & 0.009539 & 0.010234 & 0.011492 \\
\hline 0.005343 & 0.128035 & 0.005936 & 0.006521 & 0.006996 & 0.007864 \\
0.004766 & 0.114115 & 0.005296 & 0.005778 & 0.006210 & 0.006980 \\
\hline 0.012583 & 0.013303 & 0.311748 & 0.016978 & 0.015934 & 0.019019 \\
0.011173 & 0.011819 & 0.277291 & 0.015097 & 0.014152 & 0.016907 \\
0.009020 & 0.009516 & 0.223832 & 0.012215 & 0.011431 & 0.013613 \\
0.020039 & 0.019570 & 0.020213 & 0.445741 & 0.022863 & 0.027176 \\
0.015475 & 0.015086 & 0.015654 & 0.344569 & 0.017657 & 0.020974 \\
0.019712 & 0.018511 & 0.022395 & 0.024975 & 0.457770 & 0.028270 \\
0.014306 & 0.013491 & 0.016309 & 0.018135 & 0.333348 & 0.020591 \\
0.031896 & 0.027916 & 0.032541 & 0.036224 & 0.037503 & 0.754196 \\
\hline
\end{tabular}

Figura 6.31: Perfis médios em bases com outliers - Dist. Exponencial com média 1,5 - Proposta de incertezas de $5 \%$ do valor da medição

\begin{tabular}{|c|c|c|c|c|c|}
\hline 35 & 0.007740 & 0.008457 & 0.009001 & 0.008826 & \\
\hline 0.014021 & 0.007650 & 0.008373 & 0.008917 & 0.008766 & 0.009199 \\
\hline 0.013965 & 0.007620 & 0.008318 & 0.008890 & 0.008720 & $0.00915 \varepsilon$ \\
\hline .009702 & 0.005277 & 0.005802 & 0.006155 & 0.006059 & 0.006358 \\
\hline .008686 & 0.004723 & 0.005171 & 0.005492 & 0.005401 & 0.005673 \\
\hline 0.008261 & 0.014683 & 0.008581 & 0.009600 & 0.009679 & 0.010268 \\
\hline 0.007750 & 0.013792 & 0.008036 & 0.008986 & 0.009042 & 0.009608 \\
\hline 0.007330 & 0.013106 & 0.007655 & 0.008506 & 0.008567 & 0.009141 \\
\hline 0.005053 & 0.008968 & 0.005244 & 0.005842 & 0.005882 & 0.006268 \\
\hline 0.004526 & 0.008003 & 0.004686 & 0.005229 & 0.005256 & 0.005602 \\
\hline 0.013838 & 0.014645 & 0.022885 & 0.016319 & 0.015574 & 0.015974 \\
\hline 0.012251 & 0.013005 & 0.020338 & 0.014502 & 0.013816 & 0.014197 \\
\hline 0.009908 & 0.010515 & 0.016449 & 0.011712 & 0.011161 & 0.011469 \\
\hline 0.023294 & 0.022731 & 0.022746 & 0.034855 & 0.023555 & 0.024751 \\
\hline 0.017994 & 0.017591 & 0.017603 & 0.026958 & 0.018209 & 0.019096 \\
\hline 0.022414 & 0.022403 & 0.023573 & 0.024453 & 0.033119 & 0.025639 \\
\hline 0.016312 & 0.016354 & 0.017145 & 0.017820 & 0.024120 & 0.018684 \\
\hline .043099 & 0.040396 & 0.041365 & 0.043394 & 0.043635 & 0.051747 \\
\hline
\end{tabular}

Figura 6.32: Desvios padrões em bases com outliers - Dist. Exponencial com média 1,5 Proposta de incertezas de $5 \%$ do valor da medição 


\begin{tabular}{|l|l|l|l|l|l|}
\hline 0.193208 & 0.008105 & 0.009275 & 0.010666 & 0.010755 & 0.011300 \\
0.191382 & 0.008006 & 0.009184 & 0.010563 & 0.010664 & 0.011206 \\
0.190594 & 0.007994 & 0.009136 & 0.010535 & 0.010592 & 0.011139 \\
0.132218 & 0.005506 & 0.006337 & 0.007272 & 0.007338 & 0.007674 \\
0.118007 & 0.004918 & 0.005608 & 0.006458 & 0.006521 & 0.006844 \\
\hline 0.009388 & 0.208840 & 0.010073 & 0.010947 & 0.010846 & 0.013274 \\
0.008790 & 0.195608 & 0.009410 & 0.010235 & 0.010172 & 0.012424 \\
0.008320 & 0.185718 & 0.008914 & 0.009704 & 0.009648 & 0.011789 \\
\hline 0.005664 & 0.127481 & 0.006063 & 0.006635 & 0.006595 & 0.008066 \\
0.005053 & 0.113626 & 0.005411 & 0.005878 & 0.005839 & 0.007154 \\
\hline 0.013174 & 0.013236 & 0.310292 & 0.016624 & 0.017267 & 0.019074 \\
0.011686 & 0.011759 & 0.275988 & 0.014793 & 0.015338 & 0.016954 \\
\hline 0.009427 & 0.009465 & 0.222751 & 0.011963 & 0.012396 & 0.013645 \\
\hline 0.019393 & 0.019378 & 0.021740 & 0.443985 & 0.023952 & 0.026838 \\
0.014985 & 0.014908 & 0.016833 & 0.343269 & 0.018477 & 0.020700 \\
0.020261 & 0.020424 & 0.021716 & 0.024677 & 0.454797 & 0.028996 \\
0.014672 & 0.014884 & 0.015831 & 0.017904 & 0.331223 & 0.021133 \\
0.033778 & 0.030144 & 0.035438 & 0.037892 & 0.037580 & 0.751790 \\
\hline
\end{tabular}

Figura 6.33: Perfis médios em bases com outliers - Dist. Exponencial com média 1,5 - Proposta de incertezas de $10 \%$ do valor da medição

\begin{tabular}{|l|l|llll|}
0.193085 & 0.008292 & 0.009768 & 0.010150 & 0.010557 & 0.011709 \\
0.191270 & 0.008194 & 0.009667 & 0.010041 & 0.010481 & 0.011617 \\
0.190462 & 0.008181 & 0.009622 & 0.010019 & 0.010409 & 0.011548 \\
0.132128 & 0.005635 & 0.006679 & 0.006910 & 0.007203 & 0.007956 \\
0.117931 & 0.005026 & 0.005911 & 0.006143 & 0.006398 & 0.007091 \\
\hline 0.009756 & 0.207588 & 0.009952 & 0.010839 & 0.011239 & 0.013127 \\
0.009143 & 0.194427 & 0.009302 & 0.010126 & 0.010542 & 0.012291 \\
0.008649 & 0.184616 & 0.008805 & 0.009604 & 0.009991 & 0.011661 \\
\hline 0.005886 & 0.126720 & 0.005990 & 0.006560 & 0.006833 & 0.007977 \\
0.005252 & 0.112937 & 0.005348 & 0.005815 & 0.006053 & 0.007072 \\
\hline 0.012889 & 0.014019 & 0.309831 & 0.017861 & 0.016679 & 0.018839 \\
0.011414 & 0.012447 & 0.275617 & 0.015900 & 0.014801 & 0.016759 \\
0.009212 & 0.010018 & 0.222485 & 0.012847 & 0.011977 & 0.013472 \\
0.020012 & 0.020931 & 0.021078 & 0.442148 & 0.023702 & 0.027948 \\
0.015433 & 0.016098 & 0.016346 & 0.342040 & 0.018287 & 0.021551 \\
0.020108 & 0.020480 & 0.022653 & 0.026127 & 0.454152 & 0.028064 \\
0.014550 & 0.014903 & 0.016500 & 0.018978 & 0.330924 & 0.020469 \\
0.032820 & 0.029488 & 0.034446 & 0.037892 & 0.039772 & 0.750849 \\
\hline
\end{tabular}

\begin{tabular}{|l|l|l|l|l|l|}
\hline 0.014014 & 0.007681 & 0.008384 & 0.009199 & 0.009089 & 0.009445 \\
0.013930 & 0.007613 & 0.008317 & 0.009116 & 0.009011 & 0.009381 \\
0.013860 & 0.007570 & 0.008302 & 0.009088 & 0.008951 & 0.009318 \\
\hline 0.009661 & 0.005246 & 0.005746 & 0.006289 & 0.006235 & 0.006470 \\
0.008593 & 0.004706 & 0.005138 & 0.005640 & 0.005552 & 0.005775 \\
\hline 0.008418 & 0.015766 & 0.008845 & 0.009583 & 0.009486 & 0.010355 \\
0.007897 & 0.014732 & 0.008272 & 0.008983 & 0.008881 & 0.009702 \\
0.007484 & 0.014041 & 0.007856 & 0.008512 & 0.008414 & 0.009228 \\
\hline 0.005140 & 0.009593 & 0.005400 & 0.005847 & 0.005771 & 0.006325 \\
0.004591 & 0.008617 & 0.004819 & 0.005215 & 0.005153 & 0.005646 \\
\hline 0.014005 & 0.014624 & 0.022882 & 0.015517 & 0.016085 & 0.016168 \\
0.012430 & 0.013014 & 0.020341 & 0.013769 & 0.014299 & 0.014380 \\
0.010045 & 0.010512 & 0.016348 & 0.011132 & 0.011532 & 0.011589 \\
0.022823 & 0.022623 & 0.022850 & 0.034170 & 0.024220 & 0.024298 \\
0.017635 & 0.017441 & 0.017650 & 0.026397 & 0.018765 & 0.018765 \\
0.022645 & 0.023025 & 0.023429 & 0.025400 & 0.033427 & 0.026079 \\
0.016461 & 0.016748 & 0.017015 & 0.018490 & 0.024561 & 0.018976 \\
\cline { 1 - 2 } 0.043636 & 0.041598 & 0.043279 & 0.043594 & 0.044629 & 0.053135 \\
\hline
\end{tabular}

Figura 6.34: Desvios padrões em bases com outliers - Dist. Exponencial com média 1,5 Proposta de incertezas de $10 \%$ do valor da medição
Figura 6.35: Perfis médios em bases com outliers - Dist. Exponencial com média 1,5 - Proposta de incertezas de $20 \%$ do valor da medição

\begin{tabular}{|c|c|c|c|c|c|}
\hline 0.014145 & 0.007861 & 0.008471 & 0.009039 & 0.009181 & 0.009547 \\
\hline .014036 & 0.007808 & 0.008393 & 0.008972 & 0.009126 & 0.005 \\
\hline 3940 & 0.007757 & 0.008335 & 0.008914 & 0.009052 & 0.009416 \\
\hline 0.009658 & 0.005367 & 0.005799 & 0.006220 & 0.006281 & 0.006543 \\
\hline 0.008656 & 0.004818 & 0.005184 & 0.005555 & 0.005603 & 0.005835 \\
\hline .008753 & 0.015377 & 0.008927 & 0.009705 & 0.009748 & 0.010582 \\
\hline .008186 & 0.014387 & 0.008321 & 0.009068 & 0.009099 & 0.009880 \\
\hline 0.007754 & 0.013724 & 0.007894 & 0.008626 & 0.008645 & 0.009400 \\
\hline 0.005337 & 0.009401 & 0.005444 & 0.005940 & 0.005945 & 0.006468 \\
\hline 0.004791 & 0.008378 & 0.004851 & 0.005290 & 0.005295 & 0.005773 \\
\hline 0.013755 & 0.014807 & 0.023749 & 0.015776 & 0.015584 & 0.015956 \\
\hline 0.012216 & 0.013171 & 0.021083 & 0.013999 & 0.013827 & 0.014173 \\
\hline 0.009882 & 0.010638 & 0.017001 & 0.011326 & 0.011189 & 0.011480 \\
\hline 0.022512 & 0.022944 & 0.022627 & 0.033811 & 0.023819 & 0.024471 \\
\hline 0.017456 & 0.017652 & 0.017482 & 0.026208 & 0.018377 & 0.018987 \\
\hline 0.022531 & 0.023719 & 0.023773 & 0.025133 & 0.033421 & 0.025745 \\
\hline 0.016460 & 0.017296 & 0.017371 & 0.018356 & 0.024540 & 0.018823 \\
\hline .0436 & 0.040581 & 0.042791 & 0.043776 & 0.043959 & 0.052739 \\
\hline
\end{tabular}

Figura 6.36: Desvios padrões em bases com outliers - Dist. Exponencial com média 1,5 Proposta de incertezas de $20 \%$ do valor da medição 


\begin{tabular}{l|c|c|c|c|c|}
0.697326 & -0.003177 & -0.006671 & -0.004683 & -0.006609 & 0.001896 \\
0.690574 & -0.01019 & -0.006626 & -0.009034 & -0.001464 & 0.003001 \\
0.691284 & -0.004198 & -0.005222 & -0.001576 & -0.00379 & 0.000157 \\
0.594783 & -0.012311 & -0.00809 & -0.009294 & -0.004274 & -0.010555 \\
0.549267 & -0.012639 & -0.008045 & -0.009596 & -0.010216 & -0.009626 \\
\hline-0.006147 & 0.714912 & -0.005073 & -0.004156 & -0.001176 & 0.000155 \\
-0.007354 & 0.706618 & -0.002756 & -0.004586 & -0.002561 & 0.001601 \\
-0.006276 & 0.690203 & -0.003479 & -0.003651 & -0.003559 & -0.002815 \\
-0.012644 & 0.57685 & -0.010005 & -0.007258 & -0.008531 & 0.006603 \\
-0.015725 & 0.540974 & -0.009683 & -0.013878 & -0.00879 & -0.003833 \\
-0.004458 & -0.002806 & 0.835579 & -0.003802 & -0.003492 & -0.001937 \\
-0.005537 & -0.004686 & 0.818274 & -0.003355 & -0.004059 & 0.001512 \\
-0.006956 & -0.006574 & 0.787183 & -0.005447 & -0.000544 & -0.003763 \\
-0.004515 & -0.001791 & -0.003512 & 0.908365 & -0.002253 & -0.001989 \\
-0.004035 & -0.005228 & -0.004912 & 0.906902 & -0.002969 & -0.002933 \\
-0.001936 & -0.000735 & -0.002444 & -0.001816 & 0.90936 & -0.000114 \\
-0.005544 & -0.004875 & -0.002799 & -0.003705 & 0.90738 & -0.001378 \\
\cline { 2 - 4 }-0.007344 & -0.006618 & -0.00469 & -0.00542 & -0.001104 & 0.895778 \\
\hline
\end{tabular}

Figura 6.37: Perfis médios em bases com outliers - Dist. Exponencial com média 1,5 - Análise Fatorial Ortogonal - CP - Rotação Varimax

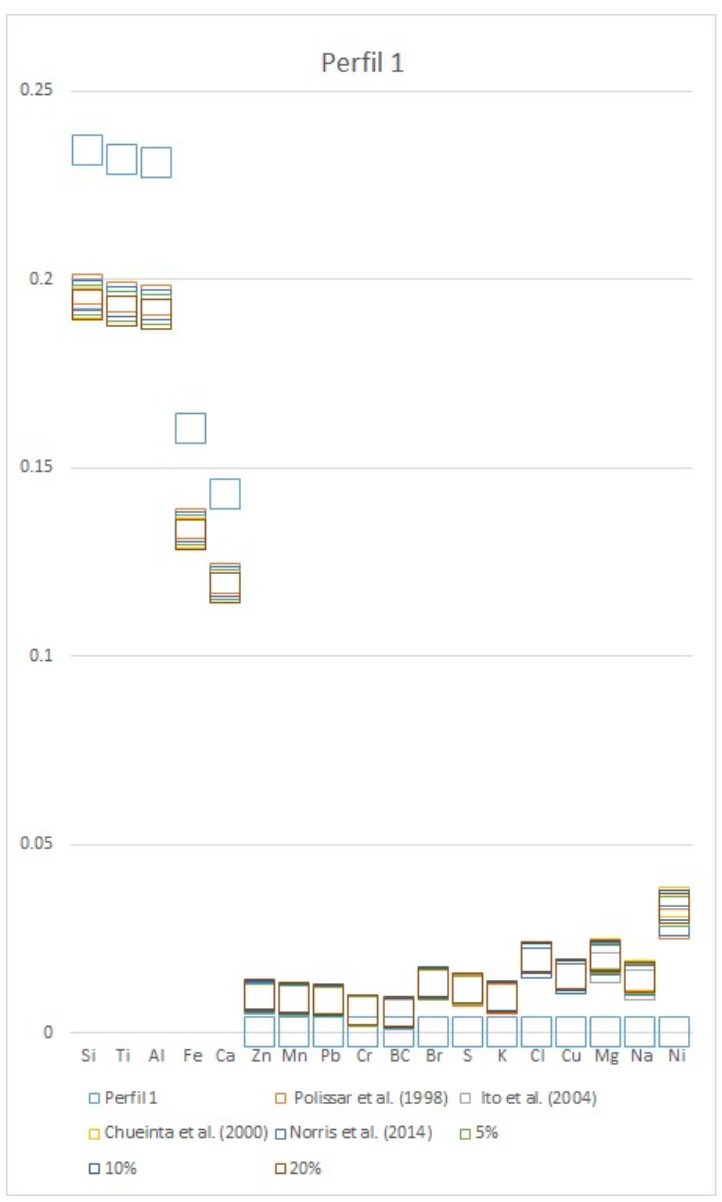

\begin{tabular}{|l|llllll|}
\hline 0.116700 & 0.055453 & 0.059430 & 0.065756 & 0.066071 & 0.120515 \\
0.110582 & 0.057536 & 0.060291 & 0.064454 & 0.069920 & 0.118999 \\
0.116846 & 0.056731 & 0.058309 & 0.069686 & 0.064210 & 0.120122 \\
0.142400 & 0.067971 & 0.069483 & 0.077769 & 0.081717 & 0.176506 \\
0.149089 & 0.067279 & 0.077332 & 0.081816 & 0.079687 & 0.208919 \\
\hline 0.055375 & 0.108307 & 0.054489 & 0.061203 & 0.067180 & 0.105814 \\
0.051935 & 0.108115 & 0.060439 & 0.062610 & 0.065793 & 0.107440 \\
0.056275 & 0.116840 & 0.060858 & 0.071103 & 0.067561 & 0.127691 \\
0.066170 & 0.147230 & 0.069952 & 0.080733 & 0.082481 & 0.194699 \\
0.067650 & 0.161844 & 0.076016 & 0.083783 & 0.086323 & 0.212276 \\
0.039215 & 0.039743 & 0.060542 & 0.047686 & 0.045311 & 0.057902 \\
0.042666 & 0.045116 & 0.070734 & 0.049222 & 0.047848 & 0.065112 \\
0.047916 & 0.048400 & 0.085854 & 0.054985 & 0.055861 & 0.080076 \\
0.031774 & 0.032700 & 0.034445 & 0.034521 & 0.039861 & 0.035304 \\
0.035473 & 0.031458 & 0.034457 & 0.035820 & 0.038494 & 0.036184 \\
0.032739 & 0.032950 & 0.036704 & 0.037421 & 0.035087 & 0.036826 \\
0.032731 & 0.032378 & 0.036010 & 0.038144 & 0.037231 & 0.039360 \\
\cline { 3 - 6 } 0.049143 & 0.049221 & 0.046138 & 0.051610 & 0.056233 & 0.112592 \\
\hline
\end{tabular}

Figura 6.38: Desvios padrões em bases com outliers - Dist. Exponencial com média 1,5 Análise Fatorial Ortogonal - CP - Rotação Varimax

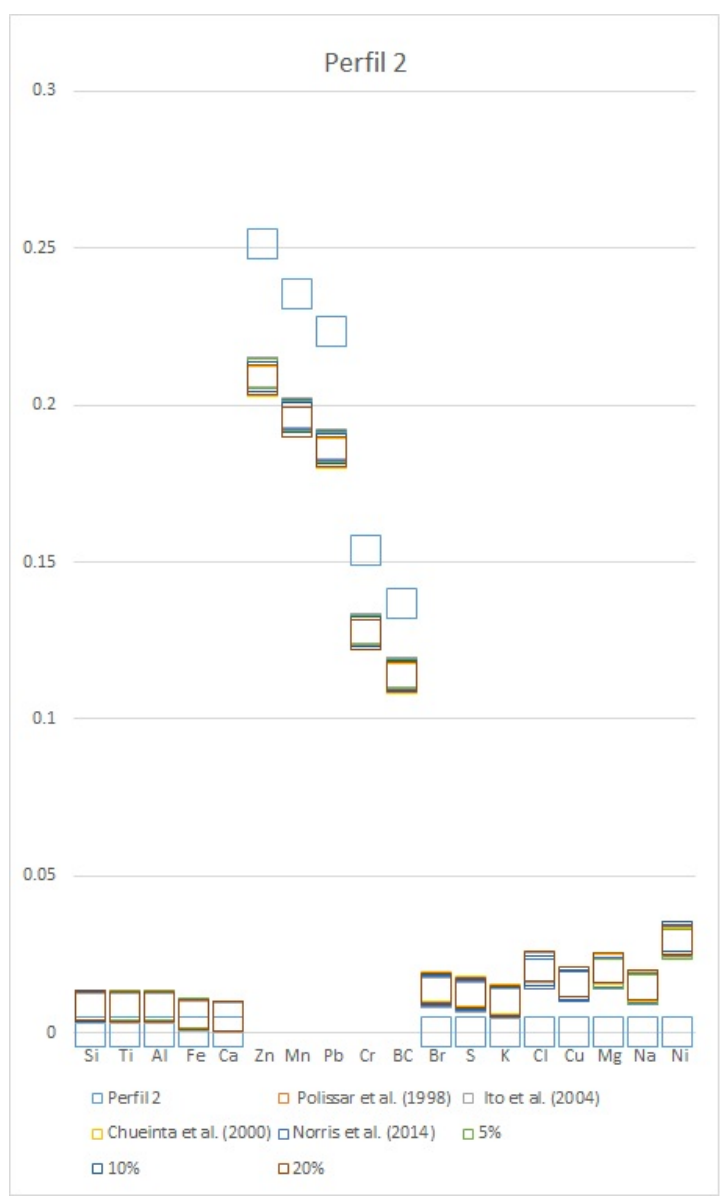

Figura 6.39: Gráfico comparativo para o Perfil 1 Figura 6.40: Gráfico comparativo para o Perfil 2 

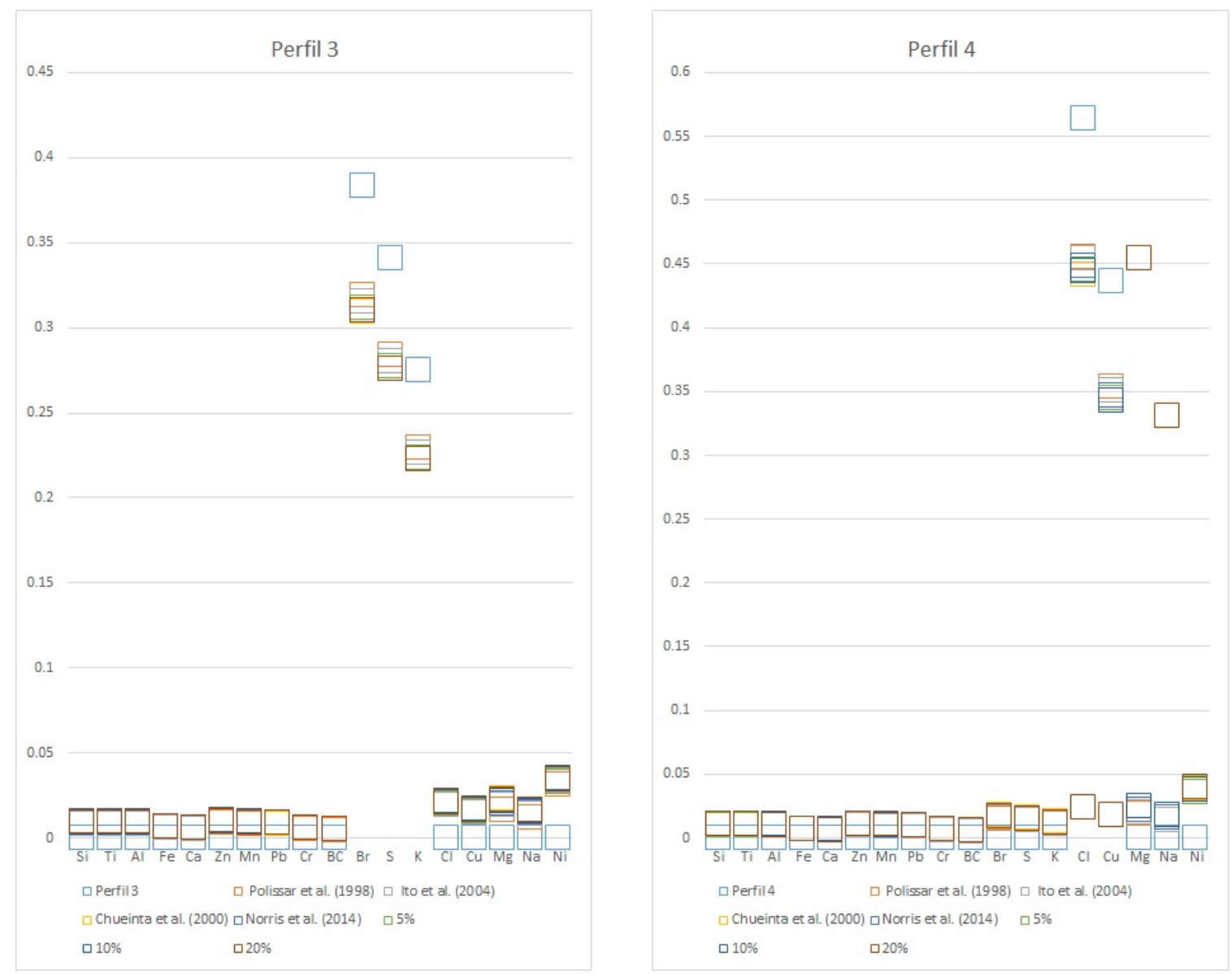

Figura 6.41: Gráfico comparativo para o Perfil 3 Figura 6.42: Gráfico comparativo para o Perfil 4 

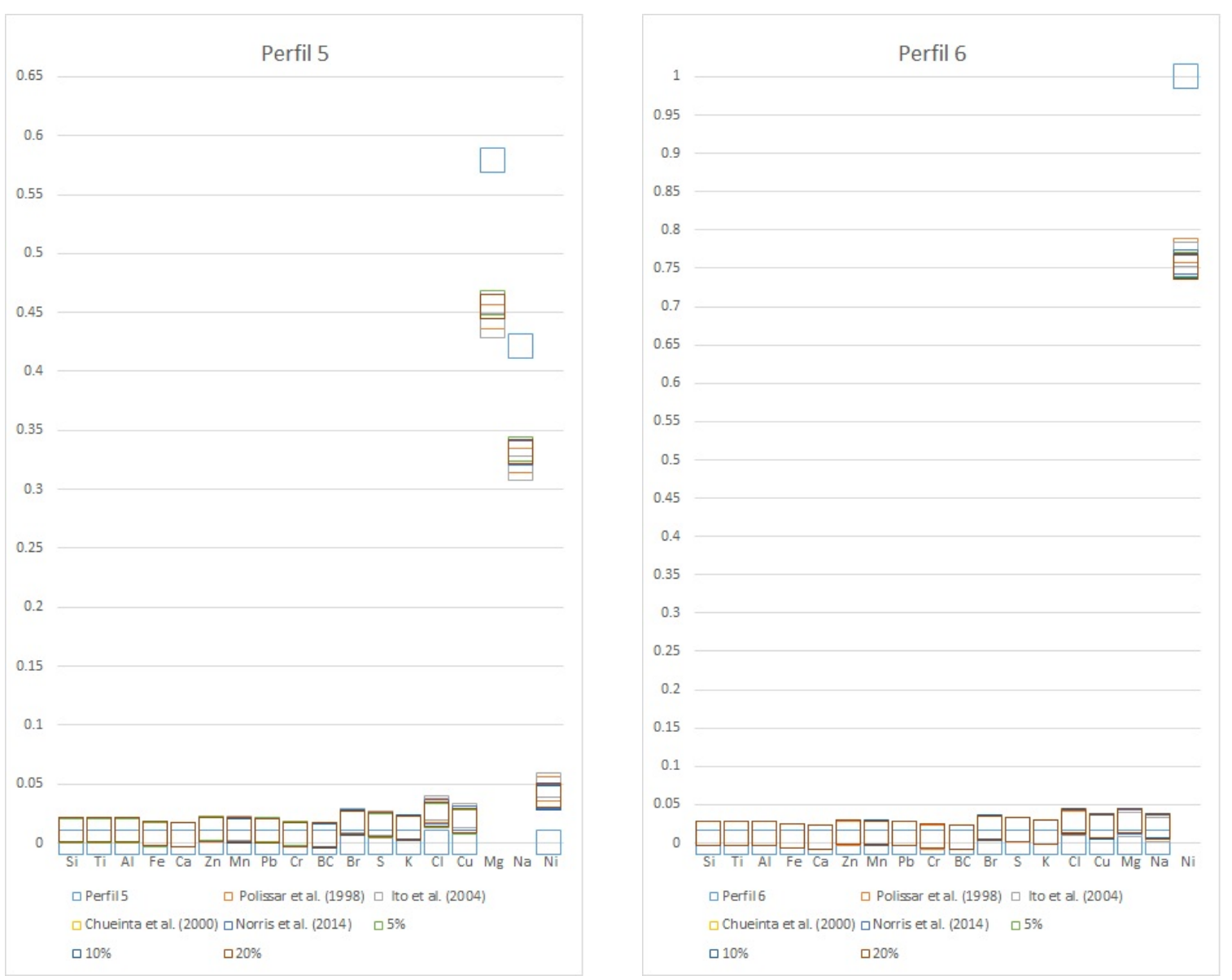

Figura 6.43: Gráfico comparativo para o Perfil 5 Figura 6.44: Gráfico comparativo para o Perfil 6

\section{Simulações com outliers - distribuição exponencial com média 3}

\begin{tabular}{c|c|c|c|c|c|}
0.194888 & 0.008283 & 0.009251 & 0.010834 & 0.010438 & 0.01036 \\
0.193112 & 0.008205 & 0.009159 & 0.010737 & 0.01032 & 0.010243 \\
0.192189 & 0.008194 & 0.009135 & 0.010697 & 0.010298 & 0.010212 \\
0.133452 & 0.005628 & 0.006298 & 0.007398 & 0.007102 & 0.007044 \\
0.119092 & 0.004998 & 0.005598 & 0.006564 & 0.00634 & 0.006288 \\
\hline 0.009082 & 0.209305 & 0.010312 & 0.011451 & 0.010883 & 0.011631 \\
0.008474 & 0.196087 & 0.009649 & 0.010738 & 0.010187 & 0.010892 \\
0.008027 & 0.186069 & 0.00916 & 0.010166 & 0.009669 & 0.010362 \\
\hline 0.005492 & 0.12779 & 0.006239 & 0.006958 & 0.006597 & 0.007054 \\
0.004867 & 0.113887 & 0.00556 & 0.006186 & 0.005845 & 0.006303 \\
\hline 0.0133 & 0.013303 & 0.312391 & 0.017205 & 0.017236 & 0.016182 \\
0.011854 & 0.011802 & 0.277869 & 0.015316 & 0.015292 & 0.014371 \\
0.009507 & 0.009537 & 0.224317 & 0.012352 & 0.012338 & 0.011623 \\
0.018806 & 0.021057 & 0.021465 & 0.444762 & 0.024878 & 0.023164 \\
0.014537 & 0.01627 & 0.016582 & 0.343668 & 0.019222 & 0.017924 \\
0.018954 & 0.01938 & 0.019779 & 0.022022 & 0.45601 & 0.025874 \\
0.013832 & 0.014109 & 0.014376 & 0.016039 & 0.331841 & 0.018827 \\
0.030535 & 0.026096 & 0.03286 & 0.036907 & 0.035504 & 0.781646 \\
\hline
\end{tabular}

Figura 6.45: Perfis médios em bases com outliers - Dist. Exponencial com média 3 - Proposta de incertezas definida em Norris et al. (2014)

\begin{tabular}{|c|c|c|c|c|c|}
\hline 0.015133 & 0.007745 & 0.008283 & 0.009457 & 0.008742 & 0.008516 \\
0.014972 & 0.007674 & 0.008194 & 0.009362 & 0.008663 & 0.008449 \\
0.014906 & 0.007649 & 0.008153 & 0.009336 & 0.008616 & 0.008408 \\
0.010367 & 0.005314 & 0.005665 & 0.00647 & 0.005979 & 0.005843 \\
0.009248 & 0.004736 & 0.005052 & 0.005768 & 0.005358 & 0.005214 \\
\hline 0.008321 & 0.015573 & 0.009104 & 0.009699 & 0.009329 & 0.009001 \\
0.007807 & 0.014578 & 0.008551 & 0.009085 & 0.008739 & 0.008429 \\
0.007394 & 0.013817 & 0.008063 & 0.008622 & 0.008296 & 0.007993 \\
\hline 0.005087 & 0.00952 & 0.005557 & 0.005929 & 0.005693 & 0.00549 \\
0.004531 & 0.008462 & 0.004953 & 0.005276 & 0.005073 & 0.004897 \\
\hline 0.013746 & 0.013474 & 0.023005 & 0.0156 & 0.015356 & 0.01451 \\
0.012181 & 0.011985 & 0.020506 & 0.013853 & 0.013655 & 0.01291 \\
0.009842 & 0.00968 & 0.016472 & 0.011196 & 0.011023 & 0.010426 \\
\cline { 1 - 5 } 0.02181 & 0.022634 & 0.022806 & 0.034079 & 0.023574 & 0.02201 \\
0.016876 & 0.017483 & 0.017574 & 0.026291 & 0.018222 & 0.017015 \\
\cline { 1 - 4 } 0.023993 & 0.024564 & 0.023941 & 0.025192 & 0.036016 & 0.023464 \\
0.017458 & 0.017878 & 0.017435 & 0.01835 & 0.026148 & 0.01709 \\
\hline 0.04247 & 0.039296 & 0.043147 & 0.043751 & 0.043628 & 0.054258 \\
\hline
\end{tabular}

Figura 6.46: Desvios padrões em bases com outliers - Dist. Exponencial com média 3 - Proposta de incertezas definida em Norris et al. (2014) 


\begin{tabular}{|c|c|c|c|c|c|}
\hline 0.196801 & 0.007799 & 0.008636 & 0.009867 & 0.01118 & 0.009754 \\
0.194987 & 0.007734 & 0.008551 & 0.009777 & 0.011062 & 0.009656 \\
0.194065 & 0.007725 & 0.008529 & 0.009746 & 0.011037 & 0.009626 \\
0.134726 & 0.005318 & 0.005882 & 0.006738 & 0.007624 & 0.006648 \\
0.120209 & 0.00472 & 0.005239 & 0.005977 & 0.006797 & 0.00593 \\
\hline 0.008682 & 0.211333 & 0.009439 & 0.010527 & 0.011477 & 0.011551 \\
0.008107 & 0.197987 & 0.008827 & 0.009868 & 0.010744 & 0.010817 \\
0.007681 & 0.187885 & 0.00839 & 0.009343 & 0.010204 & 0.010292 \\
\hline 0.005259 & 0.129005 & 0.005718 & 0.006401 & 0.00697 & 0.007016 \\
0.004645 & 0.115001 & 0.005078 & 0.005677 & 0.006166 & 0.006255 \\
\hline 0.013406 & 0.012567 & 0.319087 & 0.016735 & 0.017069 & 0.016376 \\
0.011949 & 0.011152 & 0.283807 & 0.014893 & 0.015151 & 0.014547 \\
0.009596 & 0.009015 & 0.229249 & 0.012016 & 0.01223 & 0.011771 \\
\hline 0.017988 & 0.019376 & 0.019491 & 0.453286 & 0.026342 & 0.022895 \\
0.01388 & 0.014933 & 0.015028 & 0.351536 & 0.020353 & 0.01769 \\
0.016323 & 0.018368 & 0.017741 & 0.018994 & 0.446336 & 0.020554 \\
0.011963 & 0.013409 & 0.012933 & 0.013868 & 0.323836 & 0.015009 \\
\cline { 5 - 6 } 0.029733 & 0.026673 & 0.028375 & 0.034751 & 0.045422 & 0.793613 \\
\hline
\end{tabular}

Figura 6.47: Perfis médios em bases com outliers - Dist. Exponencial com média 3 - Proposta de incertezas definida em Polissar et al. (1998)

\begin{tabular}{|c|c|c|c|c|c|}
\hline 0.014988 & 0.007652 & 0.008478 & 0.009016 & 0.009811 & 0.008616 \\
0.014796 & 0.007566 & 0.0084 & 0.00893 & 0.009705 & 0.008519 \\
0.014744 & 0.007538 & 0.008354 & 0.008893 & 0.009678 & 0.008472 \\
0.010272 & 0.00523 & 0.005786 & 0.006164 & 0.006719 & 0.005893 \\
0.009151 & 0.004666 & 0.00517 & 0.005516 & 0.005997 & 0.005264 \\
\hline 0.008185 & 0.015742 & 0.008468 & 0.009334 & 0.01004 & 0.009207 \\
0.007688 & 0.014718 & 0.007948 & 0.008756 & 0.009382 & 0.008626 \\
0.007293 & 0.013964 & 0.00753 & 0.008316 & 0.008934 & 0.008203 \\
\hline 0.005 & 0.009628 & 0.005176 & 0.005717 & 0.006146 & 0.005625 \\
0.004454 & 0.00859 & 0.004627 & 0.005114 & 0.005465 & 0.005009 \\
\hline 0.013361 & 0.013468 & 0.024053 & 0.015137 & 0.015729 & 0.014316 \\
0.011878 & 0.011955 & 0.0214 & 0.01345 & 0.013959 & 0.012727 \\
0.009583 & 0.009671 & 0.017235 & 0.010875 & 0.011275 & 0.010282 \\
\cline { 4 - 6 } 0.02129 & 0.022135 & 0.022241 & 0.035697 & 0.024424 & 0.022269 \\
0.016548 & 0.017137 & 0.017245 & 0.027737 & 0.018916 & 0.017288 \\
0.023398 & 0.024947 & 0.023444 & 0.023848 & 0.035078 & 0.022823 \\
0.01694 & 0.018132 & 0.017005 & 0.017346 & 0.025539 & 0.016541 \\
\hline 0.040757 & 0.040058 & 0.03941 & 0.042891 & 0.046242 & 0.056899 \\
\hline
\end{tabular}

Figura 6.48: Desvios padrões em bases com outliers - Dist. Exponencial com média 3 - Proposta de incertezas definida em Polissar et al. (1998)

\begin{tabular}{|l|l|l|l|l|l|}
\hline 0.195235 & 0.007713 & 0.008542 & 0.010057 & 0.011772 & 0.010010 \\
0.193438 & 0.007645 & 0.008446 & 0.009963 & 0.011638 & 0.009909 \\
0.192568 & 0.007633 & 0.008447 & 0.009938 & 0.011619 & 0.009881 \\
0.133642 & 0.005250 & 0.005817 & 0.006863 & 0.008018 & 0.006820 \\
0.119250 & 0.004665 & 0.005177 & 0.006096 & 0.007158 & 0.006086 \\
\hline 0.009102 & 0.210693 & 0.009376 & 0.010870 & 0.012449 & 0.011076 \\
0.008502 & 0.197387 & 0.008775 & 0.010195 & 0.011653 & 0.010375 \\
0.008052 & 0.187300 & 0.008331 & 0.009653 & 0.011062 & 0.009874 \\
0.005513 & 0.128591 & 0.005677 & 0.006611 & 0.007562 & 0.006727 \\
0.004883 & 0.114635 & 0.005051 & 0.005871 & 0.006702 & 0.006007 \\
\hline 0.013478 & 0.012638 & 0.314453 & 0.015546 & 0.019381 & 0.016044 \\
0.012012 & 0.011215 & 0.279707 & 0.013825 & 0.017203 & 0.014254 \\
0.009641 & 0.009059 & 0.225789 & 0.011157 & 0.013883 & 0.011532 \\
0.018998 & 0.019799 & 0.021753 & 0.452852 & 0.026554 & 0.023929 \\
0.014678 & 0.015302 & 0.016806 & 0.349936 & 0.020519 & 0.018520 \\
0.016792 & 0.017527 & 0.018427 & 0.019980 & 0.439849 & 0.022422 \\
0.012384 & 0.012859 & 0.013474 & 0.014596 & 0.318690 & 0.016425 \\
0.031832 & 0.030089 & 0.035952 & 0.035991 & 0.044288 & 0.790109 \\
\hline & & & & &
\end{tabular}

Figura 6.49: Perfis médios em bases com outliers - Dist. Exponencial com média 3 - Proposta de incertezas definida em Ito et al. (2004)

\begin{tabular}{|c|c|c|c|c|c|}
\hline 0.014958 & 0.007862 & 0.00838 & 0.009052 & 0.009989 & 0.008707 \\
0.01481 & 0.00777 & 0.008296 & 0.008955 & 0.009877 & 0.008636 \\
0.014737 & 0.007743 & 0.00827 & 0.008927 & 0.009863 & 0.00859 \\
\hline 0.010226 & 0.00538 & 0.005737 & 0.0062 & 0.006857 & 0.005969 \\
0.009162 & 0.004787 & 0.005144 & 0.005529 & 0.006103 & 0.005333 \\
\hline 0.008431 & 0.015756 & 0.008625 & 0.009591 & 0.010239 & 0.009037 \\
0.00789 & 0.014766 & 0.00806 & 0.00897 & 0.009569 & 0.008475 \\
0.007489 & 0.014 & 0.007635 & 0.00851 & 0.009107 & 0.008036 \\
\hline 0.005135 & 0.009617 & 0.005252 & 0.005856 & 0.006254 & 0.005513 \\
0.004576 & 0.008578 & 0.004698 & 0.005212 & 0.005577 & 0.004909 \\
\hline 0.013817 & 0.013186 & 0.024271 & 0.015358 & 0.016141 & 0.014479 \\
0.012267 & 0.011717 & 0.021667 & 0.013643 & 0.014342 & 0.012869 \\
0.009919 & 0.009453 & 0.017443 & 0.011021 & 0.011586 & 0.010384 \\
0.021672 & 0.022278 & 0.023034 & 0.036941 & 0.024193 & 0.021932 \\
0.016781 & 0.01719 & 0.017802 & 0.028585 & 0.01868 & 0.016947 \\
0.024236 & 0.02499 & 0.024342 & 0.025808 & 0.033288 & 0.022968 \\
0.017529 & 0.01816 & 0.017734 & 0.018716 & 0.024209 & 0.016692 \\
\hline 0.043529 & 0.042423 & 0.044327 & 0.043436 & 0.046869 & 0.054226 \\
\hline & & & & &
\end{tabular}

Figura 6.50: Desvios padrões em bases com outliers - Dist. Exponencial com média 3 Proposta de incertezas definida em Ito et al. (2004) 


\begin{tabular}{|l|l|l|l|l|l|}
\hline 0.192907 & 0.008404 & 0.009216 & 0.010808 & 0.010879 & 0.010521 \\
0.191209 & 0.008328 & 0.009108 & 0.010706 & 0.010760 & 0.010410 \\
0.190291 & 0.008307 & 0.009096 & 0.010665 & 0.010716 & 0.010370 \\
0.132082 & 0.005709 & 0.006264 & 0.007378 & 0.007398 & 0.007155 \\
0.117866 & 0.005072 & 0.005567 & 0.006540 & 0.006599 & 0.006386 \\
\hline 0.009633 & 0.206557 & 0.010043 & 0.011840 & 0.011327 & 0.011130 \\
0.008985 & 0.193470 & 0.009391 & 0.011109 & 0.010602 & 0.010423 \\
0.008506 & 0.183624 & 0.008916 & 0.010519 & 0.010052 & 0.009914 \\
\hline 0.005812 & 0.126062 & 0.006069 & 0.007185 & 0.006862 & 0.006749 \\
0.005155 & 0.112271 & 0.005404 & 0.006395 & 0.006075 & 0.006031 \\
\hline 0.013829 & 0.014109 & 0.311415 & 0.016187 & 0.017300 & 0.017780 \\
0.012297 & 0.012541 & 0.277138 & 0.014398 & 0.015338 & 0.015782 \\
\hline 0.009874 & 0.010100 & 0.223737 & 0.011629 & 0.012375 & 0.012776 \\
\hline 0.019813 & 0.021215 & 0.023455 & 0.438484 & 0.025057 & 0.022813 \\
0.015289 & 0.016343 & 0.018135 & 0.339751 & 0.019356 & 0.017638 \\
0.021979 & 0.021586 & 0.021990 & 0.025537 & 0.451534 & 0.025271 \\
0.016025 & 0.015724 & 0.015954 & 0.018560 & 0.328342 & 0.018396 \\
\cline { 2 - 5 } 0.028448 & 0.030578 & 0.029102 & 0.042309 & 0.039428 & 0.780455 \\
\hline
\end{tabular}

Figura 6.51: Perfis médios em bases com outliers - Dist. Exponencial com média 3 - Proposta de incertezas definida em Chueinta et al. (2000)

\begin{tabular}{|l|l|l|l|l|l|}
\hline 0.014622 & 0.007677 & 0.008278 & 0.009074 & 0.009097 & 0.008554 \\
0.014485 & 0.007605 & 0.008229 & 0.008979 & 0.009031 & 0.008485 \\
0.014468 & 0.007591 & 0.008157 & 0.008956 & 0.008976 & 0.008441 \\
\hline 0.010059 & 0.005251 & 0.005644 & 0.006207 & 0.006261 & 0.005881 \\
0.008968 & 0.004692 & 0.005058 & 0.005549 & 0.005555 & 0.005222 \\
\hline 0.008551 & 0.015249 & 0.008982 & 0.010119 & 0.009415 & 0.009066 \\
\hline 0.008005 & 0.014238 & 0.008407 & 0.009481 & 0.008801 & 0.00848 \\
\hline 0.007603 & 0.013549 & 0.007973 & 0.009017 & 0.008372 & 0.008044 \\
\hline 0.005219 & 0.009334 & 0.005488 & 0.006191 & 0.005763 & 0.005531 \\
0.004655 & 0.008291 & 0.004899 & 0.00551 & 0.00511 & 0.004924 \\
\hline 0.013976 & 0.014398 & 0.023697 & 0.015212 & 0.015606 & 0.014726 \\
0.012389 & 0.012815 & 0.021094 & 0.013502 & 0.013846 & 0.013089 \\
\hline 0.009974 & 0.010358 & 0.017022 & 0.010914 & 0.01118 & 0.010585 \\
\hline 0.022304 & 0.022819 & 0.023469 & 0.033126 & 0.023583 & 0.022053 \\
0.017253 & 0.017712 & 0.018159 & 0.025829 & 0.018297 & 0.017048 \\
\hline 0.02356 & 0.023654 & 0.023246 & 0.025221 & 0.033796 & 0.022789 \\
0.01715 & 0.017229 & 0.016948 & 0.018353 & 0.024558 & 0.016594 \\
\hline 0.04212 & 0.042565 & 0.040192 & 0.044715 & 0.045053 & 0.053831 \\
\hline
\end{tabular}

Figura 6.52: Desvios padrões em bases com outliers - Dist. Exponencial com média 3 - Proposta de incertezas definida em Chueinta et al. (2000)

\begin{tabular}{|c|c|c|c|c|c|}
\hline 0.195348 & .008373 & 0.009256 & 0.010471 & & \\
\hline & & & & & \\
\hline & & & & & \\
\hline & 90 & & & & \\
\hline & & & & & \\
\hline & & & & & \\
\hline & & & & & \\
\hline 0.00 & & 0.00 & 0.00 & & 950 \\
\hline & & & & & \\
\hline & & & & & \\
\hline & & & & & 0.01 \\
\hline & & & & & \\
\hline & & 0.223225 & 0.012 & & \\
\hline & & & & & \\
\hline & & & & & \\
\hline & & & & & \\
\hline & & & & 0.334061 & 0.018441 \\
\hline & & & & & \\
\hline
\end{tabular}

\begin{tabular}{|l|l|l|l|l|l|}
\hline 0.015060 & 0.007731 & 0.007976 & 0.008813 & 0.008664 & 0.008688 \\
0.014901 & 0.007681 & 0.007905 & 0.008709 & 0.008576 & 0.008630 \\
0.014899 & 0.007658 & 0.007879 & 0.008679 & 0.008527 & 0.008589 \\
\hline 0.010323 & 0.005313 & 0.005469 & 0.006021 & 0.005919 & 0.005977 \\
0.009234 & 0.004729 & 0.004892 & 0.005374 & 0.005260 & 0.005297 \\
\hline 0.008305 & 0.015981 & 0.009002 & 0.009741 & 0.009446 & 0.009071 \\
0.007776 & 0.014959 & 0.008448 & 0.009096 & 0.008805 & 0.008522 \\
\hline 0.007376 & 0.014220 & 0.007988 & 0.008631 & 0.008388 & 0.008068 \\
\hline 0.005060 & 0.009786 & 0.005513 & 0.005949 & 0.005764 & 0.005541 \\
0.004520 & 0.008708 & 0.004906 & 0.005296 & 0.005127 & 0.004947 \\
\hline 0.014311 & 0.014522 & 0.023315 & 0.015687 & 0.015433 & 0.014736 \\
0.012709 & 0.012906 & 0.020755 & 0.013945 & 0.013688 & 0.013114 \\
0.010226 & 0.010406 & 0.016737 & 0.011248 & 0.011041 & 0.010594 \\
\hline 0.022890 & 0.021746 & 0.023304 & 0.034250 & 0.023717 & 0.022725 \\
0.017692 & 0.016818 & 0.018046 & 0.026519 & 0.018361 & 0.017588 \\
\cline { 1 - 4 } 0.022699 & 0.022824 & 0.023574 & 0.025273 & 0.034995 & 0.023339 \\
0.016529 & 0.016620 & 0.017152 & 0.018397 & 0.025447 & 0.016983 \\
\hline 0.041715 & 0.040292 & 0.042756 & 0.043667 & 0.043649 & 0.053888 \\
\hline
\end{tabular}

Figura 6.54: Desvios padrões em bases com outliers - Dist. Exponencial com média 3 -
Proposta de incertezas de $20 \%$ do valor da medição
Figura 6.53: Perfis médios em bases com outliers - Dist. Exponencial com média 3 - Proposta de incertezas de $20 \%$ do valor da medição 


\begin{tabular}{|l|l|l|l|l|l|}
\hline 0.193437 & 0.008713 & 0.009359 & 0.010937 & 0.010844 & 0.010403 \\
0.191664 & 0.008641 & 0.009264 & 0.010843 & 0.010717 & 0.010285 \\
0.190773 & 0.008615 & 0.009246 & 0.010796 & 0.010680 & 0.010253 \\
0.132425 & 0.005923 & 0.006374 & 0.007469 & 0.007375 & 0.007072 \\
0.118186 & 0.005262 & 0.005661 & 0.006619 & 0.006580 & 0.006313 \\
\hline 0.009328 & 0.208210 & 0.010478 & 0.011385 & 0.011914 & 0.011018 \\
0.008700 & 0.195039 & 0.009805 & 0.010677 & 0.011153 & 0.010315 \\
0.008242 & 0.185085 & 0.009300 & 0.010110 & 0.010582 & 0.009817 \\
\hline 0.005630 & 0.127098 & 0.006337 & 0.006909 & 0.007225 & 0.006679 \\
0.004993 & 0.113246 & 0.005643 & 0.006152 & 0.006403 & 0.005971 \\
\hline 0.013647 & 0.013430 & 0.310386 & 0.016764 & 0.016699 & 0.017299 \\
0.012154 & 0.011920 & 0.276077 & 0.014922 & 0.014805 & 0.015367 \\
0.009747 & 0.009624 & 0.222823 & 0.012038 & 0.011949 & 0.012432 \\
0.019743 & 0.020014 & 0.023171 & 0.441400 & 0.024114 & 0.024450 \\
\cline { 3 - 6 } 0.015260 & 0.015457 & 0.017915 & 0.340986 & 0.018620 & 0.018924 \\
0.020325 & 0.019236 & 0.021272 & 0.024929 & 0.453321 & 0.026113 \\
0.014814 & 0.013987 & 0.015445 & 0.018135 & 0.329981 & 0.018987 \\
0.030932 & 0.030500 & 0.031444 & 0.038929 & 0.037038 & 0.778302 \\
\hline
\end{tabular}

Figura 6.55: Perfis médios em bases com outliers - Dist. Exponencial com média 3 - Proposta de incertezas de $10 \%$ do valor da medição

\begin{tabular}{|l|l|l|l|l|l|}
\hline 0.015123 & 0.008002 & 0.008209 & 0.009152 & 0.009252 & 0.008524 \\
0.014957 & 0.007935 & 0.008113 & 0.009059 & 0.009166 & 0.008458 \\
0.014881 & 0.007924 & 0.008078 & 0.009026 & 0.009133 & 0.008408 \\
\hline 0.010331 & 0.005491 & 0.005609 & 0.006241 & 0.006364 & 0.005839 \\
0.009263 & 0.004896 & 0.005011 & 0.005602 & 0.005671 & 0.005200 \\
\hline 0.008466 & 0.015396 & 0.009095 & 0.009611 & 0.009908 & 0.008941 \\
0.007932 & 0.014398 & 0.008522 & 0.008997 & 0.009270 & 0.008364 \\
0.007517 & 0.013705 & 0.008091 & 0.008538 & 0.008809 & 0.007940 \\
\hline 0.005146 & 0.009458 & 0.005565 & 0.005879 & 0.006029 & 0.005470 \\
0.004561 & 0.008391 & 0.004967 & 0.005237 & 0.005375 & 0.004855 \\
\hline 0.014214 & 0.013996 & 0.024606 & 0.015663 & 0.015660 & 0.014476 \\
0.012620 & 0.012445 & 0.021862 & 0.013926 & 0.013917 & 0.012863 \\
0.010176 & 0.010028 & 0.017627 & 0.011227 & 0.011214 & 0.010370 \\
\cline { 1 - 5 } 0.022827 & 0.022568 & 0.023982 & 0.032801 & 0.024140 & 0.021997 \\
0.017668 & 0.017400 & 0.018502 & 0.025385 & 0.018629 & 0.017016 \\
0.023285 & 0.022820 & 0.022955 & 0.025024 & 0.034569 & 0.023632 \\
0.016974 & 0.016615 & 0.016700 & 0.018204 & 0.025086 & 0.017226 \\
\cline { 1 - 2 } 0.030932 & 0.030500 & 0.031444 & 0.038929 & 0.037038 & 0.778302 \\
\hline
\end{tabular}

Figura 6.56: Desvios padrões em bases com outliers - Dist. Exponencial com média 3 Proposta de incertezas de $10 \%$ do valor da medição

\begin{tabular}{|c|c|c|c|c|c|}
\hline 0.193083 & 0.008347 & 0.009929 & 0.010716 & 0.010670 & 0.010566 \\
\hline & .008269 & 0.009819 & & & \\
\hline & 002 & 02 & 0.010 & 010512 & \\
\hline 0.132170 & .005670 & 0.006755 & 0.007311 & 0.007258 & 0.007185 \\
\hline 0.117954 & 005038 & 0.006005 & 0.00 & 0.006470 & \\
\hline 0.009500 & 206910 & 0.010327 & 0.011775 & 0.011029 & 0.011386 \\
\hline 0.008859 & 193809 & 0.009664 & 0.0 & 0.010322 & 0.010663 \\
\hline 0.008390 & 0.183923 & 0.009168 & 0460 & 0.009789 & 0.010142 \\
\hline 0.005733 & 0.126276 & 0.006245 & 0.007147 & 0.006680 & 0.006903 \\
\hline 0.005084 & 0.112502 & 0.005562 & & 0.005915 & 0.00 \\
\hline 0.013 & 0.013619 & 0.310257 & 6763 & 0.017030 & 0.017557 \\
\hline 0.011833 & 0.012108 & 0.275985 & 0.014906 & 0.015092 & 0.015590 \\
\hline 0.009497 & 0.009755 & 0.222722 & 0.012036 & 0.012179 & 0.012618 \\
\hline 0.020501 & 0.021458 & 0.022329 & 0.440092 & 0.025017 & 0.023408 \\
\hline & 0.016557 & 0.017279 & 0.340018 & 0.019320 & 0.018118 \\
\hline 0.022109 & 0.021584 & 0.022035 & 0.025064 & 0.453307 & 0.025298 \\
\hline 0.016107 & 0.015712 & 0.015983 & 0.018200 & 0.330071 & 0.018405 \\
\hline & & & & & \\
\hline
\end{tabular}

\begin{tabular}{|l|l|l|l|l|l|}
\hline 0.014988 & 0.007601 & 0.008393 & 0.008890 & 0.009081 & 0.008612 \\
0.014805 & 0.007536 & 0.008332 & 0.008802 & 0.008988 & 0.008543 \\
0.014817 & 0.007508 & 0.008273 & 0.008748 & 0.008930 & 0.008502 \\
\hline 0.010269 & 0.005187 & 0.005741 & 0.006078 & 0.006202 & 0.005914 \\
0.009199 & 0.004641 & 0.005123 & 0.005410 & 0.005527 & 0.005269 \\
\hline 0.008349 & 0.014966 & 0.009285 & 0.010057 & 0.009275 & 0.009068 \\
0.007829 & 0.014025 & 0.008707 & 0.009436 & 0.008686 & 0.008483 \\
0.007427 & 0.013351 & 0.008269 & 0.008936 & 0.008254 & 0.008053 \\
\hline 0.005077 & 0.009198 & 0.005650 & 0.006128 & 0.005669 & 0.005526 \\
0.004546 & 0.008209 & 0.005051 & 0.005468 & 0.005034 & 0.004926 \\
\hline 0.013627 & 0.014494 & 0.023482 & 0.015135 & 0.015711 & 0.014950 \\
0.012072 & 0.012886 & 0.020934 & 0.013437 & 0.013935 & 0.013299 \\
0.009720 & 0.010403 & 0.016812 & 0.010845 & 0.011237 & 0.010725 \\
0.023260 & 0.023373 & 0.023279 & 0.034669 & 0.023728 & 0.022620 \\
0.017909 & 0.018093 & 0.017953 & 0.026705 & 0.018348 & 0.017470 \\
0.023729 & 0.023482 & 0.022640 & 0.024845 & 0.034308 & 0.022807 \\
0.017358 & 0.017087 & 0.016450 & 0.018174 & 0.025068 & 0.016622 \\
\cline { 1 - 2 } 0.042136 & 0.041851 & 0.041530 & 0.044830 & 0.045328 & 0.054361 \\
\hline & & & & &
\end{tabular}

Figura 6.57: Perfis médios em bases com outliers - Dist. Exponencial com média 3 - Proposta de incertezas de $20 \%$ do valor da medição
Figura 6.58: Desvios padrões em bases com outliers - Dist. Exponencial com média 3 Proposta de incertezas de $20 \%$ do valor da medição 


\begin{tabular}{|l|l|l|l|l|l|}
0.550817 & -0.014559 & -0.010491 & -0.010513 & -0.015248 & -0.004681 \\
0.541374 & -0.018086 & -0.01454 & -0.017558 & -0.011646 & -0.013018 \\
0.548216 & -0.010562 & -0.015096 & -0.015179 & -0.017529 & -0.009683 \\
0.425515 & -0.031188 & -0.034452 & -0.027854 & -0.026406 & -0.003618 \\
0.381521 & -0.041443 & -0.028398 & -0.024384 & -0.026928 & -0.010378 \\
\hline-0.012223 & 0.567434 & -0.012797 & -0.016111 & -0.01263 & -0.005838 \\
-0.013803 & 0.555297 & -0.014552 & -0.018295 & -0.01071 & -0.005168 \\
-0.015432 & 0.535886 & -0.020149 & -0.016117 & -0.023314 & 0.00146 \\
-0.033086 & 0.407356 & -0.02831 & -0.026811 & -0.01809 & -0.02667 \\
-0.035904 & 0.380604 & -0.031189 & -0.023772 & -0.02427 & -0.018207 \\
-0.007855 & -0.008044 & 0.705685 & -0.010623 & -0.008771 & -0.002272 \\
-0.009774 & -0.011773 & 0.684215 & -0.013087 & -0.016724 & -0.004009 \\
-0.017981 & -0.019549 & 0.623976 & -0.009897 & -0.016017 & -0.007846 \\
-0.005704 & -0.006157 & -0.009233 & 0.805909 & -0.007075 & -0.00153 \\
-0.008693 & -0.008481 & -0.009232 & 0.799973 & -0.009581 & -0.007154 \\
-0.005831 & -0.004713 & -0.008034 & -0.002937 & 0.80696 & -0.007211 \\
-0.007673 & -0.010247 & -0.012052 & -0.012955 & 0.79734 & -0.001742 \\
-0.018671 & -0.018115 & -0.011409 & -0.013374 & -0.010563 & 0.760187 \\
\hline
\end{tabular}

Figura 6.59: Perfis médios em bases com outliers - Dist. Exponencial com média 3 - Análise Fatorial Ortogonal - CP - Rotação Varimax

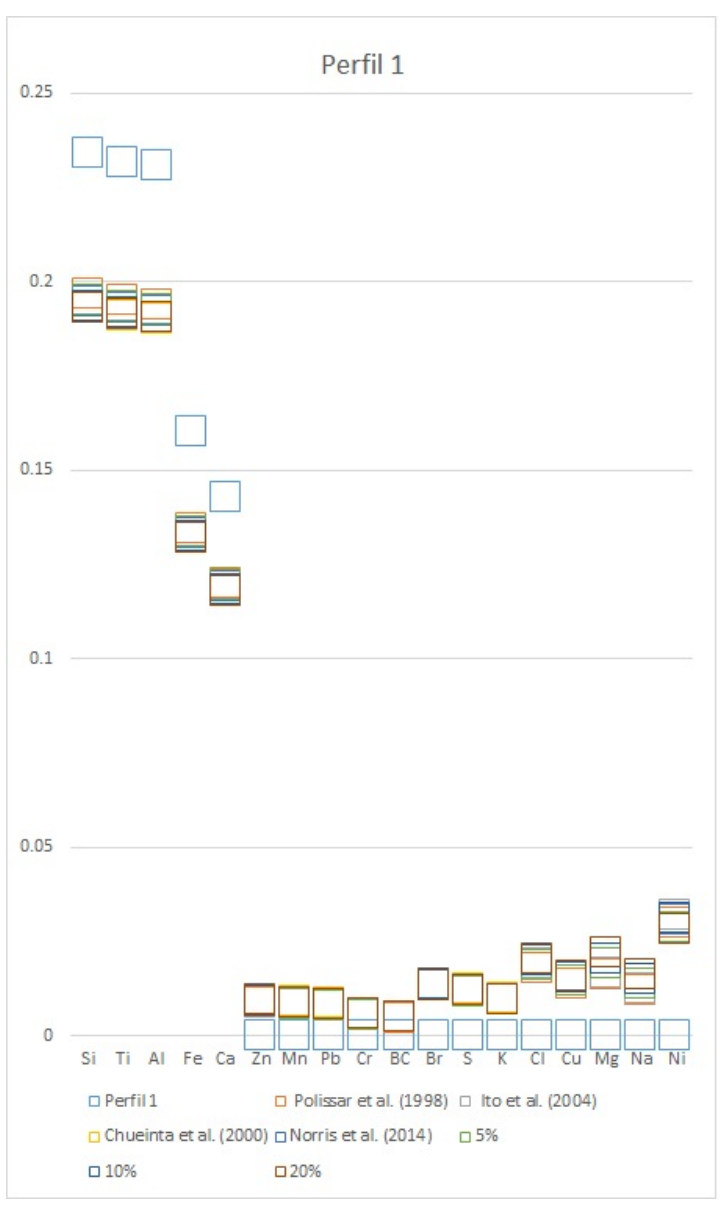

\begin{tabular}{|l|c|c|c|c|c|}
\hline 0.157714 & 0.093497 & 0.093453 & 0.095441 & 0.098063 & 0.172071 \\
0.159931 & 0.091068 & 0.091184 & 0.102268 & 0.099152 & 0.174855 \\
0.161909 & 0.097447 & 0.092217 & 0.099334 & 0.096968 & 0.173176 \\
0.188339 & 0.113641 & 0.106596 & 0.113824 & 0.111796 & 0.234875 \\
0.191662 & 0.1209 & 0.114672 & 0.120407 & 0.118857 & 0.265741 \\
\hline 0.093436 & 0.145981 & 0.089492 & 0.095599 & 0.095857 & 0.175197 \\
0.093958 & 0.148397 & 0.089591 & 0.093678 & 0.095501 & 0.170915 \\
0.096705 & 0.16239 & 0.089505 & 0.101961 & 0.094421 & 0.191139 \\
0.11563 & 0.187642 & 0.109523 & 0.112111 & 0.118267 & 0.236116 \\
0.117581 & 0.192268 & 0.110272 & 0.118334 & 0.119077 & 0.252273 \\
0.065589 & 0.065741 & 0.093782 & 0.072907 & 0.065697 & 0.097763 \\
0.068825 & 0.064477 & 0.096819 & 0.075069 & 0.075333 & 0.105995 \\
0.080688 & 0.081799 & 0.123741 & 0.08814 & 0.087451 & 0.138713 \\
0.047896 & 0.046635 & 0.048527 & 0.061592 & 0.054233 & 0.064354 \\
0.04377 & 0.048586 & 0.046743 & 0.06463 & 0.054113 & 0.068654 \\
0.047845 & 0.047577 & 0.047873 & 0.055122 & 0.05136 & 0.060412 \\
0.048293 & 0.051499 & 0.049325 & 0.054154 & 0.058495 & 0.068396 \\
\hline 0.086964 & 0.074503 & 0.085731 & 0.086803 & 0.084259 & 0.225792 \\
\hline
\end{tabular}

Figura 6.60: Desvios padrões em bases com outliers - Dist. Exponencial com média 3 - Análise Fatorial Ortogonal - CP - Rotação Varimax

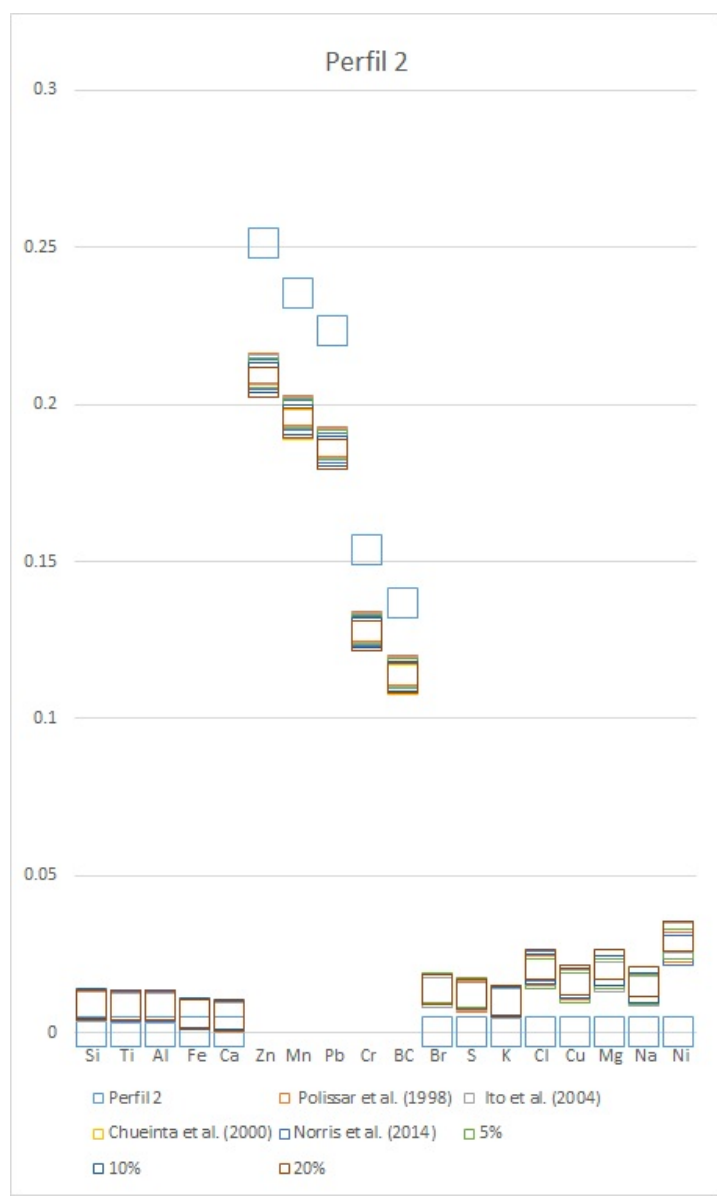

Figura 6.61: Gráfico comparativo para o Perfil 1 Figura 6.62: Gráfico comparativo para o Perfil 2 

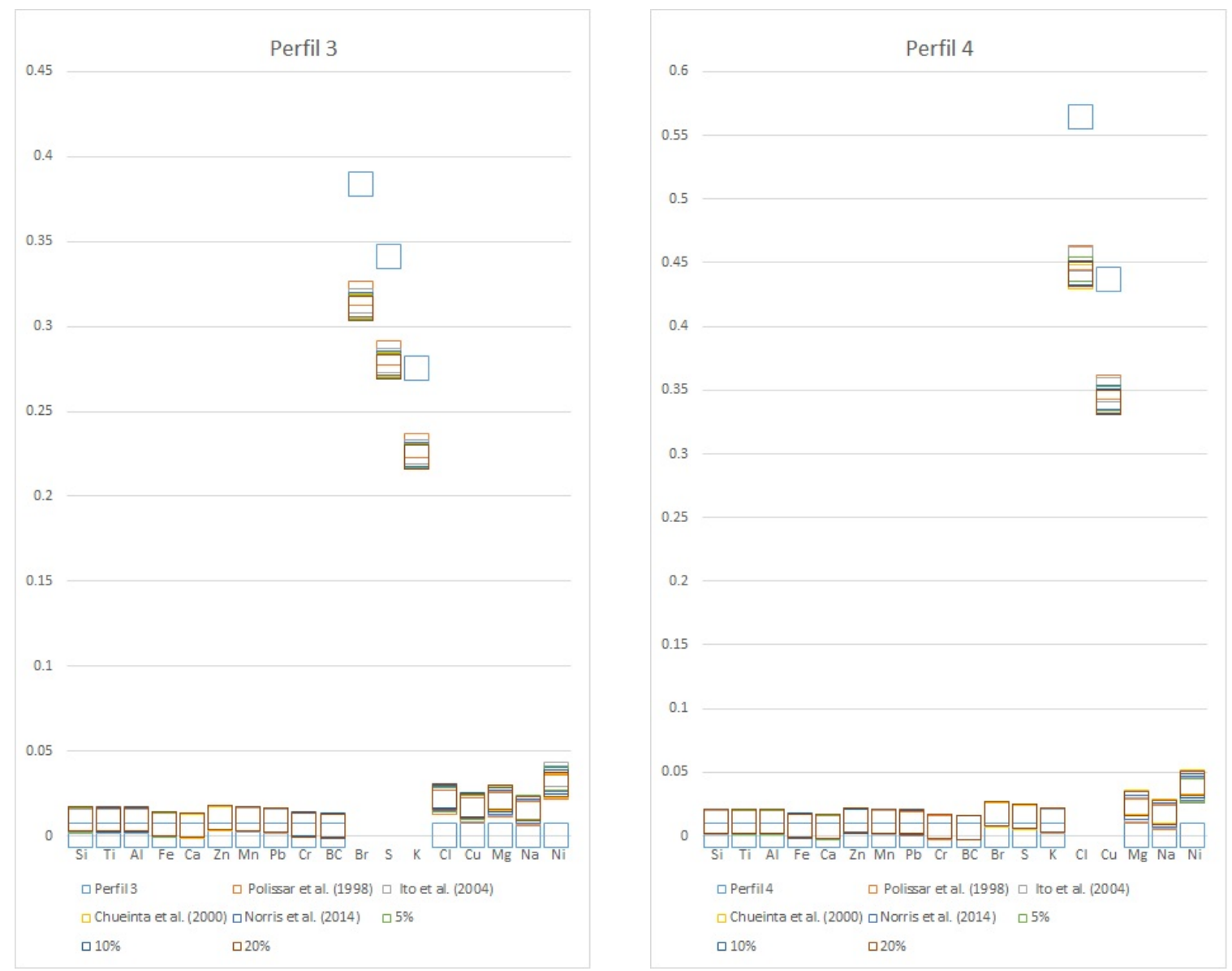

Figura 6.63: Gráfico comparativo para o Perfil 3 Figura 6.64: Gráfico comparativo para o Perfil 4 

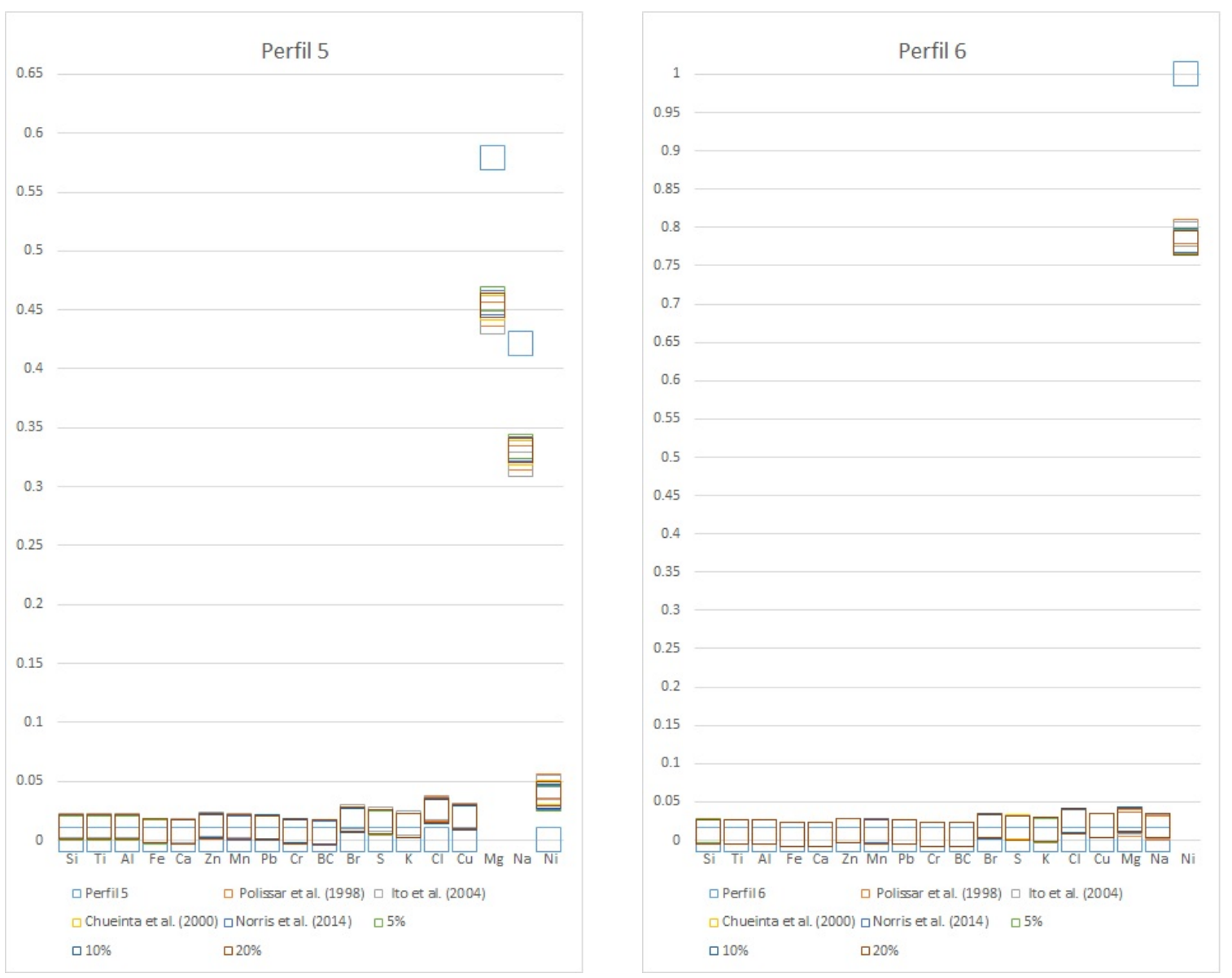

Figura 6.65: Gráfico comparativo para o Perfil 5 Figura 6.66: Gráfico comparativo para o Perfil 6

\section{Simulações com outliers - distribuição exponencial com média 9}

\begin{tabular}{|c|c|c|c|c|c|}
\hline & .008553 & 0.010464 & 0.011443 & 0.011231 & \\
\hline & & & & & \\
\hline & & & & & \\
\hline & & & & & \\
\hline & 005170 & & & & \\
\hline & & & & & \\
\hline & & & & & \\
\hline & & & & & \\
\hline & 0.12 & & & & \\
\hline & 0.1142 & & & & \\
\hline & & & & & \\
\hline & & & & 0.0 & 0.00 \\
\hline & 0.010599 & & 0.012392 & & 0.007 \\
\hline & 0.019677 & 0.023 & & 0.02 & \\
\hline & & & & & \\
\hline & & & & & \\
\hline & 0.013834 & & & 0.328341 & 0.011837 \\
\hline & & & & & \\
\hline
\end{tabular}

Figura 6.67: Perfis médios em bases com outliers - Dist. Exponencial com média 9 - Proposta de incertezas definida em Norris et al. (2014)

\begin{tabular}{|c|c|c|c|c|c|}
\hline 0.014872 & 0.007723 & 0.008369 & 0.008882 & 0.008565 & 0.005576 \\
0.014762 & 0.007676 & 0.008299 & 0.008811 & 0.008455 & 0.005532 \\
0.014646 & 0.007629 & 0.008252 & 0.008766 & 0.008425 & 0.005504 \\
0.010142 & 0.005336 & 0.005727 & 0.006112 & 0.005858 & 0.00383 \\
0.009076 & 0.004727 & 0.005122 & 0.005419 & 0.005225 & 0.003423 \\
\hline 0.008303 & 0.015352 & 0.008857 & 0.009696 & 0.009428 & 0.006008 \\
0.007781 & 0.014428 & 0.008313 & 0.0091 & 0.008817 & 0.00562 \\
0.007391 & 0.01365 & 0.00787 & 0.008595 & 0.008374 & 0.005334 \\
\hline 0.005088 & 0.009362 & 0.005388 & 0.005939 & 0.005728 & 0.003657 \\
0.004526 & 0.00837 & 0.004837 & 0.00528 & 0.005126 & 0.003273 \\
\hline 0.014084 & 0.014359 & 0.023571 & 0.015411 & 0.015066 & 0.009519 \\
0.012498 & 0.012785 & 0.020982 & 0.013718 & 0.013402 & 0.008485 \\
\hline 0.01012 & 0.01032 & 0.016971 & 0.011097 & 0.01082 & 0.006827 \\
\hline 0.022027 & 0.02306 & 0.02365 & 0.035286 & 0.024129 & 0.014064 \\
0.017011 & 0.017813 & 0.018259 & 0.027302 & 0.018629 & 0.010867 \\
\cline { 1 - 3 } 0.023047 & 0.023282 & 0.023841 & 0.024676 & 0.034008 & 0.015131 \\
0.01675 & 0.016952 & 0.017343 & 0.017978 & 0.024731 & 0.011026 \\
\hline 0.037609 & 0.037563 & 0.038869 & 0.042382 & 0.039154 & 0.050604 \\
\hline
\end{tabular}

Figura 6.68: Desvios padrões em bases com outliers - Dist. Exponencial com média 9 - Proposta de incertezas definida em Norris et al. (2014) 


\begin{tabular}{|l|l|l|l|l|l|}
\hline 0.198178 & 0.008071 & 0.008679 & 0.010786 & 0.011709 & 0.006497 \\
0.196340 & 0.008002 & 0.008594 & 0.010701 & 0.011609 & 0.006426 \\
0.195461 & 0.007970 & 0.008579 & 0.010650 & 0.011575 & 0.006402 \\
0.135713 & 0.005472 & 0.005910 & 0.007374 & 0.007979 & 0.004442 \\
0.121050 & 0.004889 & 0.005251 & 0.006553 & 0.007126 & 0.003955 \\
\hline 0.008878 & 0.212264 & 0.010262 & 0.011323 & 0.012958 & 0.007302 \\
0.008270 & 0.198832 & 0.009612 & 0.010613 & 0.012157 & 0.006827 \\
0.007886 & 0.188729 & 0.009133 & 0.010060 & 0.011516 & 0.006483 \\
\hline 0.005395 & 0.129521 & 0.006234 & 0.006889 & 0.007884 & 0.004437 \\
0.004755 & 0.115513 & 0.005510 & 0.006091 & 0.006991 & 0.003935 \\
\hline 0.013792 & 0.013350 & 0.318302 & 0.016983 & 0.018427 & 0.010739 \\
0.012269 & 0.011865 & 0.283111 & 0.015098 & 0.016365 & 0.009559 \\
0.009879 & 0.009583 & 0.228688 & 0.012194 & 0.013221 & 0.007699 \\
0.018226 & 0.020761 & 0.021962 & 0.450939 & 0.027453 & 0.014637 \\
0.014096 & 0.016024 & 0.016971 & 0.349148 & 0.021225 & 0.011315 \\
0.016326 & 0.016299 & 0.017346 & 0.018682 & 0.440795 & 0.014668 \\
0.011932 & 0.011905 & 0.012651 & 0.013599 & 0.320305 & 0.010706 \\
0.021554 & 0.020950 & 0.023205 & 0.032317 & 0.040705 & 0.863971 \\
\hline
\end{tabular}

Figura 6.69: Perfis médios em bases com outliers - Dist. Exponencial com média 9 - Proposta de incertezas definida em Polissar et al. (1998)

\begin{tabular}{|l|l|l|l|l|l|}
\hline 0.014374 & 0.007549 & 0.007772 & 0.008697 & 0.009296 & 0.005684 \\
0.014266 & 0.007468 & 0.007680 & 0.008653 & 0.009226 & 0.005630 \\
0.014191 & 0.007445 & 0.007669 & 0.008598 & 0.009162 & 0.005598 \\
0.009855 & 0.005192 & 0.005310 & 0.005968 & 0.006357 & 0.003903 \\
0.008783 & 0.004609 & 0.004737 & 0.005321 & 0.005684 & 0.003476 \\
\hline 0.008048 & 0.016229 & 0.008656 & 0.009241 & 0.010069 & 0.005891 \\
0.007523 & 0.015187 & 0.008113 & 0.008651 & 0.009431 & 0.005508 \\
0.007158 & 0.014399 & 0.007688 & 0.008212 & 0.008942 & 0.005220 \\
\hline 0.004914 & 0.009916 & 0.005271 & 0.005645 & 0.006129 & 0.003586 \\
0.004397 & 0.008866 & 0.004703 & 0.005046 & 0.005496 & 0.003197 \\
\hline 0.013599 & 0.013110 & 0.024478 & 0.015045 & 0.015563 & 0.009291 \\
0.012081 & 0.011664 & 0.021811 & 0.013369 & 0.013849 & 0.008283 \\
0.009759 & 0.009419 & 0.017625 & 0.010806 & 0.011163 & 0.006676 \\
\hline 0.020886 & 0.022564 & 0.023178 & 0.034592 & 0.024192 & 0.013795 \\
0.016188 & 0.017443 & 0.017940 & 0.026843 & 0.018736 & 0.010668 \\
\cline { 2 - 5 } 0.023592 & 0.023959 & 0.024591 & 0.023712 & 0.033987 & 0.014633 \\
0.017142 & 0.017410 & 0.017887 & 0.017235 & 0.024664 & 0.010636 \\
\hline 0.036361 & 0.035386 & 0.038040 & 0.042096 & 0.045241 & 0.047974 \\
\hline
\end{tabular}

Figura 6.70: Desvios padrões em bases com outliers - Dist. Exponencial com média 9 - Proposta de incertezas definida em Polissar et al. (1998)

\begin{tabular}{|l|l|l|l|l|l|}
\hline 0.195097 & 0.008186 & 0.009021 & 0.010197 & 0.012140 & 0.006321 \\
0.193278 & 0.008104 & 0.008924 & 0.010110 & 0.012028 & 0.006249 \\
0.192449 & 0.008078 & 0.008915 & 0.010073 & 0.011997 & 0.006229 \\
0.133584 & 0.005546 & 0.006142 & 0.006965 & 0.008268 & 0.004320 \\
0.119169 & 0.004958 & 0.005456 & 0.006193 & 0.007386 & 0.003849 \\
\hline 0.009446 & 0.210227 & 0.010350 & 0.011494 & 0.012974 & 0.007495 \\
0.008805 & 0.196946 & 0.009698 & 0.010776 & 0.012169 & 0.007007 \\
0.008387 & 0.186903 & 0.009208 & 0.010214 & 0.011528 & 0.006653 \\
0.005737 & 0.128264 & 0.006287 & 0.006996 & 0.007892 & 0.004555 \\
0.005069 & 0.114430 & 0.005570 & 0.006193 & 0.007009 & 0.004045 \\
\hline 0.014255 & 0.013868 & 0.314503 & 0.017113 & 0.018948 & 0.010710 \\
0.012679 & 0.012328 & 0.279710 & 0.015220 & 0.016822 & 0.009529 \\
0.010210 & 0.009958 & 0.225849 & 0.012282 & 0.013582 & 0.007675 \\
0.020529 & 0.020252 & 0.023081 & 0.449950 & 0.028885 & 0.013739 \\
0.015891 & 0.015632 & 0.017838 & 0.347679 & 0.022326 & 0.010632 \\
0.017569 & 0.017999 & 0.018509 & 0.018613 & 0.437709 & 0.014339 \\
0.012872 & 0.013194 & 0.013549 & 0.013576 & 0.317747 & 0.010482 \\
0.024974 & 0.025127 & 0.027390 & 0.036356 & 0.040590 & 0.866171 \\
\hline
\end{tabular}

Figura 6.71: Perfis médios em bases com outliers - Dist. Exponencial com média 9 - Proposta de incertezas definida em Ito et al. (2004)

\begin{tabular}{|l|c|c|c|c|c|}
\hline 0.015138 & 0.007945 & 0.008416 & 0.008911 & 0.009732 & 0.005711 \\
0.015023 & 0.007883 & 0.008352 & 0.008824 & 0.009621 & 0.005658 \\
0.014942 & 0.007835 & 0.008318 & 0.008782 & 0.009585 & 0.00563 \\
\hline 0.010348 & 0.005458 & 0.005749 & 0.0061 & 0.006655 & 0.003927 \\
0.009249 & 0.004858 & 0.005132 & 0.005434 & 0.005939 & 0.003489 \\
\hline 0.008486 & 0.016275 & 0.009021 & 0.009557 & 0.010035 & 0.006061 \\
0.007964 & 0.015305 & 0.008455 & 0.008961 & 0.00939 & 0.005668 \\
0.007557 & 0.014501 & 0.008024 & 0.008476 & 0.00889 & 0.005385 \\
\hline 0.005191 & 0.009965 & 0.005501 & 0.00582 & 0.006093 & 0.003699 \\
0.004633 & 0.008909 & 0.004936 & 0.005221 & 0.005451 & 0.003282 \\
\hline 0.013675 & 0.014085 & 0.024654 & 0.015675 & 0.015912 & 0.009264 \\
0.012135 & 0.012522 & 0.021931 & 0.013939 & 0.014183 & 0.008242 \\
\hline 0.009788 & 0.0101 & 0.01775 & 0.01128 & 0.011432 & 0.006647 \\
\hline 0.021533 & 0.023112 & 0.023869 & 0.036271 & 0.024899 & 0.01374 \\
0.016622 & 0.017875 & 0.018452 & 0.028013 & 0.019248 & 0.010623 \\
\cline { 1 - 3 } 0.024657 & 0.025149 & 0.025148 & 0.023977 & 0.034 & 0.014437 \\
0.017932 & 0.018299 & 0.018241 & 0.017402 & 0.024698 & 0.010501 \\
\hline 0.039074 & 0.039394 & 0.040314 & 0.045056 & 0.04466 & 0.049145 \\
\hline & & & & &
\end{tabular}

Figura 6.72: Desvios padrões em bases com outliers - Dist. Exponencial com média 9 Proposta de incertezas definida em Ito et al. (2004) 


\begin{tabular}{|l|l|l|l|l|l|}
\hline 0.192522 & 0.009082 & 0.010043 & 0.011836 & 0.011004 & 0.006675 \\
0.190750 & 0.009000 & 0.009937 & 0.011747 & 0.010909 & 0.006599 \\
0.189950 & 0.008950 & 0.009912 & 0.011680 & 0.010870 & 0.006574 \\
0.131802 & 0.006153 & 0.006829 & 0.008089 & 0.007484 & 0.004559 \\
0.117598 & 0.005497 & 0.006068 & 0.007178 & 0.006682 & 0.004059 \\
\hline 0.009816 & 0.206031 & 0.010744 & 0.012167 & 0.012933 & 0.007183 \\
0.009147 & 0.193015 & 0.010064 & 0.011405 & 0.012127 & 0.006717 \\
0.008718 & 0.183161 & 0.009558 & 0.010804 & 0.011488 & 0.006378 \\
\hline 0.005958 & 0.125692 & 0.006508 & 0.007395 & 0.007850 & 0.004361 \\
0.005263 & 0.112065 & 0.005774 & 0.006557 & 0.006975 & 0.003874 \\
\hline 0.014301 & 0.015611 & 0.307770 & 0.018293 & 0.017291 & 0.010629 \\
0.012717 & 0.013877 & 0.273723 & 0.016272 & 0.015343 & 0.009455 \\
\hline 0.010218 & 0.011205 & 0.221005 & 0.013132 & 0.012391 & 0.007612 \\
\hline 0.020675 & 0.022663 & 0.024011 & 0.436514 & 0.026511 & 0.015332 \\
0.015979 & 0.017462 & 0.018519 & 0.337698 & 0.020482 & 0.011868 \\
\cline { 3 - 6 } 0.023733 & 0.021378 & 0.024665 & 0.026489 & 0.448934 & 0.015101 \\
0.017281 & 0.015590 & 0.017959 & 0.019272 & 0.326293 & 0.011023 \\
0.023572 & 0.023568 & 0.026911 & 0.033472 & 0.034433 & 0.862001 \\
\hline
\end{tabular}

Figura 6.73: Perfis médios em bases com outliers - Dist. Exponencial com média 9 - Proposta de incertezas definida em Chueinta et al. (2000)

\begin{tabular}{|c|c|c|c|c|c|}
\hline 0.195409 & 0.008956 & 0.009966 & 0.011311 & 0.011027 & 0.006548 \\
\hline 0.193577 & 0.008873 & 0.009860 & 0.011219 & 0.010932 & 0.006475 \\
\hline 192762 & 0.008830 & 0.009837 & 0.011157 & 0.010893 & 0.006447 \\
\hline 0.133824 & 0.006064 & 0.006775 & 0.007728 & 0.007503 & 0.004475 \\
\hline 0.119416 & 0.005419 & 0.006021 & 0.006861 & 0.006694 & 0.003981 \\
\hline .009134 & 0.209832 & 0.010785 & 0.012206 & 0.012266 & 0.007327 \\
\hline .008510 & 0.196570 & 0.010104 & 0.011442 & 0.011509 & 0.006847 \\
\hline 0.008108 & 0.186553 & 0.009597 & 0.010842 & 0.010897 & 0.006504 \\
\hline 0.005540 & 0.128077 & 0.006536 & 0.007422 & 0.007450 & 0.004447 \\
\hline 0.004897 & 0.114220 & 0.005803 & 0.006586 & 0.006619 & 0.003949 \\
\hline 0.014014 & 0.014585 & 0.309931 & 0.016223 & 0.017593 & 0.010836 \\
\hline 0.012468 & 0.012961 & 0.275650 & 0.014425 & 0.015618 & 0.009641 \\
\hline 0.010030 & 0.010465 & 0.222587 & 0.011642 & 0.012610 & 0.007763 \\
\hline 0.018954 & 0.020294 & 0.024448 & 0.442658 & 0.026049 & 0.014480 \\
\hline 0.014673 & 0.015659 & 0.018890 & 0.342048 & 0.020133 & 0.011207 \\
\hline 0.021464 & 0.019672 & 0.022836 & 0.025899 & 0.454298 & 0.015672 \\
\hline 0.015631 & 0.014330 & 0.016620 & 0.018825 & 0.330758 & 0.011423 \\
\hline & & & & & \\
\hline
\end{tabular}

Figura 6.75: Perfis médios em bases com outliers - Dist. Exponencial com média 9 - Proposta de incertezas de $5 \%$ do valor da medição
Figura 6.74: Desvios padrões em bases com outliers - Dist. Exponencial com média 9 - Proposta de incertezas definida em Chueinta et al. (2000)

\begin{tabular}{|c|c|c|c|c|c|}
\hline 0.014789 & 0.008002 & 0.008521 & 0.009056 & 0.008956 & 0.005797 \\
0.01467 & 0.007943 & 0.008458 & 0.008981 & 0.008859 & 0.005759 \\
0.014604 & 0.007903 & 0.008432 & 0.008924 & 0.008817 & 0.005727 \\
\hline 0.010129 & 0.005498 & 0.005836 & 0.006203 & 0.006127 & 0.003987 \\
0.009011 & 0.004887 & 0.00521 & 0.005521 & 0.005469 & 0.003556 \\
\hline 0.008503 & 0.015333 & 0.009047 & 0.009844 & 0.009295 & 0.005912 \\
0.007978 & 0.014346 & 0.0085 & 0.009249 & 0.00871 & 0.005528 \\
0.007579 & 0.013635 & 0.008032 & 0.008756 & 0.008242 & 0.005249 \\
\hline 0.005203 & 0.009319 & 0.005526 & 0.006013 & 0.005666 & 0.0036 \\
0.004637 & 0.008374 & 0.004936 & 0.005372 & 0.005051 & 0.003212 \\
\hline 0.014458 & 0.015266 & 0.024 & 0.015344 & 0.015032 & 0.009514 \\
0.012837 & 0.013579 & 0.021466 & 0.013688 & 0.013376 & 0.008467 \\
0.010387 & 0.010958 & 0.017322 & 0.011046 & 0.010808 & 0.006823 \\
0.022892 & 0.023422 & 0.023617 & 0.034365 & 0.023889 & 0.014104 \\
0.017738 & 0.018073 & 0.018282 & 0.026598 & 0.018534 & 0.010898 \\
\cline { 5 - 6 } 0.023316 & 0.022964 & 0.024362 & 0.024407 & 0.034856 & 0.014576 \\
0.016913 & 0.016745 & 0.017744 & 0.017752 & 0.025288 & 0.010613 \\
\hline 0.038127 & 0.038149 & 0.040254 & 0.042847 & 0.043661 & 0.051028 \\
\hline
\end{tabular}

\begin{tabular}{|c|c|c|c|c|c|}
\hline 0.014327 & 0.007795 & 0.008232 & 0.008935 & 0.008594 & 0.005728 \\
\hline 0.014231 & 0.007720 & 0.008160 & 0.008859 & 0.008506 & 0.005690 \\
\hline 014172 & 0.007680 & 0.008146 & 0.008828 & 0.008456 & 0.005656 \\
\hline 0.009794 & 0.005377 & 0.005659 & 0.006131 & 0.005875 & 0.003928 \\
\hline 0.008794 & 0.004766 & 0.005037 & 0.005466 & 0.005255 & 0.003509 \\
\hline .008292 & 0.015650 & 0.008694 & 0.009687 & 0.009359 & 0.006113 \\
\hline .007775 & 0.014692 & 0.008141 & 0.009090 & 0.008771 & 0.005716 \\
\hline 0.007363 & 0.013900 & 0.007725 & 0.008600 & 0.008308 & 0.005424 \\
\hline 0.005098 & 0.009548 & 0.005301 & 0.005933 & 0.005708 & 0.003724 \\
\hline 0.004523 & 0.008542 & 0.004750 & 0.005267 & 0.005098 & 0.003322 \\
\hline .013970 & 0.014228 & 0.023665 & 0.014830 & 0.014836 & 0.009596 \\
\hline 0.012402 & 0.012643 & 0.021043 & 0.013177 & 0.013196 & 0.008554 \\
\hline 0.010030 & 0.010209 & 0.017046 & 0.010660 & 0.010650 & 0.006891 \\
\hline 0.022104 & 0.023362 & 0.023683 & 0.034111 & 0.024404 & 0.013817 \\
\hline 0.017081 & 0.018059 & 0.018315 & 0.026382 & 0.018848 & 0.010663 \\
\hline 0.022346 & 0.022434 & 0.023112 & 0.024648 & 0.034210 & 0.013758 \\
\hline 0.016257 & 0.016344 & 0.016820 & 0.017971 & 0.024863 & 0.010023 \\
\hline . 036 & S/Y/ & 0.038 & 0.04189 & 0.039395 & \\
\hline
\end{tabular}

Figura 6.76: Desvios padrões em bases com outliers - Dist. Exponencial com média 9 -

Proposta de incertezas de $5 \%$ do valor da medição 


\begin{tabular}{|l|l|l|l|l|l|}
\hline 0.193429 & 0.008735 & 0.010447 & 0.011201 & 0.011771 & 0.006329 \\
0.191623 & 0.008658 & 0.010342 & 0.011107 & 0.011668 & 0.006259 \\
0.190825 & 0.008611 & 0.010309 & 0.011048 & 0.011625 & 0.006234 \\
0.132448 & 0.005917 & 0.007106 & 0.007652 & 0.008005 & 0.004324 \\
0.118182 & 0.005285 & 0.006319 & 0.006793 & 0.007147 & 0.003849 \\
\hline 0.009482 & 0.208596 & 0.010916 & 0.012410 & 0.012531 & 0.007261 \\
0.008833 & 0.195414 & 0.010226 & 0.011631 & 0.011752 & 0.006786 \\
0.008415 & 0.185445 & 0.009709 & 0.011023 & 0.011135 & 0.006443 \\
\hline 0.005750 & 0.127299 & 0.006613 & 0.007542 & 0.007609 & 0.004407 \\
0.005084 & 0.113525 & 0.005874 & 0.006691 & 0.006761 & 0.003912 \\
\hline 0.013934 & 0.015205 & 0.307030 & 0.018637 & 0.018038 & 0.010183 \\
0.012394 & 0.013513 & 0.273030 & 0.016571 & 0.016015 & 0.009060 \\
0.009969 & 0.010914 & 0.220442 & 0.013370 & 0.012932 & 0.007295 \\
0.020927 & 0.020730 & 0.023465 & 0.437884 & 0.026369 & 0.015465 \\
0.016200 & 0.015992 & 0.018119 & 0.338226 & 0.020381 & 0.011974 \\
0.022190 & 0.021201 & 0.024211 & 0.025367 & 0.449296 & 0.016410 \\
0.016159 & 0.015442 & 0.017630 & 0.018443 & 0.326976 & 0.011964 \\
0.024156 & 0.019518 & 0.028212 & 0.034404 & 0.029989 & 0.861845 \\
\hline
\end{tabular}

Figura 6.77: Perfis médios em bases com outliers - Dist. Exponencial com média 9 - Proposta de incertezas de $10 \%$ do valor da medição

\begin{tabular}{|l|l|l|l|l|l|}
0.192654 & 0.009106 & 0.010389 & 0.011562 & 0.011318 & 0.006738 \\
0.190859 & 0.009024 & 0.010283 & 0.011473 & 0.011218 & 0.006661 \\
0.190071 & 0.008976 & 0.010255 & 0.011405 & 0.011174 & 0.006637 \\
0.131883 & 0.006167 & 0.007066 & 0.007903 & 0.007693 & 0.004604 \\
0.117675 & 0.005510 & 0.006281 & 0.007010 & 0.006873 & 0.004098 \\
\hline 0.009805 & 0.206634 & 0.011020 & 0.012612 & 0.012292 & 0.007220 \\
0.009134 & 0.193592 & 0.010320 & 0.011825 & 0.011529 & 0.006749 \\
0.008705 & 0.183694 & 0.009802 & 0.011201 & 0.010921 & 0.006409 \\
0.005949 & 0.126067 & 0.006673 & 0.007667 & 0.007460 & 0.004382 \\
0.005260 & 0.112417 & 0.005928 & 0.006804 & 0.006628 & 0.003894 \\
\hline 0.014447 & 0.014743 & 0.307377 & 0.017534 & 0.018206 & 0.010722 \\
0.012846 & 0.013115 & 0.273298 & 0.015598 & 0.016156 & 0.009535 \\
0.010329 & 0.010588 & 0.220626 & 0.012585 & 0.013051 & 0.007677 \\
0.021223 & 0.021403 & 0.024237 & 0.439524 & 0.026402 & 0.015860 \\
0.016424 & 0.016503 & 0.018713 & 0.339375 & 0.020404 & 0.012284 \\
0.023205 & 0.022445 & 0.023342 & 0.026760 & 0.448682 & 0.014984 \\
0.016895 & 0.016361 & 0.016987 & 0.019450 & 0.326414 & 0.010932 \\
0.022636 & 0.023655 & 0.027403 & 0.029712 & 0.033579 & 0.860614 \\
\hline
\end{tabular}

\begin{tabular}{|l|l|l|l|l|l|}
\hline 0.014271 & 0.007936 & 0.008626 & 0.008881 & 0.008988 & 0.005627 \\
0.014168 & 0.007833 & 0.008555 & 0.008800 & 0.008898 & 0.005588 \\
0.014146 & 0.007804 & 0.008512 & 0.008762 & 0.008866 & 0.005569 \\
\hline 0.009744 & 0.005440 & 0.005883 & 0.006084 & 0.006170 & 0.003877 \\
0.008753 & 0.004821 & 0.005275 & 0.005432 & 0.005511 & 0.003451 \\
\hline 0.008285 & 0.015488 & 0.008761 & 0.009645 & 0.009606 & 0.005897 \\
0.007764 & 0.014512 & 0.008193 & 0.009039 & 0.009001 & 0.005529 \\
0.007352 & 0.013762 & 0.007764 & 0.008556 & 0.008527 & 0.005241 \\
\hline 0.005069 & 0.009437 & 0.005331 & 0.005893 & 0.005852 & 0.003582 \\
0.004509 & 0.008460 & 0.004761 & 0.005248 & 0.005241 & 0.003205 \\
\hline 0.014339 & 0.014706 & 0.023822 & 0.015700 & 0.015264 & 0.009329 \\
0.012755 & 0.013060 & 0.021174 & 0.013989 & 0.013574 & 0.008300 \\
0.010320 & 0.010560 & 0.017154 & 0.011290 & 0.010971 & 0.006697 \\
\hline 0.022458 & 0.023522 & 0.023544 & 0.033604 & 0.024257 & 0.014328 \\
0.017339 & 0.018149 & 0.018218 & 0.026034 & 0.018723 & 0.011055 \\
0.024041 & 0.022979 & 0.024314 & 0.024169 & 0.035200 & 0.015096 \\
0.017445 & 0.016740 & 0.017699 & 0.017604 & 0.025722 & 0.010991 \\
\hline 0.039477 & 0.034919 & 0.040842 & 0.044229 & 0.041105 & 0.050607 \\
\hline
\end{tabular}

Figura 6.78: Desvios padrões em bases com outliers - Dist. Exponencial com média 9 Proposta de incertezas de $10 \%$ do valor da medição
Figura 6.79: Perfis médios em bases com outliers - Dist. Exponencial com média 9 - Proposta de incertezas de $20 \%$ do valor da medição

\begin{tabular}{|l|l|l|l|l|l|}
\hline 0.014342 & 0.007900 & 0.008599 & 0.008960 & 0.008964 & 0.005917 \\
0.014244 & 0.007820 & 0.008539 & 0.008895 & 0.008869 & 0.005862 \\
0.014234 & 0.007799 & 0.008477 & 0.008840 & 0.008822 & 0.005839 \\
\hline 0.009833 & 0.005436 & 0.005887 & 0.006132 & 0.006142 & 0.004058 \\
0.008788 & 0.004833 & 0.005253 & 0.005476 & 0.005470 & 0.003626 \\
\hline 0.008524 & 0.014934 & 0.009045 & 0.009723 & 0.009408 & 0.006099 \\
0.007979 & 0.014011 & 0.008473 & 0.009134 & 0.008813 & 0.005686 \\
0.007577 & 0.013284 & 0.008019 & 0.008646 & 0.008332 & 0.005415 \\
\hline 0.005198 & 0.009112 & 0.005490 & 0.005927 & 0.005738 & 0.003709 \\
0.004637 & 0.008145 & 0.004918 & 0.005288 & 0.005116 & 0.003312 \\
\hline 0.014375 & 0.014975 & 0.023973 & 0.015633 & 0.015256 & 0.009697 \\
0.012769 & 0.013292 & 0.021365 & 0.013911 & 0.013554 & 0.008650 \\
0.010304 & 0.010742 & 0.017266 & 0.011218 & 0.010952 & 0.006949 \\
\hline 0.022467 & 0.022960 & 0.023309 & 0.034671 & 0.023603 & 0.014543 \\
0.017397 & 0.017728 & 0.018009 & 0.026810 & 0.018218 & 0.011237 \\
\cline { 1 - 2 } 0.023639 & 0.023227 & 0.023939 & 0.024658 & 0.035747 & 0.014487 \\
0.017199 & 0.016928 & 0.017421 & 0.017958 & 0.025959 & 0.010549 \\
\cline { 1 - 2 } 0.037994 & 0.038753 & 0.041901 & 0.040894 & 0.043573 & 0.050678 \\
\hline
\end{tabular}

Figura 6.80: Desvios padrões em bases com outliers - Dist. Exponencial com média 9 Proposta de incertezas de $20 \%$ do valor da medição 


\begin{tabular}{|c|c|c|c|c|c|}
\hline .112934 & -0.049973 & -0.049889 & -0.042433 & -0.047904 & -0.027941 \\
\hline 415 & -0.038865 & -0.048012 & -0.040901 & -0.037231 & -0.029963 \\
\hline 091888 & -0.048725 & -0.044945 & -0.052181 & -0.050981 & -0.030312 \\
\hline 273 & -0.030231 & -0.027679 & -0.03892 & -0.031295 & -0.029736 \\
\hline 0.042353 & -0.03612 & -0.032586 & -0.043559 & -0.043612 & -0.023216 \\
\hline .045324 & 0.119914 & -0.044636 & -0.035 & -0.04 & -0.01 \\
\hline .047778 & 0.118341 & -0.039768 & -0.045195 & -0.044919 & -0.028487 \\
\hline 0.039369 & 0.099938 & -0.041287 & -0.047114 & -0.043269 & -0.024093 \\
\hline-0.028779 & 0.052561 & -0.035025 & -0.04595 & -0.035181 & -0.035795 \\
\hline 0.004325 & 0.046095 & -0.034633 & -0.04 & -0.04 & -0.011966 \\
\hline-0.027793 & -0.02044 & 0.228944 & -0.016793 & -0.014817 & -0.015898 \\
\hline-0.024836 & -0.023742 & 0.211873 & -0.029871 & -0.020026 & -0.008102 \\
\hline-0.033236 & -0.030184 & 0.181617 & -0.026657 & -0.025003 & -0.016397 \\
\hline-0.010216 & -0.016492 & -0.001411 & 0.410071 & -0.001153 & 0.019329 \\
\hline-0.014921 & -0.014321 & -0.01195 & 0.391052 & -0.009204 & 0.01573 \\
\hline-0.008049 & 0.003711 & -0.019024 & -0.007492 & 0.378 & 0.028458 \\
\hline-0.008817 & -0.001293 & -0.014441 & -0.006157 & 0.354469 & 0.021298 \\
\hline & 0.0155 & 0.019312 & 0.029513 & 0.027712 & 0.405 \\
\hline
\end{tabular}

Figura 6.81: Perfis médios em bases com outliers - Dist. Exponencial com média 9 - Análise Fatorial Ortogonal - CP - Rotação Varimax

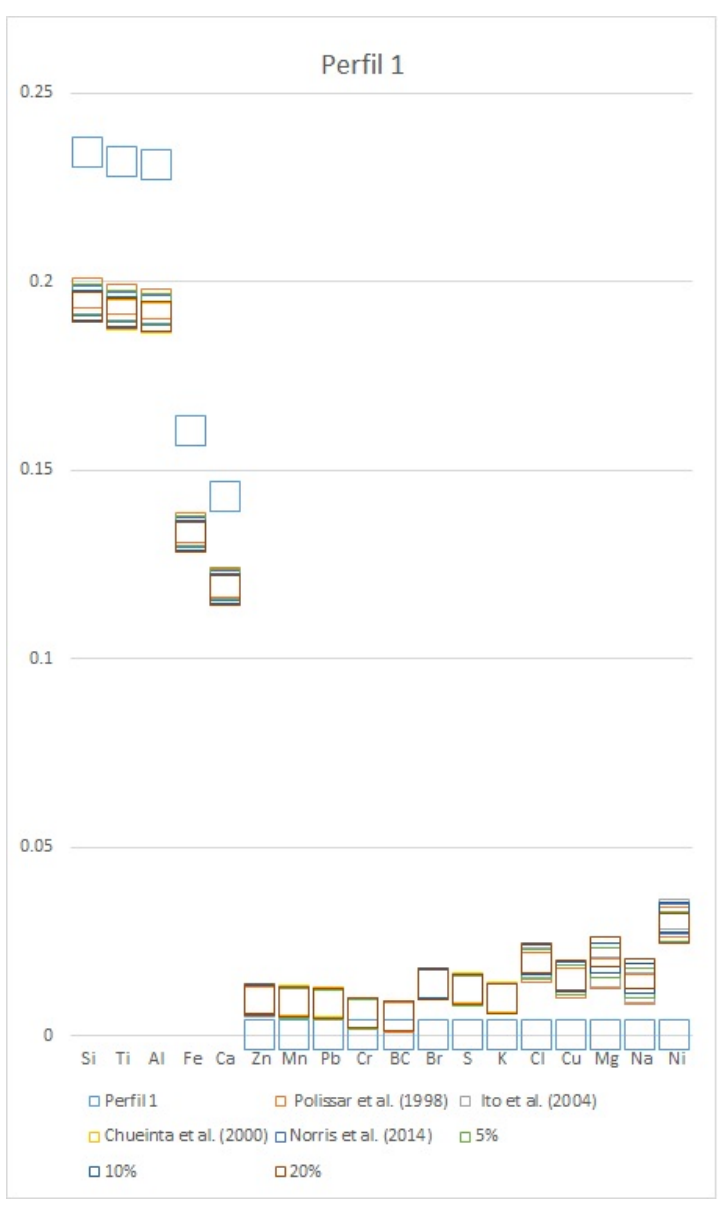

\begin{tabular}{|c|c|c|c|c|c|}
\hline 0.330727 & 0.222104 & 0.201357 & 0.181321 & 0.186171 & 0.211255 \\
0.336386 & 0.22267 & 0.188982 & 0.187503 & 0.192184 & 0.2189 \\
0.323418 & 0.219117 & 0.201694 & 0.189456 & 0.185766 & 0.226483 \\
0.273589 & 0.264833 & 0.231947 & 0.195191 & 0.202985 & 0.218582 \\
0.267253 & 0.272367 & 0.237046 & 0.201827 & 0.19505 & 0.222177 \\
\hline 0.20531 & 0.34048 & 0.201872 & 0.180343 & 0.183751 & 0.232073 \\
0.216559 & 0.327537 & 0.204521 & 0.190571 & 0.194999 & 0.21701 \\
0.213297 & 0.317445 & 0.2044 & 0.188597 & 0.197442 & 0.216961 \\
0.26237 & 0.268199 & 0.214894 & 0.186509 & 0.208955 & 0.214648 \\
0.293153 & 0.255374 & 0.234583 & 0.197472 & 0.203623 & 0.231291 \\
\hline 0.189938 & 0.193366 & 0.365657 & 0.1801 & 0.18956 & 0.194612 \\
0.202114 & 0.20483 & 0.346252 & 0.172357 & 0.182501 & 0.199566 \\
0.201581 & 0.209029 & 0.330666 & 0.183494 & 0.186192 & 0.203315 \\
0.162572 & 0.160863 & 0.167021 & 0.356619 & 0.168554 & 0.198255 \\
0.165809 & 0.167416 & 0.160982 & 0.337237 & 0.170147 & 0.193612 \\
0.175321 & 0.180242 & 0.159085 & 0.170034 & 0.376661 & 0.211475 \\
0.169196 & 0.180775 & 0.167776 & 0.166955 & 0.347927 & 0.199509 \\
\hline 0.233667 & 0.212146 & 0.206448 & 0.212896 & 0.205263 & 0.40787 \\
\hline
\end{tabular}

Figura 6.82: Desvios padrões em bases com outliers - Dist. Exponencial com média 9 - Análise Fatorial Ortogonal - CP - Rotação Varimax

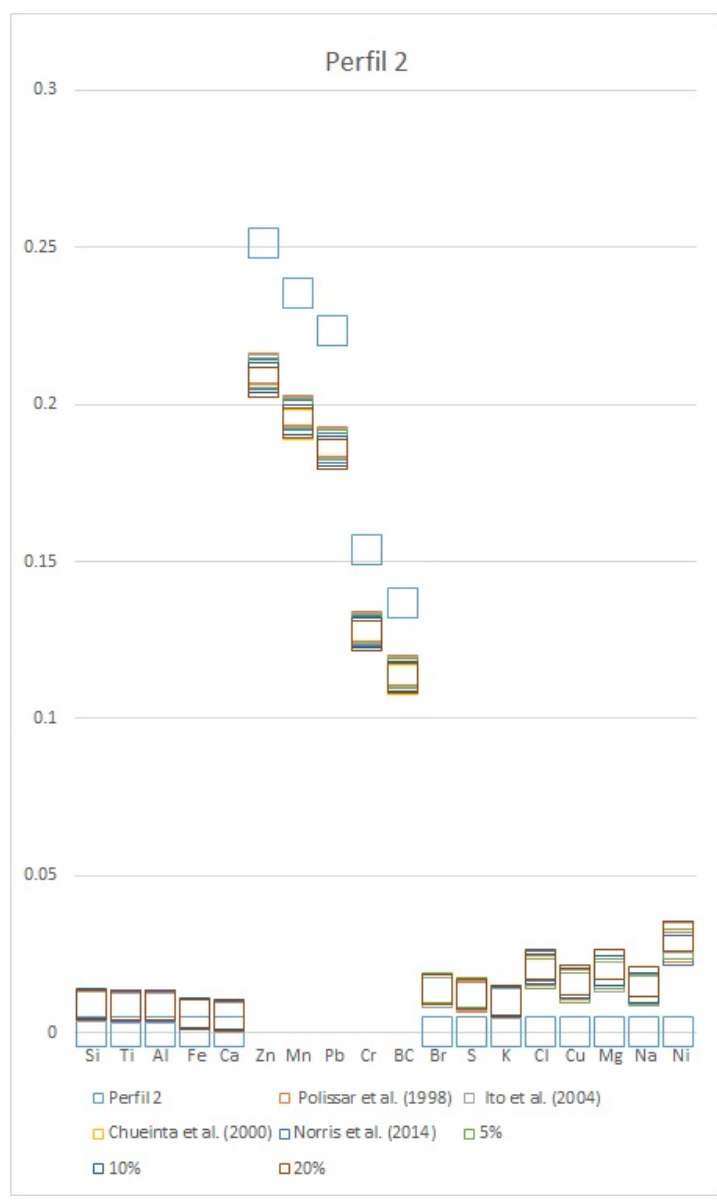

Figura 6.83: Gráfico comparativo para o Perfil 1 Figura 6.84: Gráfico comparativo para o Perfil 2 

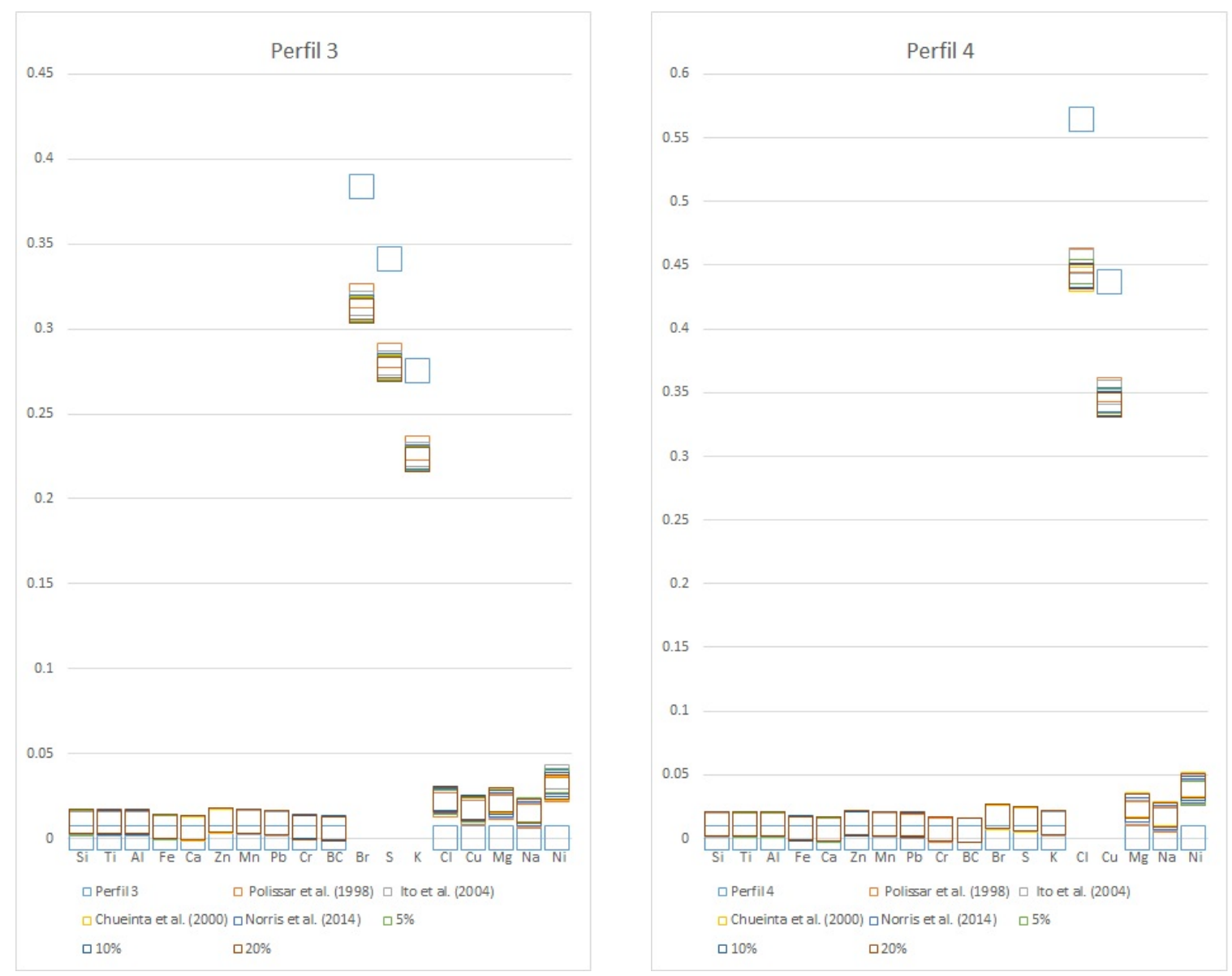

Figura 6.85: Gráfico comparativo para o Perfil 3 Figura 6.86: Gráfico comparativo para o Perfil 4 

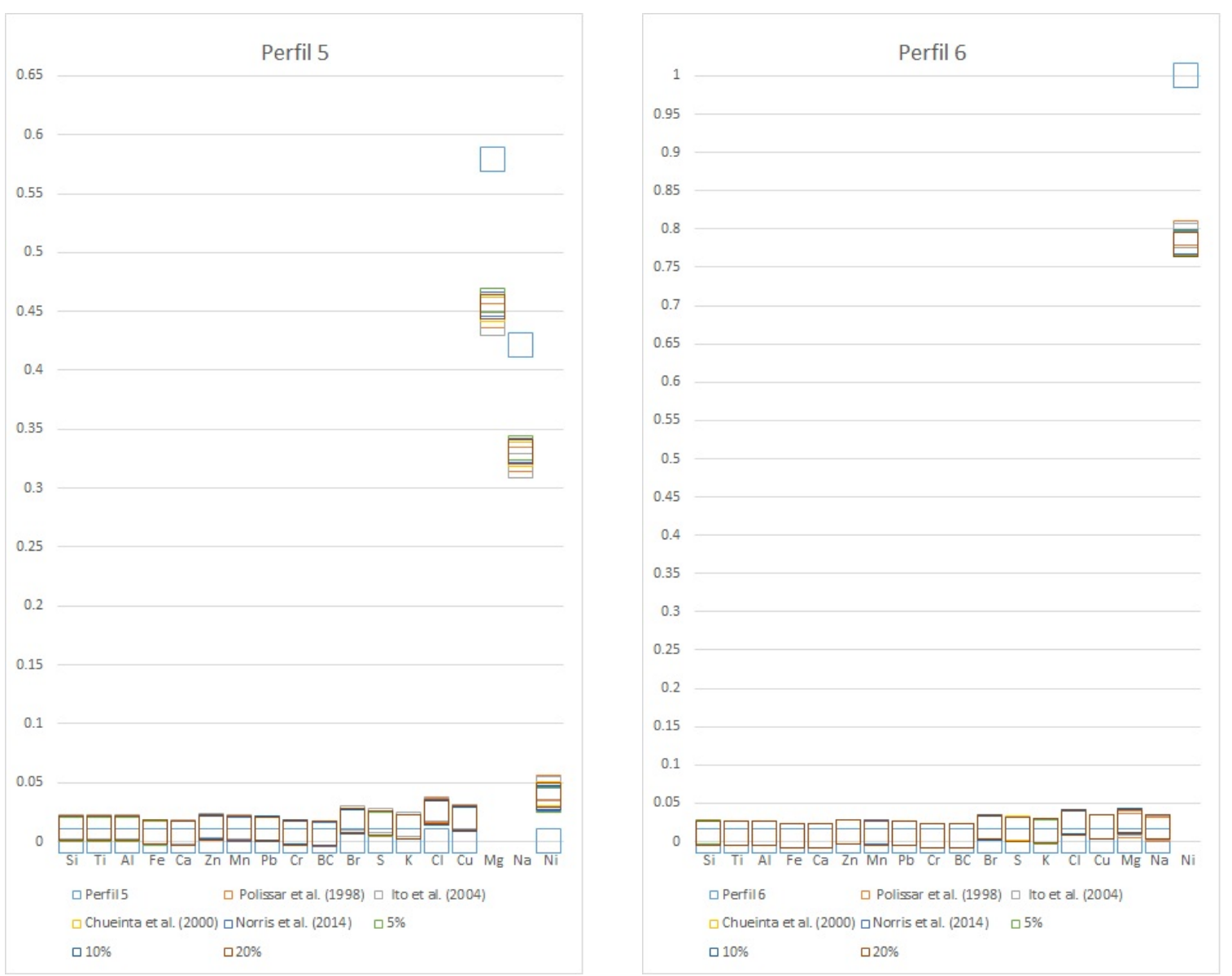

Figura 6.87: Gráfico comparativo para o Perfil 5 Figura 6.88: Gráfico comparativo para o Perfil 6

\section{Sumarização dos resultados}

Para cada cenário de simulação, e para cada proposta de definição de incerteza, também foram sumarizados os valores médios de $Q$ Robusto e os desvios padrões que podem ser verificados nas tabelas a seguir.

Tabela 6.2: Valores médios de Q Robusto e desvios padrões para propostas de incertezas aplicadas em bases simuladas sem outliers

\begin{tabular}{ccc}
\hline \hline Referência & Média(Q Robusto) & Desvio padrão \\
\hline Norris et al. (2014) & 957,40 & 71,98 \\
Polissar et al. $(1998)$ & $2.548,14$ & 155,73 \\
Ito et al. $(2004)$ & 723,14 & 48,81 \\
Chueinta et al. $(2000)$ & 47,07 & 3,88 \\
5\% do valor da medição & 983,80 & 75,79 \\
10\% do valor da medição & 247,46 & 20,41 \\
20\% do valor da medição & 61,87 & 5,11 \\
\hline
\end{tabular}


Tabela 6.3: Valores médios de Q Robusto e desvios padrões para propostas de incertezas aplicadas em bases simuladas com outliers - Dist. Exponencial média 1,5

\begin{tabular}{ccc}
\hline \hline Referência & Média(Q Robusto) & Desvio padrão \\
\hline Norris et al. $(2014)$ & $8.466,29$ & 524,74 \\
Polissar et al. $(1998)$ & $16.366,83$ & $1.013,55$ \\
Ito et al. $(2004)$ & $7.980,65$ & 513,34 \\
Chueinta et al. (2000) & $1.390,02$ & 105,30 \\
$5 \%$ do valor da medição & $8.506,44$ & 525,70 \\
$10 \%$ do valor da medição & $3.939,75$ & 262,48 \\
$20 \%$ do valor da medição & $1.714,25$ & 126,75 \\
\hline
\end{tabular}

Tabela 6.4: Valores médios de Q Robusto e desvios padrões para propostas de incertezas aplicadas em bases simuladas com outliers - Dist. Exponencial média 3

\begin{tabular}{ccc}
\hline \hline Referência & Média(Q Robusto) & Desvio padrão \\
\hline Norris et al. (2014) & $9.610,89$ & 587,19 \\
Polissar et al. $(1998)$ & $18.545,14$ & $1.161,08$ \\
Ito et al. (2004) & $9.169,88$ & 574,52 \\
Chueinta et al. $(2000)$ & $1.725,74$ & 122,50 \\
$5 \%$ do valor da medição & $9.645,40$ & 587,89 \\
$10 \%$ do valor da medição & $4.543,85$ & 292,83 \\
$20 \%$ do valor da medição & $2.081,00$ & 144,24 \\
\hline
\end{tabular}

Tabela 6.5: Valores médios de Q Robusto e desvios padrões para propostas de incertezas aplicadas em bases simuladas com outliers - Dist. Exponencial média 9

\begin{tabular}{ccc}
\hline \hline Referência & Média(Q Robusto) & Desvio dadrão \\
\hline Norris et al. (2014) & $10.913,73$ & 632,56 \\
Polissar et al. $(1998)$ & $21.008,92$ & $1.239,25$ \\
Ito et al. $(2004)$ & $10.554,44$ & 625,02 \\
Chueinta et al. $(2000)$ & $2.126,42$ & 135,84 \\
$5 \%$ do valor da medição & $10.943,21$ & 633,23 \\
$10 \%$ do valor da medição & $5.219,93$ & 316,41 \\
$20 \%$ do valor da medição & $2.495,62$ & 157,53 \\
\hline
\end{tabular}

Para auxiliar a interpretação dos valores médios de $Q$ Robusto também foram calculados os coeficientes de variação de cada cenário simulado, Tabela 6.6.

Tabela 6.6: Coeficiente de variação para Q Robusto nos cenários de simulação

\begin{tabular}{ccccc}
\hline \hline Referência & Sem outliers & Exp média 1,5 & Exp média 3 & Exp média 9 \\
\hline Norris et al. $(2014)$ & 0,0752 & 0,0620 & 0,0611 & 0,0580 \\
Polissar et al. $(1998)$ & 0,0611 & 0,0619 & 0,0626 & 0,0590 \\
Ito et al. $(2004)$ & 0,0675 & 0,0643 & 0,0627 & 0,0592 \\
Chueinta et al. $(2000)$ & 0,0824 & 0,0758 & 0,0710 & 0,0639 \\
$5 \%$ do valor da medição & 0,0770 & 0,0618 & 0,0610 & 0,0579 \\
$10 \%$ do valor da medição & 0,0825 & 0,0666 & 0,0644 & 0,0606 \\
$20 \%$ do valor da medição & 0,0826 & 0,0739 & 0,0693 & 0,0631 \\
\hline
\end{tabular}


Na Tabela 6.7 podemos avaliar a relação de grandeza dos valores médios de Q-Robusto com base na referência Chueinta et al. (2000) em relação às quatro situações de simulação realizadas, e identificar as tendências de uniformização das relações conforme aumenta o tamanho dos outliers.

Tabela 6.7: Relação de grandeza entre os valores médios de Q-Robusto com base na referência Chueinta et al. (2000) para quatro situações de simulação

\begin{tabular}{ccccc}
\hline \hline Referência & $\begin{array}{c}\text { Tabela 6.2 } \\
\text { Sem } \text { outliers }\end{array}$ & $\begin{array}{c}\text { Tabela 6.3 } \\
\text { Exp média 1,5 }\end{array}$ & $\begin{array}{c}\text { Tabela 6.4 } \\
\text { Exp média 3 }\end{array}$ & $\begin{array}{c}\text { Tabela 6.5 } \\
\text { Exp média 9 }\end{array}$ \\
\hline 20 \% do valor da medição & 1,3 & 1,2 & 1,2 & 1,2 \\
10 \% do valor da medição & 5,3 & 2,8 & 2,6 & 2,5 \\
Ito et al. (2004) & 15,4 & 5,7 & 5,3 & 5,0 \\
Norris et al. (2014) & 20,3 & 6,1 & 5,6 & 5,1 \\
$5 \%$ do valor da medição & 20,9 & 6,1 & 5,6 & 5,1 \\
Polissar et al. (1998) & 54,1 & 11,8 & 10,7 & 9,9 \\
\hline
\end{tabular}

Nota-se que essas relações são muito parecidas nos casos em que os bancos de dados possuem outliers, apresentando pequenas variações mesmo tendo outliers com tamanhos diferentes gerados pelas distribuições exponenciais de média 1,5; 3 e 9. Essas relações são maiores se não há outliers, mas notemos que os Q-Robustos médios são bem menores. 


\section{Capítulo 7}

\section{Conclusões e trabalhos futuros}

Ao comparar a matriz com os perfis originais da Tabela 4.2, usada na simulação das bases de dados, com as matrizes contendo os perfis médios da Seção 6.2 - resultantes das aplicações da fatoração PMF nas bases simuladas com as diversas propostas de incertezas -, podemos notar que as porcentagens de massa de cada espécie química dentro de cada perfil tendem a ser distruibuídas de maneira mais homogênea entre as espécies químicas, mas não apresentando grandes alterações entre as proporções internas, e como consequência estas porcentagens resultantes são todas menores do que as dos perfis utilizados para gerar as bases de dados. Embora as porcentagens dentro de cada perfil tenham se reduzido devido à tendência que constatamos de homogeneização dos valores, ainda assim as espécies com elementos traçadores possuem valores que os destacam dentro de cada coluna, não impossibilitando a identificação dos perfis resultantes frente aos originais, pois como constatado, as proporções internas não se alteraram de maneira significante. Ainda ao analisar as matrizes da Seção 6.2, que estão com as células com cores variando de tons de verde a tons de vermelho, de acordo com variação interna das entradas - verde para maiores valores e vermelho para os menores valores - podemos notar a tendência de surgimento de gradientes - nas posições que correpondem aos valores zero da Tabela 4.2 - entre as linhas correspondentes aos blocos com valores diferentes de zero, relativos aos elementos traçadores. Tais variações seguem o decréscimo dos valores das porcentagens dentro dos blocos.

Analisando as matrizes de desvios padrões é possível notar que as linhas correspondentes a blocos menores de elementos traçadores, tenderam a apresentar maiores variações entre as simulações. Embora haja este aumento, os desvios padrões em relação aos valores que representam os elementos traçadores são pequenos.

Apesar do método ter sido aplicado em bases de dados com e sem outliers, os resultados permaneceram sem grandes variações nas porcentagens relativas aos perfis, e sem grandes variações também nos desvios padrões, o que verifica a robustez do método, conforme proposto em Paatero e Tapper (1994). Tal robustez não se verifica nos resultados da aplicação da Análise Fatorial. Podemos notar nas matrizes das Figuras 6.15, 6.37, 6.59 e 6.81, que são cargas fatoriais resultantes da aplicação da Análise Fatorial, que há redução da correlação dos fatores com as variáveis que são os elementos químicos, com aumento da variabilidade dos resultados conforme podemos verificar nas matrizes dos correspondentes desvios padrões nas Figuras 6.16, 6.38, 6.60 e 6.82 .

Analisando as matrizes da Seção 6.2, e os gráficos das Figuras 6.17 a 6.22 sob o ponto de vista da aplicação de diferentes propostas de definição de incertezas, notamos que a adoção de diferentes abordagens não levou a resultados discrepantes nas aplicações das bases de dados que foram obtidas conforme simulação descrita no Capítulo 4.

Ao analisar as Tabelas 6.2, 6.3, 6.4 e 6.5, é possível notar uma grande variação do valor médio de Q-Robusto entre as abordagens de definição de incerteza aplicada em bases de dados com e sem outliers. Estes valores são aparentemente estáveis dentro de cada cenário de simulação, pois apresentam coeficiente de variação pequeno como é possível verificar na Tabela 6.6.

Uma estratégia que pode ser encontrada na literatura sobre como definir o número de fatores, baseia-se em analisar o valor de Q-Robusto, conforme pode ser verificado em Reff et al. (2007), 
seção PMF Analysis, item 2. Esta grande variação nos valores de Q-Robusto conforme a proposta de incerteza adotada revela que tal estratégia pode não ser eficaz.

Nota-se que o valor médio do Q-Robusto descresce quando a incerteza aumenta em termos percentuais do valor da medição.

Tanto os valores de Q-Robusto médio quanto os desvios padrões correspondentes nos métodos propostos por Ito et al. (2004) e Norris et al. (2014) são próximos dos valores Q-Robusto médio de quando se considera a incerteza como sendo $5 \%$ do valor da medição.

Se ordenarmos os valores dos Q-Robustos, a ordem é a mesma nas quatro situações consideradas - do menor para o maior valor, os métodos de Chueinta et al. (2000), 20\% do valor da medição, $10 \%$ do valor da medição, Ito et al. (2004), Norris et al. (2014), 5\% do valor da medição, e Polissar et al. (1998).

Os valores médios de Q-Robusto são menores quando não há outliers, para todos os métodos, e crescem à medida em que aumenta a média da distribuição exponencial que os gerou.

A Tabela 6.7 mostra a relação entre os valores médios de Q-Robusto dos métodos considerados tomando como base o Q-Robusto médio do método de Chueinta et al. (2000), que é o menor.

Nota-se que essas relações são muito parecidas nos casos em que os bancos de dados possuem outliers, apresentando pequenas variações mesmo tendo outliers com tamanhos diferentes gerados pelas distribuições exponenciais de média 1,5; 3 e 9. Essas relações são maiores se não há outliers, mas notemos que os Q-Robustos médios são bem menores.

Em trabalhos futuros de análise do método PMF, há possibilidade de simular bases de dados em que a distribuição utilizada na geração seja gama ou weibull, e também inserir outliers mais concentrados em determinadas variáveis, ao contrário da abordagem uniforme aplicada neste trabalho, conforme descrito na Seção 4.5. A simulação de bases de dados com existência de sequências de dados obtidos de distribuições diferentes, representando efeitos de sazonalidade, também seria de grande interesse para estudo de comportamento do método PMF, e do uso de recursos como bootstrap, descrito na Seção 3.1.5. Conforme discutimos na Seção 2.2.1, existem diversos algoritmos para se obter a fatoração $G F$ da matriz de dados. No trabalho de Ramadan et al. (2003), é feita uma comparação de resultados entre a versão do software ME-2, que o é utilizado no EPA PMF 5.0 e o software PMF2 que era utilizado em versões anteriores do EPA PMF. Em trabalhos futuros, há a possibilidade de realizar uma comparação como esta, mas utilizando outros algoritmos, como por exemplo, o apresentado em Wang et al. (2006), que é uma adaptação do algoritmo apresentado em Lee e Seung (1999), mas com a possibilidade de inserir as incertezas de medição. 


\section{Apêndice A}

\section{Códigos}

\section{A.1 Implementação Computacional - SAS}

1

2

3 libname simRecCo

ComOutliers";

4

5 \%MACRO simRecifeCMB (n);

6

$7 \%$ do i $=1 \%$ to \&n;

8

9

10

11

12

13

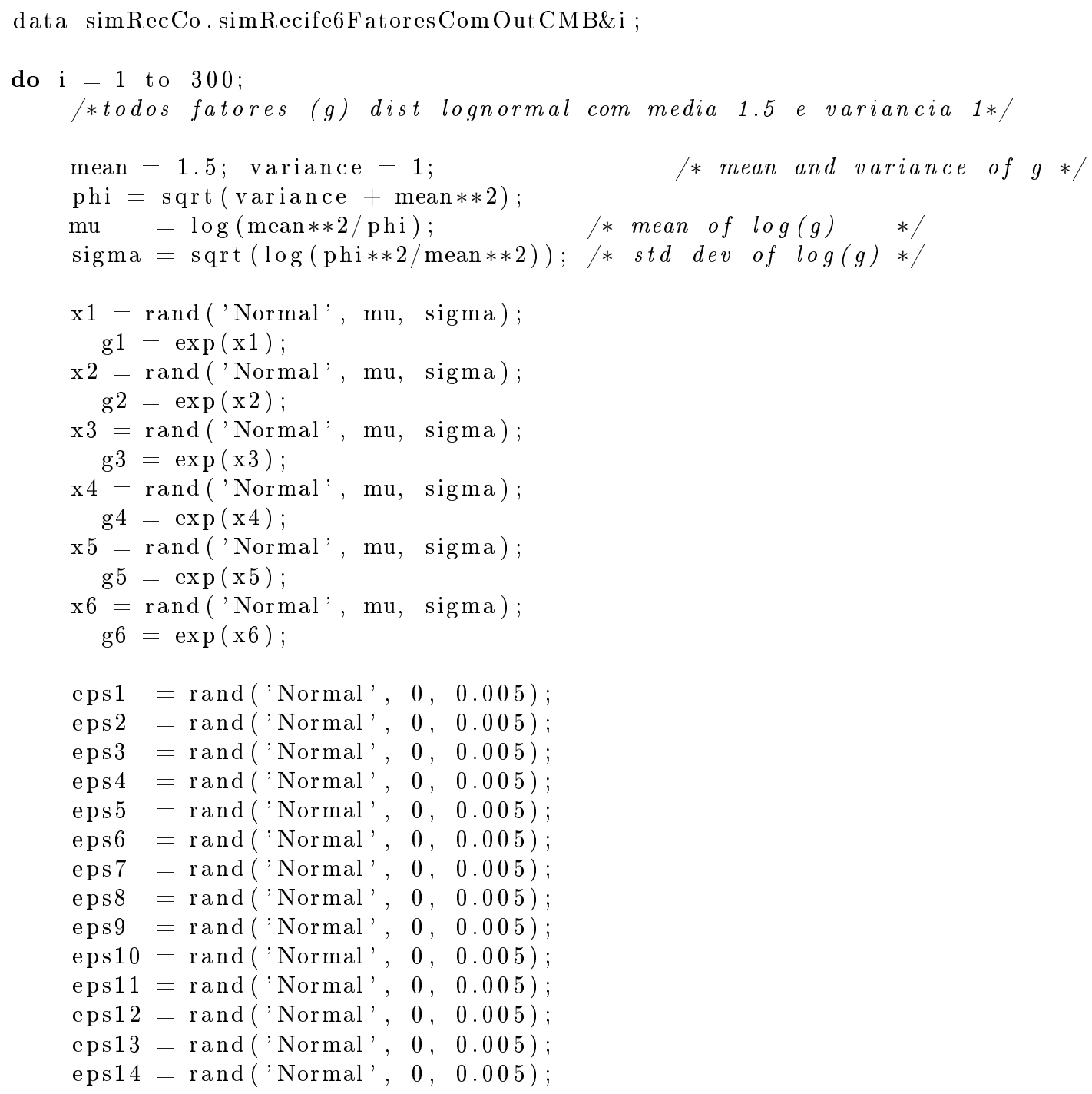




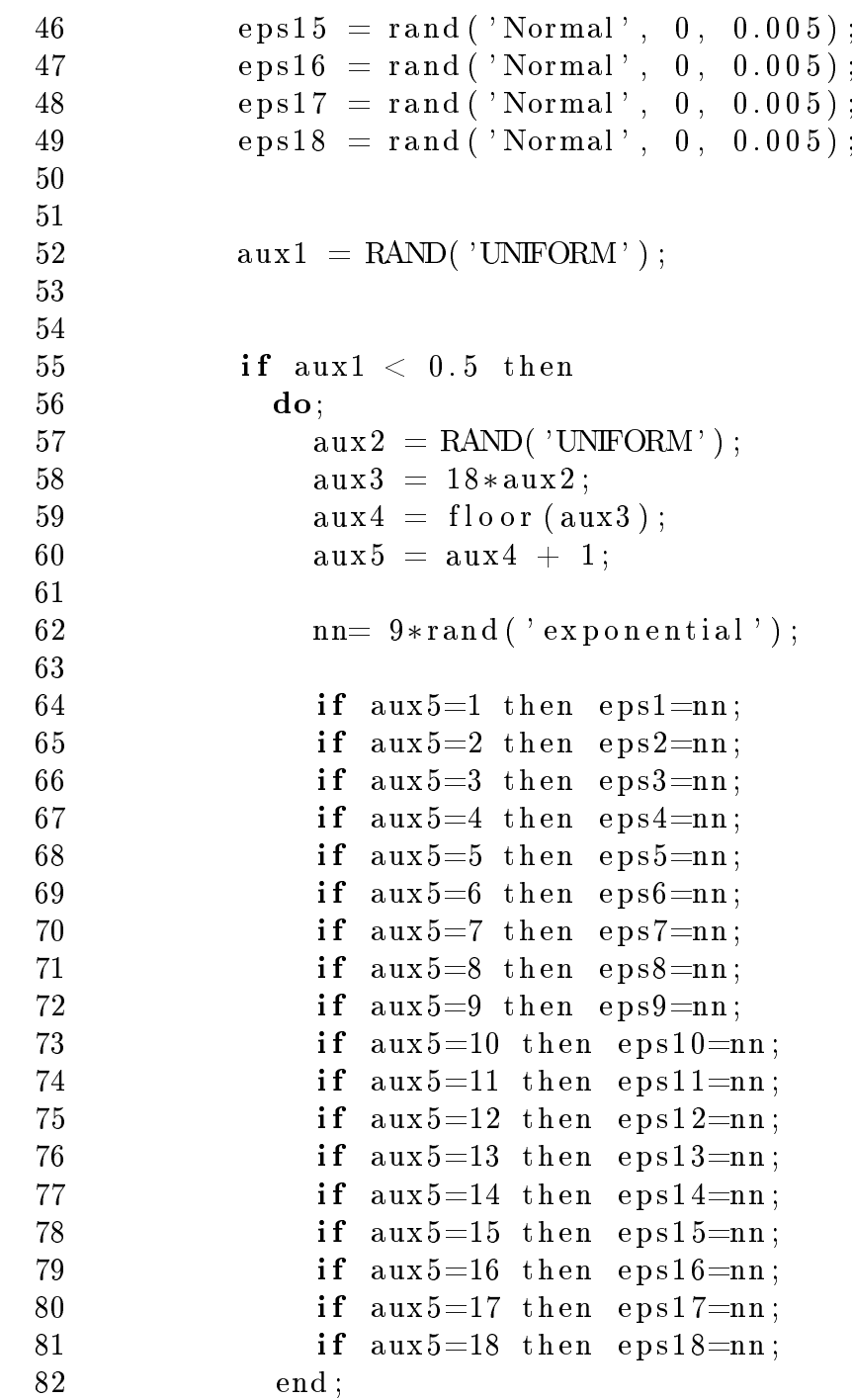

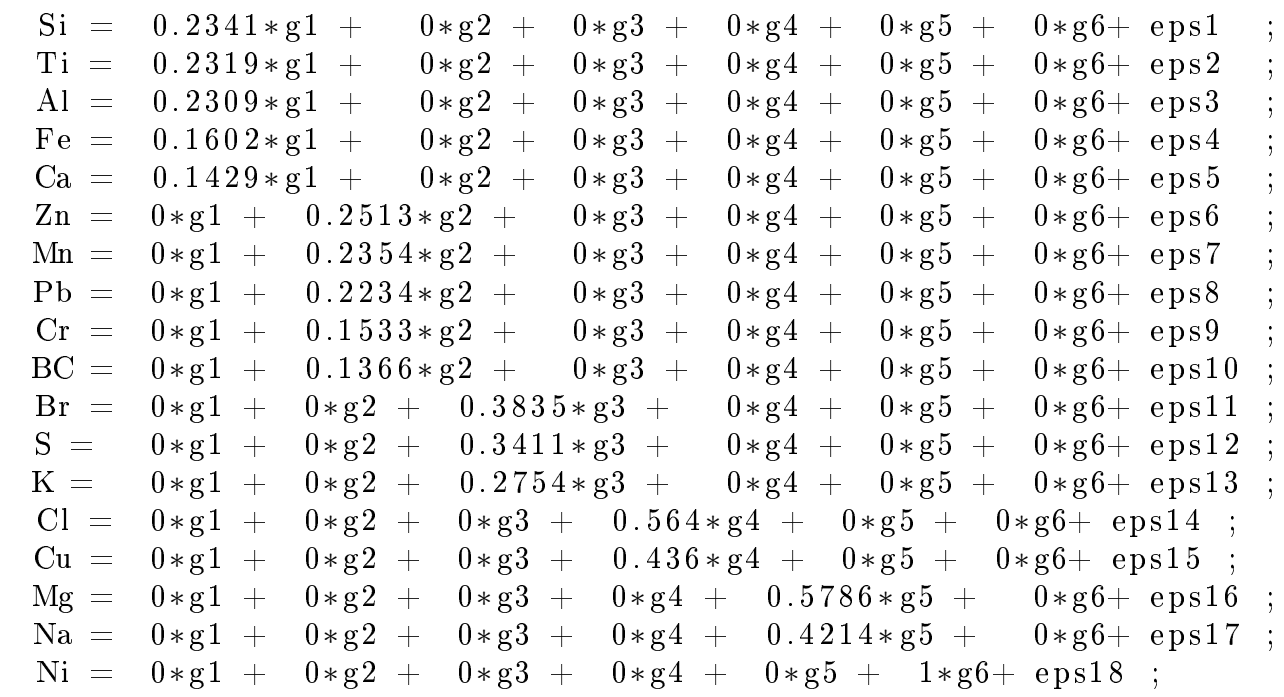

output ;

end ;

110 drop i mean variance phi mu sigma x1 g1 x2 g2 x3 g3 x4 g4 x5 g5 x6 g6 eps1 


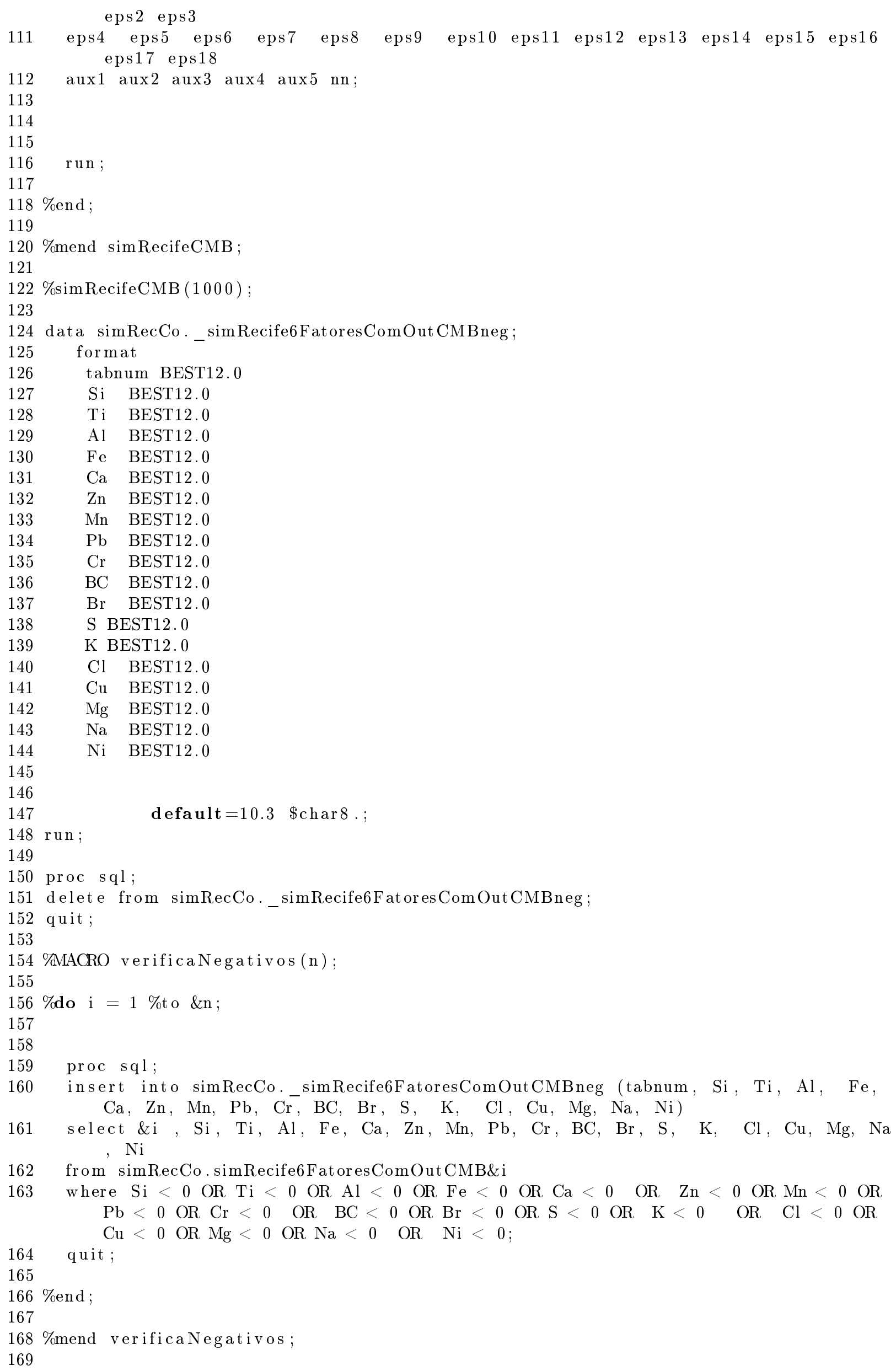


$170 \%$ verificaNegativos $(1000)$;

171

172

173

$174 \%$ MACRO exportsimRecifeCMB (n);

$175 \%$ do i $=1 \%$ to \&n;

176 proc export data=simRecCo.simRecife6FatoresComOutCMB\&i

177 outfile= "F: $\backslash$ MAE_Dissertacao $\backslash$ Multivar $\backslash$ SimPMF $\backslash$ Bases_SAS $\backslash$ SimArtRecife $\backslash$ ComOutliers $\backslash$ simRecife6FatoresComOutCMB_\&i ..txt"

$178 \quad$ dbms $=$ dlm;

179 delimiter=" , " ;

$180 \quad$ putnames $=$ no;

181 run;

$182 \%$ end;

$183 \%$ mend exportsimRecifeCMB ;

184

185 \%exportsimRecifeCMB (1000);

186

$187 \%$ MACRO afsimRecifeCMB (n);

188

$189 \%$ do i $=1 \%$ to \&n;

190 PROC FACTOR DATA=simRecCo.simRecife6FatoresComOutCMB\&i norm=raw METHOD=PRIN NFACTORS $=6$ NOPRINT

191 ROTATE-varimax OUTSTAT=simRecCo. AFsimRecife6FatoresComOutCMB\&i ;

$\begin{array}{lllllllllllllllllllllll}192 & \text { VAR } & \mathrm{Si} & \mathrm{Ti} & \mathrm{Al} & \mathrm{Fe} & \mathrm{Ca} & \mathrm{Zn} & \mathrm{Mn} & \mathrm{Pb} & \mathrm{Cr} & \mathrm{BC} & \mathrm{Br} & \mathrm{S} & \mathrm{K} & \mathrm{Cl} & \mathrm{Cu} & \mathrm{Mg} & \mathrm{Na} & \mathrm{Ni}\end{array}$

193

$194 ;$

195 run;

196

197 \%end;

198

199

$200 \%$ mend afsimRecifeCMB;

$201 \%$ afsimRecifeCMB (1000);

202

203

204 data simRecCo. AF todas;

205 format

206 Si BEST12.0

207 Ti BEST12.0

$208 \quad$ Al BEST12.0

209 Fe BEST12.0

210 Ca BEST12.0

211 Zn BEST12.0

212 Mn BEST12.0

$213 \mathrm{~Pb}$ BEST12.0

214 Cr BEST12.0

215 BC BEST12.0

$216 \quad \mathrm{Br}$ BEST12.0

217 S BEST12.0

218 K BEST12.0

219 Cl BEST12.0

$220 \quad \mathrm{Cu}$ BEST12.0

$221 \quad \mathrm{Mg}$ BEST12.0

222 Na BEST12.0

223 Ni BEST12.0

227 run ;

230 delete from simRecCo._AF_todas;

231 quit; 


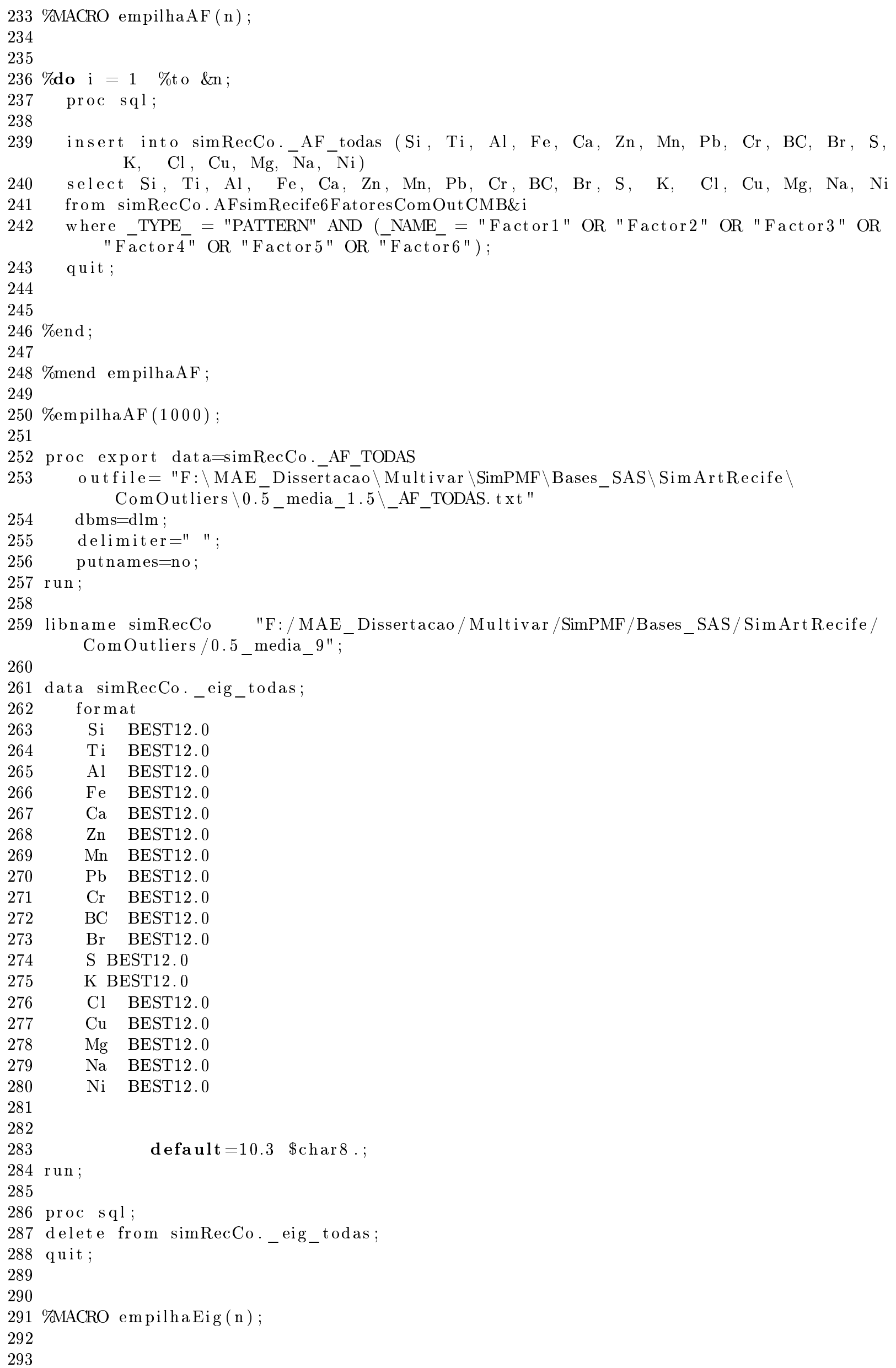


$294 \%$ do $\mathrm{i}=1 \%$ to \&n;

295 proc sql;

296

297

insert into simRecCo. eig todas ( $\mathrm{Si}, \mathrm{Ti}, \mathrm{Al}, \mathrm{Fe}, \mathrm{Ca}, \mathrm{Zn}, \mathrm{Mn}, \mathrm{Pb}, \mathrm{Cr}, \mathrm{BC}, \mathrm{Br}$, $\mathrm{S}, \mathrm{K}, \mathrm{Cl}, \mathrm{Cu}, \mathrm{Mg}, \mathrm{Na}, \mathrm{Ni}$ )

298 select $\mathrm{Si}, \mathrm{Ti}, \mathrm{Al}, \mathrm{Fe}, \mathrm{Ca}, \mathrm{Zn}, \mathrm{Mn}, \mathrm{Pb}, \mathrm{Cr}, \mathrm{BC}, \mathrm{Br}, \mathrm{S}, \mathrm{K}, \mathrm{Cl}, \mathrm{Cu}, \mathrm{Mg}, \mathrm{Na}, \mathrm{Ni}$

299 from simRecCo.AFsimRecife6Fatores Com OutCMB\&i

300 where _TYPE_ = "EIGENVAL" ;

301 quit;

302

303

$304 \%$ end ;

305

$306 \%$ mend empilhaEig;

307

308 \%empilhaEig (1000);

309

310

311 proc sql;

312 select

313 mean( $\mathrm{Si}$ ) as Media_AV_1,

314 mean $(\mathrm{Ti})$ as Media_AV_2,

315 mean $(\mathrm{Al})$ as Media_AV_3,

316 mean $(\mathrm{Fe})$ as Media $\mathrm{AV}^{-}$,

317 mean $(\mathrm{Ca})$ as Media $\mathrm{AV}^{-} 5$,

318 mean $(\mathrm{Zn})$ as Media_AV_6,

319 mean (Mn) as Media $\mathrm{AV}^{-} 7$,

320 mean $(\mathrm{Pb})$ as Media_AV_8,

321 mean $(\mathrm{Cr})$ as Media_AV_9,

322 mean (BC) as Media_AV_10,

323 mean $(\mathrm{Br})$ as Media $\mathrm{AV}^{-} 11$,

324 mean $(\mathrm{S})$ as Media_AV_12,

325 mean $(\mathrm{K})$ as Media AV 13,

326 mean $(\mathrm{Cl})$ as Media $\_A \bar{V} \_14$,

327 mean $(\mathrm{Cu})$ as Media $\mathrm{AV}^{-} 15$,

328 mean $(\mathrm{Mg})$ as Media_AV_16,

$329 \operatorname{mean}(\mathrm{Na})$ as Media $\mathrm{AV}^{-} 17$,

330 mean $(\mathrm{Ni})$ as Media_AV_18

331

332 from simRecCo._eig_todas

333

334 quit;

\section{A.2 Implementação Computacional - C}

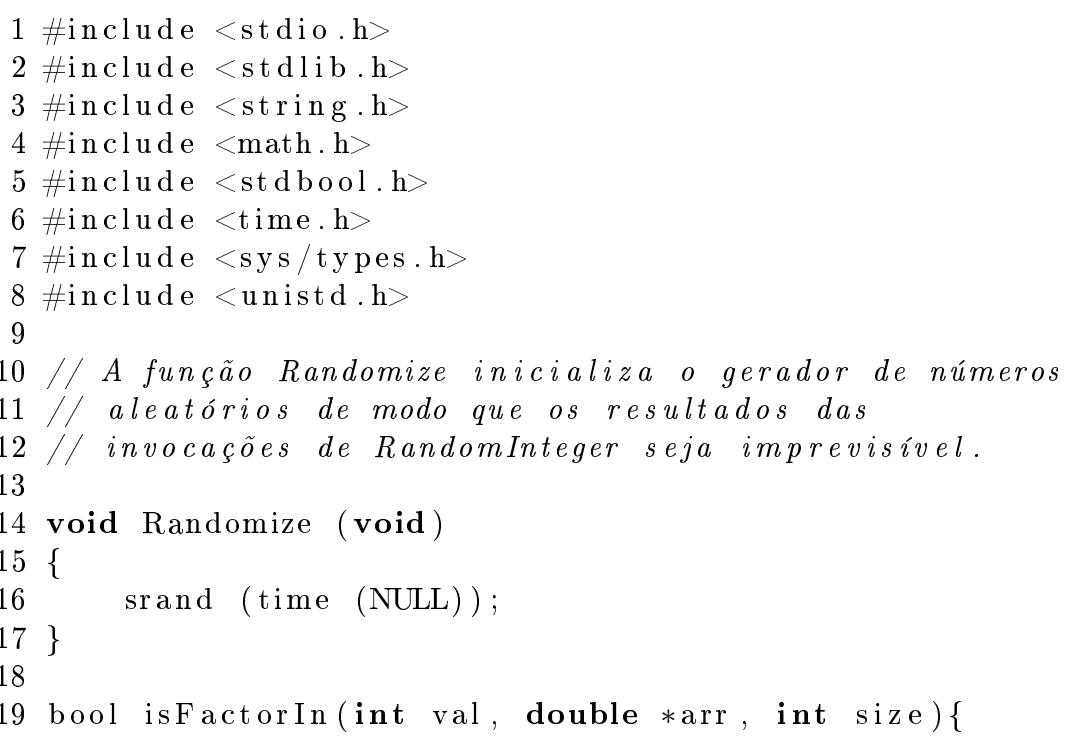




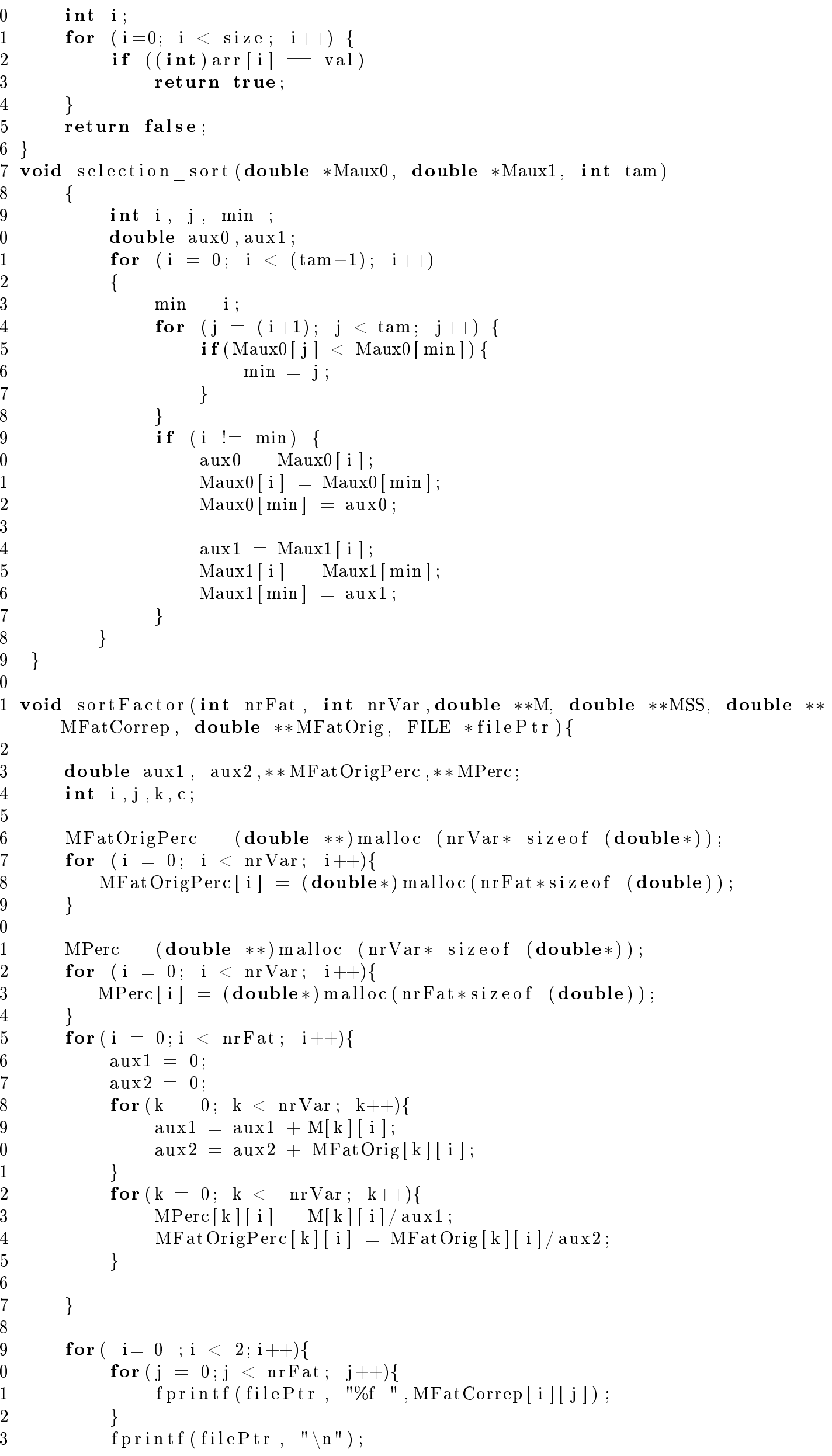




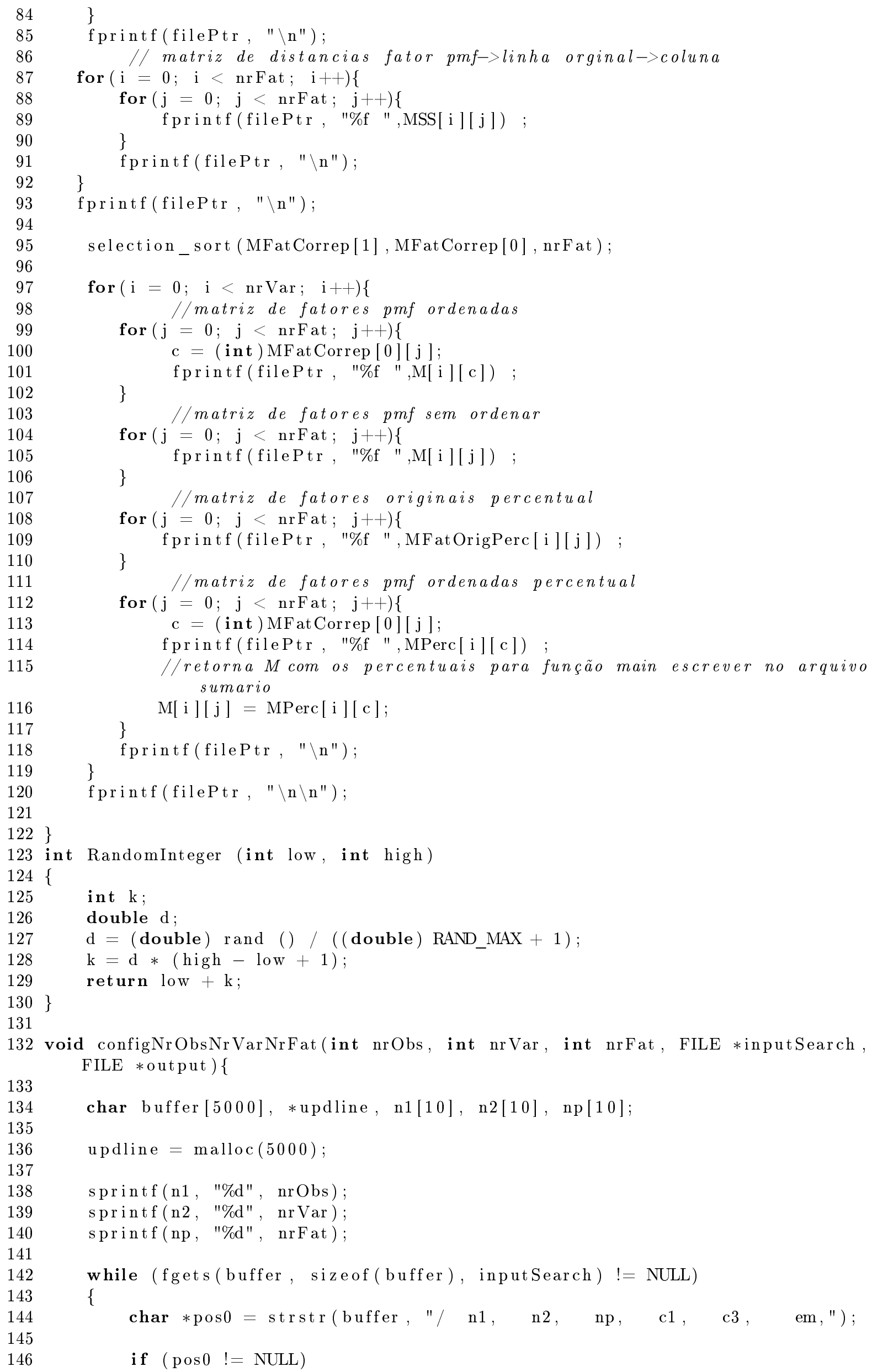




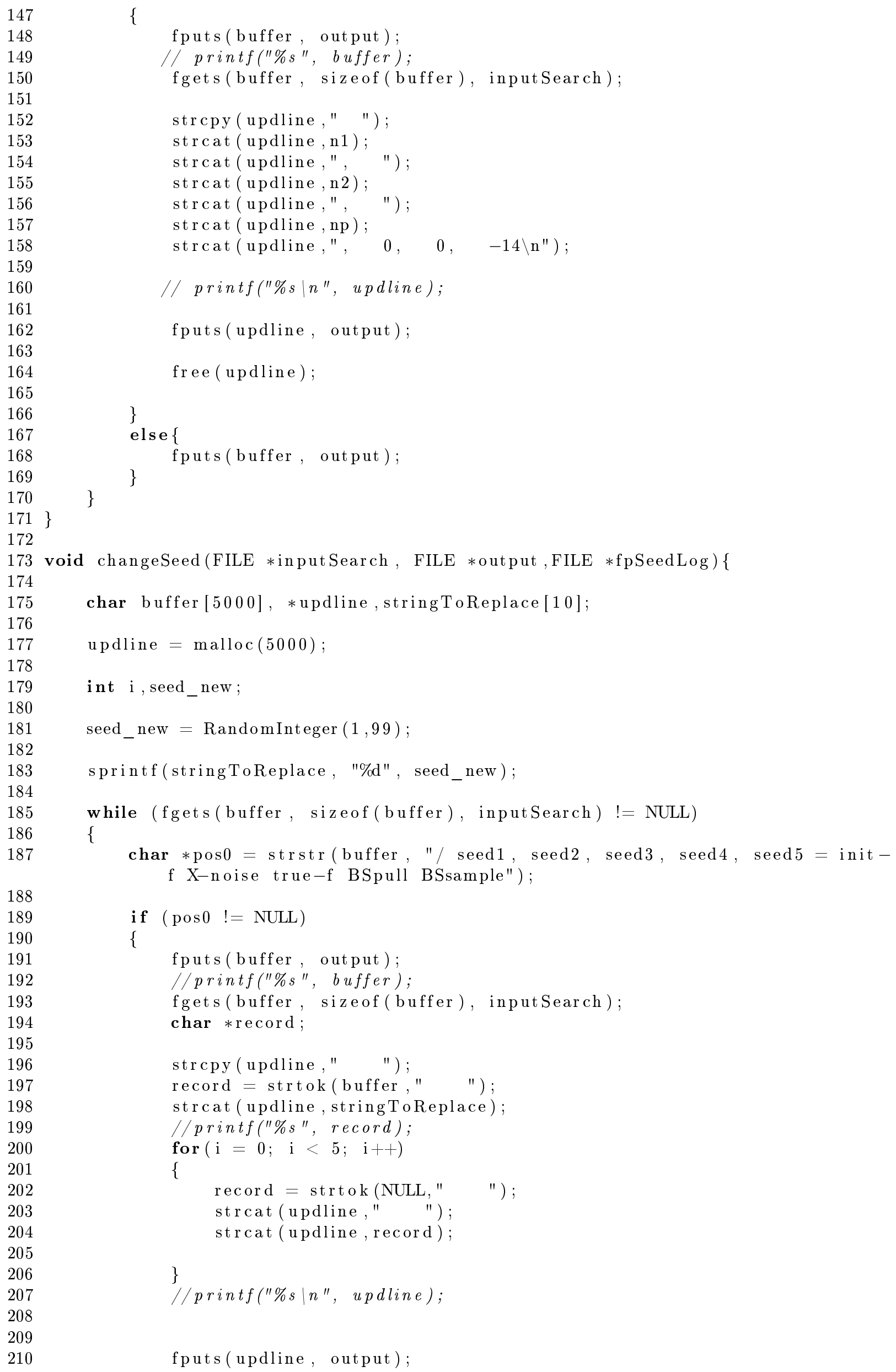


211

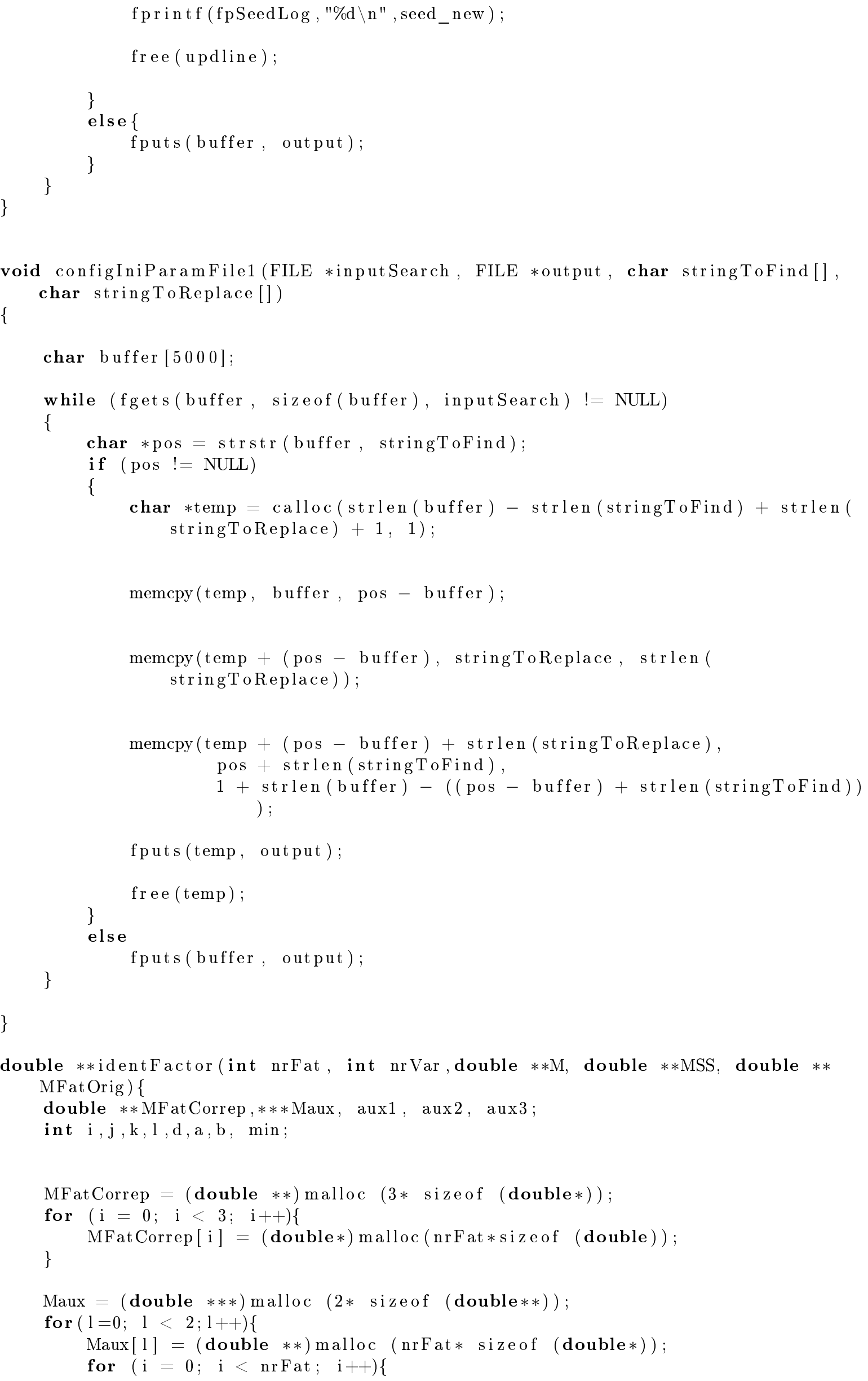


299

300

301

302

303

304

305

306

307

308

309

310

311

312

313

314

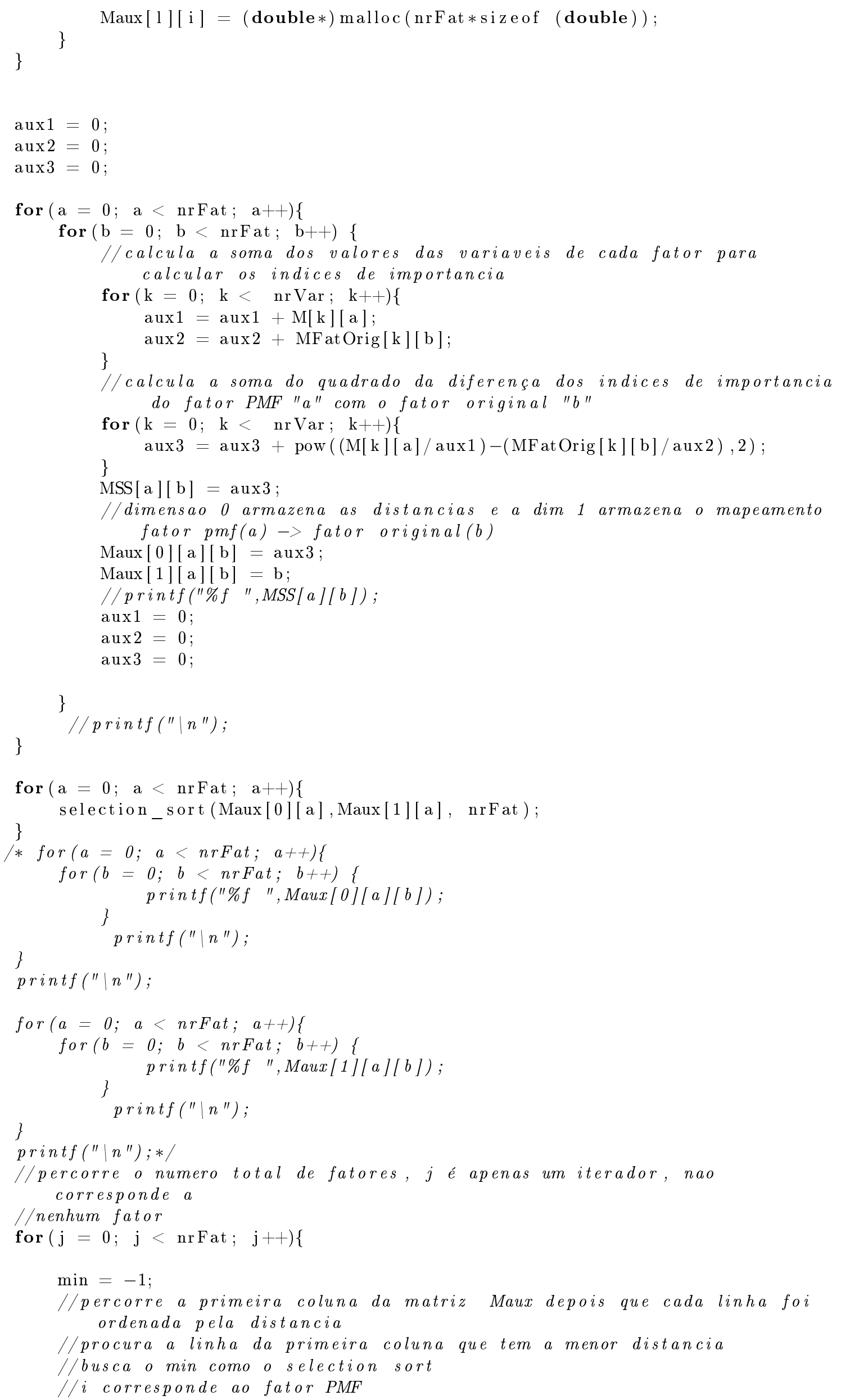


331

332

333

334

335

336

337

338

339

340

341

342

343

344

345

346

347

348

349

350

351

352

353

354

355

356

357

358

359

360

361

362

363

364

365

366

367

368

369

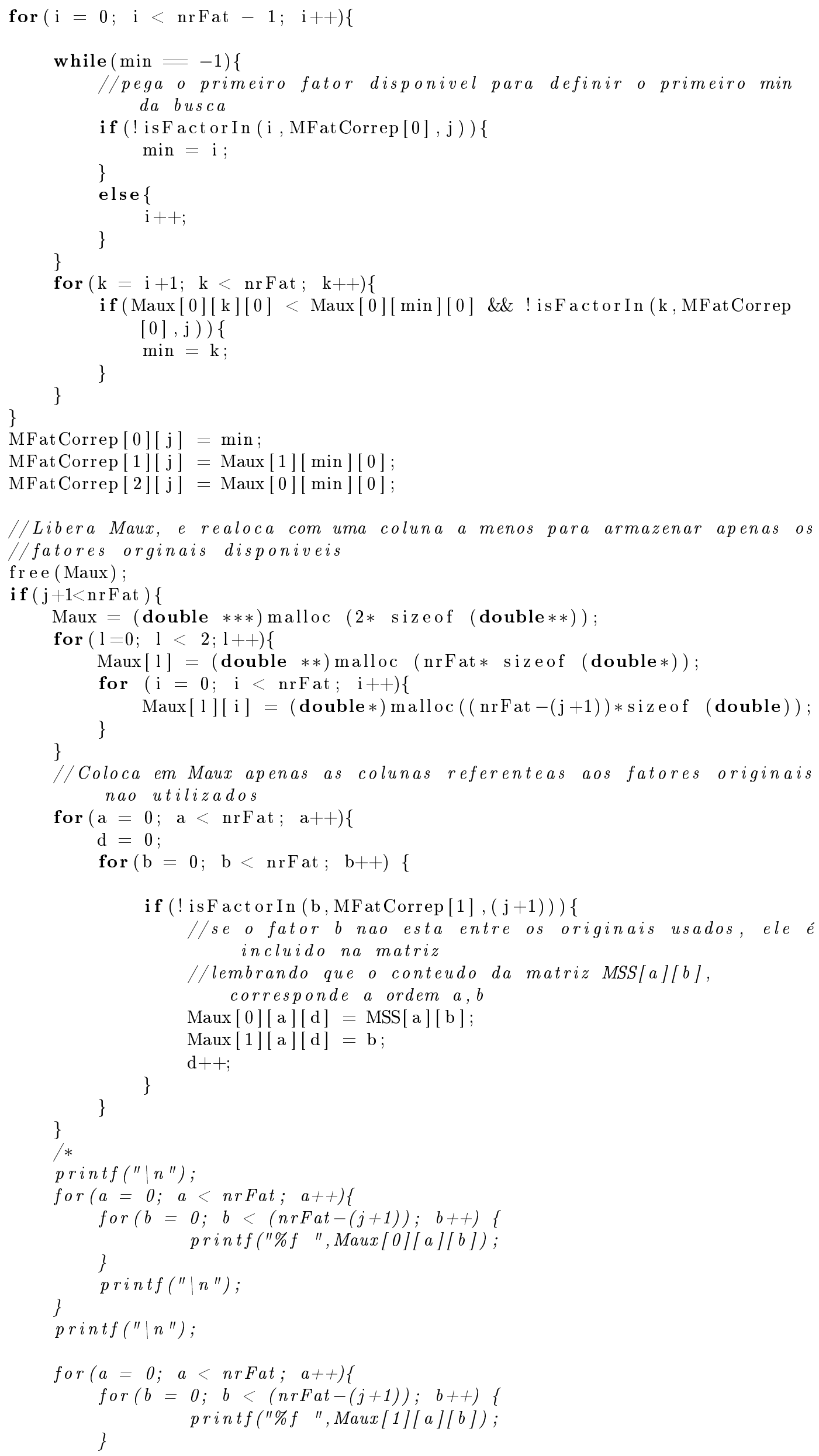




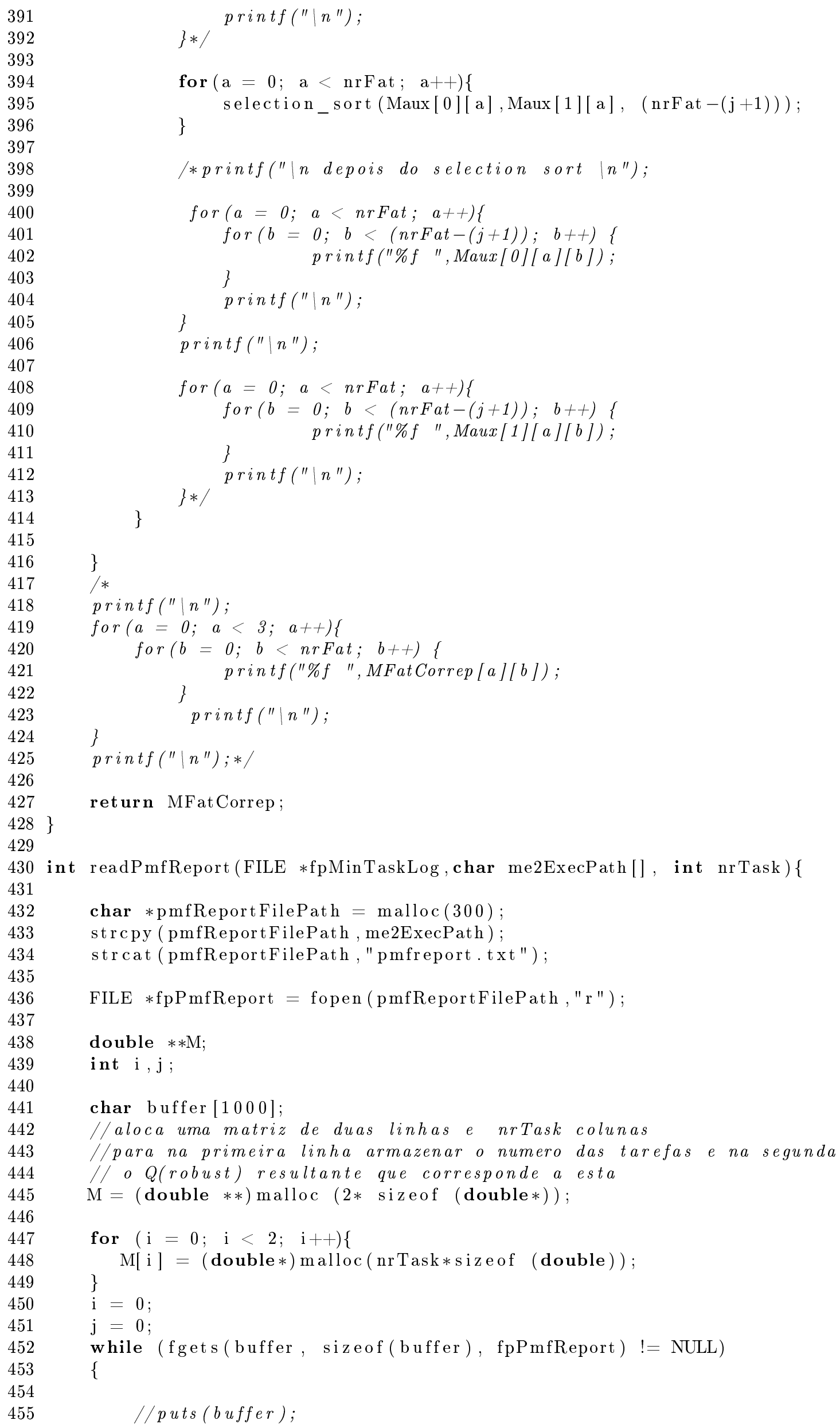


456

457

458

459

460

461

462

463

464

465

466

467

468

469

470

471

472

473

474

475

476

477 *

478

479

480

481

482

483

484

485

486

487

488

489

490

491

492

$493\}$

494

495

496 double $* *$ readOutputFile(int nrFat, int nrVar, int nrObs, char filename[], int $\operatorname{minTask})\{$

497

498

499

500

501

502

503

504

505

506

507

508

509

510

511

512

513

514

515

516

517

char $*$ record;

record = strtok (buffer," ");

$\mathrm{M}[0][\mathrm{j}]=$ (double) strtod (record , NULL);

$/$ numero de colunas no arquivo pmfreport.txt, pega somente a terceira for $(\mathrm{i}=0 ; \mathrm{i}<10 ; \mathrm{i}++)$

\{

if $(\mathrm{i}=2)\{$

$\mathrm{M}[1][\mathrm{j}]=($ double $) \operatorname{strtod}(\operatorname{record}, \mathrm{NULL}) ;$

\}

\} record $=$ strtok (NULL, " ") ;

\}

/*

for $(i=0 ; i<2 ; i++)\{$

for $(j=0 ; j<n r T a s k ; j++)\{$

\}

printf("\%lf ", $M[i][j])$;

printf ("|n");

\}

puts ("depois do selection sort");

selection_sort (M[1],M[0],nrTask);

for $(i=0 ; i<2 ; i++)\{$

for $(j=0 ; j<n r$ Task $; j++)\{$

printf("\%lf ", $M[i][j])$;

\}

\}$* /$

printf $(" \mid n ")$;

fclose (fpPmfReport);

free ( pmfReportFilePath);

fprintf (fpMinTaskLog, "\%d $\%$ lf $\backslash \mathrm{n}^{\prime}$, , int $) \mathrm{M}[0][0], \mathrm{M}[1][0]$ );

return (int) $\mathrm{M}[0][0]$

FILE $* \mathrm{file}$;

double $* * \mathrm{M}$;

double $\mathrm{n} 1$;

int i, k, l, ptrPos;

ptrPos $=0$;

$\mathrm{M}=($ double $* *)$ malloc $($ nrVar $*$ sizeof $\quad($ double $*))$

for $(\mathrm{i}=0 ; \mathrm{i}<\operatorname{nrVar} ; \mathrm{i}++)\{$

$\mathrm{M}[\mathrm{i}]=($ double $*)$ malloc $($ nrFat $*$ sizeof (double) $)$;

\}

file $=$ fopen (filename, "r");

int count $=0$;

if ( file $!=$ NULL )

\{

$\mathrm{k}=0$;

$1=0$;

//como no arquivo PMF_ab_baseXX.dat é gravado todas as tarefas, é necessario posicioñar

// o ponteiro de leitura no inicio da matriz de fatores gerada pelo tarefa minTask

/ que gerou o menor menor $Q($ robusto $)$ 


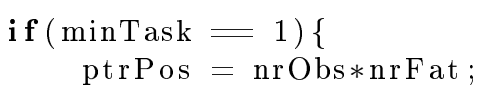




$\begin{array}{ll}580 & \mathrm{LD}[15]=0.015 ; \\ 581 & \mathrm{LD}[16]=0.03 ; \\ 582 & \mathrm{LD}[17]=0.0003 \\ 583 & \mathrm{u}\end{array}$

602

603

604

605

606

607

608

609

610

611

612

613

614

615

616

617

618

619

620

621

622

623

624

625

626

627

628

629

630

631

632

633

634

635

636

637

638

639

640

$\mathrm{M}=($ double $* *)$ malloc $($ nrObs $*$ sizeof $($ double $*))$;

for $(\mathrm{i}=0 ; \mathrm{i}<\operatorname{nrObs} ; \mathrm{i}++)\{$ \}

$\mathrm{M}[\mathrm{i}]=($ double $*)$ malloc $($ nrVar $*$ sizeof $\quad($ double $))$;

char Mchar [15];

char buffer [1 1024$]$;

char *record, $*$ line ;

if (file != NULL)

\{

$$
\begin{aligned}
& \mathrm{i}=0 ; \\
& \mathrm{j}=0 ; \\
& / / \text { while ((line=fgets (buffer, sizeof (buffer), file))!=NULL) }
\end{aligned}
$$$$
\text { for }(\mathrm{i}=0 ; \mathrm{i}<\operatorname{nrObs} ; \mathrm{i}++)
$$$$
\{
$$$$
\text { line }=\text { fgets (buffer, size of (buffer), file ); }
$$$$
/ / p u t s(\text { line); }
$$$$
\text { record = strtok (line," ,"); }
$$

$/ /$ while (record $!=N U L L)$

for $(\mathrm{j}=0 ; \mathrm{j}<\operatorname{nrVar} ; \mathrm{j}++)$

\{

//printf("\%.12f ",(double) atof(record));

$\mathrm{M}[\mathrm{i}][\mathrm{j}]=$ (double $) \operatorname{strtod}($ record, NULL $)$;

//printf("\%.12f ",M[i][j]);

\} record = strtok (NULL, "," );

$/ / p \operatorname{rintf}\left("|n \% d| n^{\prime \prime}, i\right)$;

\}

\}

else \{

printf("Nao foi possivel abrir o arquivo de entrada(insertUncertainty) $\left.\mathrm{n}^{\prime \prime}\right)$

system ("pause");

exit $(0)$;

\} 


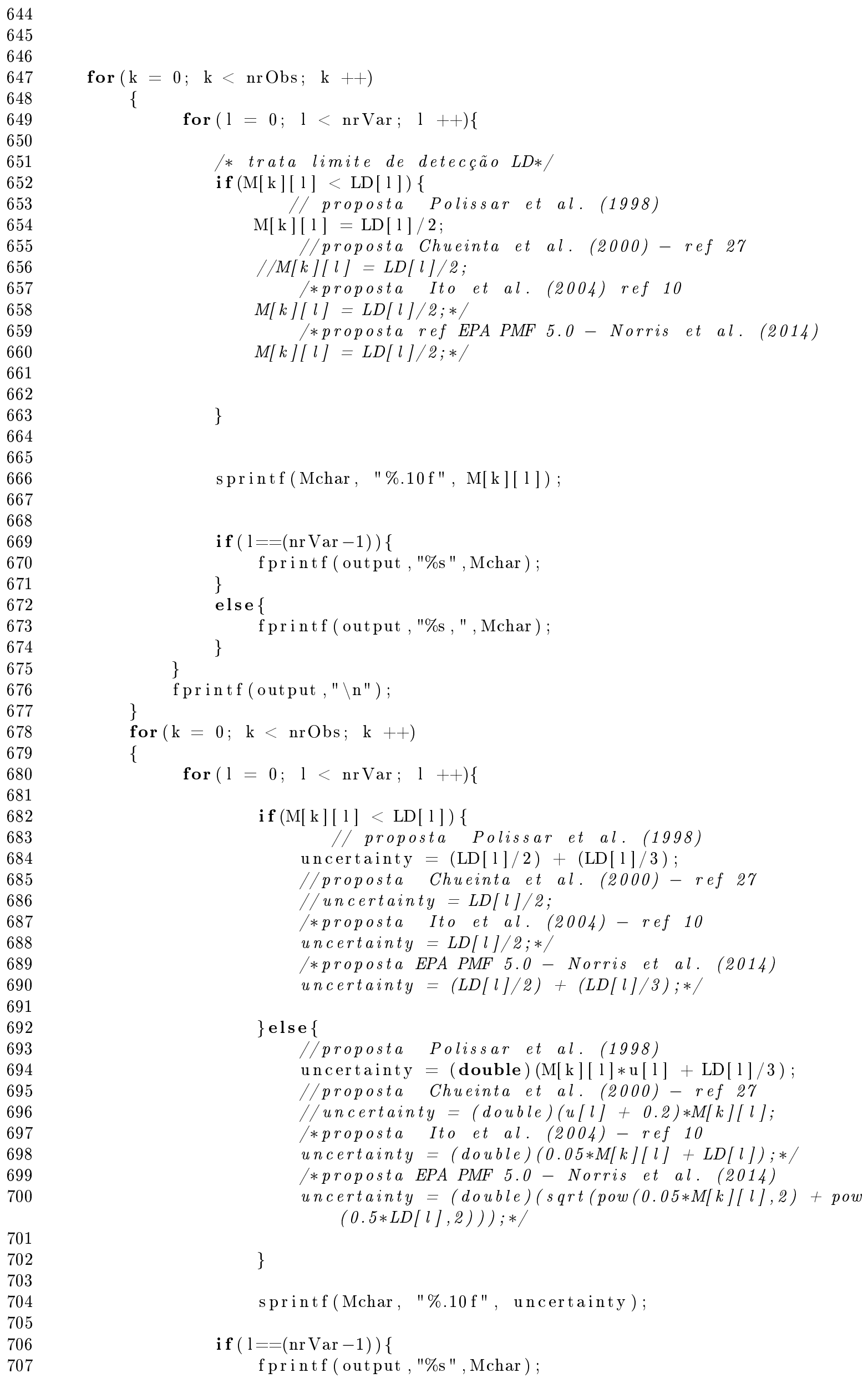




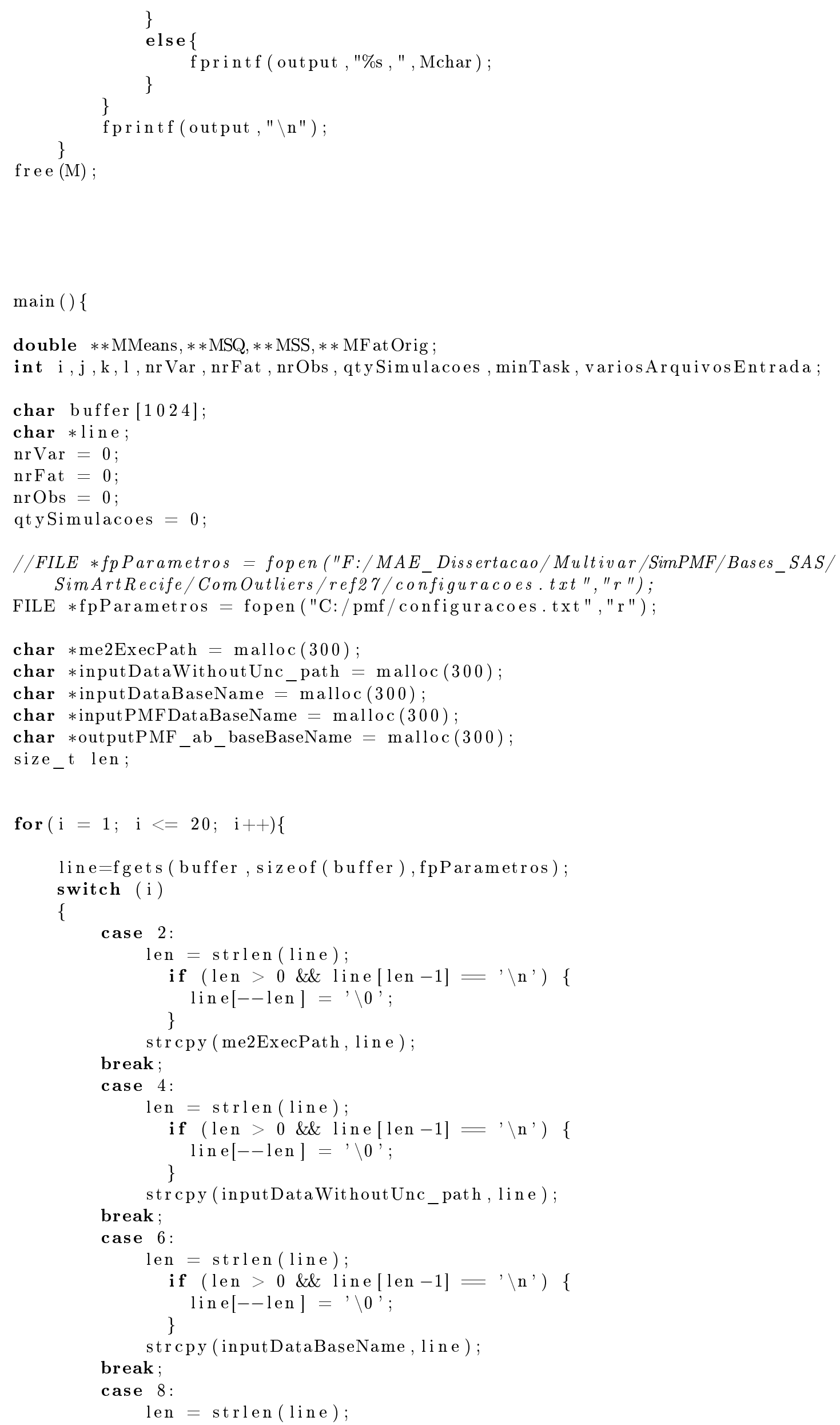




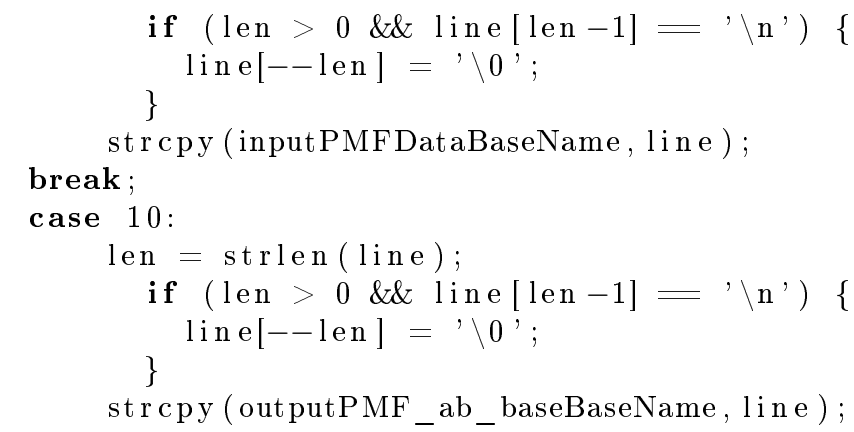

break;

case 12 :

break;

varios ArquivosEntrada = atoi (line);

case 14 :

qtySimulacoes $=$ atoi (line);

break;

case 16 :

$\operatorname{nrObs}=\operatorname{atoi}(\operatorname{line})$;

break;

case 18 :

nrVar $=\operatorname{atoi}($ line $)$;

break;

case 20 :

break; nrFat $=$ atoi $($ line $)$;

\}

\}

fclose (fpParametros);

char $*$ seedLogPath $=$ malloc $(300)$;

strcpy ( seedLogPath, me2ExecPath);

strcat ( seedLogPath, "Seeds.txt");

char $*$ minTaskLogPath $=$ malloc $(300)$;

strcpy (minTaskLogPath, me2ExecPath);

strcat (minTaskLogPath, "minTaskLog.txt");

char $*$ sumarioPath $=$ malloc $(300)$;

strcpy (sumarioPath, me2ExecPath);

strcat (sumarioPath, "sumario.txt");

char $*$ fatOrigPath $=$ malloc $(300) ;$

strcpy (fatOrigPath, me2ExecPath);

strcat (fatOrigPath, "loads1.txt");

char $*$ saidaPath $=$ malloc $(300)$;

strcpy (saidaPath, me2ExecPath);

strcat (saidaPath, "saida.txt");

FILE $*$ fpSeedLog $=$ fopen $($ seedLogPath,$" w ") ;$

FILE $*$ fpMinTaskLog $=$ fopen $(\operatorname{minTaskLogPath}, " w ")$;

FILE $*$ fpSumario = fopen (sumarioPath, "w");

FILE $*$ fpFatOrig $=$ fopen (fatOrigPath, "r");

FILE $*$ fpSaida $=$ fopen $($ saidaPath, "w" );

free ( seedLogPath);

free (minTaskLogPath);

free (sumarioPath);

free (fatOrigPath);

free (saidaPath); 
837

838

839

840

841

842

843

844

845

846

847

848

849

850

851

852

853

854

855

856

857

858

859

860

861

862

863

864

865

866

867

868

869

870

871

872

873

874

875

876

877

878

879

880

881

882

883

884

885

886

887

888

889

890

891

892

893

894

895

896

897

898

899

//Randomize () ;

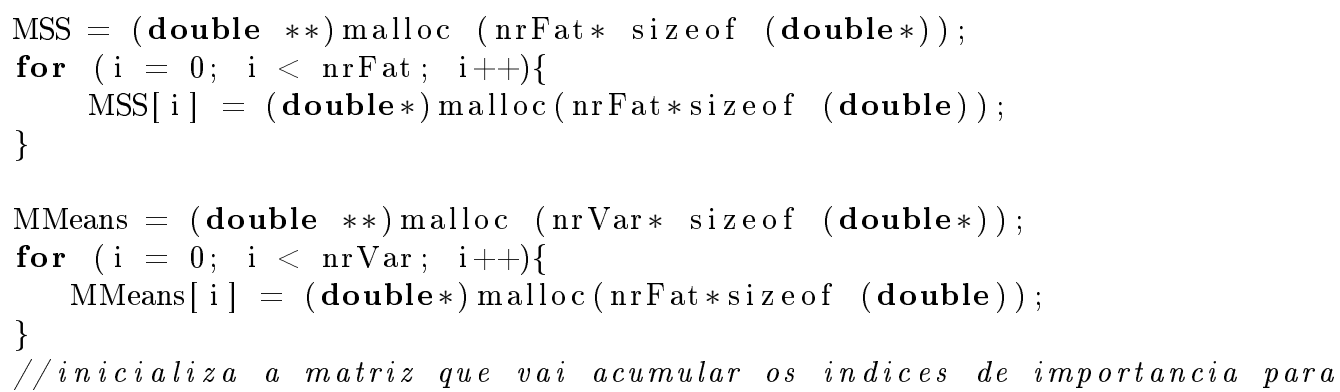


strcpy (systemExecME2FilePath, me2ExecPath); strcat (systemExecME2FilePath, "me2gfP4_1345c4.exe PMF_bs_6f8xx_sealed_GUI. ini");

printf("\n \%d \n", qtySimulacoes );

for $(\mathrm{i}=1 ; \mathrm{i}<=$ qtySimulacoes $; \mathrm{i}++)\{$

double $* * \mathrm{M}, \quad * *$ MFatCorrep;

char ichar [3];

sprintf(ichar, "\%d", i );

char $*$ inputDataWithUnc pathFileName $=$ malloc $(300)$;

char $*$ outputDataWithUnc_pathFileName $=$ malloc $(300)$;

strcpy (inputDataWithUnc_pathFileName, inputDataWithoutUnc_path); strcat (inputDataWithUnc_pathFileName, inputDataBaseName);

strcpy (outputDataWithUnc pathFileName, me2ExecPath); strcat (outputDataWithUnc_pathFileName, inputPMFDataBaseName);

if (varios ArquivosEntrada $=0)\{$ \} strcat (inputDataWithUnc_pathFileName, ichar);

strcat (inputDataWithUnc_pathFileName,".txt");

strcat (outputDataWithUnc_pathFileName, ichar);

strcat (outputDataWithUnc_pathFileName,".txt");

FILE $*$ fpInputDataWithoutUnc $=$ fopen (inputDataWithUnc pathFileName, "a+"); FILE $*$ fpOutputDataWithUnc $=$ fopen(outputDataWithUnc_pathFileName, "w" ); insert Uncertainty ( nrVar, nrObs, fpInputDataWithoutUnc, fpOutputDataWithUnc) ;

fclose (fpInputDataWithoutUnc); fclose (fpOutputDataWithUnc);

free (inputDataWithUnc_pathFileName); free (outputDataWithUnc_pathFileName);

char $*$ main_data_filename $=$ malloc $(50)$;

char *previous_results_filename $=$ malloc $(50)$;

char *output_filename $=$ malloc $(50)$;

strcpy (main_data_filename, inputPMFDataBaseName);

strcpy (previous_results_filename, outputPMF_ab_baseBaseName); strcpy (output_filename, outputPMF_ab_baseBaseName);

strcat (main_data_filename, ichar);

strcat (main_data_filename,".txt");

strcat (previous_results_filename, ichar);

strcat (previous_results_filename,".dat");

strcat (output_filename, ichar);

l/abre o arquive de config no formato padrao e um arquivo temporario para armazenar o texto com a modificacao 
FILE $*$ inputIniParams $=$ fopen (inputIniParamsCopyFilePath, "r"); FILE $*$ output $=$ fopen (tempIniParamsFilePath, "w+");

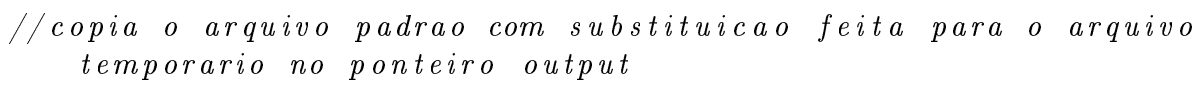


1014 cria novamente um arquivo temporario

inputIniParams = fopen(iniParamsFilePath, "r");

output = fopen(tempIniParamsFilePath, "w");

//copia o arquivo base com substituicao feita para o arquivo temporario no ponteiro output

changeSeed (inputIniParams, output, fpSeedLog);

fclose (inputIniParams);

fclose (output);

//remove a versao anterior do arquivo iniParams.txt remove (iniParamsFilePath);

//renomeia o arquivo temporario com a substituicao feita para iniParams . $t x t$

rename (tempIniParamsFilePath, iniParamsFilePath);

free (main_data_filename);

free (previous results filename);

free (output_filename);

free (inputIn̄iParams);

free (output);

system ( systemExecME2FilePath);

//system ("runbatch");

//printf("|n Simul: \%d |n",i);

minTask $=$ readPmfReport (fpMinTaskLog, me2ExecPath, 20);

printf(" $\backslash \mathrm{n}$ Simul: \%d minTask: \%d $\backslash \mathrm{n} ", \mathrm{i}$, minTask) ;

char $*$ inputPMF_ab_basePath $=$ malloc $(300)$;

strcpy (inputPMF_-a $\bar{b}_{-}$basePath, me2ExecPath);

strcat (inputPMF_ab_basePath, outputPMF_ab_baseBaseName);

strcat (inputPMF_ab_basePath, ichar);

strcat (inputPMF ${ }^{-}{ }^{-}$basePath,".dat");

$\mathrm{M}=$ readOutputFile(nrFat, nrVar, nrObs, inputPMF_ab_basePath, minTask); MFatCorrep = identFactor (nrFat, nrVar,M, MSS, MFatOrig);

sortFactor(nrFat, nrVar, M, MSS, MFatCorrep, MFatOrig,fpSaida);

free (MFatCorrep) ;

for $(\mathrm{k}=0 ; \mathrm{k}<\mathrm{nrVar} ; \mathrm{k}++)\{$

for $(1=0 ; 1<\operatorname{nrFat} ; 1++)\{$

MMeans [k][1] = MMeans[k][l] + M[k][l];

\}

$\operatorname{MSQ}[\mathrm{k}][1]=\operatorname{MSQ}[\mathrm{k}][1]+\operatorname{pow}(\mathrm{M}[\mathrm{k}][1], 2) ;$

\}

free(inputPMF_ab_basePath);

free $(\mathrm{M})$;

\}

for $(\mathrm{i}=0 ; \mathrm{i}<\operatorname{nrVar} ; \mathrm{i}++)\{$

for $(j=0 ; j<\operatorname{nrFat} ; j++)\{$ \}

fprintf(fpSumario, "\%f ",MMeans[i][j]/qtySimulacoes ) ;

\}

fprintf (fpSumario, " $\backslash \mathrm{n} ")$;

fprintf (fpSumario, "\n"); 
1076

1077

1078

1079

1080

1081

1082

1083

1084

1085

1086

1087

1088

1089

1090

1091

1092

1093

1094

1095

1096

1097

1098

1099

1100

1101

1102

$1103\}$

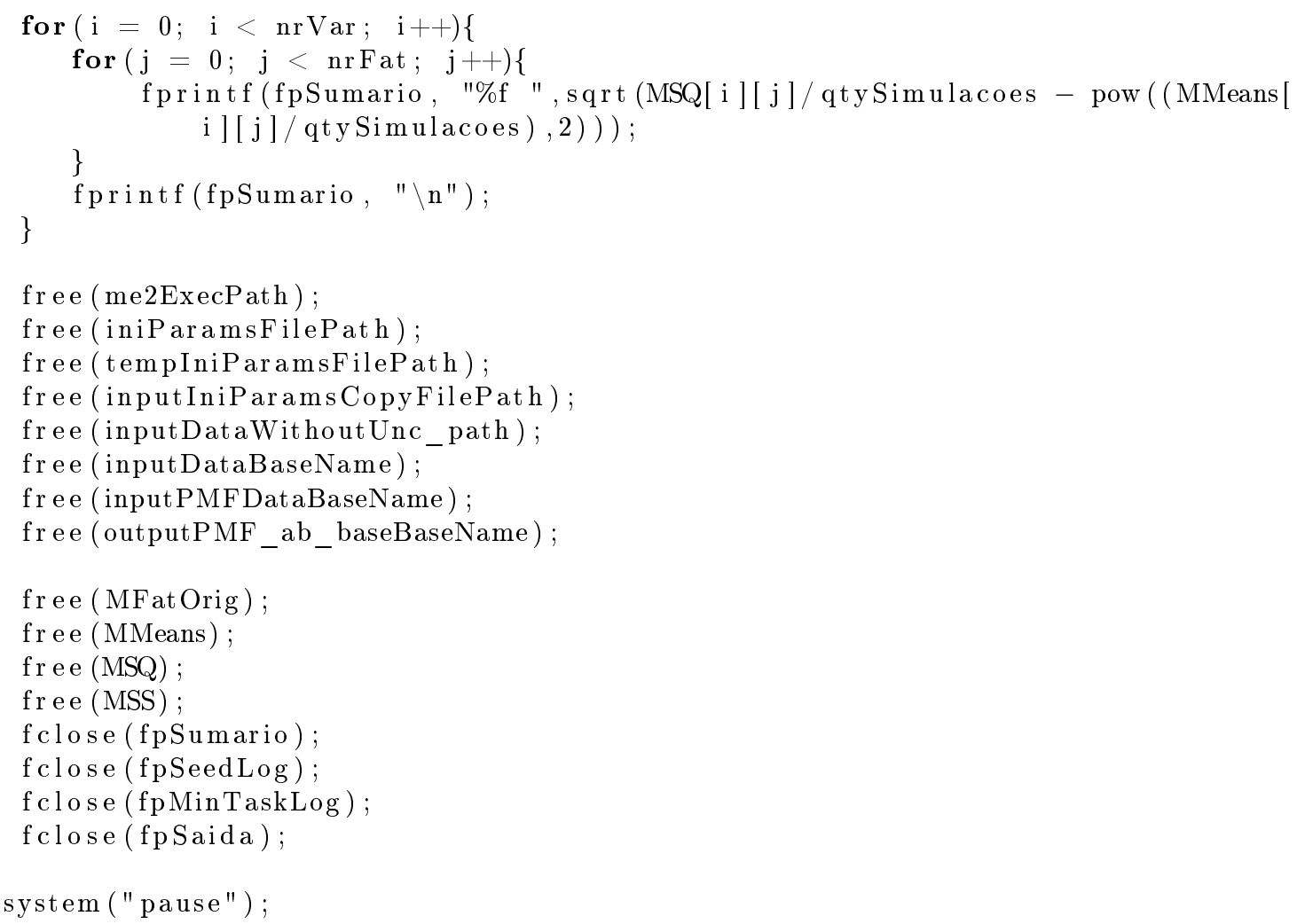




\section{Apêndice B}

\section{Gráficos}

B.1 Exemplo de séries de tempo simuladas sem outliers

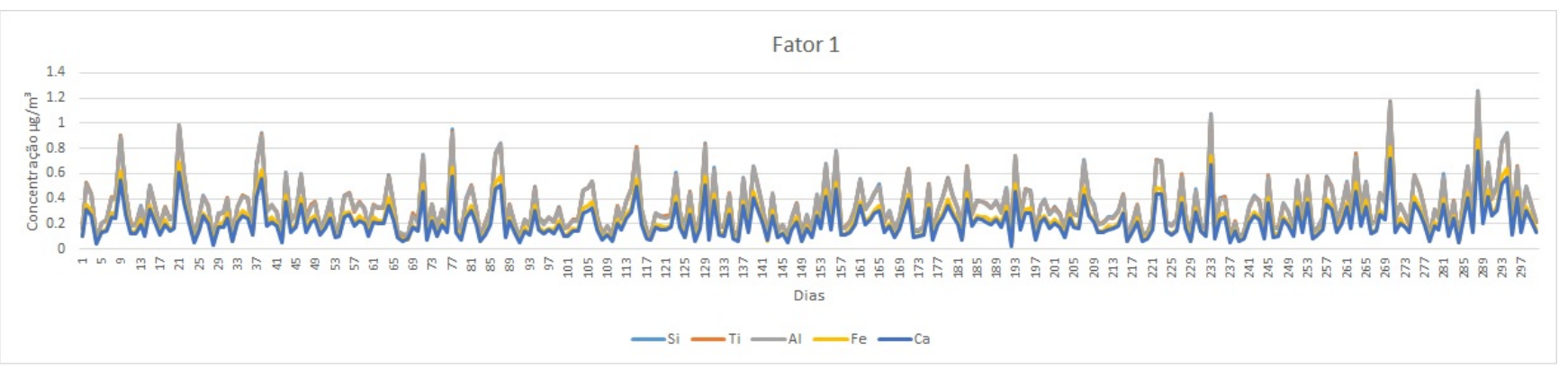

Figura B.1: séries de emissões simuladas segundo perfis da tabela 4.2 - Fator 1

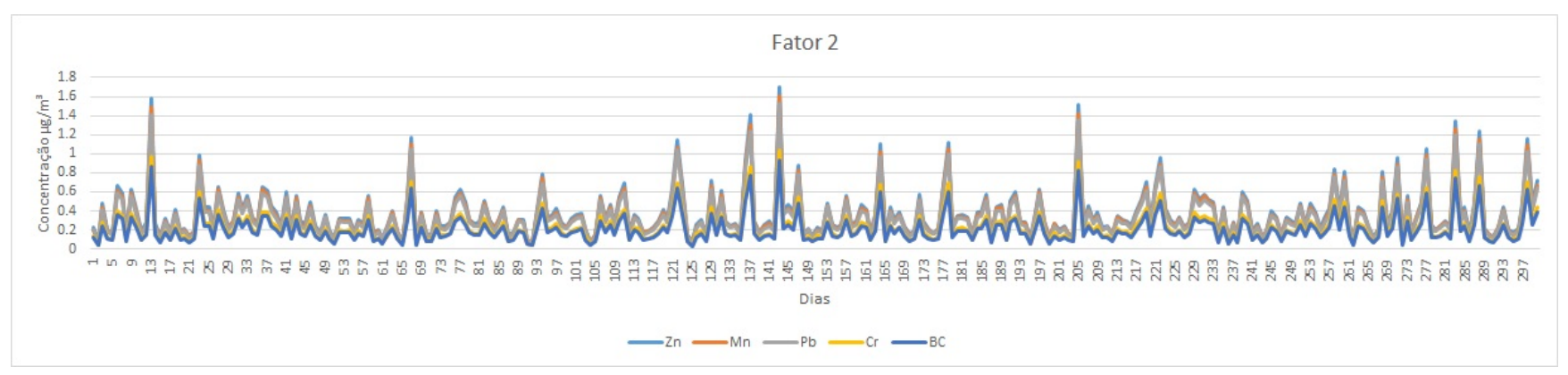

Figura B.2: séries de emissões simuladas segundo perfis da tabela 4.2 - Fator 2

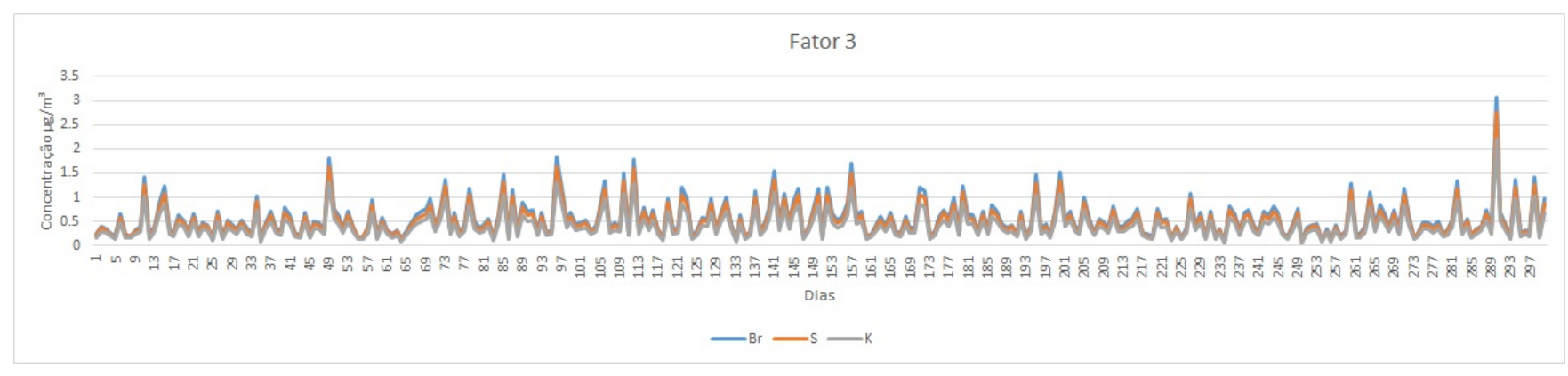

Figura B.3: séries de emissões simuladas segundo perfis da tabela 4.2 - Fator 3 


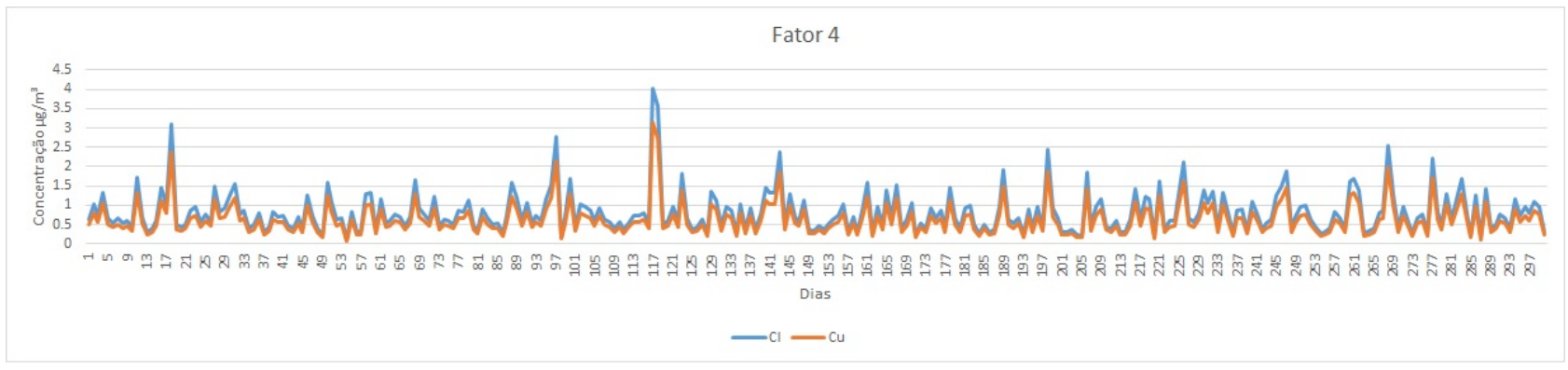

Figura B.4: séries de emissões simuladas segundo perfis da tabela 4.2 - Fator 4

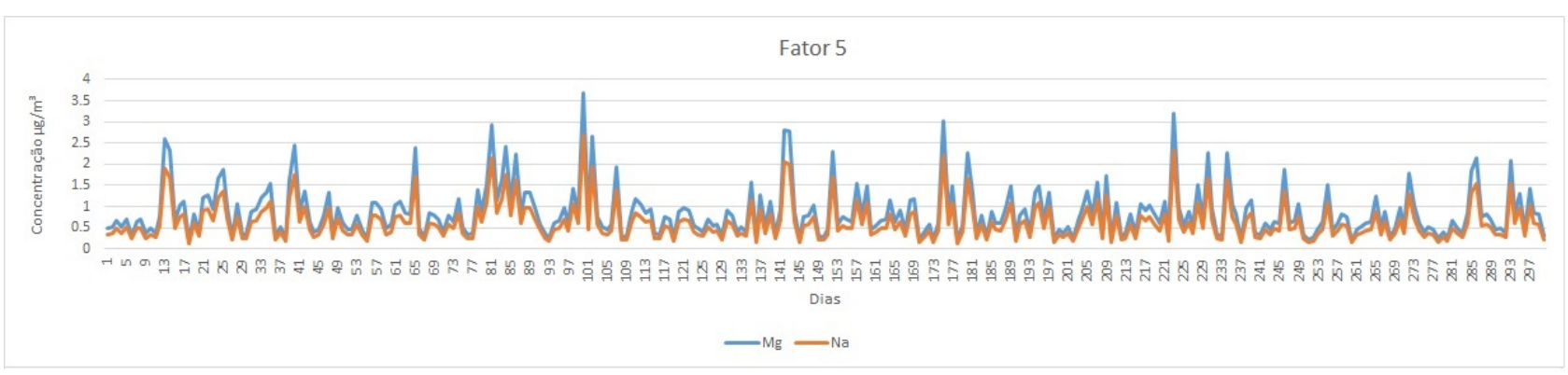

Figura B.5: séries de emissões simuladas segundo perfis da tabela 4.2 - Fator 5

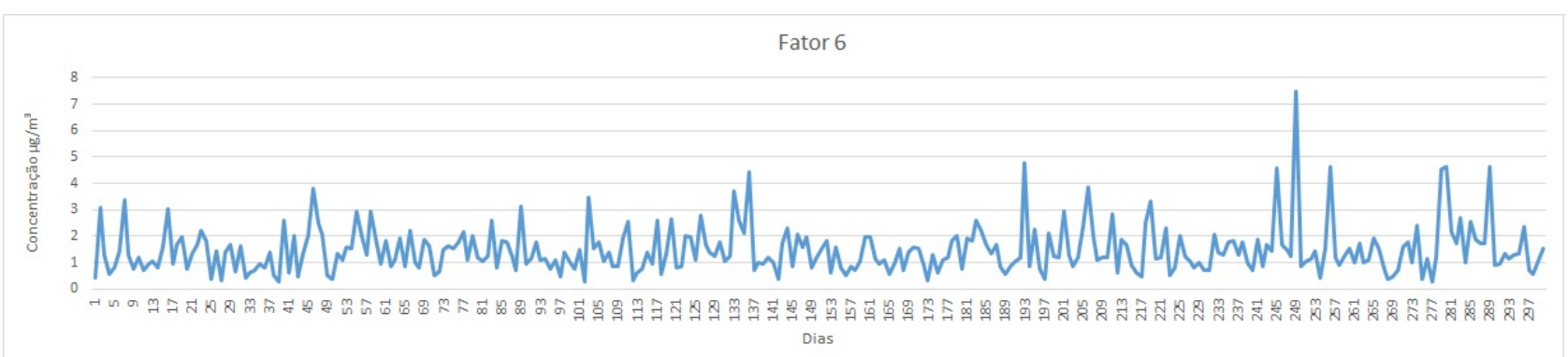

Figura B.6: séries de emissões simuladas segundo perfis da tabela 4.2 - Fator 6 


\section{B.2 Exemplo de séries de tempo simuladas com outliers - Expo- nencial com média 1,5}

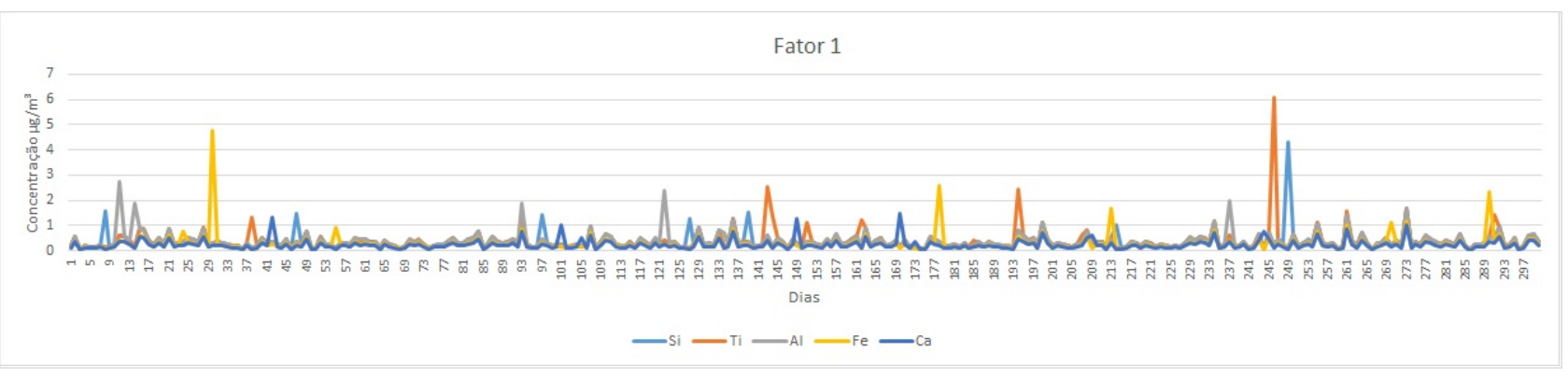

Figura B.7: séries de emissões simuladas segundo perfis da tabela 4.2 com outliers - Exponencial com média 1,5 - Fator 1

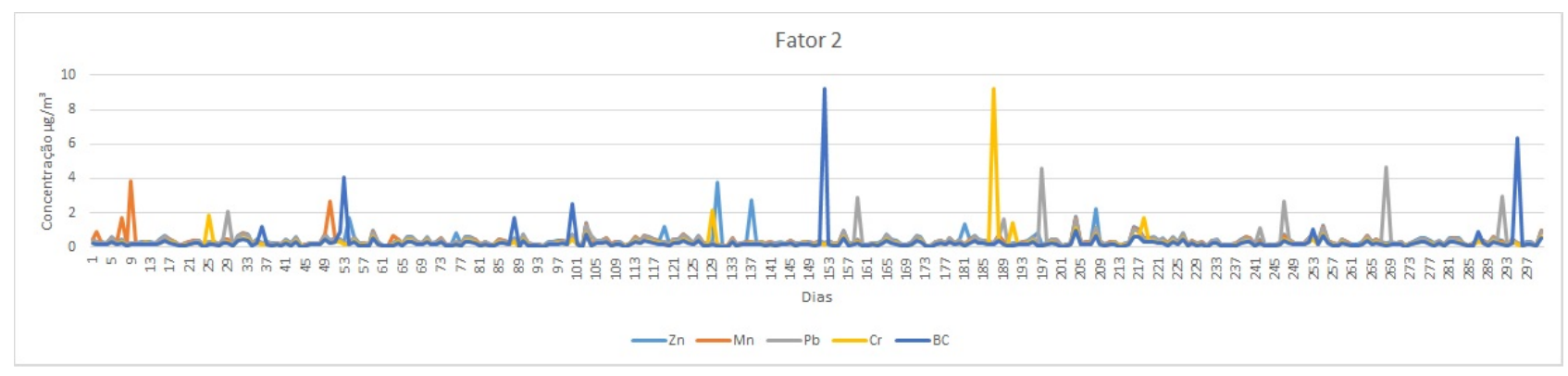

Figura B.8: séries de emissões simuladas segundo perfis da tabela 4.2 com outliers - Exponencial com média 1,5 - Fator 2

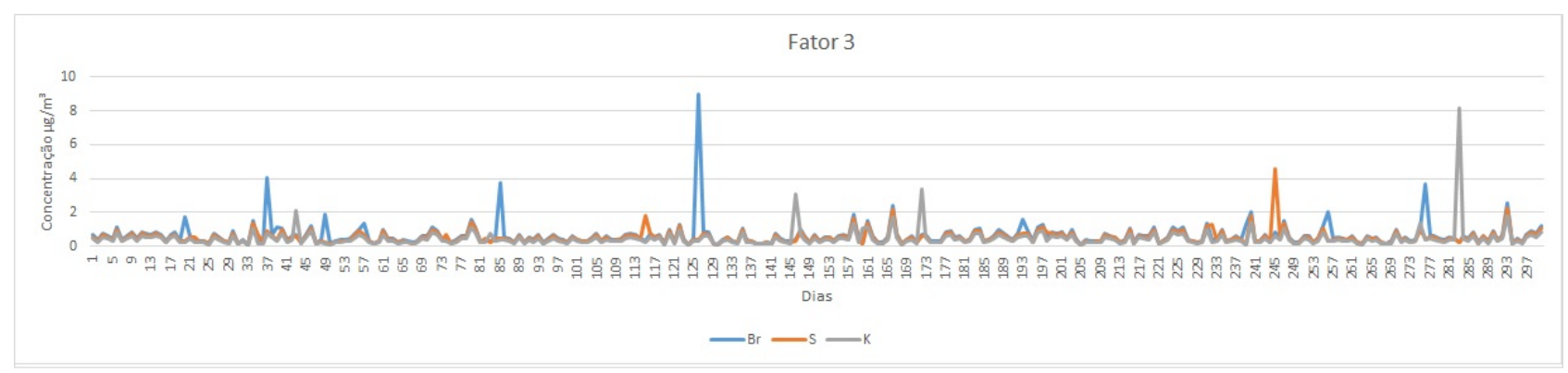

Figura B.9: séries de emissões simuladas segundo perfis da tabela 4.2 com outliers - Exponencial com média 1,5 - Fator 3 


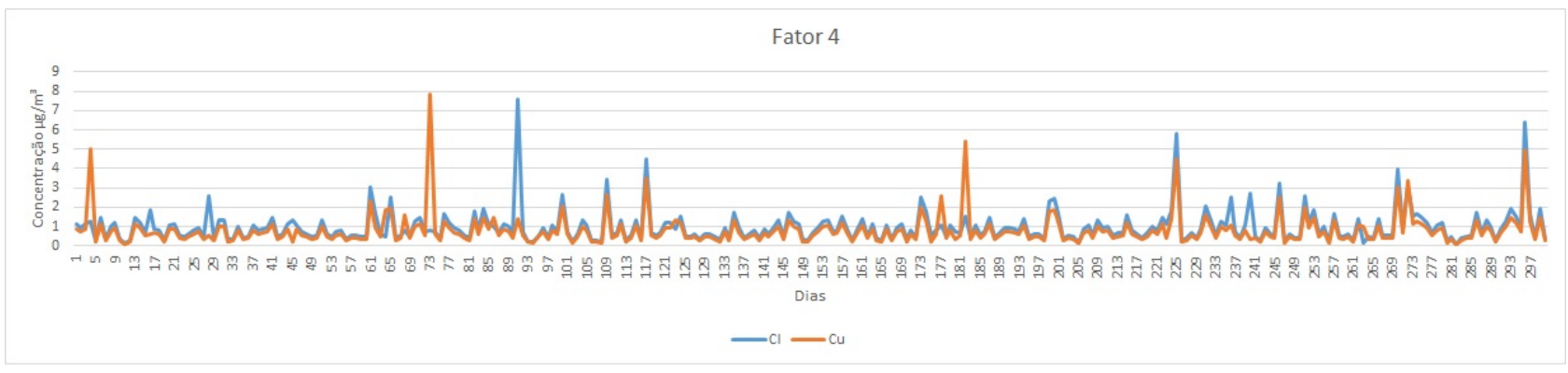

Figura B.10: séries de emissões simuladas segundo perfis da tabela 4.2 com outliers - Exponencial com média 1,5 - Fator 4

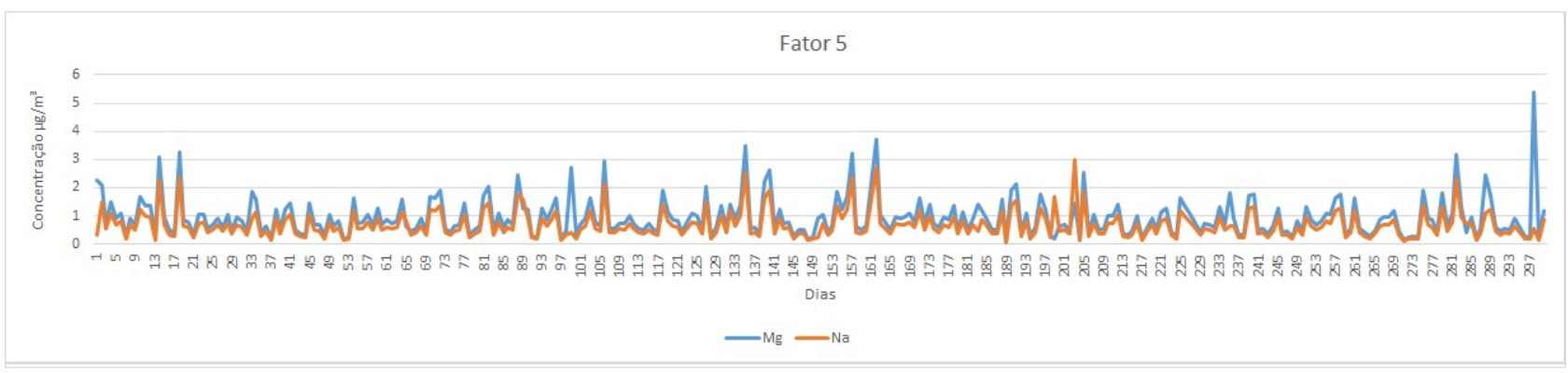

Figura B.11: séries de emissões simuladas segundo perfis da tabela 4.2 com outliers - Exponencial com média 1,5 - Fator 5

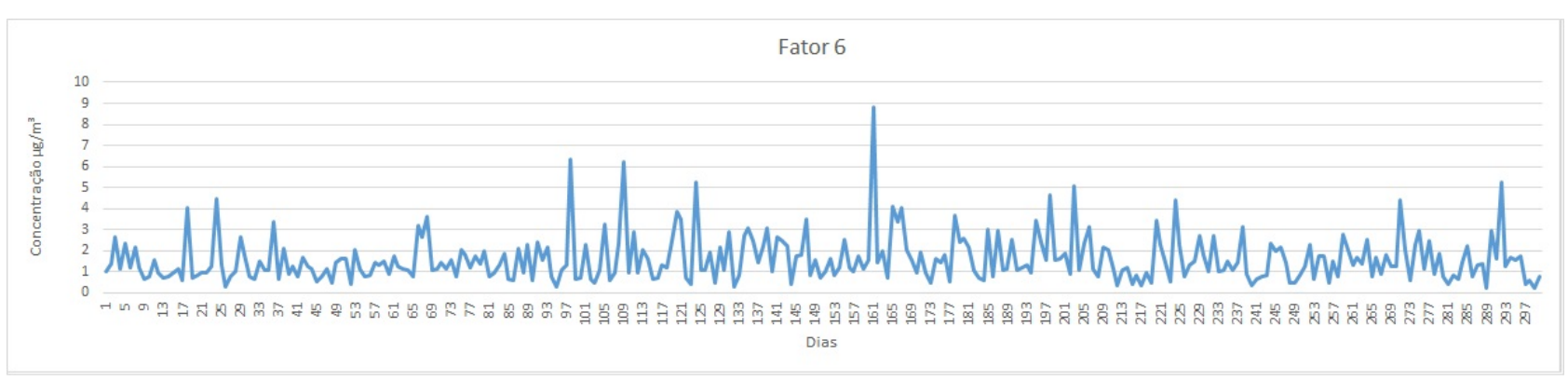

Figura B.12: séries de emissões simuladas segundo perfis da tabela 4.2 com outliers - Exponencial com média 1,5 - Fator 6 


\section{B.3 Exemplo de séries de tempo simuladas com outliers - Expo- nencial média 3}

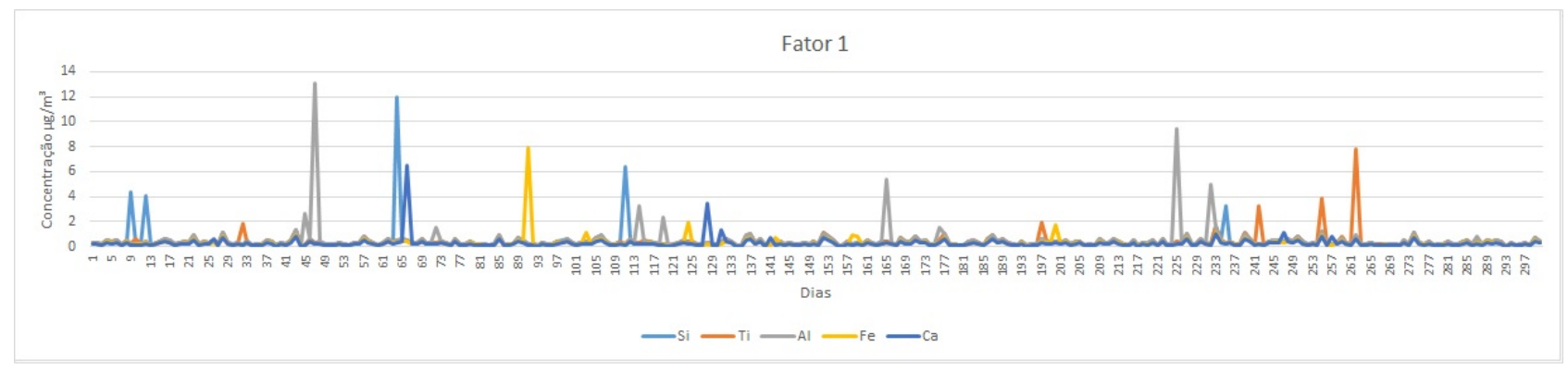

Figura B.13: séries de emissões simuladas segundo perfis da tabela 4.2 com outliers - Exponencial com média 3 - Fator 1

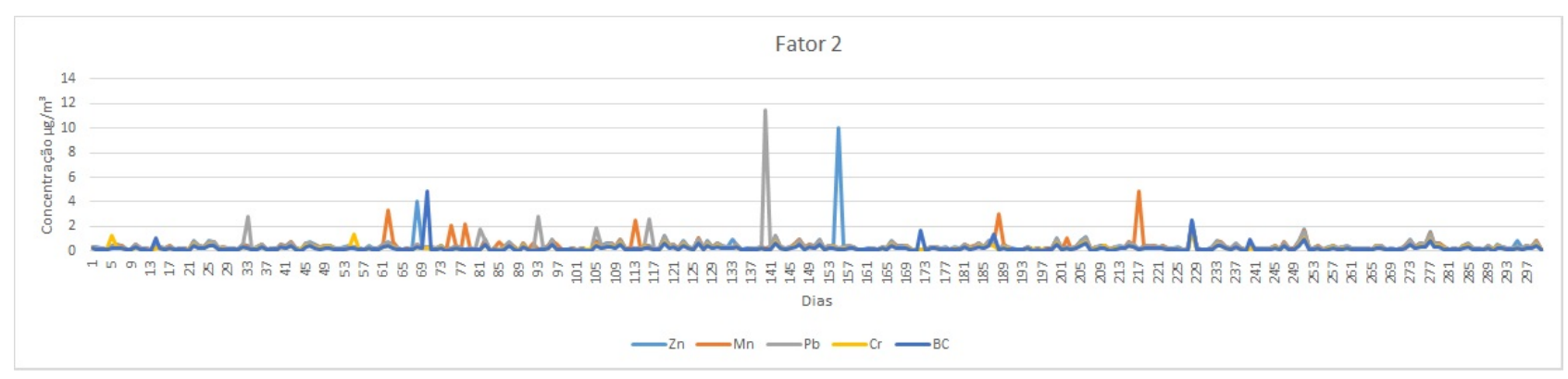

Figura B.14: séries de emissões simuladas segundo perfis da tabela 4.2 com outliers - Exponencial com média 3 - Fator 2

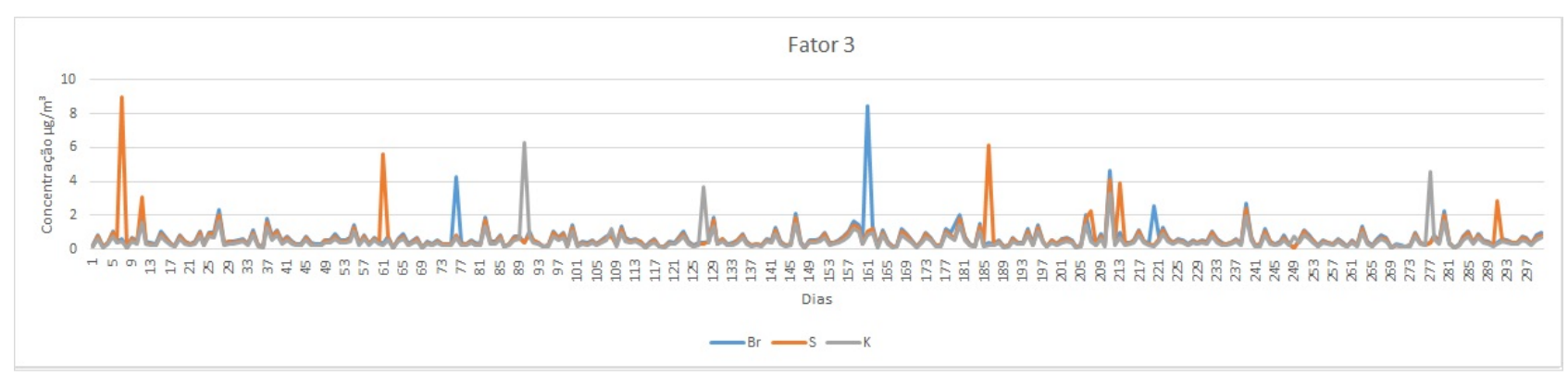

Figura B.15: séries de emissões simuladas segundo perfis da tabela 4.2 com outliers - Exponencial com média 3 - Fator 3 


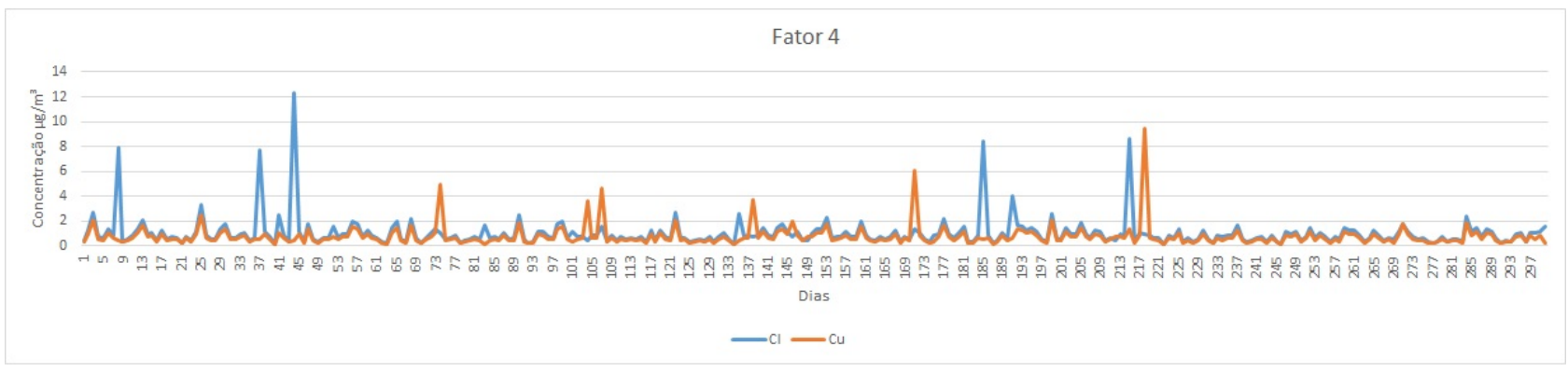

Figura B.16: séries de emissões simuladas segundo perfis da tabela 4.2 com outliers - Exponencial com média 3 - Fator 4

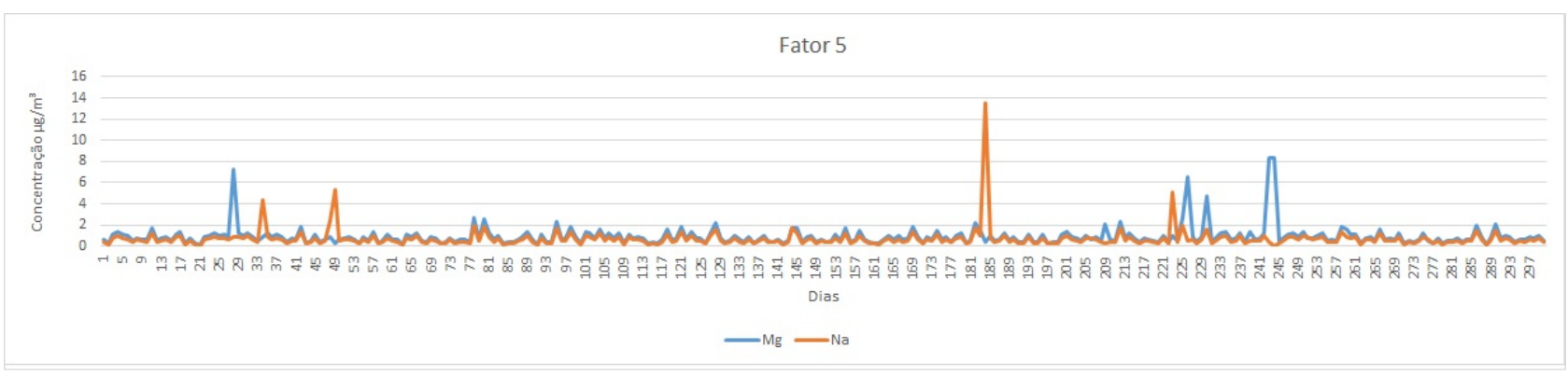

Figura B.17: séries de emissões simuladas segundo perfis da tabela 4.2 com outliers - Exponencial com média 3 - Fator 5

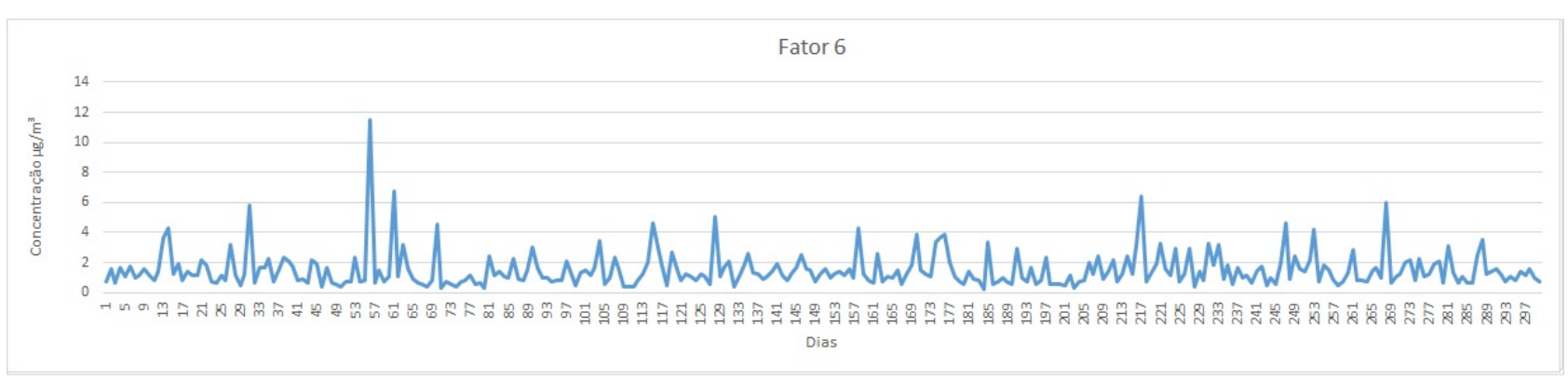

Figura B.18: séries de emissões simuladas segundo perfis da tabela 4.2 com outliers - Exponencial com média 3 - Fator 6 


\section{B.4 Exemplo de séries de tempo simuladas com outliers - Expo- nencial média 9}

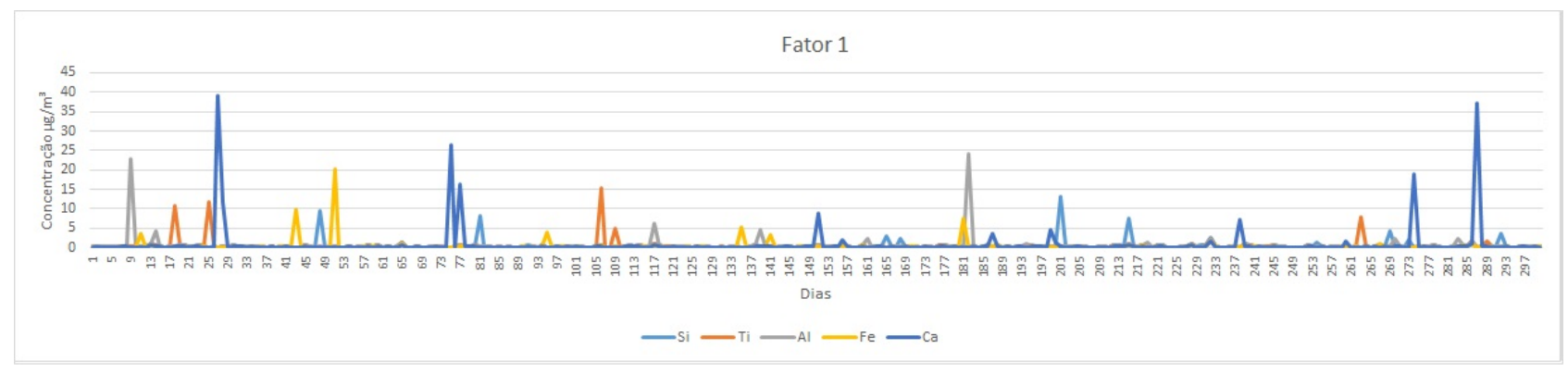

Figura B.19: séries de emissões simuladas segundo perfis da tabela 4.2 com outliers - Exponencial com média 9 - Fator 1

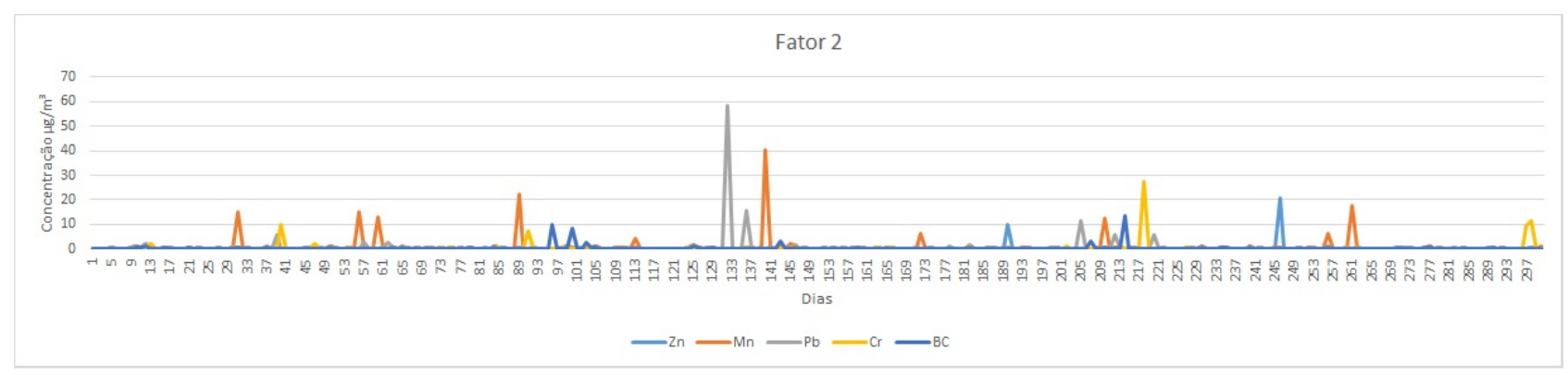

Figura B.20: séries de emissões simuladas segundo perfis da tabela 4.2 com outliers - Exponencial com média 9 - Fator 2

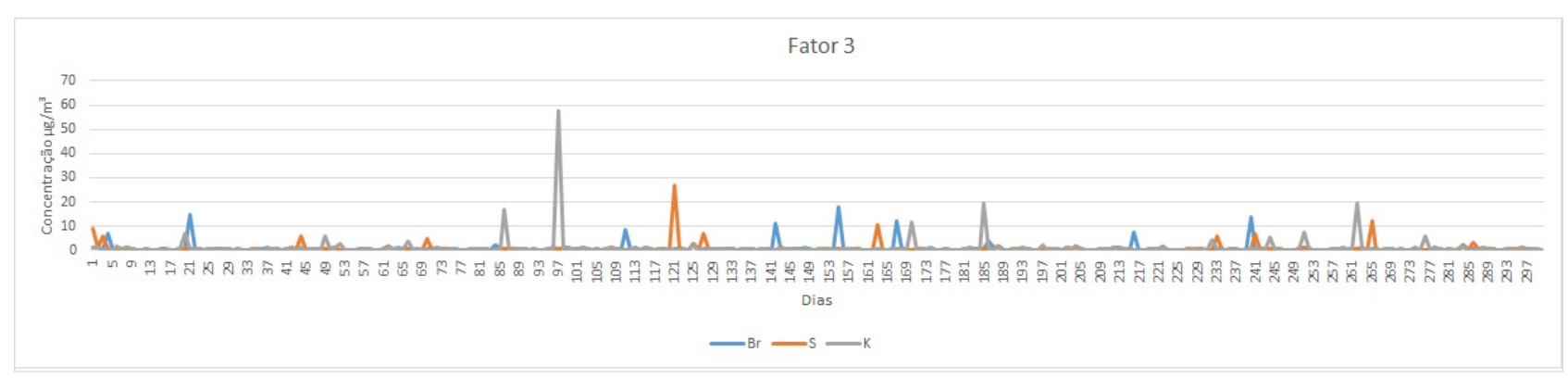

Figura B.21: séries de emissões simuladas segundo perfis da tabela 4.2 com outliers - Exponencial com média 9 - Fator 3 


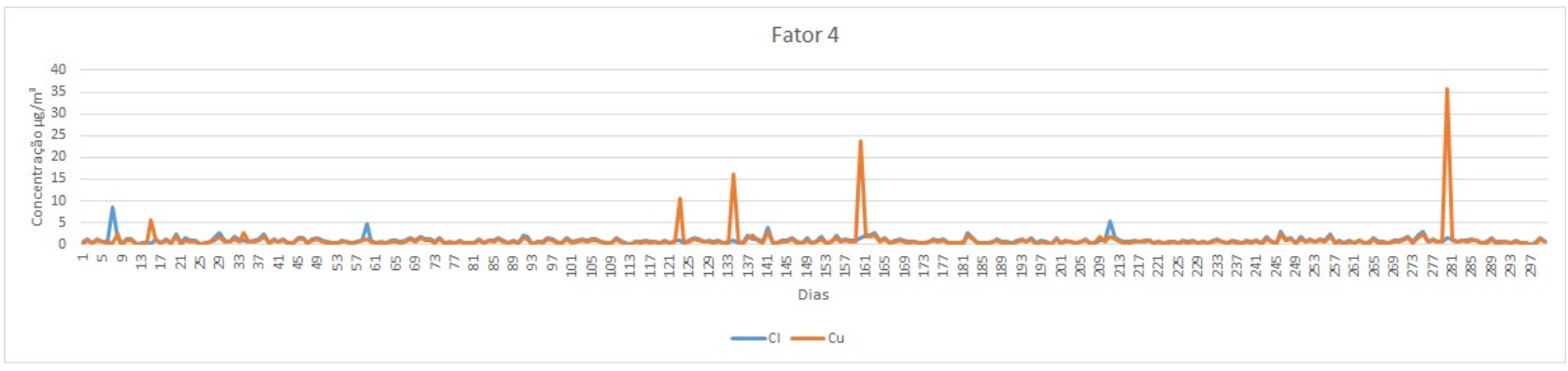

Figura B.22: séries de emissões simuladas segundo perfis da tabela 4.2 com outliers - Exponencial com média 9 - Fator 4

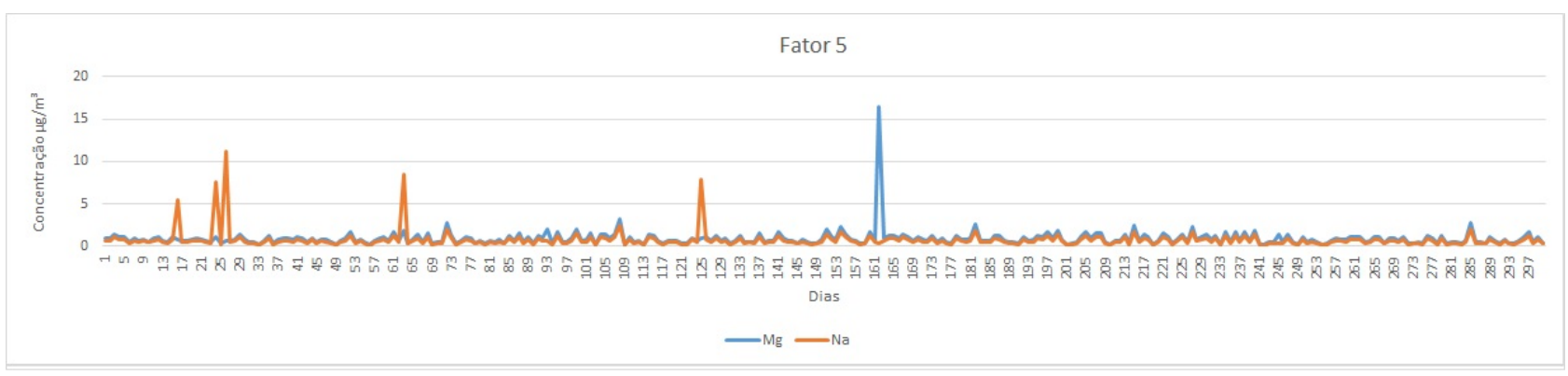

Figura B.23: séries de emissões simuladas segundo perfis da tabela 4.2 com outliers - Exponencial com média 9 - Fator 5

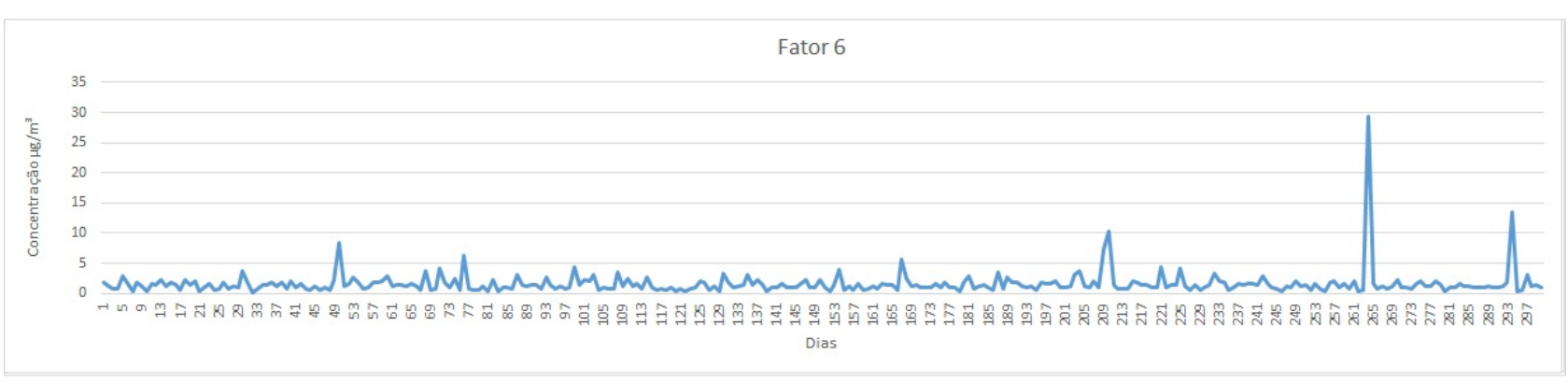

Figura B.24: séries de emissões simuladas segundo perfis da tabela 4.2 com outliers - Exponencial com média 9 - Fator 6 


\section{B.5 Exemplo de incertezas para uma mesma base simulada sem outliers}

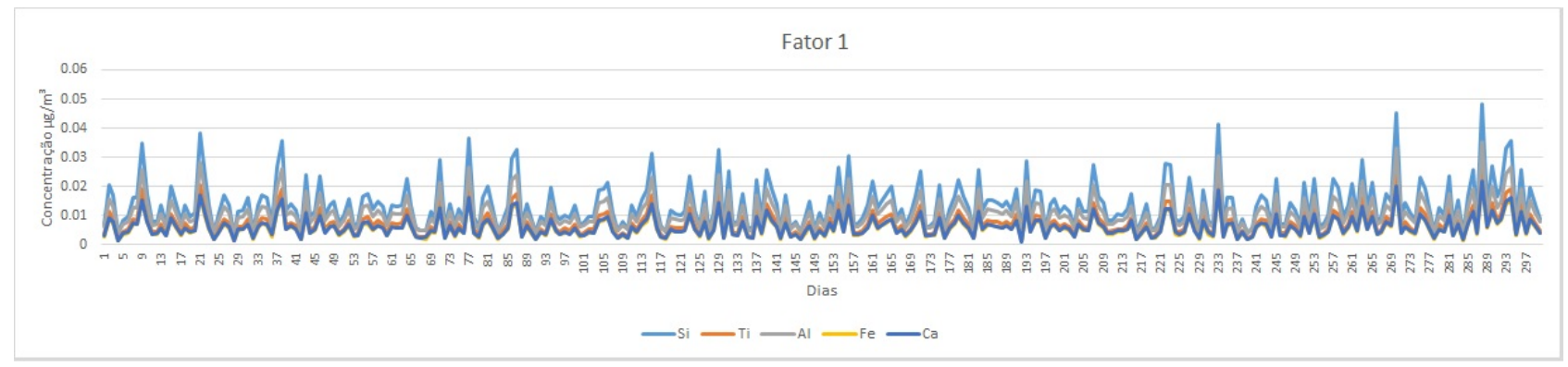

Figura B.25: séries de incertezas com proposta ref. Polissar et al. (1998) de emissões simuladas sem outliers segundo perfis da tabela 4.2 - Fator 1

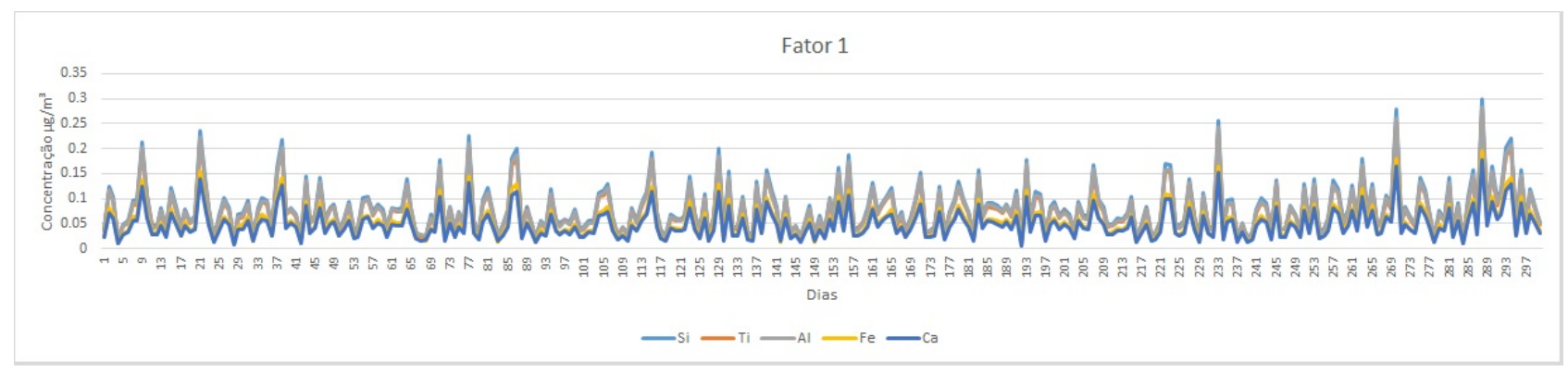

Figura B.26: séries de incertezas com proposta ref. Chueinta et al. (2000) de emissões simuladas sem outliers segundo perfis da tabela 4.2 - Fator 1

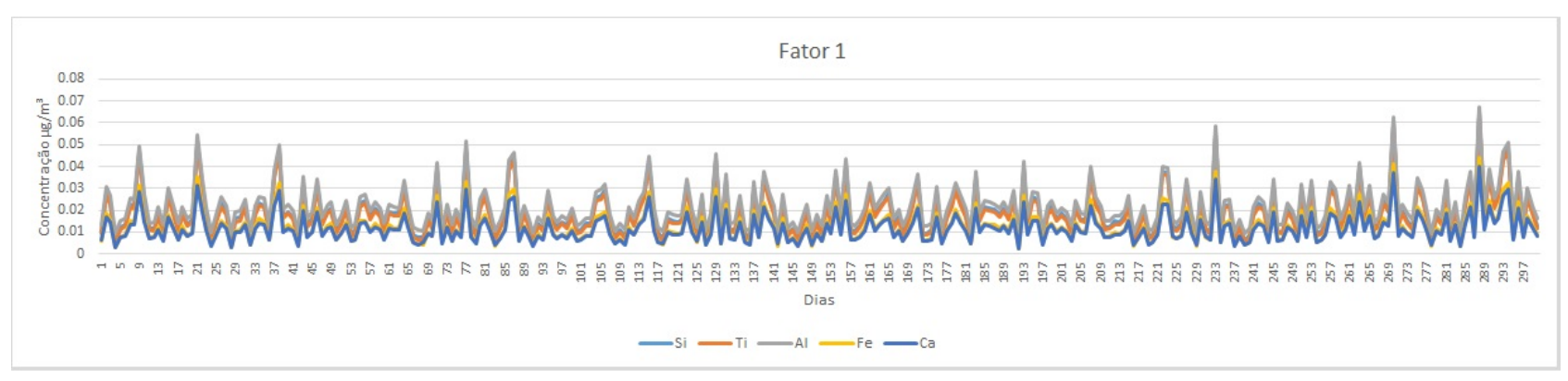

Figura B.27: séries de incertezas com proposta ref. Ito et al. (2004) de emissões simuladas sem outliers segundo perfis da tabela 4.2 - Fator 1 


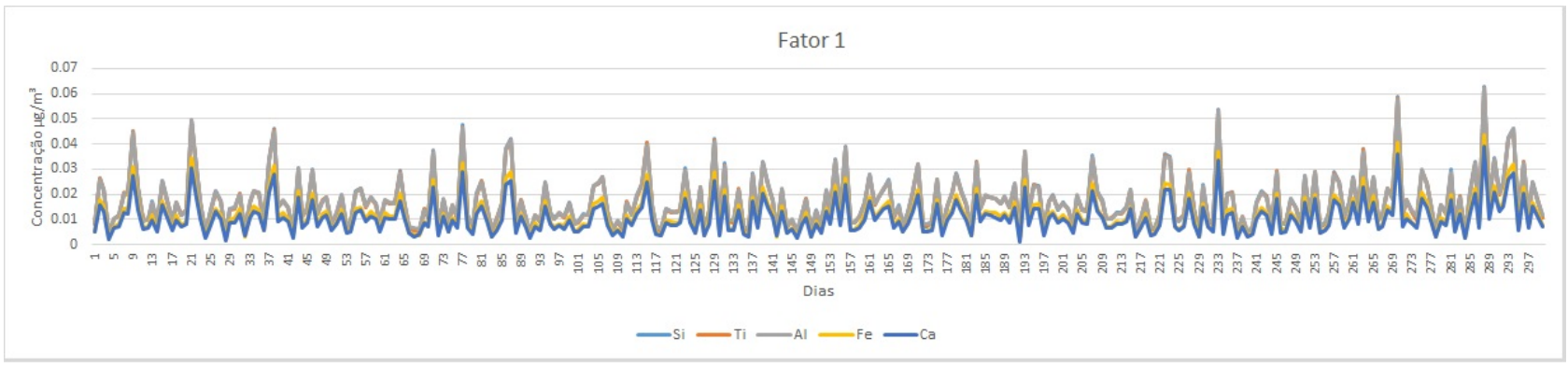

Figura B.28: séries de incertezas com proposta ref. Norris et al. (2014) de emissões simuladas sem outliers segundo perfis da tabela 4.2 - Fator 1

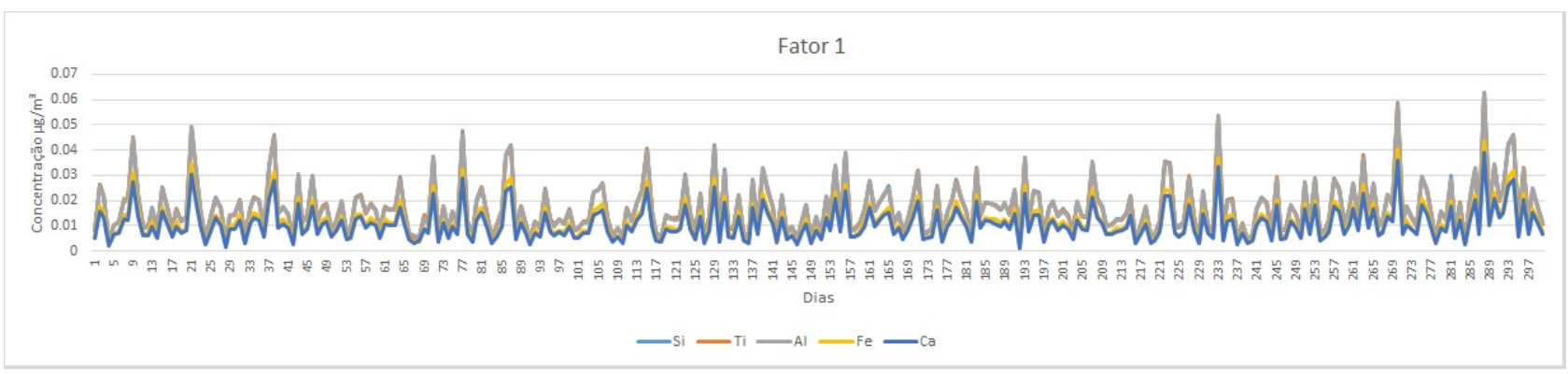

Figura B.29: séries de incertezas com proposta de $5 \%$ do valor de emissões simuladas sem outliers segundo perfis da tabela 4.2 - Fator 1

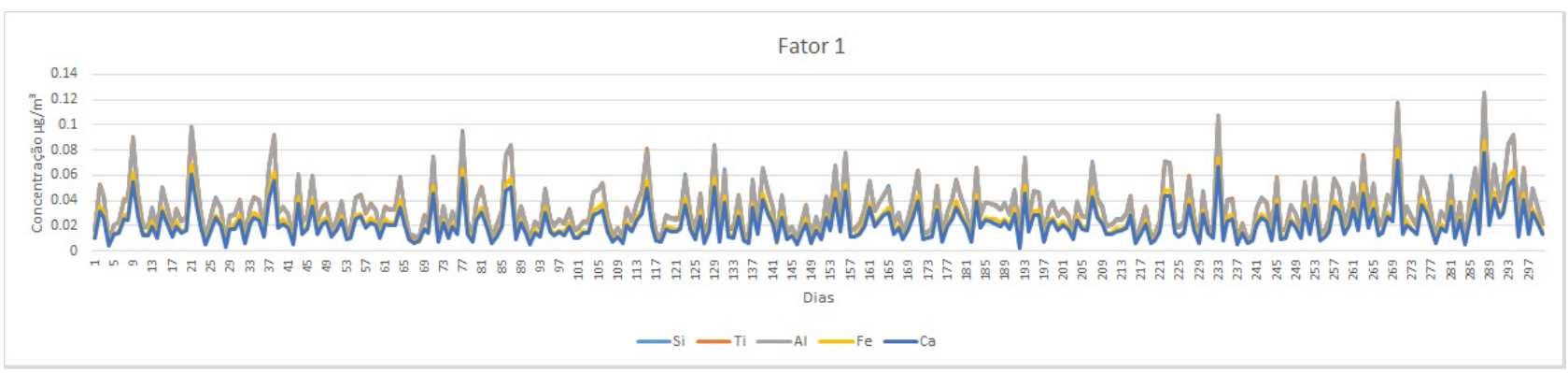

Figura B.30: séries de incertezas com proposta de $10 \%$ do valor de emissões simuladas sem outliers segundo perfis da tabela 4.2 - Fator 1

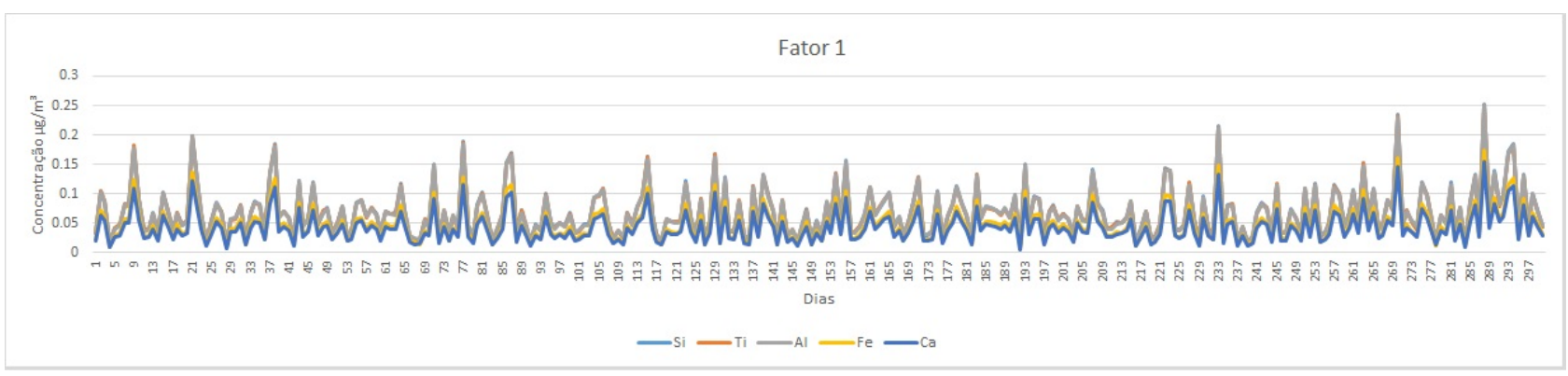

Figura B.31: séries de incertezas com proposta de $20 \%$ do valor de emissões simuladas sem outliers segundo perfis da tabela 4.2 - Fator 1 


\section{B.6 Exemplo de incertezas para uma mesma base simulada com outliers - Exponencial com média 1,5}

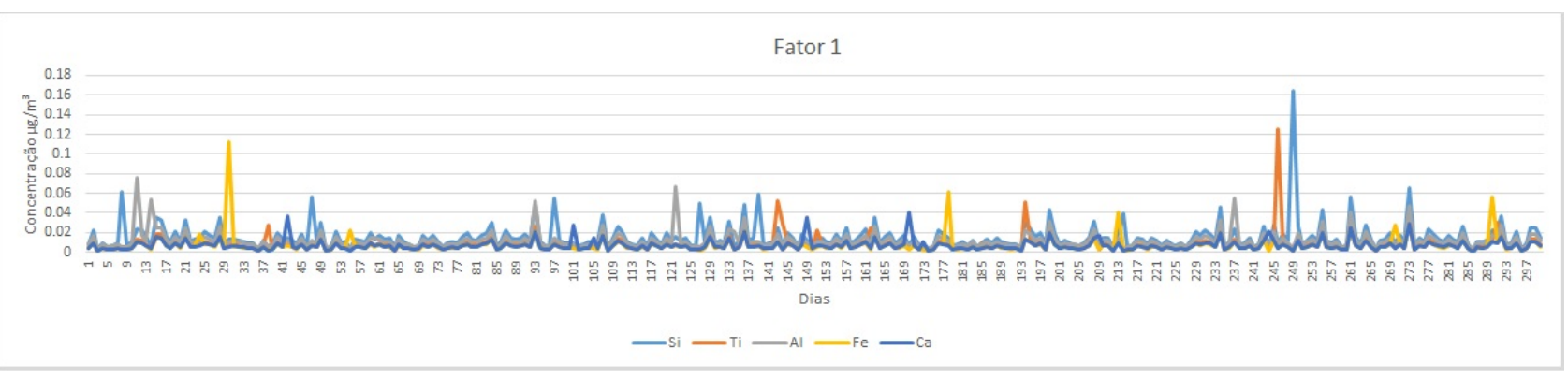

Figura B.32: séries de incertezas com proposta ref. Polissar et al. (1998) de emissões simuladas com outliers - Exponencial com média 1,5 - segundo perfis da tabela 4.2 - Fator 1

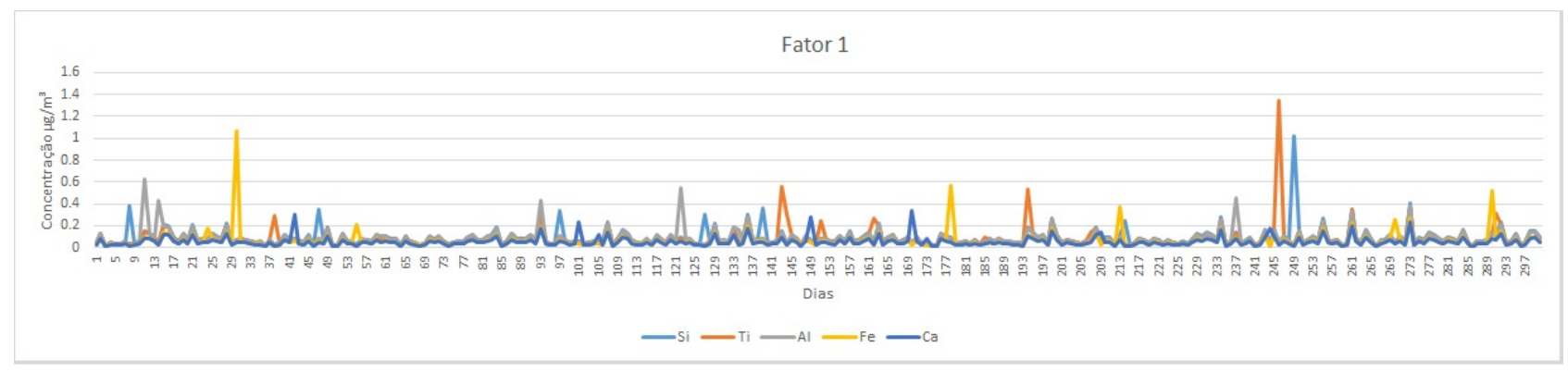

Figura B.33: séries de incertezas com proposta ref. Chueinta et al. (2000) de emissões simuladas com outliers - Exponencial com média 1,5 - segundo perfis da tabela 4.2 - Fator 1

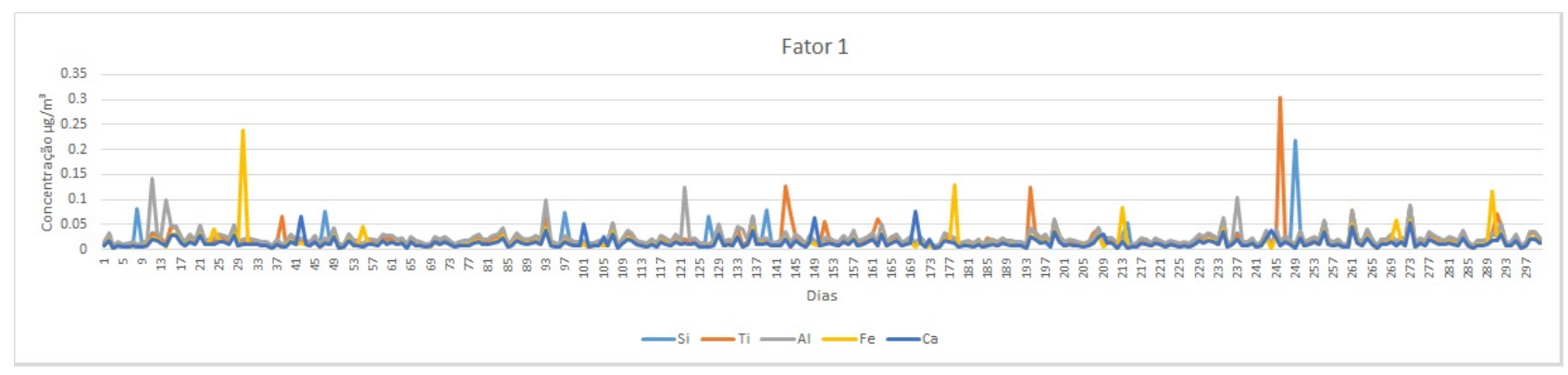

Figura B.34: séries de incertezas com proposta ref. Ito et al. (2004) de emissões simuladas com outliers Exponencial com média 1,5 - segundo perfis da tabela 4.2 - Fator 1 


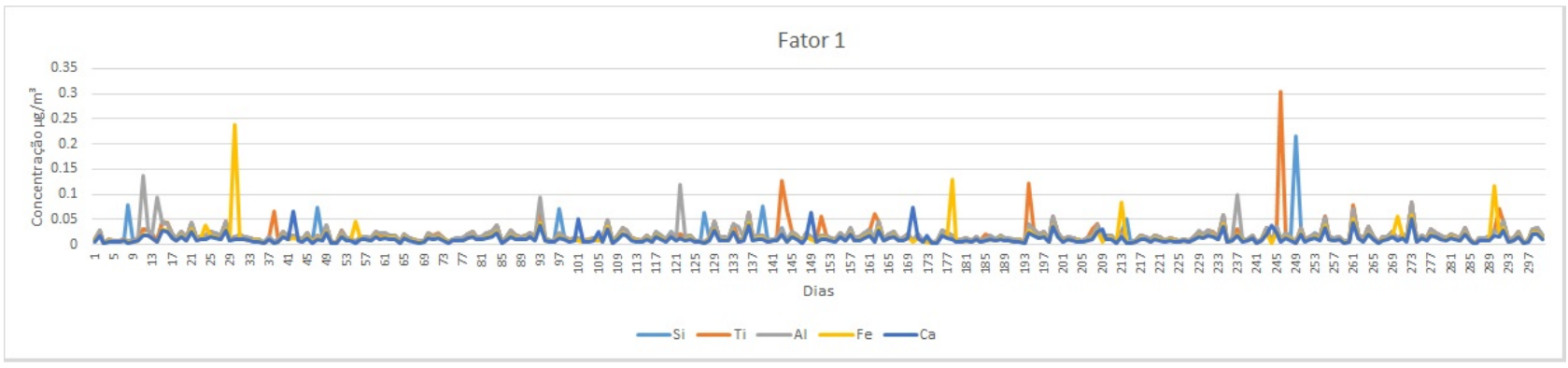

Figura B.35: séries de incertezas com proposta ref. Norris et al. (2014) de emissões simuladas com outliers - Exponencial com média 1,5 - segundo perfis da tabela 4.2 - Fator 1

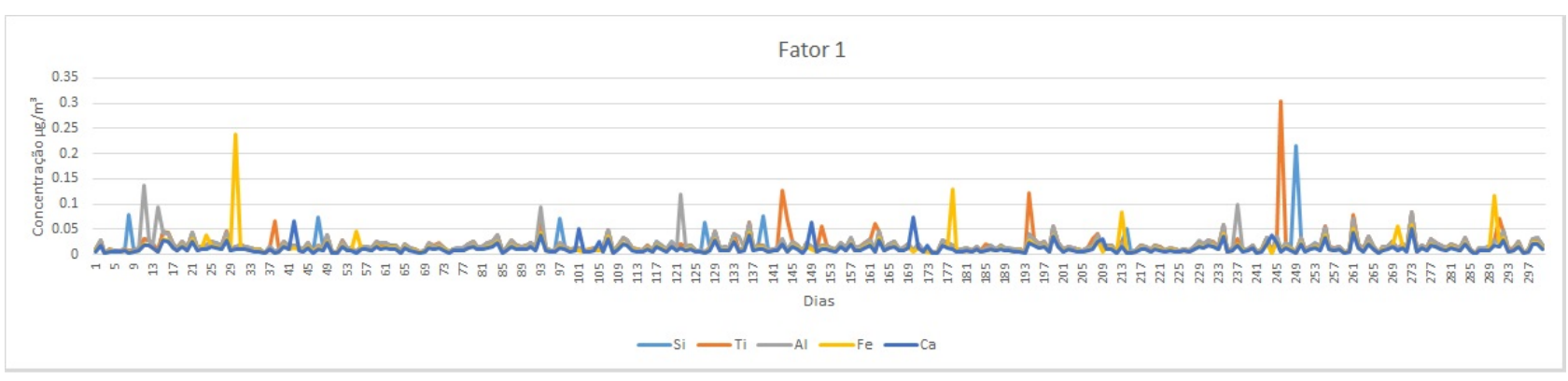

Figura B.36: séries de incertezas com proposta de $5 \%$ do valor de emissões simuladas com outliers Exponencial com média 1,5 - segundo perfis da tabela 4.2 - Fator 1

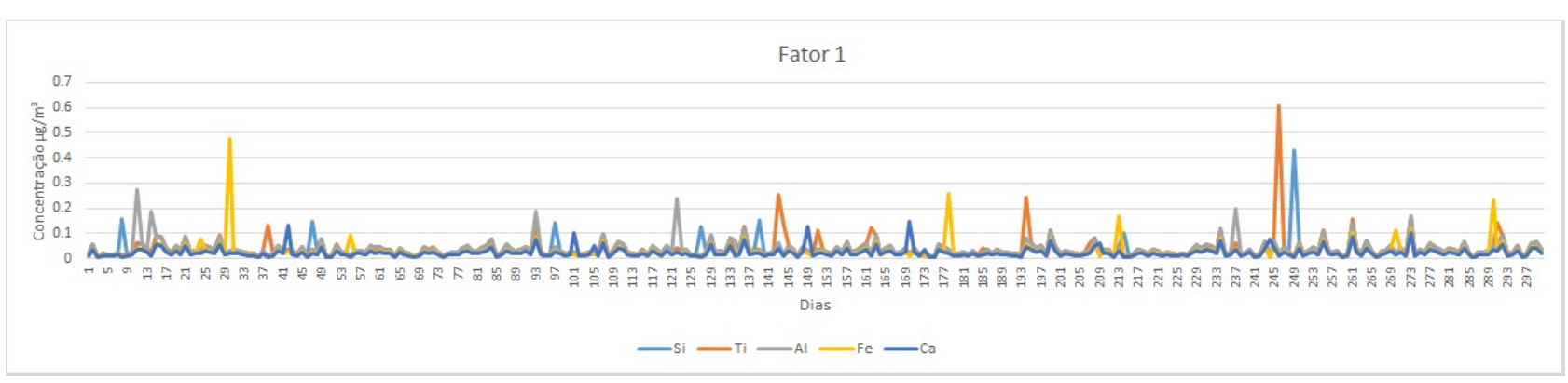

Figura B.37: séries de incertezas com proposta de $10 \%$ do valor de emissões simuladas com outliers Exponencial com média 1,5 - segundo perfis da tabela 4.2 - Fator 1

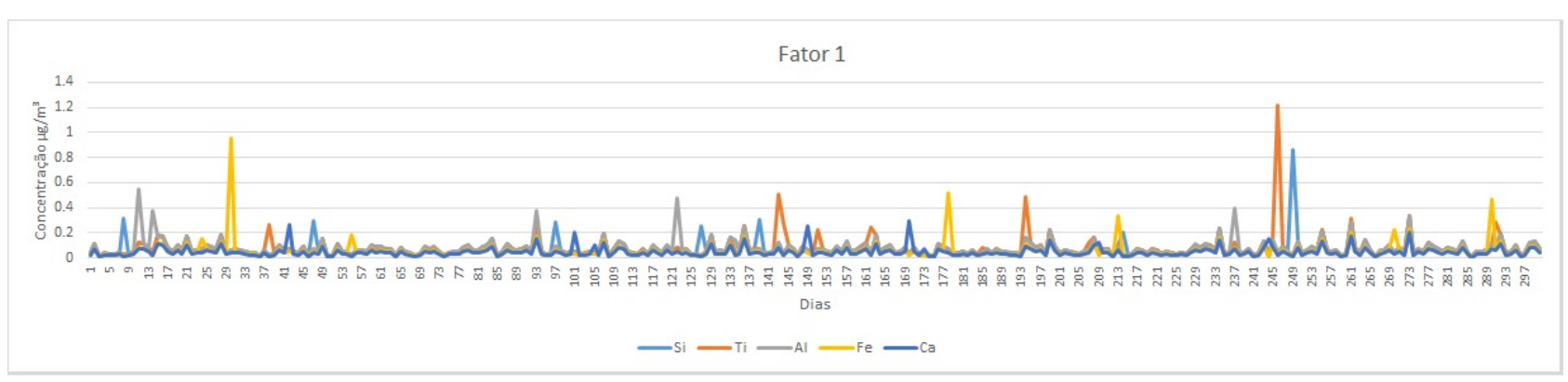

Figura B.38: séries de incertezas com proposta de $20 \%$ do valor de emissões simuladas com outliers Exponencial com média 1,5 - segundo perfis da tabela 4.2 - Fator 1 


\section{B.7 Exemplo de incertezas para uma mesma base simulada com outliers - Exponencial com média 3}

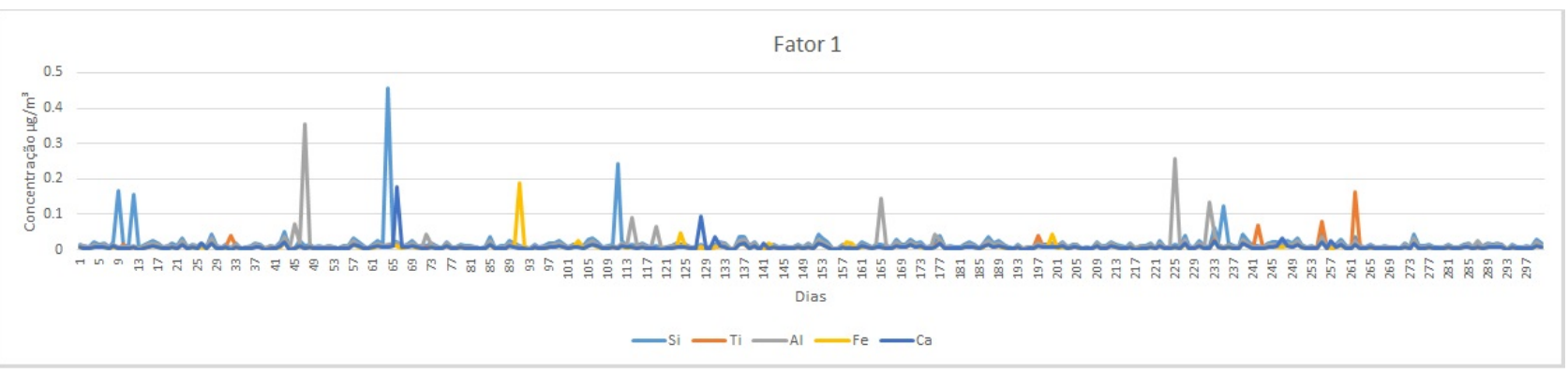

Figura B.39: séries de incertezas com proposta ref. Polissar et al. (1998) de emissões simuladas com outliers - Exponencial com média 3 - segundo perfis da tabela 4.2 - Fator 1

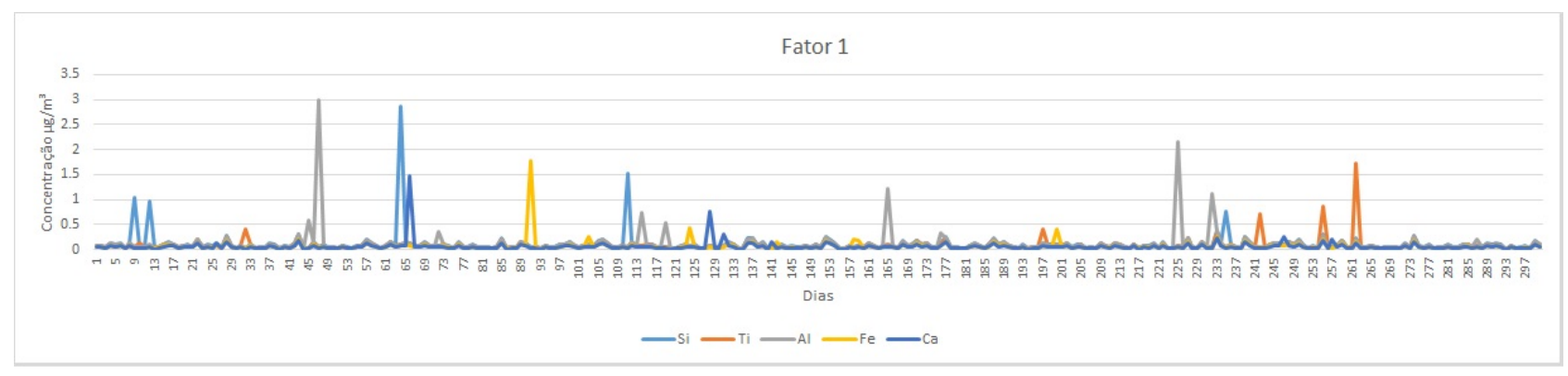

Figura B.40: séries de incertezas com proposta ref. Chueinta et al. (2000) de emissões simuladas com outliers - Exponencial com média 3 - segundo perfis da tabela 4.2 - Fator 1

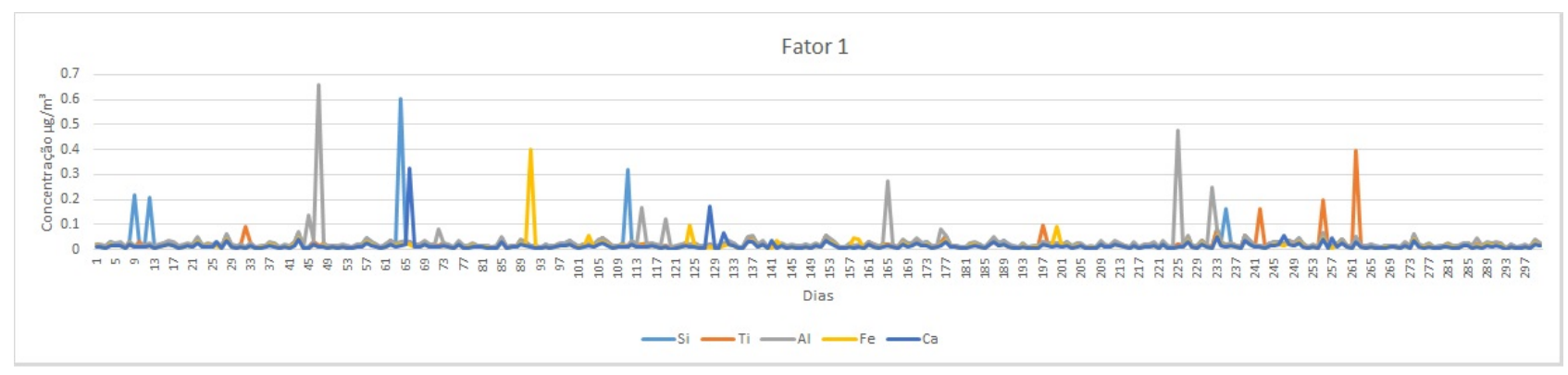

Figura B.41: séries de incertezas com proposta ref. Ito et al. (2004) de emissões simuladas com outliers Exponencial com média 3 - segundo perfis da tabela 4.2 - Fator 1 


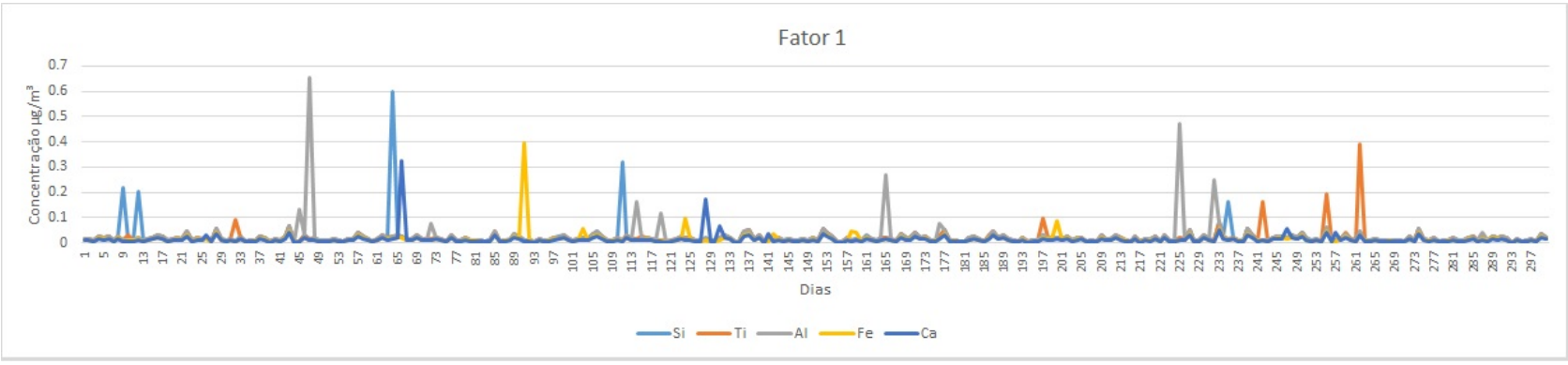

Figura B.42: séries de incertezas com proposta ref. Norris et al. (2014) de emissões simuladas com outliers - Exponencial com média 3 - segundo perfis da tabela 4.2 - Fator 1

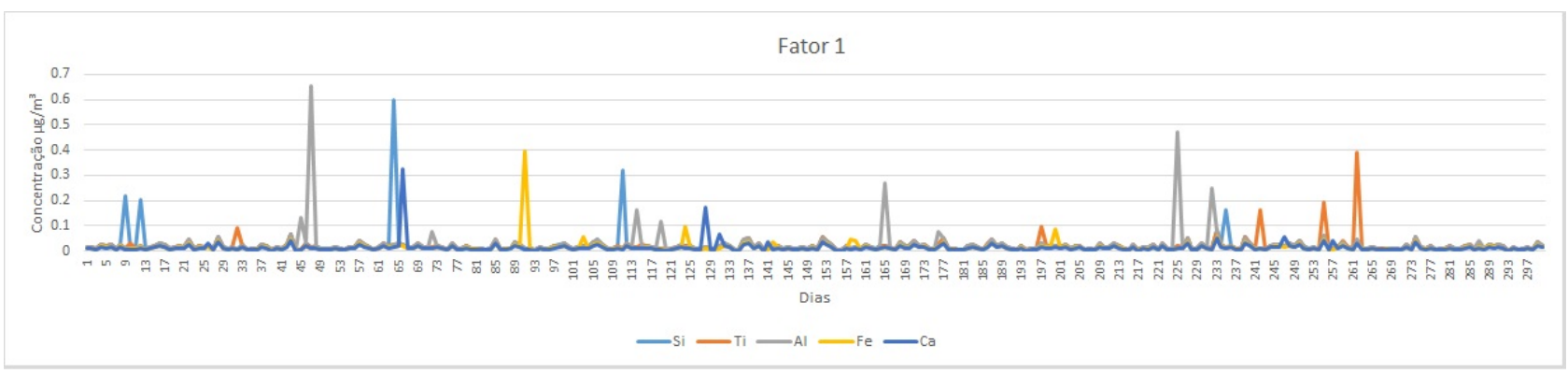

Figura B.43: séries de incertezas com proposta de $5 \%$ do valor de emissões simuladas com outliers Exponencial com média 3 - segundo perfis da tabela 4.2 - Fator 1

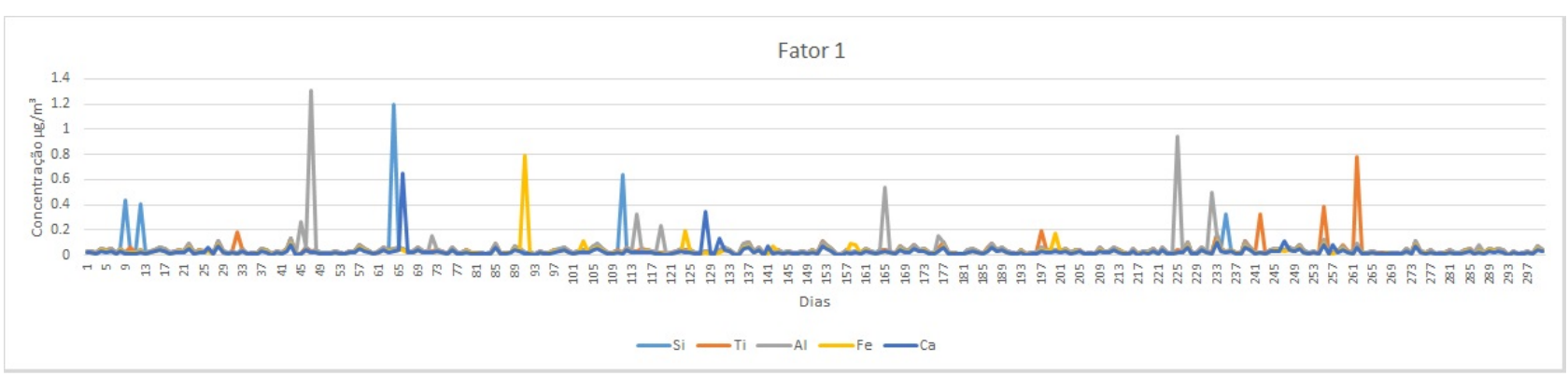

Figura B.44: séries de incertezas com proposta de $10 \%$ do valor de emissões simuladas com outliers Exponencial com média 3 - segundo perfis da tabela 4.2 - Fator 1

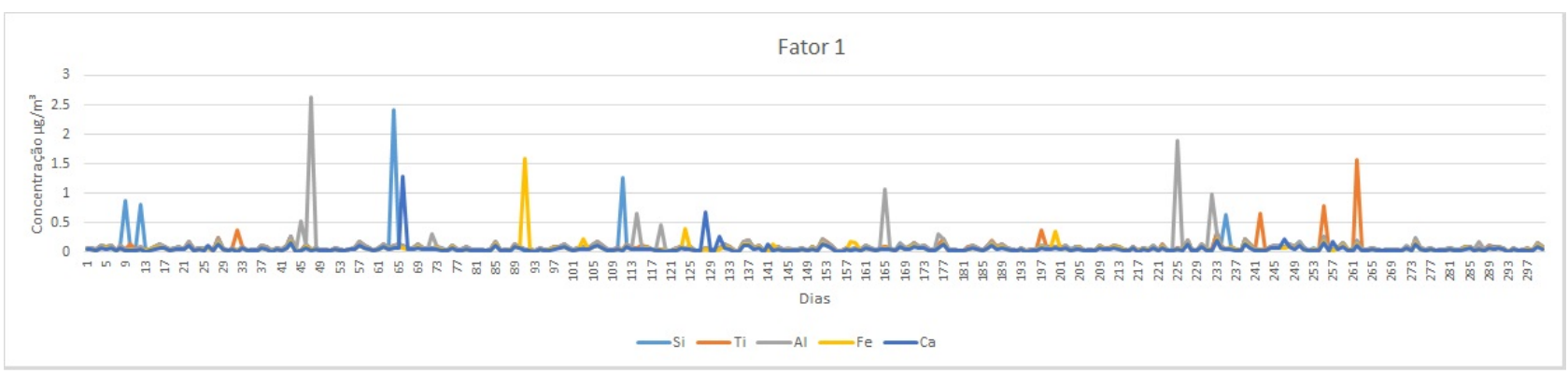

Figura B.45: séries de incertezas com proposta de $20 \%$ do valor de emissões simuladas com outliers Exponencial com média 3 - segundo perfis da tabela 4.2 - Fator 1 


\section{B.8 Exemplo de incertezas para uma mesma base simulada com outliers - Exponencial com média 9}

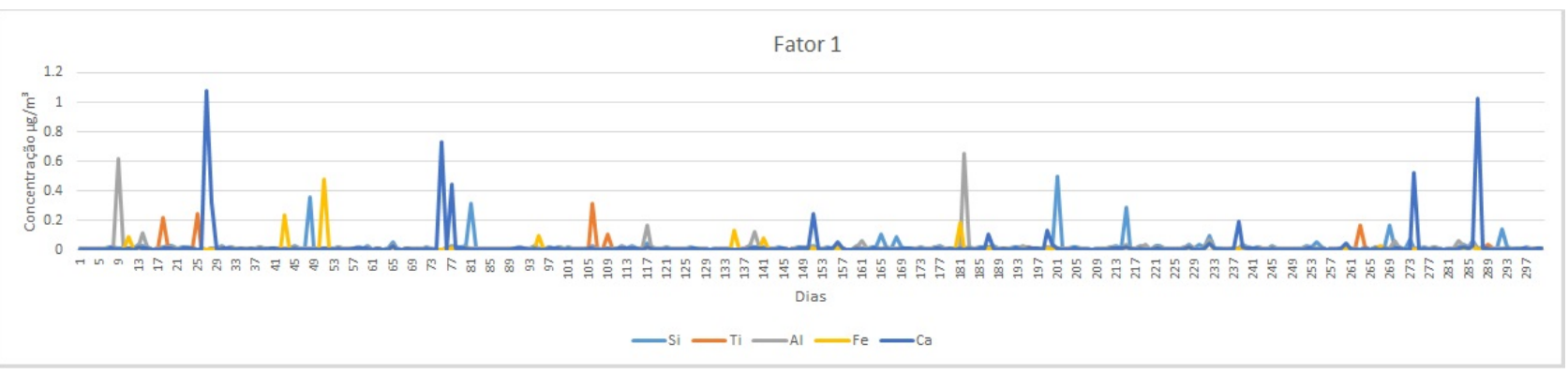

Figura B.46: séries de incertezas com proposta ref. Polissar et al. (1998) de emissões simuladas com outliers - Exponencial com média 9 - segundo perfis da tabela 4.2 - Fator 1

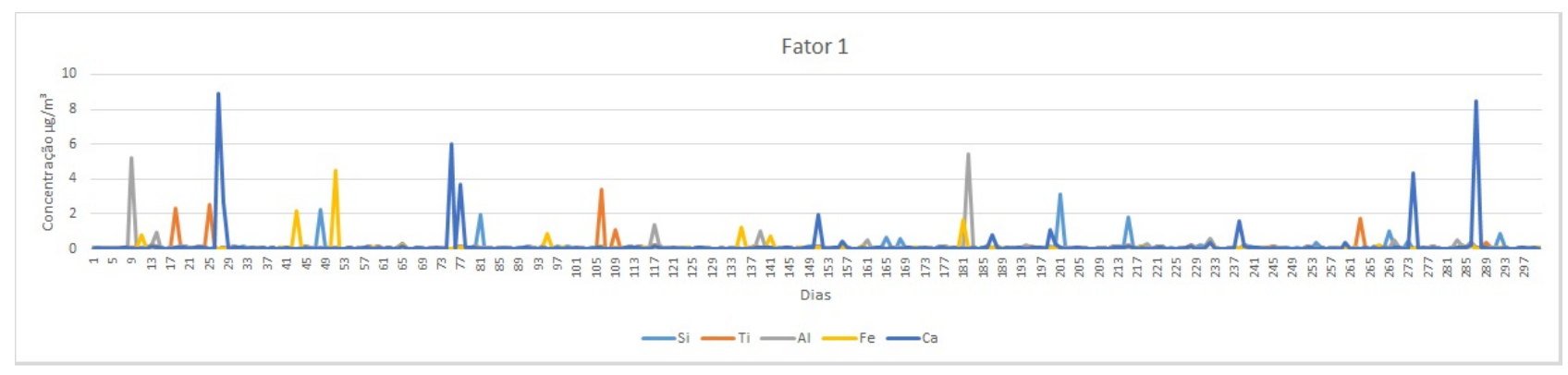

Figura B.47: séries de incertezas com proposta ref. Chueinta et al. (2000) de emissões simuladas com outliers - Exponencial com média 9 - segundo perfis da tabela 4.2 - Fator 1

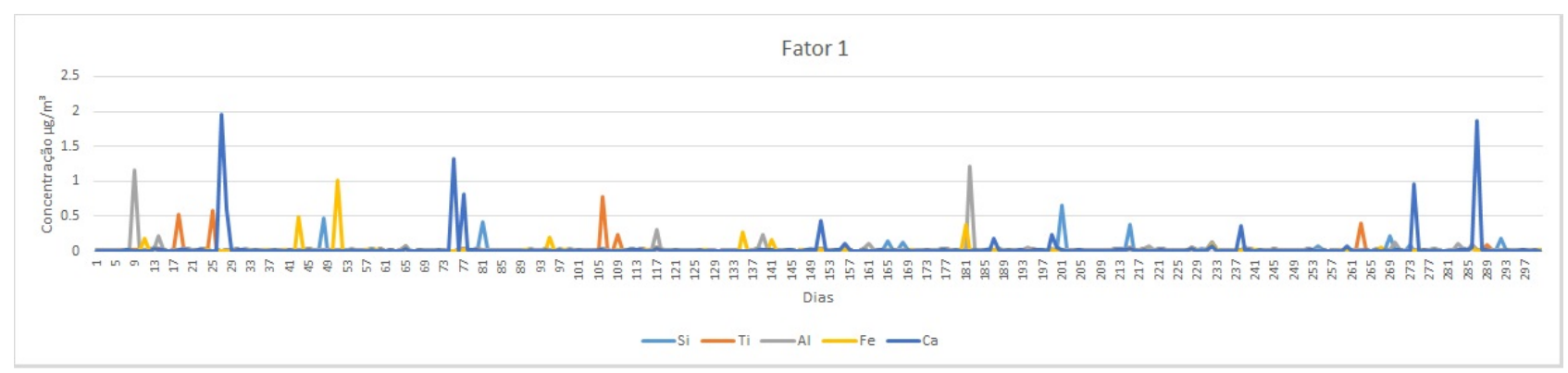

Figura B.48: séries de incertezas com proposta ref. Ito et al. (2004) de emissões simuladas com outliers Exponencial com média 9 - segundo perfis da tabela 4.2 - Fator 1 


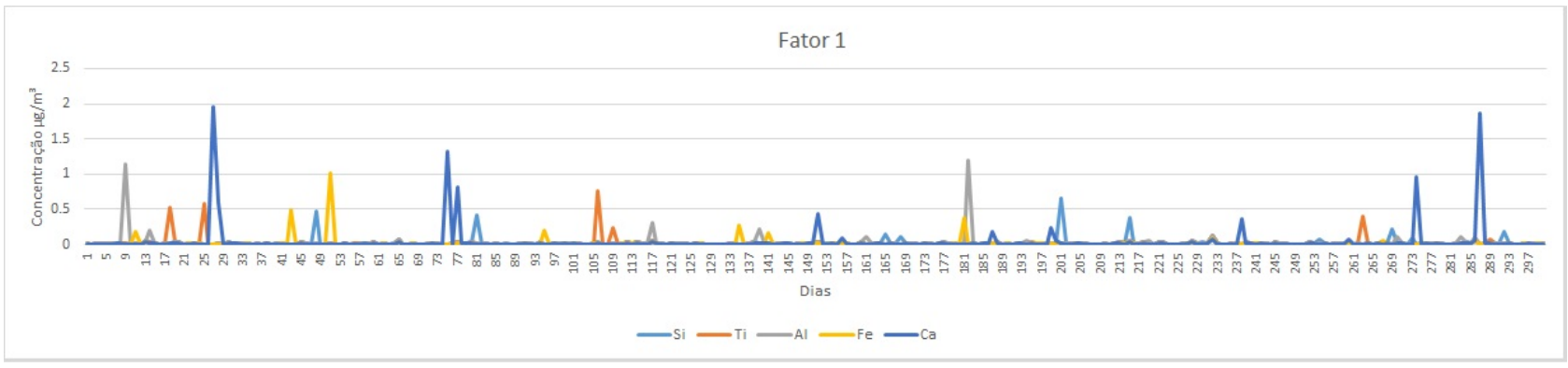

Figura B.49: séries de incertezas com proposta ref. Norris et al. (2014) de emissões simuladas com outliers - Exponencial com média 9 - segundo perfis da tabela 4.2 - Fator 1

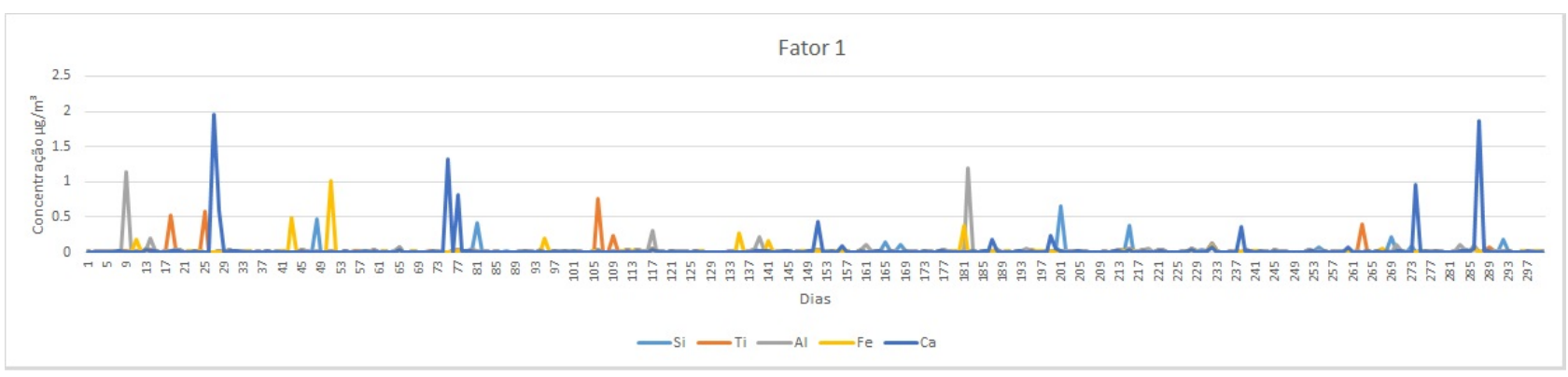

Figura B.50: séries de incertezas com proposta de $5 \%$ do valor de emissões simuladas com outliers Exponencial com média 9 - segundo perfis da tabela 4.2 - Fator 1

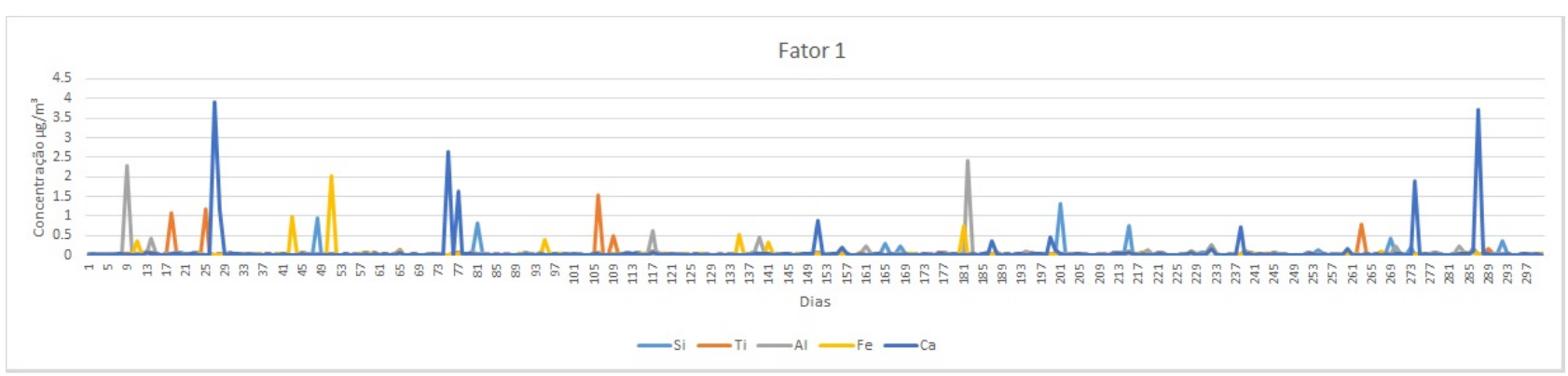

Figura B.51: séries de incertezas com proposta de $10 \%$ do valor de emissões simuladas com outliers Exponencial com média 9 - segundo perfis da tabela 4.2 - Fator 1

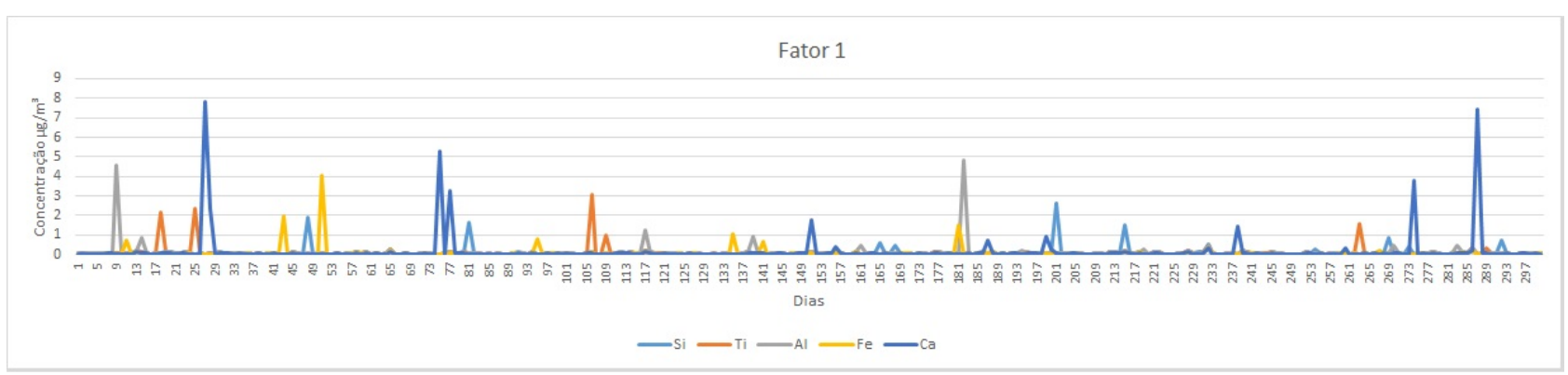

Figura B.52: séries de incertezas com proposta de $20 \%$ do valor de emissões simuladas com outliers Exponencial com média 9 - segundo perfis da tabela 4.2 - Fator 1 


\section{Referências Bibliográficas}

Arana(2014) Andrea Araujo Arana. Aerossois Atmosfericos na Amazonia Composicao elementar organica e inorganica em regioes com diferentes usos do solo. Tese de Doutorado, Instituto Nacional de Pesquisa da Amazonia, Universidade do Estado do Amazonas, Brasil. Citado na pág. xi, xix, 9, 10, 11, 12

Castanho e Artaxo(2001) Andrea D.A. Castanho e Paulo Artaxo. Wintertime and summertime sao paulo aerosol source apportionment study. Atmospheric Environment, 35:4889-4902. Citado na pág. xix, 7,8

Chueinta et al.(2000) Wanna Chueinta, Philip K. Hopke e Pentti Paatero. Investigation of sources of atmospheric aerosol at urban and suburban residential areas in thailand by positive matrix factorization. Atmospheric Environment, 34:3319-3329. Citado na pág. xii, xiii, xiv, xv, xvi, xvii, xix, 41, 42, 45, 52, 58, 64, 68, 69, 70, 72, 105, 107, 109, 111

dos Santos et al.(2014) Luis H.M. dos Santos, Americo A.F.S. Kerr, Thiago G. Verissimo, Maria de Fatima Andrade, Regina Maura de Miranda, Adalgiza Fornaro e Paulo Saldiva. Analysis of atmospheric aerosol(pm2.5) in recife city, brazil. Journal of the Air and Waste Management Association, 64:519-528. Citado na pág. xix, 4, 28, 29, 31

dos Santos Junior(2015) Djacinto Aparecido Monteiro dos Santos Junior. Emissoes veiculares em sao paulo quantificacao de fontes com modelos receptores e caracterizacao do material carbonaceo. Dissertação de Mestrado, Instituto de Fisica, Universidade de Sao Paulo, Brasil. Citado na pág. 7

Gieken e Markowicz(2002) Rene E. Van Gieken e Andrzej A. Markowicz. Handbook of X-Ray Spectrometry. Marcel Dekker, Inc., 2 edição. Practical Spectroscopy Series Volume 29. Citado na pág. 12

Henry et al.(1984) R.C. Henry, C.L. Lewis, P. K. Hopke e H. J. Williamson. Review of receptor model fundamentals. Atmospheric Environment, 18:1507-1515. Citado na pág. 1, 3

Ito et al.(2004) Kazuhiko Ito, Nan Xue e George Thurston. Spatial variation of pm 2.5 chemical species and source-apportioned mass concentrations in new york city. Atmospheric Environment, 38:5269-5282. Citado na pág. xii, xiii, xiv, xvi, xvii, 41, 42, 45, 51, 57, 63, 68, 69, 70, 72, 105, 107, 109,111

Kan e Chen(2004) Hai-Dong Kan e Bing-Heng Chen. Statistical distributions of ambient air pollutants in shanghai china. Biomedical and Environmental Sciences, 17:366-371. Citado na pág. 27

Kosusko(2014) Michael Kosusko. SPECIATE Version 4.4 Database Development Documentation, Fevereiro 2014. EPA 600/R-13/307. Citado na pág. 9

Landsberger e Creatchman(1999) Shelson Landsberger e Marsha Creatchman. Elemental Analysis of Airbone Particles. Gordon and Breach Science Publishers, 1 edição. Advances in environmental, industrial and process control technologies volume 1. Citado na pág. 42 
Lee e Seung(1999) D. D. Lee e H. S. Seung. Learning the parts of objects by non-negative matrix factorization. Nature, 401:788-791. Citado na pág. 5, 72

Norris et al.(2014) G. Norris, R.Duvall, S. Brown e S. Bai. EPA Positive Matrix Factorization(PMF) 5.0 Fundamentals and User Guide, Abril 2014. EPA/600/R-14/108. Citado na pág. xi, xii, xiii, xiv, xvi, xvii, 5, 14, 15, 16, 18, 20, 21, 22, 23, 24, 25, 26, 35, 41, 44, 50, 56, 62, 68, 69, $70,72,106,108,110,112$

Norris et al.(2009) Gary Norris, Ram Vedantham, Katie Wade, Patrick Zahn e Steve Brown. Guidance Document for PMF Applications with the Multilinear Engine, Abril 2009. EPA 600/R09/032. Citado na pág. 5

Oyama(2010) Beatriz Sayuri Oyama. Identificacao de fontes de particulas finas na atmosfera urbana de sao paulo. Dissertação de Mestrado, Instituto de Astronomia Geofisica e Ciencias Atmosfericas, Universidade de Sao Paulo, Brasil. Citado na pág. xi, 7, 12

Paatero(1999) P. Paatero. The multilinear engine: a table-driven, least squares program for solving multilinear problems including the n-way parallel factor analysis model. Journal of Computational and GRaphical Statistics, 8:4:854-888. Citado na pág. 5

Paatero e Tapper(1994) P. Paatero e U. Tapper. Positive matrix factorization: A non-negative factor model with optimal utilization of error estimates of data values. Environmetrics, 5:111-126. Citado na pág. $1,3,4,71$

Paatero et al.(2002) P. Paatero, Philip K. Hopke, Xin-Hua Song e Ziad Ramadan. Understanding and controlling rotations in factor analytic models. Chemometrics and Intelligent laboratory systems, 60:253-264. Citado na pág. 24

Paatero et al.(2014) P. Paatero, S. Eberly, S. G. Brown e G. A. Norris. Methods for estimating uncertainty in factor analytic solutions. Atmospheric Measurement Techniques, 7:781-797. Citado na pág. 21

Polissar et al.(1998) A. V. Polissar, P. K. Hopke, P. Paatero, W. C. Malm e J. F. Sisler. Atmospheric aerosol over alaska 2. elemental composition and sources. Journal of Geophysical Research, 103:19045-19057. Citado na pág. xii, xiii, xiv, xvi, xvii, 6, 41, 44, 51, 57, 63, 68, 69, 70, 72, 105, 107, 109,111

Ramadan et al.(2003) Ziad Ramadan, Bass Eickhout, Xin-Hua Song, L.M.C. Buydens e Philip K. Hopke. Comparison of positive matrix factorization and multilinear engine for the source apportionment of particulate pollutants. Chemometrics and intelligent laboratory systems, 66:15-28. Citado na pág. 5,72

Reff et al.(2007) A. Reff, S.I Eberly e P.V Bhave. Receptor modeling of ambient particulate matter data using positive matrix factorization: Review of existing methods. Journal of Air Waste Management Association, 57:2:146-154. Citado na pág. 4, 5, 6, 15, 71

Rumburg et al.(2001) Brian Rumburg, Richard Alldredge e Candis Claiborn. Statistical distributions of particulate matter and the error associated with the sampling frequency. Atmospheric Environment, 35:2907-2920. Citado na pág. 27

Shahnaz et al.(2006) F. Shahnaz, M. W. Berry, V. P. Pauca e R. J. Plemmons. Document clustering using nonnegative matrix factorization. Information Processing and Management, 42: 373-386. Citado na pág. 5

Wang et al.(2006) G. Wang, A. V. Kossenkov e M. F. Ochs. A modified non-negative factorization algorithm utilizing uncertatinty estimates. BMC Bioinformatics, 7:1-10. Citado na pág. 5, 72 